\title{
MODELING OIL PALM MONOCULTURE AND ITS ASSOCIATED IMPACTS ON LAND-ATMOSPHERE CARBON, WATER AND ENERGY FLUXES IN INDONESIA
}

Dissertation

zur Erlangung des akademischen Grades Doctor of Philosophy (PhD) der Fakultät für Forstwissenschaften und Waldökologie der Georg-August-Universität Göttingen

\author{
vorgelegt von \\ Yuanchao Fan \\ geboren in Hubei, China
}

Göttingen, 2016 
Betreuer : Alexander KNOHL, Prof., University of Göttingen, Germany

Co-Betreuer : Martial BERNOUX, Dr., Institut de Recherche pour le Développement, France

1. Gutachter: Alexander KNOHL, Prof., University of Göttingen, Germany

2. Gutachterin: Kerstin WIEGAND, Prof., University of Göttingen, Germany

3. Gutachterin: Maoyi HUANG, Dr., Pacific Northwest National Laboratory, U.S.

Tag der mündlichen Prüfung: 25.04.2016 


\title{
AgroParisTech
}

$\mathrm{N}^{\circ}: 2016$ AGPT XXXX

\section{Doctorat AgroParisTech}

\author{
THÈ SE
}

pour obtenir le grade de docteur délivré par

\section{L'Institut des Sciences et Industries du Vivant et de l'Environnement}

\section{(AgroParisTech)}

Spécialité : Écologie Fonctionnelle et Sciences Agronomiques

\author{
présentée et soutenue publiquement par \\ Yuanchao Fan \\ le 25 Avril 2016
}

\section{Modélisation de la monoculture du palmier à huile et de ses impacts sur les échanges de carbone, d'eau et d'énergie entre l'atmosphère et la surface terrestre en}

Directeur de thèse : Alexander KNOHL

Co-encadrement de la thèse : Martial BERNOUX

Jury

Mme. Kerstin WIEGAND, Prof., University of Göttingen, Germany

Rapporteur

Mme. Maoyi HUANG, Dr., Pacific Northwest National Laboratory, U.S.

Rapporteur

M. Alexander KNOHL, Prof., University of Göttingen, Germany

Examinateur

M. Olivier ROUPSARD, Dr., CIRAD / CATIE, Costa Rica

Examinateur

M. Oleg PANFEROV, Prof., University of Applied Sciences Bingen, Germany

Examinateur 



\title{
Modeling oil palm monoculture and its associated impacts on land-atmosphere carbon, water and energy fluxes in Indonesia
}

\author{
Dissertation \\ for obtaining the academic degree Doctor of Philosophy $(\mathrm{PhD})$ \\ under the Cotutelle between \\ the University of Göttingen and AgroParisTech \\ within the Erasmus Mundus Joint Doctorate Programme \\ Forest and Nature for Society (FONASO) \\ presented by \\ Yuanchao FAN \\ born in Hubei, China \\ Göttingen, 2016 \\ Supervisor : Alexander KNOHL \\ Co-supervisor : Martial BERNOUX
}

1. Appraiser: Alexander KNOHL, Prof., University of Göttingen, Germany

2. Appraiser: Kerstin WIEGAND, Prof., University of Göttingen, Germany

3. Appraiser: Maoyi HUANG, Dr., Pacific Northwest National Laboratory, U.S.

Date of oral examination: 25 April 2016 



\section{Table of Contents}

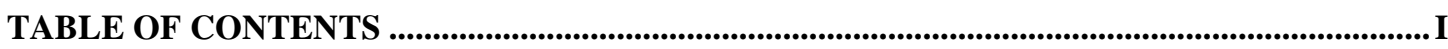

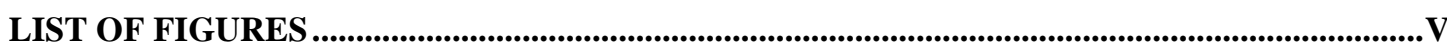

LIST OF TABLES ....................................................................................................................... VIII

ABSTRACT .................................................................................................................................................. IX

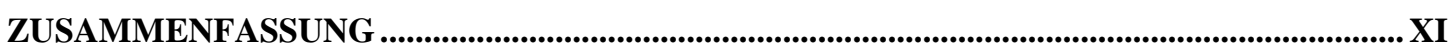

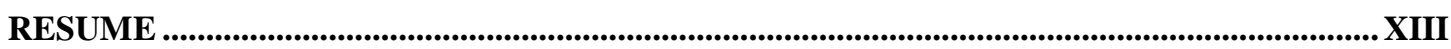

ACKNOWLEDGEMENTS ...........................................................................................................XV

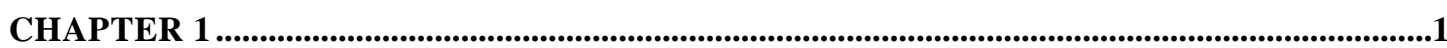

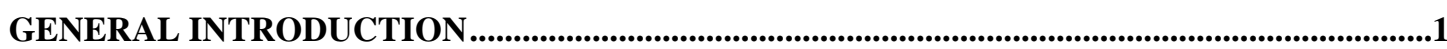

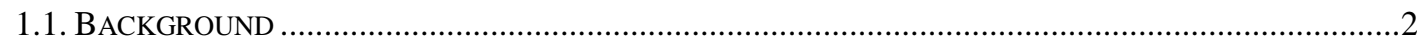

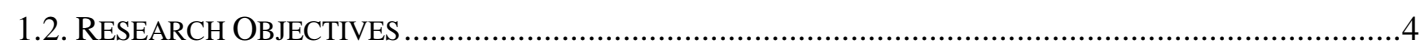

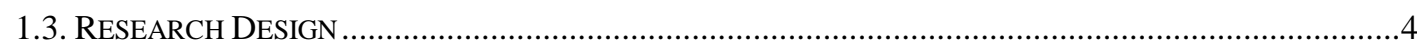

1.3.1. Hypothesis and Questions ..........................................................................................

1.3.2. Methods and Procedures.............................................................................................

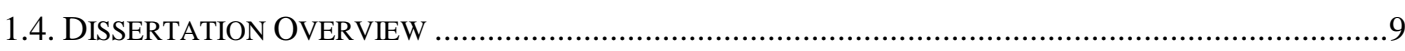

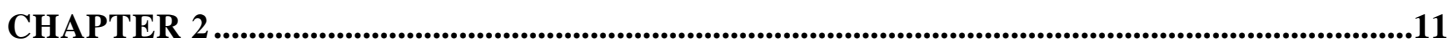

DEVELOPMENT AND EVALUATION OF CLM-PALM: PHENOLOGY, ALLOCATION AND

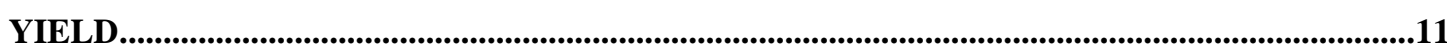

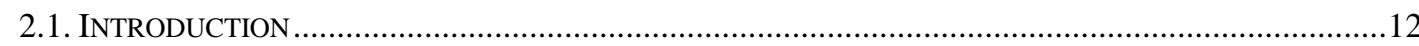

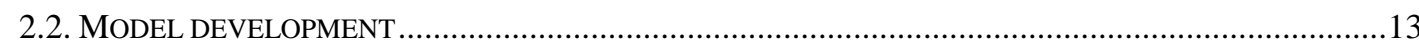

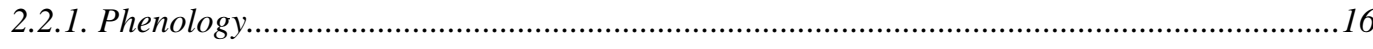

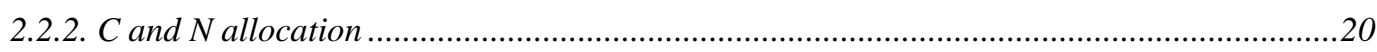

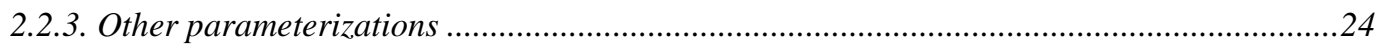

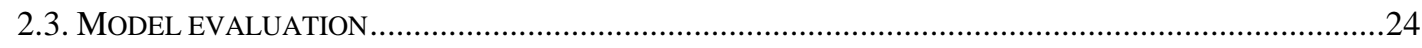

2.3.1. Site data

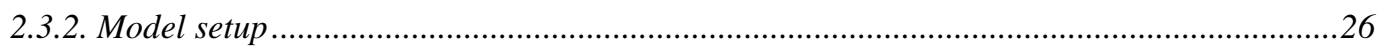

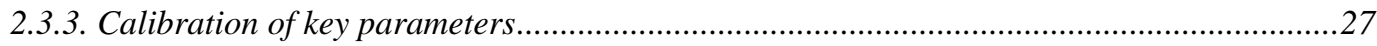




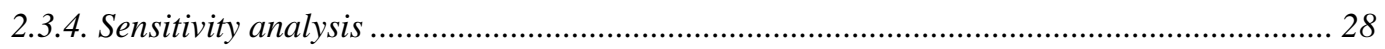

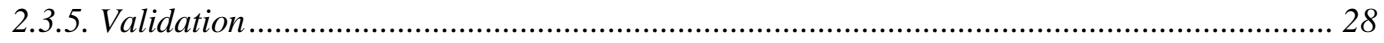

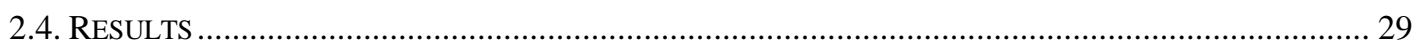

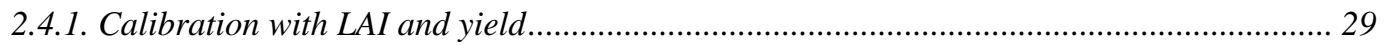

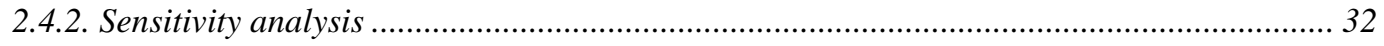

2.4.3. Model validation with independent dataset ............................................................... 34

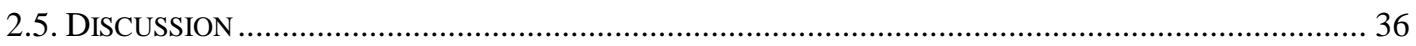

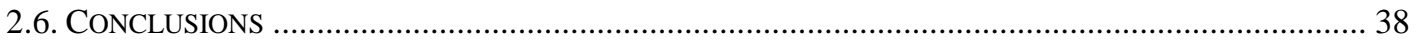

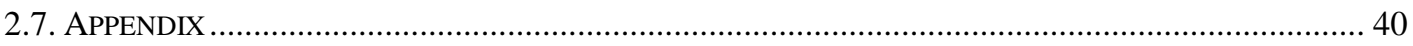

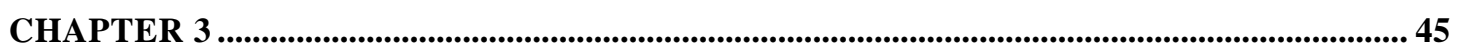

IMPLEMENTATION OF A DYNAMIC MULTILAYER RADIATIVE TRANSFER SCHEME 45

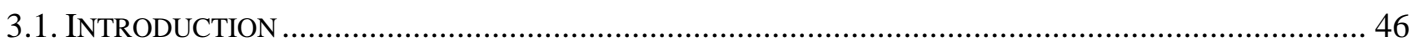

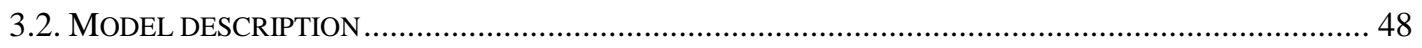

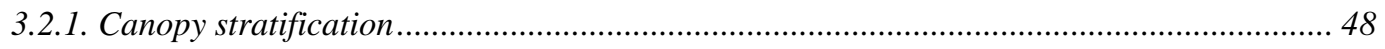

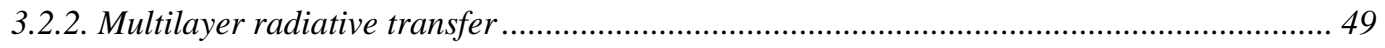

3.2.3. Sub-canopy photosynthesis and related processes ................................................... 51

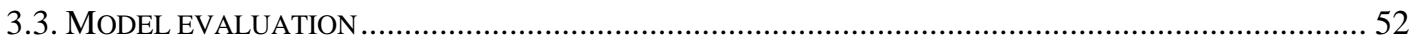

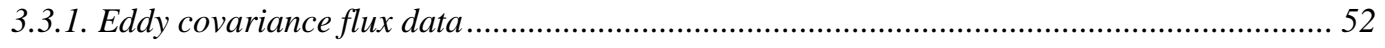

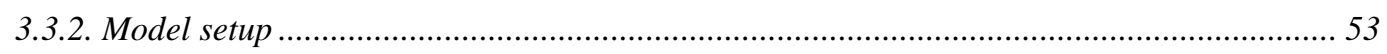

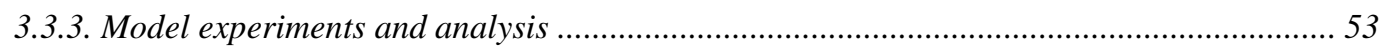

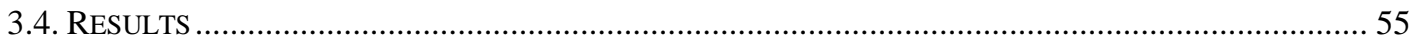

3.4.1. Radiative transfer and leaf angle distribution ........................................................... 55

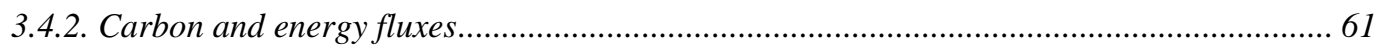

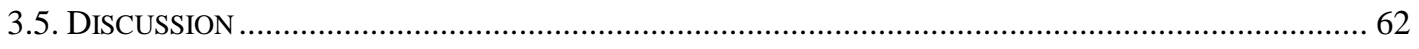

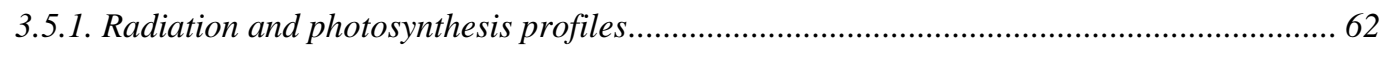

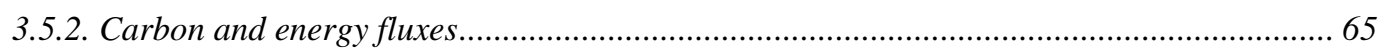

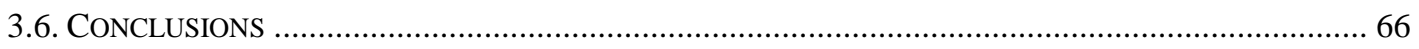

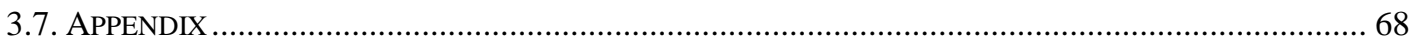


CHAPTER 4 . .75

RECONCILING CANOPY HYDROLOGICAL PARAMETERIZATION AND OBSERVED

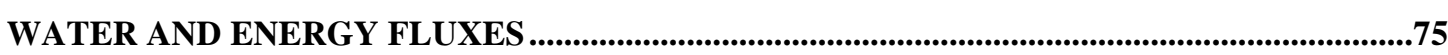

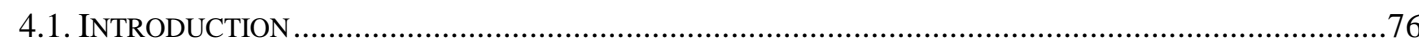

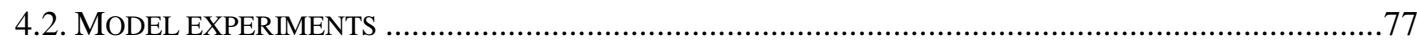

4.2.1. Description of canopy hydrology in CLM4.5 .................................................................77

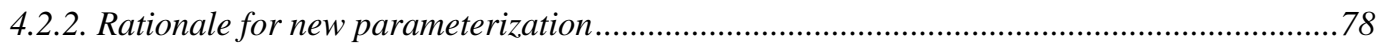

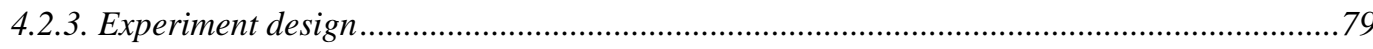

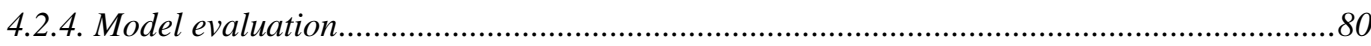

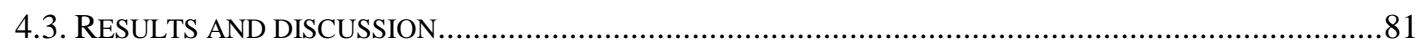

4.3.1. Water fluxes with default parameterization ............................................................82

4.3.2. Effects of increased canopy interception .................................................................8

4.3.3. Special treatment of leaf and stem surfaces .................................................................. 87

4.3.4. Remaining uncertainty in water and energy fluxes ..................................................89

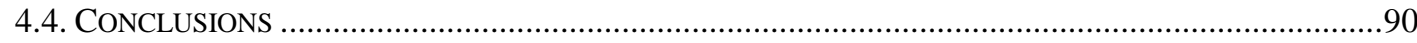

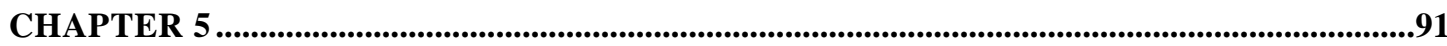

A DYNAMIC NITROGEN SCHEME FOR SIMULATING FERTILIZATION EFFECTS IN

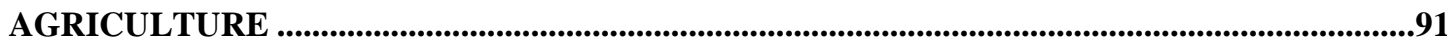

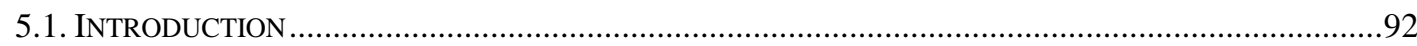

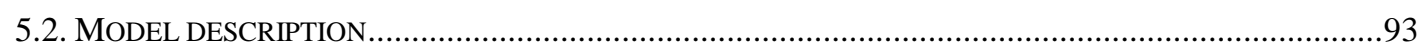

5.2.1. Original and the new dynamic nitrogen schemes.......................................................94

5.2.2. Canopy photosynthesis calculation ….................................................................. 97

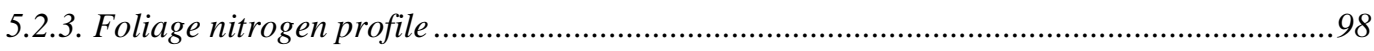

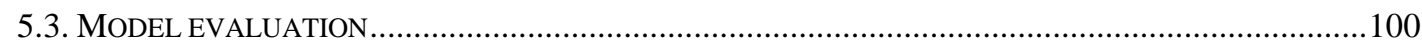

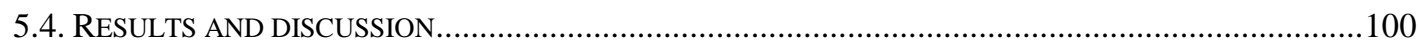

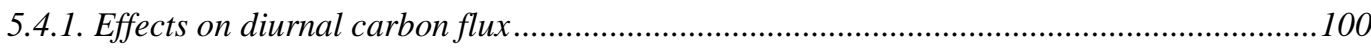

5.4.2. Fertilization effects on growth and yield .................................................................. 101

5.4.3. Leaf C:N ratio and nitrogen use efficiency ............................................................... 103

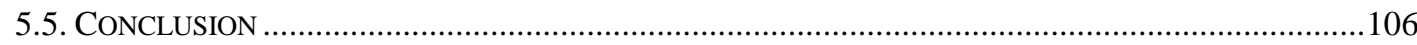




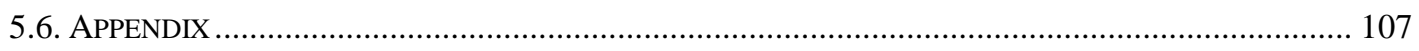

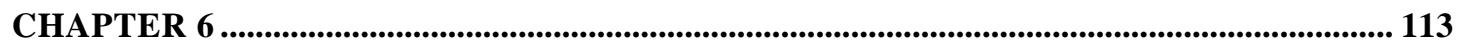

SIMULATING THE EFFECTS OF RAINFOREST TO OIL PALM CONVERSION ON

CARBON, WATER AND ENERGY FLUXES AND CARBON STOCKS ................................. 113

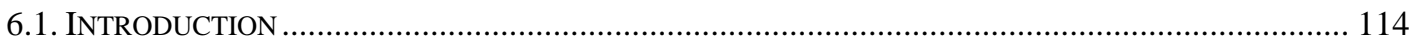

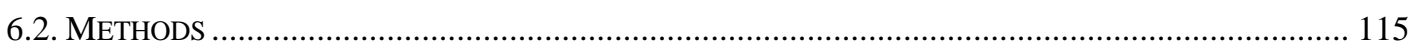

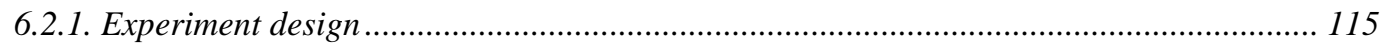

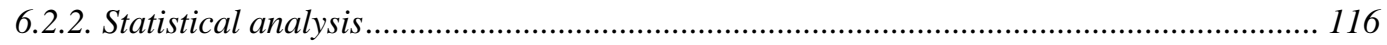

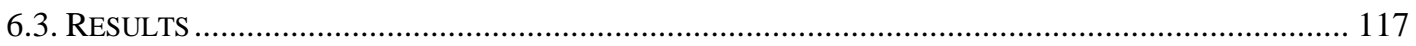

6.3.1. Comparison of diurnal carbon, water and energy flux ............................................... 117

6.3.2. Seasonal trends of $C$ flux and biogeophysical variables ......................................... 118

6.3.3. Dynamics of $C$ pools following forest to oil palm conversion ...................................... 120

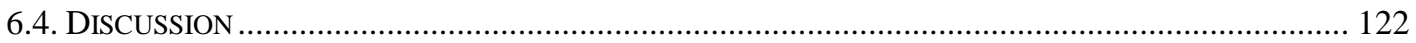

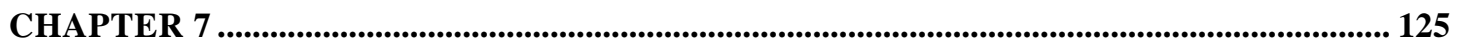

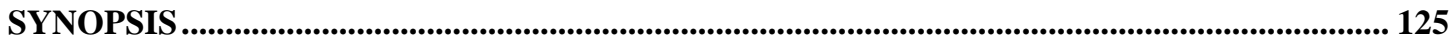

7.1. CLM-PALM IS DEVELOPED FOR SIMULATING OIL PALM MONOCULTURE.................................. 126

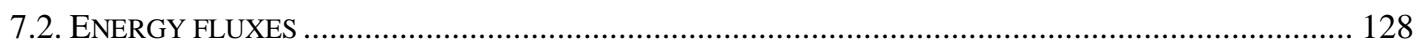

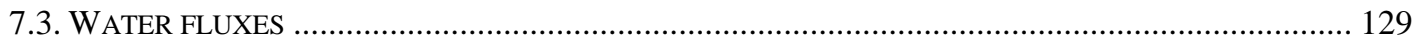

7.4. NITROGEN CYCLE AND FERTILIZATION EFFECTS ....................................................... 130

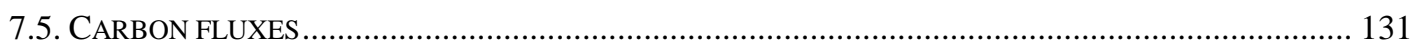

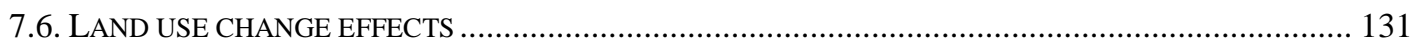

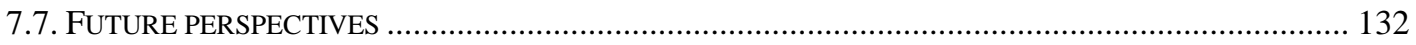

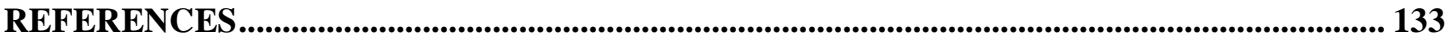

CERTIFICATE OF AUTHORSHIP/ORIGINALITY .................................................................... 149

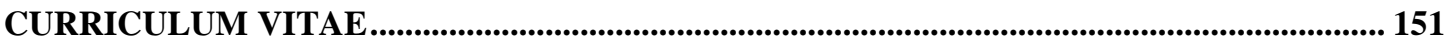




\section{List of Figures}

Figure 1.1. Primary processes and functionality in CLM4.5 (from Lawrence et al., 2011; Oleson, et al., 2013). ..6

Figure 2.1. New sub-canopy phytomer structure and phenology of CLM-Palm. . .15

Figure 2.2. Original and modified structure and functions for developing CLM-Palm in the framework of CLM4.5. 16

Figure 2.3. Time course of reproductive allocation rate (blue line) in relation to monthly NPP from the previous month $\left(N P P_{m o n}\right.$, green line) according to Eq. (2.6)

Figure 2.4. PFT-level LAI simulated by CLM-Palm, with and without the pre-expansion growth phase in the phytomer phenology and compared to field measurements used for calibration.

Figure 2.5. Simulated phytomer level LAI dynamics (horizontal color bar) compared with field observations (black crosses with measured LAI values)..... .31

Figure 2.6. Simulated PFT-level yield compared with monthly harvest data (2005-2014) from the calibration site PTPN-VI in Jambi, Sumatra.

Figure 2.7. Comparison of simulated and observed monthly yield at PTPN-VI . .32

Figure 2.8. Sensitivity analysis of key allocation parameters. . .33

Figure 2.9. Validation of LAI with eight independent oil palm sites (sequence in plantation age) from the Harapan (regular fertilization) and Bukit Duabelas (reduced fertilization) regions.... .34

Figure 2.10. Validation of yield and NPP with eight independent oil palm sites from the Harapan $(\mathrm{H})$ and Bukit Duabelas (B) regions with different fertilization treatments

Figure 3.1. Three alternative radiative transfer schemes: (a) CLM4.5 default big-leaf two-stream approximation; (b) CLM4.5 optional statistical multilayer derivative solution of two-stream approximation, with uniform canopy stratification; and (c) the Norman multilayer radiative transfer scheme with dynamic canopy stratification in CLM-Palm. .50

Figure 3.2. Sub-canopy profile of absorbed photosynthetically active radiation (APAR) and photosynthesis at noon time (12:00) simulated with two radiative transfer schemes and with different LAD functions. 
Figure 3.3. Canopy photosynthesis rate in relation to incident PAR at the top of canopy simulated with three radiative transfer schemes and with different LAD functions at the mature oil palm site... 60

Figure 3.4. Observed and simulated canopy photosynthesis light response curves at the rainforest site (BET PFT)

Figure 3.5. Correlation of observed and simulated GPP during daytime in October 2014

Figure 3.6. Comparison of observed and simulated GPP, latent heat and sensible heat fluxes for the mature oil palm plantation PTPN-VI in Jambi, Sumatra.

Figure 4.1. Simulated evapotranspiration (ET) and transpiration (T) during (a) dry and (b) rainy days compared to eddy covariance (ET) and sap flux (T) measurements.

Figure 4.2. The effects of increased water interception on (a) water fluxes (ET, T) and (b) energy fluxes (LE, H).

Figure 4.3. Special treatment of canopy water storage by leaf and stem surfaces.

Figure 5.1. (a) The CLM4.5 default coupled $C \& N$ cycles with fixed $C: N$ ratios and (b) The new independent $\mathrm{N}$ paths with dynamic $\mathrm{C}: \mathrm{N}$ ratios and dynamic $\mathrm{N}$ uptake and allocation. 95

Figure 5.2. The mean diurnal curve of net ecosystem exchange (NEE) between the default $\mathrm{N}$ scheme and the dynamic $\mathrm{N}$ scheme with reference to eddy covariance observation from June to December 2014. 101

Figure 5.3. The simulated LAI development from plantation establishment till final rotation by the default $\mathrm{N}$ scheme and the dynamic $\mathrm{N}$ scheme under different fertilization treatment with reference to field observations on three ages of palms. 102

Figure 5.4. The simulated yield from plantation establishment till final rotation ( 25 year old) by the default $\mathrm{N}$ scheme and the dynamic $\mathrm{N}$ scheme with different $\mathrm{N}$ fertilization treatments. 103

Figure 5.5. Leaf C: $\mathrm{N}$ ratio (upper panel) by the default $\mathrm{N}$ scheme and the dynamic $\mathrm{N}$ scheme with different $\mathrm{N}$ fertilization treatments $\left(400 \mathrm{~kg} \mathrm{~N} \mathrm{ha}^{-1} \mathrm{yr}^{-1}\right.$ is the normal practice in PTPN-VI).... 104

Figure 5.6. Nitrogen use efficiency (NUE) and productivity in yield simulated by the default $\mathrm{N}$ scheme and the dynamic $\mathrm{N}$ scheme. 104

Figure 6.1. Comparison of mean diurnal fluxes of (a) GPP, (b) NEE, (c) ET and (d) H between young oil palm, mature oil palm and old-growth rainforest. 
Figure 6.2. Observed and simulated GPP, NEE, evapotranspiration (ET) and ground surface temperature (TG) between young and mature oil palm plantations and old-growth rainforest.

Figure 6.3. Trajectory of carbon stocks above- and below-ground following forest clear-cut and land cover transformation to oil palm plantation. 121

Figure 6.4. Trajectory of carbon stocks above- and below-ground through long term oil palm cultivation including plantation rotation (replanting) during 50 years. 121

Fig. 7.1. The schematics of CLM-Palm including new functions (in color) for phenology, radiation, hydrology and biogeochemistry as well as the land use change capacity. The gray texts represent the existing functions and processes in the original CLM4.5. 


\section{List of Tables}

Table 2.1. Site conditions and $\mathrm{N}$ fertilization records at the calibration and validation plots.

Table A 2.1. Summary of new phenological parameters introduced for the phenology subroutine of

CLM-Palm. 40

Table A 2.2. Summary of parameters involved in $\mathrm{C}$ and $\mathrm{N}$ allocation. 41

Table A 2.3. Other optical, morphological, and physiological parameters used in CLM-Palm. 42

Table 3.1. Model options and description for different radiative transfer schemes 54

Table A 3.1. Symbols used in the derivation of radiative transfer functions 70

Table 4.1 Mean daily water and energy fluxes summarized from June to December 2014 and the annual interception ratio of 2014 simulated by the series of experiments described in section 4.2. 82

Table 5.1. Summary of parameters used in the dynamic nitrogen scheme. 98 


\begin{abstract}
In order to quantify the effects of forests to oil palm conversion occurring in the tropics on landatmosphere carbon (C), water and energy fluxes, this study develops a new perennial crop module CLM-Palm for simulating a palm plant functional type (PFT) within the framework of the Community Land Model (CLM4.5). To fit with oil palm's morphology (i.e. around 40 stacked phytomers forming a multilayered canopy), CLM-Palm introduces a sub-canopy phenological and physiological parameterization so that each phytomer has its own prognostic leaf growth and fruit yield capacity but with shared stem and root components. CLM-Palm was tested on oil palm only but is meant of generic interest for other palm crops (e.g. coconut). The first chapter introduces the background and rationale of this study. Chapter 2 describes the core model development including phenology and allocation functions for simulating the growth and yield of the palm PFT, providing the basis for modeling biogeophyical and biogeochemical cycles within this monoculture system. New parameters for phenology and allocation were thoroughly calibrated and validated against field measurements of leaf area index (LAI), yield and net primary production (NPP) from multiple oil palm plantations in Sumatra, Indonesia. The validation showed the ability of CLM-Palm to adequately predict the average leaf growth and fruit yield across sites and sufficiently represent the significant nitrogen- and age-related site-to-site variability in NPP and yield. Chapter 3 introduces further model development on implementing a Norman multilayer radiative transfer scheme to fit with oil palm's multilayer canopy. The Norman multilayer radiative transfer scheme showed slight improvements on simulating photosynthesis-light responses compared to the CLM4.5 default big-leaf model and only marginal advantages over CLM4.5's alternative statistical multilayer solution. Nevertheless, the Norman scheme does provide more detailed and realistic representation of foliage status such as dynamic LAI and leaf angle distribution across layers, and more balanced profile of absorbed photosynthetically active radiation (PAR). Validation with eddy covariance flux data showed the strength of CLM-Palm for simulating C fluxes but revealed biases in simulating evapotranspiration (ET), sensible heat (H) and latent energy (LE) fluxes. A series of canopy hydrology experiments were conducted in Chapter 4 including adaptation of the CLM4.5 default precipitation interception and storage functions to the special traits of oil palm's canopy. The revised canopy hydrology largely solved the biases in simulated water fluxes (ET and canopy transpiration), and improved energy partitioning of $\mathrm{H}$ and LE. Chapter 5 documents the implementation of a new dynamic nitrogen $(\mathrm{N})$ scheme in CLM-Palm for improving the simulation of $\mathrm{C}$ and $\mathrm{N}$ dynamics, especially $\mathrm{N}$ fertilization effects in agriculture systems. The dynamic N scheme breaks through the limitations of the CLM4.5 default fixed C$\mathrm{N}$ stoichiometry and it allows $\mathrm{C}: \mathrm{N}$ ratios in live tissues to vary in response to soil $\mathrm{N}$ availability
\end{abstract}


and plant $\mathrm{N}$ demand. A series of fertilization tests exemplified the advantages of the dynamic $\mathrm{N}$ scheme such as improved net ecosystem exchange (NEE), more realistic leaf $\mathrm{C}: \mathrm{N}$ ratio, and improved representation of nitrogen use efficiency (NUE) and fertilization effects on growth and yield. Finally, an application study employing the major model developments in preceding chapters is presented in Chapter 6. A young and a mature oil palm plantations and an old growth rainforest were simulated and compared. They exhibited clear distinctions in $\mathrm{C}$ fluxes and biophysical properties (e.g. ET, surface temperature). Oil palm plantation can catch up and surpass the $\mathrm{C}$ assimilation and water use rates of rainforest through growth development (around the age of 4), but it has a general warmer ground surface than the forested site even after maturity. A transient simulation spanning two rotation periods (replanting every 25 years) showed that long-term oil palm cultivation is only able to restore about a half of the original C storage capacity of the forested site before clear-cut. Soil C stock declines slowly and gradually due to limited litter return in the managed plantation. Overall, rainforest to oil palm conversion reduces long-term $\mathrm{C}$ stocks and $\mathrm{C}$ sequestration capacity and has potential warming effects on the land surface at the site scale, despite the fast growth and high $\mathrm{C}$ assimilation rate of the heavily fertilized plantation. An upscaling study is needed in the future to assess the regional or global effects of oil palm expansion on land-atmosphere exchanges and climate across space and time. 


\section{Zusammenfassung}

In dieser Studie wird ein neues Modul "CLM-Palm" für mehrjährige Nutzpflanzen zur Modellierung einer funktionellen Gruppe (plant functional type) für Ölpalmen im Rahmen des Community Land Models (CLM4.5) entwickelt, um die Auswirkungen der Transformation eines tropischen Waldes in eine Ölpalmenplantage auf die Kohlenstoff-, Wasser- und Energieflüsse zwischen Land und Atmosphäre zu quantifizieren. Um die Morphologie der Ölpalme möglichst detailgetreu darzustellen (das heißt, dass ungefähr 40 Phytomere einen mehrschichtigen Kronenraum formen), wird in dem Modul CLM-Palm eine phänologische und physiologische Parametrisierung auf Skalen unterhalb des Kronraums eingeführt, so dass jedem Phytomer sein eigenes prognostisches Blattwachstum und seine Erntekapazität zugeordnet wird, während Stamm und Wurzeln gemeinsam genutzt werden. Das Modul CLMPalm wurde ausschließlich für Ölpalmen getestet, ist aber auch für andere Palmarten (z. B. Kokospalmen) interessant. Im ersten Kapitel dieser Arbeit werden Hintergrund und Motivation dieser Arbeit vorgestellt. In Kapitel 2 wird die Entwicklung des Haupt- bzw. Kernmodells beschrieben, inklusive Phänologie und Allokationsfunktionen zur Simulation des Wachstums und des Ertrags der Palme PFT, wodurch die Basis zur Modellierung der biophysikalischen und biogeochemicalischen Kreisläufe innerhalb dieser Monokultur bereitgestellt wird. Die neuen Parameter für die Phänologie und die Allokation wurden sorgfältig mit Feldmessungen des Blattflächenindexes (LAI), des Ertrags und der Nettoprimärproduktion (NPP) verschiedener Ölpalmenplantagen auf Sumatra (Indonesien) kalibriert und validiert. Die Validierung zeigte die Eignung von CLM-Palm zur adäquaten Vorhersage des mittleren Blattwachstums und Ertrags für verschiedene Standorte und repräsentiert in ausreichendem Maß die signifikante Variabilität bezüglich des Stickstoffs und Alters von Standort zu Standort. In Kapitel 3 wird die weitere Modellentwicklung und die Implementierung eines NormanMehrschichtmodells für den Strahlungstransport vorgestellt, das an den mehrschichtigen Kronenraum der Ölpalme angepasst ist. Dieses Norman-Mehrschichtmodell des Strahlungstransports zeigte im Vergleich zu dem in CLM4.5 implementierten Standardmodell (basierend auf großen Blättern) bei der Simulation der Licht-Photosynthese-Kurve leichte Verbesserungen und hat lediglich marginale Vorteile gegenüber dem ebenfalls in CLM4.5 implementierten alternativen statistischen Mehrschichtmodell.

Dennoch liefert das Norman-Modell eine detailliertere und realistischere Repräsentation des Belaubungszustands wie etwa dem dynamischen LAI, der Blattwinkelverteilung in verschiedenen Höhen, und ein ausgewogeneres Profil der absorbierten photosynthetisch aktiven Strahlung (PAR). Die Validierung mit Hilfe der Eddy-Kovarianz Flussdaten zeigte die Stärke von CLM-Palm bei der Simulation der Kohlenstoffflüsse, offenbarte aber auch 
Abweichungen in der simulierten Evapotranspiration (ET), dem sensiblen und dem latenten Wärmefluss (H und LE). Eine Reihe von hydrologischen Messungen im Kronenraum wird in Kapitel 4 beschrieben. Dies beinhaltet eine Adaption des in CLM4.5 eingebauten Standardmodells für Niederschlag, Interzeption und Speicherfunktionen für die speziellen Merkmale eines Ölpalmen-Kronenraums. Die überarbeitete Hydrologie des Kronenraums behob die Probleme bei der Simulation der Wasserflüsse (ET und Transpiration im Kronenraum) und verbesserte die Energieaufteilung zwischen $\mathrm{H}$ und LE. Kapitel 5 dokumentiert die Implementierung eines neuen dynamischen Modells für Stickstoff (nitrogen, N) in CLM-Palm zur Verbesserung der Simulation der C- und N-Dynamik, insbesondere mit Bezug auf den N-Düngeeffekte in landwirtschaftlich genutzten Systemen. Das dynamische NModell durchbricht die Limitierung des Standardmodells in CLM4.5, mit fixierter C-NStöchiometrie und erlaubt die Variation des C:N-Verhältnisses in lebendem Gewebe in Abhängigkeit der N-Verfügbarkeit und dem N-Bedarf der Pflanze. Eine Reihe von Tests bezüglich der Düngung zeigte beispielhaft die Vorteile des dynamischen N-Modells, wie zum Beispiel die Verbesserung des Netto-Ökosystemaustauschs (net ecosystem exchange, NEE), ein realistischeres C:N-Verhältnis im Blatt, eine verbesserte Repräsentation der Effizienz des Stickstoffeinsatzes (nitrogen-use efficiency, NUE), sowie der Effekte von Düngung auf Wachstum und Ertrag. Abschließend wird in Kapitel 6 eine Anwendungsstudie gezeigt, in der die zentralen Modellentwicklungen aus den vorangegangenen Kapiteln verwendet werden. Eine junge und eine erntereife Ölpalmenplantage sowie ein Primärregenwald wurden simuliert und verglichen. Sie wiesen klare Unterschiede in den C-Flüssen und in den biophysikalischen Merkmalen (z.B. ET und Oberflächentemperatur) auf. Ölpalmenplantagen können durch Wachstumsentwicklung (im Alter von etwa 4 Jahren) ebenso hohe und darüber hinausgehende C-Assimilation und Wassernutzungsraten erreichen wie Regenwälder, haben jedoch im Allgemeinen eine höhere Oberflächentemperatur als eine bewaldete Fläche - dies gilt auch für erntereife Plantagen. Eine Simulation des Übergangs, die zwei Rotationsperioden mit Neubepflanzungen alle 25 Jahre umspannt, zeigte dass der Anbau von Ölpalmen auf längeren Zeitskalen lediglich in etwa die Hälfte des ursprünglichen C-Speichers der bewaldeten Fläche vor dem Kahlschlag rückspeichern kann. Das im Boden gespeicherte $\mathrm{C}$ nimmt in einer bewirtschafteten Plantage aufgrund des begrenzten Streurücklaufs langsam und graduell ab. Insgesamt reduziert die Umwandlung eines Regenwaldes in eine Ölpalmenplantage die langfristigen C-Speicher und die Kapazität der Fläche zur C-Sequestrierung und trägt potentiell zur Erwärmung der Landoberfläche bei - trotz des schnellen Wachstums und der hohen CAssimilationsrate einer stark gedüngten Plantage. Zur Einschätzung der regionalen und globalen Effekte der Ausbreitung der Kultivierung von Ölpalmen auf die Austauschprozesse zwischen Land und Atmosphäre und auf das Klima ist es notwendig eine Upscaling-Studie durchzuführen. 


\section{Résumé}

Afin de quantifier les effets de la conversion des forêts tropicales en plantations de palmier à huile sur les échanges de carbone, d'eau et d'énergie entre l'atmosphère et la surface terrestre, cette étude propose un nouveau module de culture pérenne intitulé «CLM-Palm » pour simuler le type fonctionnel de plante (PFT pour Plant Functional Type) correspondant au palmier pour le modèle générique Community Land Model (CLM 4.5). CLM-Palm a été testé seulement sur le palmier à huile, mais il peut représenter de façon générique d'autres cultures de palmiers (par exemple celui de la noix de coco). Le chapitre 2 décrit l'élaboration du modèle de base, y compris les fonctions de phénologie et de répartition pour simuler la croissance et le rendement par le PFT du palmier, fournissant ainsi la base pour la modélisation biogéophysique et des cycles biogéochimiques dans ce système de monoculture. De nouveaux paramètres ont été soigneusement calibrés et validés avec des mesures sur le terrain de l'indice de surface foliaire (LAI pour Leaf Area Index), le rendement et la production primaire nette (NPP pour Net Primary Productivity) à partir de plusieurs plantations de palmiers à huile à Sumatra, en Indonésie. La validation a montré la capacité de CLM-Palm à prédire de manière adéquate la croissance moyenne des feuilles et le rendement moyen en fruits pour différents sites. Il permet également de bien représenter la variabilité observée pour la NPP et les rendements, en lien avec l'azote et l'âge. Le chapitre 3 présente la poursuite du développement du modèle sur la mise en œuvre d'un système multicouche de transfert radiatif du type Norman pour prendre en considération les différentes couches de la canopée du palmier à huile. Le transfert radiatif selon ce modèle a montré une légère amélioration sur la simulation des réponses de la photosynthèse par rapport au modèle monocouche du type «big-leaf» qui est proposé par défaut dans CLM. Par contre les améliorations sont marginales par rapport à la solution multicouche statistique également proposée par CLM. Néanmoins, le modèle de type Norman offre une représentation plus détaillée et réaliste de l'état du feuillage comme la dynamique de la surface foliaire et l'orientation des feuilles à travers les couches, et au total un comportement plus équilibré de l'absorption du rayonnement photosynthétiquement actif (PAR for Photosynthetically Active Radiation). La procédure de validation avec les données issues de la méthode des corrélations turbulentes a montré l'intérêt de CLM-Palm pour simuler les flux de C, mais a révélé des biais dans la simulation de l'évapotranspiration (ET), de la chaleur sensible (H) et de l'énergie latente (LE). Une série d'expérimentation d'hydrologie de la canopée ont été menées dans le chapitre 4, y compris l'adaptation des fonctions de l'interception par défaut des précipitations et du stockage aux spécificités de la canopée du palmier à huile. La révision de l'hydrologie du couvert a largement permis de résoudre les biais dans les flux d'eau simulés (ET et transpiration de la canopée) et contribue à une meilleure répartition de l'énergie (H et 
LE). Le Chapitre 5 concerne la mise en place d'une nouvelle dynamique de l'azote (N) dans le système CLM-Palm pour améliorer la simulation de la dynamique du C et de l'N en particulier pour représenter la fertilisation azotée dans les systèmes agricoles. Le système dynamique de l'azote permet de s'affranchir des limites des rapports stœchiométriques par défaut du modèle CLM et permet que les rapports $\mathrm{C}: \mathrm{N}$ dans les tissus vivants puissent varier en réponse à l'azote disponible dans le sol et la demande par la plante. Les avantages des systèmes dynamiques du $\mathrm{N}$ sont illustrés par une série de tests de fertilisation et des comparaisons avec les rapports C:N des feuilles, le rendement et l'efficacité d'utilisation de l'azote. Enfin, une application concrète qui utilise les principaux développements du modèle des chapitres précédents est présentée dans le chapitre 6. Des simulations de plantations de palmiers à huile jeune et à maturité, avec une forêt âgée ont été comparées. Ces simulations montrent des différences claires dans les flux de $\mathrm{C}$ et les propriétés biophysiques. La plantation de palmier à huile peut rattraper et dépasser d'assimilation du C et d'utilisation de l'eau de la forêt lors de sa croissance (autour de l'âge de 4 ans), mais elle présente en général une surface au sol plus chaude que le couvert forestier, même à maturité. Une simulation transitoire représentant deux rotations (replantation tous les 25 ans) a montré que la culture du palmier à huile sur le long terme est en mesure de ne restaurer que seulement environ la moitié de la capacité d'origine de stockage de $\mathrm{C}$ du site forestier. Les stocks de $\mathrm{C}$ du sol diminuent lentement et progressivement en raison d'un retour limité via les litières dans la plantation gérée. Dans l'ensemble, la conversion de la forêt tropicale en plantation de palmier à huile réduit les stocks de carbone à long terme et la capacité de séquestration du C. La conversion s'accompagne de réchauffements potentiels à l'échelle du site, et ce malgré la croissance rapide et le taux d'assimilation élevé de $\mathrm{C}$ des plantations fortement fertilisées. 


\section{Acknowledgements}

If this is the moment to conclude my "school" time, a more than 20-year quest for knowledge of the world, people and nature, I am grateful to all my teachers and advisors along the path. To my main PhD advisor Prof. Dr. Alexander Knohl, I want to express my deep appreciation for his attentive advisement and ever enthusiastic support during the past three years in Germany. I am also grateful to my co-advisors Dr. Martial Bernoux and Dr. Olivier Roupsard for their friendly and valuable guidance during my stay in France and even remotely throughout my PhD study. I also appreciate the insightful comments, encouragement and helps from Prof. Dr. Oleg Panferov, another remote advisor of mine.

As Confucius said, "Three people; One is a teacher". I must thank all my colleagues from whom I have learnt. I enjoyed the free and enthusiastic studying and working environment in the Bioclimatology group where I received many encouragements and had deep communications. I especially thank Ana Meijide and Martyna Kotowska for their collaboration and sharing data. My modeling work could not have been completed without their support. CRC990 colleagues including Kara Allen, Thomas Guillaume, Furong Niu, Alexander Röll, Michael Euler and others also provided important information for my work and with whom I really enjoyed the short field trips to Sumatra and Sulawesi. I am also thankful for the helps from Jelka and Nina on English to German translations. I would like to personally thank my friends and roommates who have been the most important part of my leisure life in Göttingen. The artworks for the CLM-Palm model presented in Synopsis were made by my roommate Anna Matz.

I gratefully acknowledge the support by the European Commission Erasmus Mundus FONASO Doctorate fellowship (grant number 2012-1722/001-001-EMJD) which provided sufficient funding for my research and mobility between Germany and France. Field trips to Sumatra and Sulawesi, Indonesia were partly supported by the Collaborative Research Centre 990 (EFForTs project) funded by the German Research Foundation (DFG). I am grateful to the essential supports from the professors and colleagues in Indonesia (including but not limited to Dr. Tania June, Dr. Dodo Gunawan, Dr. Bambang Irawan, Dr. Aiyen Tjoa, Rizky, Bayu and the office of PTPN-VI plantation), who have made my research on the rainforests and oil palm plantations in Indonesia feasible and more meaningful.

The source code of the post-4.5 version CLM model was provided by Dr. Samuel Levis from the National Center for Atmospheric Research (NCAR), Boulder, CO, USA. I appreciate his help and also communications with other scientists from the CLM community. 
Most importantly, my grandfather and parents instilled in me the beliefs, kindness, perseverance and love that have motivated me on the whole long educational path, which does not lack hardship and challenges but has been always meaningful to me. Nothing can express my gratitude to my family.

My deep appreciation also goes to all those new people in different cultures with whom I interacted and experienced outside of my homeland, during nearly eight years studying abroad in the U.S., Austria, Germany and France. 


\section{CHAPTER 1}

General introduction 


\subsection{Background}

The significance of agriculture for feeding a growing world population and its impacts on ecosystems and climate under global change are drawing increasing attention among scientists and policymakers when food security, water scarcity, degradation of natural ecosystems and climate change become the major global challenges in the $21^{\text {st }}$ century (Pachauri et al., 2014). According to the latest IPCC report (Smith et al., 2014), the agriculture, forestry and other land use (AFOLU) sector was responsible for almost a quarter (10-12 $\mathrm{Gt} \mathrm{CO}_{2}$-eq yr ${ }^{-1}$ ) of global anthropogenic greenhouse gas (GHG) emissions in the 2000s. Of this value, nearly a half (4.3$5.5 \mathrm{Gt} \mathrm{CO}_{2}$-eq $\mathrm{yr}^{-1}$ ) was contributed by land use and land-use change (LUC, mainly deforestation) and the rest by agriculture production (e.g. $\mathrm{N}_{2} \mathrm{O}, \mathrm{CH}_{4}$ emissions).

Agriculture-driven LUCs, notably the conversion of carbon-rich ecosystems such as forests to cropping systems, result in net GHG emissions by destructing large existing carbon (C) stocks and deteriorating the potential $\mathrm{C}$ sequestration capacity or $\mathrm{C}$ sinks of natural systems (Fargione et al., 2008; Gibbs et al., 2008). Since the 1980s, tropical forests have been the primary sources of new agricultural land (Gibbs et al., 2010) and will likely continue to be so due to increasing global agricultural demand (Tilman et al., 2001) and weak environmental regulation enforcement in the tropical regions (Laurance, 1999). Cropland expansion in the tropics has been most dramatic for soybeans, maize, rice, oil palm and sugarcane during the past two decades (FAO, 2015). Among these key crops, oil palm (Elaeis guineensis) is one of the main drivers of tropical deforestation because it is currently the most high-yielding oil-producing crop (Carrasco et al., 2014) and the global demand for palm oil is projected to increase in the future (Corley, 2009).

Oil palm plantations have been mainly established in Southeast Asia since the 1960s (68\% by 2014; FAO, 2015) as a result of LUCs stimulated by economic development and policy changes (Casson, 2000; Gellert, 2005). Among these regions, Indonesia has become the largest global palm-oil producer due to its consistently high growth rate of oil palm area in the last two decades (nearly 10\% annually; Gunarso et al., 2013). In 2015 its harvested area of oil palm plantations was 7.4 million ha, accounting for $40 \%$ of world total followed by Malaysia's 4.7 million ha (FAO, 2015). Yet, Indonesia has planned to double its oil palm planted area to 18 million ha by 2020 (Koh and Ghazoul, 2010). Since oil palms favor a tropical-humid climate with consistently high temperatures and humidity, the plantations have already converted large areas of rainforest including those on carbon-rich peat soils (Carlson et al., 2012). The continuing oil palm expansion is contributing heavily to Indonesia's high deforestation rate (Miettinen et al., 2011) and C emissions (Koh et al., 2011). This conflicts its readiness and 
commitment to the Reducing Emissions from Deforestation and forest Degradation (REDD) program (Cerbu et al., 2011).

Tropical forests are essential agents in regional and global climate by recycling water, storing C, and transforming energy (Bonan, 2008), alongside of their immense value of biodiversity and other ecosystem services (Ghazoul, 2015). Unregulated oil palm expansion poses a serious threat to the continued provision of such ecosystem services in the tropics (Fitzherbert et al., 2008; Lee et al., 2012). Undisturbed forests have long-lasting capacity to store carbon in comparison to disturbed or managed vegetation (Luyssaert et al., 2008). Tropical forest to oil palm conversion has shown significant impacts on above- and belowground $\mathrm{C}$ stocks (Guillaume et al., 2015; Kotowska et al., 2015). However, accurate quantification of long-term and large-scale forest - oil palm replacement effects is difficult as the GHG balance of oil palms is still uncertain due to insufficient monitoring of the dynamics of oil palm plantations (including transition between growth stages), and lack of understanding of the $\mathrm{C}$, nitrogen $(\mathrm{N})$, water and energy exchange between oil palms, soil and the atmosphere at ecosystem scales. Besides that, the assessment of these processes in agricultural ecosystems is complicated by human activities e.g. crop management, including planting and pruning, irrigation and fertilization, litter and residues management, and yield outputs.

To tackle these challenges, integrated process-based modelling is an appropriate approach that can go beyond limitations of traditional field-based methods and can examine complex ecosystem processes and land-atmosphere interactions under diverse and dynamic environmental conditions. With the advances in computer science and modern supercomputing facilities, Earth system modelling has become a powerful means for quantifying land surface dynamics and the associated effects on biogeophysical and biogeochemical cycles across a variety of spatial and temporal scales (Fisher et al., 2014). To model the oil palm monoculture and investigate its climate impacts, previous studies have provided the general guidance on the functioning of terrestrial ecosystems (Chapin III et al., 2011) and the biological and ecological basis of the oil palm plantation system (Corley and Tinker, 2016).

A series of agricultural models already exist for simulating oil palm such as OPSIM (Van Kraalingen et al., 1989), ECOPALM (Combres et al., 2013), APSIM-Oil Palm (Huth et al., 2014), and PALMSIM (Hoffmann et al., 2014). However, these models are specialized for simulating the growth and yield of oil palm, but do not aim yet at the full biogeophysical and biogeochemical cycles and the interactions between land and atmosphere that are necessary for understanding climate impacts of land-surface perturbations. In contrast, land surface modelling or terrestrial biosphere modeling schemes (see review by Fisher et al., 2014) usually 
simulate energy, water and material (e.g. $\mathrm{C}$ and $\mathrm{N}$ ) cycling in a prognostic manner and at fine time steps (e.g. half-hourly). A land surface model is meant to be coupled to climate models by providing land-atmosphere fluxes so that the feedbacks of terrestrial biosphere to climate can be simulated in a coupled Earth system modelling framework.

Given the current and potential large-scale deforestation driven by the expansion of oil palm plantations, it is useful to incorporate a suitable modelling capacity for oil palm into an Earth system modeling or land surface modeling framework. This study thus develops a modelling scheme for palm species within a commonly used land surface model the Community Land Model (CLM; Oleson, et al., 2013). Beyond the growth and yield capacity of an agriculture model, a suit of new parameterizations on biogeophysics (e.g. phenology, productivity, radiative transfer, and evapotranspiration) and on biogeochemistry ( $\mathrm{C}$ and $\mathrm{N}$ dynamics) are introduced. The model development is based on existing eco-physiological knowledge of oil palm and substantial field data collected in oil palm plantations in Indonesia. The new model (named CLM-Palm) is then applied to simulate oil palm plantations and to evaluate its ecosystem services such as yield, $\mathrm{C}$ sequestration, microclimate, energy and water balance in order to estimate the overall impact of oil palm induced LUC on the environment including regional and global climate.

\subsection{Research Objectives}

This study is aimed to characterize quantitatively (i) the biogeophysical and biogeochemical functions of the oil palm monoculture and its interaction with the atmosphere through material and energy cycling and (ii) how LUC in Indonesia, specifically rainforest conversion to oil palm plantation, affects $\mathrm{C}$ sequestration and water and energy exchanges of tropical landscapes. The means of research is through terrestrial biosphere modeling or land surface modeling. New model components and parameterization are developed to simulate oil palm monocultures and to address the above objectives. Key variables of land-atmosphere fluxes and land surface properties are identified and analyzed for the linkage between agriculture practice and climate impacts.

\subsection{Research Design}

\subsubsection{Hypothesis and Questions}

This study is based on the hypothesis that land transformation from natural ecosystems to managed agricultural systems such as the oil palm plantation alters land surface properties and, 
consequently, changes the patterns of land-atmosphere energy, water and carbon fluxes which could impact local or regional climate. Based on this hypothesis and the research objectives, I will answer the following questions through land surface modelling:

1) What are the key processes specific for oil palm that need to be implemented for simulating biogeophysical (e.g. evapotranspiration and energy cycling) and biogeochemical processes ( $\mathrm{C}$ and $\mathrm{N}$ dynamics)?

2) How well do modeled growth, yield, and carbon, water, energy fluxes of oil palm plantations compare to observations from different sites in Indonesia?

3) What are the impacts of oil palm monoculture on carbon stocks and land surface water and energy balances, both short and long term?

\subsubsection{Methods and Procedures}

One of the suitable tools for evaluating climatic impacts of oil palm expansion is terrestrial biosphere modeling or land surface modeling (Fisher et al., 2014). Land surface models have been widely used to characterize the two-way interactions between climate and human activities in terrestrial ecosystems such as deforestation, agricultural expansion, and urbanization (Jin and Miller, 2011; Oleson et al., 2004 a; Di Vittorio et al., 2014). A variety of land models have been adapted to simulate land-atmosphere energy and matter exchanges for major crops such as the Community Land Model (CLM; Oleson, et al., 2013), LPJ-mL (Bondeau et al., 2007), JULES-CROP (Osborne et al., 2015), and ORCHIDEE-STICS (Gervois et al., 2004; Valade et al., 2014) models. The CLM is a third-generation land surface model (Sellers et al., 1997), and is the land component of the Community Earth System Model (CESM, a fully-coupled global climate model; Gent et al., 2011). When coupled to other components (e.g. atmospheric models: CAM or DATM) within the CESM framework, CLM formalizes and quantifies how natural and anthropogenic changes in land cover and vegetation affect climate, through land-atmosphere cycling of energy, GHGs, water, and other chemical elements (Fig. 1.1; Oleson, et al., 2013). As an open-source and well-documented community model, CLM has experienced extensive validation from local to global scales and been continuously updated by many research groups around the world (Lawrence et al., 2011). CLM has been included in the coupled model inter-comparison project phase 5 (CMIP5; Taylor et al., 2012) and its performance has been evaluated in biogeophysical (Wang et al., 2013), hydrological (Du et al., 2016; Wang et al., 2007a) and global carbon cycle (Jones et al., 2013) studies. 

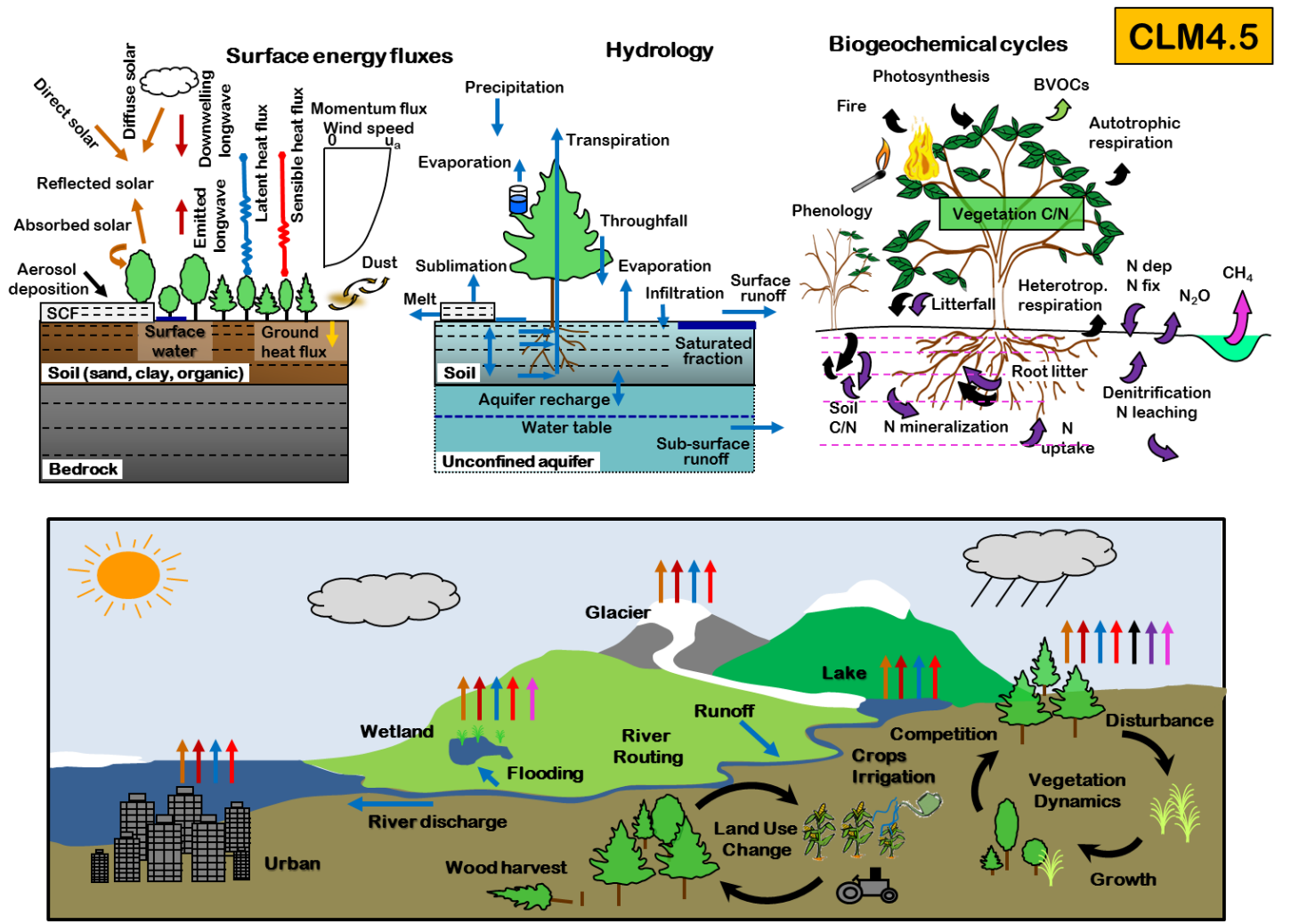

Figure 1.1. Primary processes and functionality in CLM4.5 (from Lawrence et al., 2011; Oleson, et al., 2013).

CLM represents the land surface as a hierarchy of sub-grid types: glacier; lake; wetland; urban; crop and vegetated land units (Oleson et al., 2013). The crop and naturally vegetated land units are the focus of this study and are currently represented as patches of plant functional types (PFTs) defined by their key ecological functions (Bonan, 2008; Poulter et al., 2011). Each PFT is assigned with specific phenology, $\mathrm{C}$ and $\mathrm{N}$ allocation functions for simulating growth and senescence, and yield for crop PFTs, and is associated with carbon, energy and water fluxes from radiative transfer, photosynthesis and stomata-related processes. The coupled stomatal conductance and photosynthesis model within CLM calculates leaf-level photosynthetic processes and scales them over canopy depth for sunlit and shaded leaves based on leaf area index (LAI) to give canopy-level conductance and photosynthesis. Canopy photosynthesis is then used to estimate gross primary production (GPP) and net ecosystem exchange (NEE) of carbon dioxide $\left(\mathrm{CO}_{2}\right)$. Stomatal resistance is needed in calculating water fluxes which are also involved in the biogeophysical modules for energy balance accounting and for calculating latent and sensible heat fluxes. The biogeochemistry modules of CLM couple $\mathrm{N}$ fluxes with C fluxes with prescribed C:N ratios for different tissue types (leaf, stem, fine root, etc.) and the availability of $\mathrm{N}$ can feedback to the $\mathrm{C}$ cycle and down-regulate GPP. The $\mathrm{C}-\mathrm{N}$ biogeochemistry is necessary for crop modeling as fertilization and effects of nutrient availability on crop yield 
must be considered. Overall, the CLM and CESM framework enables the coupling of biogeophysically-based climate models with biogeochemically-based ecosystem dynamics models, providing systematic approaches for studying land-atmosphere interactions including the feedbacks of agricultural management or land cover change onto climate (Levis et al., 2012) and the effects of climate change on vegetation dynamics (Levis et al., 2004).

Most of the biogeophysical and biogeochemical functions in CLM are shared by all the PFTs, except that different PFTs may have different physical properties and different phenology and resource allocation strategies. Such differences can be prescribed as inputs by PFT parameters (optical, morphological, phenological and physiological), and the parameter values per PFT are usually fixed during a model simulation (Alton, 2011). The PFT parameterization reduces the complexity of species diversity in ecological function to a few key types which works generally well for natural vegetation and better than earlier generations of land models that use a few types of biomes (Poulter et al., 2011). However, crops require more detailed treatment of phenology and reproductive allocation strategy, specifically down to the level of species, for the sake of predicting biomass and yield. Perennial crops may even require dynamic physiological parameters during the course of growth development such as changing allocation pattern through aging. Currently, most of the crops represented in land surface models are annual crops such as wheat, corn, and soybean. Their phenological cycles are usually represented as three stages of development from planting to leaf emergence, to fruit-fill and to harvest, all within a year. Attempts were also made to evaluate the climate effects of perennial deciduous crops, e.g. by extending the annual growing season to simulate earlier green-up and lagged senescence (Georgescu et al., 2011). However, the perennial evergreen crops such as oil palm, cacao, coffee, rubber, coconut, etc. and their long-term biophysical processes are not represented in the above land models yet, despite the worldwide growing demand (FAO, 2015).

Moving beyond the limitations of PFTs and considering variation in functional traits among species is now encouraged in the terrestrial biosphere modeling community (Van Bodegom et al., 2012; Verheijen et al., 2015). The starting point of this study is thus to adapt CLM to the land-use types in Indonesia, especially oil palm plantations. Given the unsuitability of the crop model capacity of CLM for perennial evergreen oil palm plantations, a suit of new processes and parameterizations need to be developed. It entails the creation and parameterization of a new PFT for oil palm and the construction of palm specific phenology and allocation functions for modeling its development and productivity. Other processes in energy, water and biogeochemical cycles may also need to adapt to oil palm's morphological and physiological characteristics. More specifically, the following procedures are taken. 
1) First of all, growth and yield of oil palm must be accurately simulated from plantation establishment to full maturity and rotation because the crop phenology and productivity through the course of plantation development are important controls on the $\mathrm{C}$ and $\mathrm{N}$ cycles. The modeled growth and yield should be compared with available observed growth and harvest data in Sumatra, Indonesia. Parameterization of the physiological characteristics of the new PFT is accomplished through field measurements in the oil palm plantation in Indonesia and collaboration with other research groups. Most of the parameters are generalized over the life cycle of oil palm while a few key parameters such as allocation ratios are allowed to vary through aging to differentiate from noncrop PFTs or annual crops. A sensitivity analysis is also conducted to examine the key parameters and guide their calibration. Generalizable parameters are obtained from literature.

2) Second, as a land surface modeling approach the oil palm module should have the capacity to predict the daily and long-term $\mathrm{C}$, water and energy fluxes that is comparable to field measurements in the study area. Two eddy covariance flux towers provide data for validation. One is located in an old-growth montane tropical rainforest in Central Sulawesi (Bariri, Olchev et al., 2008). Another tower was installed in a young oil palm plantation (Pompa Air) and later moved to a mature plantation (PTPNVI) in Jambi, Sumatra (Meijide et al., 2016). These flux towers provide continuous measurements of daily and annual fluxes of energy, water, $\mathrm{CO}_{2}$ and $\mathrm{CH}_{4}$ and all required environmental variables used as input in the model (e.g. radiation, air temperature and humidity, precipitation, soil microclimate).

3) Further, oil palm's morphological and physiological traits as well as plantation management may require special treatment of the biogeophysics and biogeochemistry, the two major components of the CLM model. For example, oil palm has a natural multilayer canopy structure which is suitable for implementing a multilayer radiative transfer model for the sake of improved accuracy in simulating energy fluxes given Indonesia's highly diffuse radiative condition. The tropical climate with frequent precipitation and oil palm's unique canopy structure may require adaption of some hydrological processes such as canopy water interception given evidence raised from model validation with measured water fluxes. Moreover, the heavy $\mathrm{N}$ fertilization in oil palm plantations might not be sufficiently represented with CLM's current fertilization routine designed for annual crops and its fixed C \& N stoichiometry (fixed $\mathrm{C}: \mathrm{N}$ ratios are used for all tissue types). An adapted $\mathrm{N}$ cycle and allocation scheme with dynamic $\mathrm{C}: \mathrm{N}$ ratios may be favorable to be implemented.

4) At last, to address the main objective of this study a LUC simulation is conducted by applying the improved model to simulate land conversion from rainforest to oil palm 
plantation and quantify the associated short- and long-term effects on $\mathrm{C}$ storage and other land surface biogeophysical properties.

The resulting sub-model including the collection of new functions is called CLM-Palm. It fully conforms to the CLM and CESM framework. After installing, porting, configuring and testing, various model parameters and input data are collected for simulating the selected oil palm plantations and rainforest sites in the study area of Indonesia. The technical adaptations and improvements on CLM are not covered in detail here. The key model developments, validations and applications are described in the respective chapters.

\subsection{Dissertation Overview}

The dissertation consists of five main chapters of model development, evaluation and application, plus an overall summary. Chapter 2 describes the base model development of CLM-Palm including phenology and allocation functions. Chapter 3 further develops CLMPalm by implementing a multilayer radiative transfer model for simulating energy and carbon fluxes. Chapter 4 includes model experiments on canopy hydrology and Chapter 5 implements a new dynamic $\mathrm{N}$ scheme. Finally, Chapter 6 presents an application study using the major new features of CLM-Palm for a long-term transient simulation to quantify the effects of rainforest to oil palm conversion on $\mathrm{C}$ stocks and carbon sequestration capacity. Each of the above core chapters constitutes an individual article for publication. Chapter 2 was published in the journal Geoscientific Model Development (Fan et al., 2015). Chapters 3 to 6 are in preparation for publication in international peer-reviewed journals. Their contents are closely related to the overarching theme of the study for addressing the effects of tropical land-use change driven by the expansion of oil palm monoculture. 


\section{CHAPTER 2}

\section{Development and evaluation of CLM-Palm: phenology, allocation and yield}

Yuanchao Fan, Olivier Roupsard, Martial Bernoux, Guerric Le Maire, Oleg Panferov, Martyna M. Kotowska, Alexander Knohl

Main content of this chapter was published in Geoscientific Model Development, 8, 3785-3800, 2015, doi:10.5194/gmd-8-3785-2015 


\subsection{Introduction}

Land surface modeling has been widely used to characterize the two-way interactions between climate and human activities in terrestrial ecosystems such as deforestation, agricultural expansion, and urbanization (Jin and Miller, 2011; Oleson et al., 2004 a; Di Vittorio et al., 2014). A variety of land models (or terrestrial biosphere models, see review by Fisher et al., 2014) have been adapted to simulate land-atmosphere energy and matter exchanges for major crops including the Community Land Model (CLM, Oleson, et al., 2013). CLM represents the crop and naturally vegetated land units as patches of plant functional types (PFTs) defined by their key ecological functions (Bonan et al., 2002). Currently most of the crop PFTs being simulated are annual crops such as wheat, corn, soybean, etc. Their phenological cycles are usually represented as three stages of development from planting to leaf emergence, to fruit-fill and to harvest, all within a year. A perennial evergreen crop PFT has yet to be parameterized in order to simulate the biogeophysical and biogeochemical functions of oil palm in land surface models.

To represent a palm PFT and its specific phenological and physiological processes in a land surface model, it has to first understand the oil palm's ecophysiological characteristics. The morphology, especially of canopy, is important for radiative transfer, photosynthesis and transpiration which together decide the rate of energy and material cycling. The phenology, i.e. both inter- and intra- annual life history of oil palm, controls the temporal pattern of energy and material fluxes which responds and provides feedbacks to the temporal variations of climate. In addition, the resource use strategies of oil palm including carbon and nitrogen (C \& N) allocation for the growth and regeneration of different vegetative pools have to be represented in the land model. Such strategies can be intrinsically unique for this species or could be modified by human management, such as leaf pruning, fruit harvesting, irrigation and fertilization. Some of the managements have to be represented in modern land surface models too in order to better reflect the human dimension in this heavily managed monoculture system.

Oil palm is a perennial evergreen crop which can be described by the Corner's architectural model (Hallé et al., 1978). A number of phytomers, each carrying a large leaf (frond) and axillating a fruit bunch, emerge successively (nearly two per month) from a single meristem (the bud) at the top of a solitary stem. They form a multilayer canopy with old leaves progressively being covered by new ones, until being pruned at senescence. Each phytomer has its own phenological stage and yield, according to respective position in the crown. The oil palm is productive for more than 25 years, including a juvenile stage of around 2 years. In order to capture the inter- and intra-annual dynamics of growth and yield and land-atmosphere 
energy, water and $\mathrm{C}$ fluxes in the oil palm system, a new structure and dimension detailing the phytomer-level phenology, $\mathrm{C}$ and $\mathrm{N}$ allocation and agricultural managements have to be added to the current integrated plant-level physiological parameterizations in the land models. This specific refinement needs to remain compliant with the current model structure though, and be simple to parameterize.

In this study, we develop a new CLM-Palm sub-model for simulating the growth, yield, and energy and material cycling of oil palm within the framework of CLM4.5. It introduces a subcanopy phenological and physiological parameterization, so that multiple leaf and fruit components operate in parallel but at delayed steps. A phytomer in the model is meant to represent the average condition of an age-cohort of actual oil palm phytomers across the whole plantation landscape. The overall gross primary production (GPP) by leaves and C output by fruit harvests rely on the development trends of individual phytomers. The functions implemented for oil palm combine the characteristics of both trees and crops, such as the woody-like stem growth and turnover but the crop-like vegetative and reproductive allocations which enable fruit $\mathrm{C}$ and $\mathrm{N}$ output. Agricultural practices such as transplanting, fertilization, and leaf pruning are also represented.

The main objectives of this chapter are to: i) describe the development of CLM-Palm including its phenology, $\mathrm{C}$ and $\mathrm{N}$ allocation, and yield output; ii) optimize model parameters using fieldmeasured leaf area index (LAI) and observed long-term monthly yield data from a mature oil palm plantation in Sumatra, Indonesia; and iii) validate the model against independent LAI, yield and net primary production (NPP) data from eight oil palm plantations of different age in Sumatra, Indonesia.

\subsection{Model development}

For adequate description of oil palm functioning, we adapted the CLM4.5 crop phenology, allocation and vegetative structure subroutines to the monopodial morphology and sequential phenology of oil palm so that each phytomer evolves independently in growth and yield (Fig. 2.1). Their phenology sequence is determined by the phyllochron (the period in thermal time between initiations of two subsequent phytomers). A maximum of 40 phytomers with expanded leaves, each growing up to 7-m long, are usually maintained in plantations by pruning management. There are also around 60 initiated phytomers developing slowly inside the bud. The largest ones, already emerged at the top of the crown but unexpanded yet, are named "spear" leaves (Fig. 2.1a). Each phytomer can be considered a sub-PFT component that has its own prognostic leaf growth and fruit yield capacity but having 1) the stem and root components 
that are shared by all phytomers, 2) the soil water content, $\mathrm{N}$ resources, and resulting photosynthetic assimilates that are also shared and partitioned among all phytomers, and 3) a vertical structure of the foliage, with the youngest at the top and the oldest at the bottom of the canopy. Within a phytomer the fruit and leaf components do not compete for growth allocation because leaf growth usually finishes well before fruit-fill starts. However one phytomer could impact the other ones through competition for assimilates, which is controlled by the $\mathrm{C}$ and $\mathrm{N}$ allocation subroutine according to their respective phenological stages.

(a)

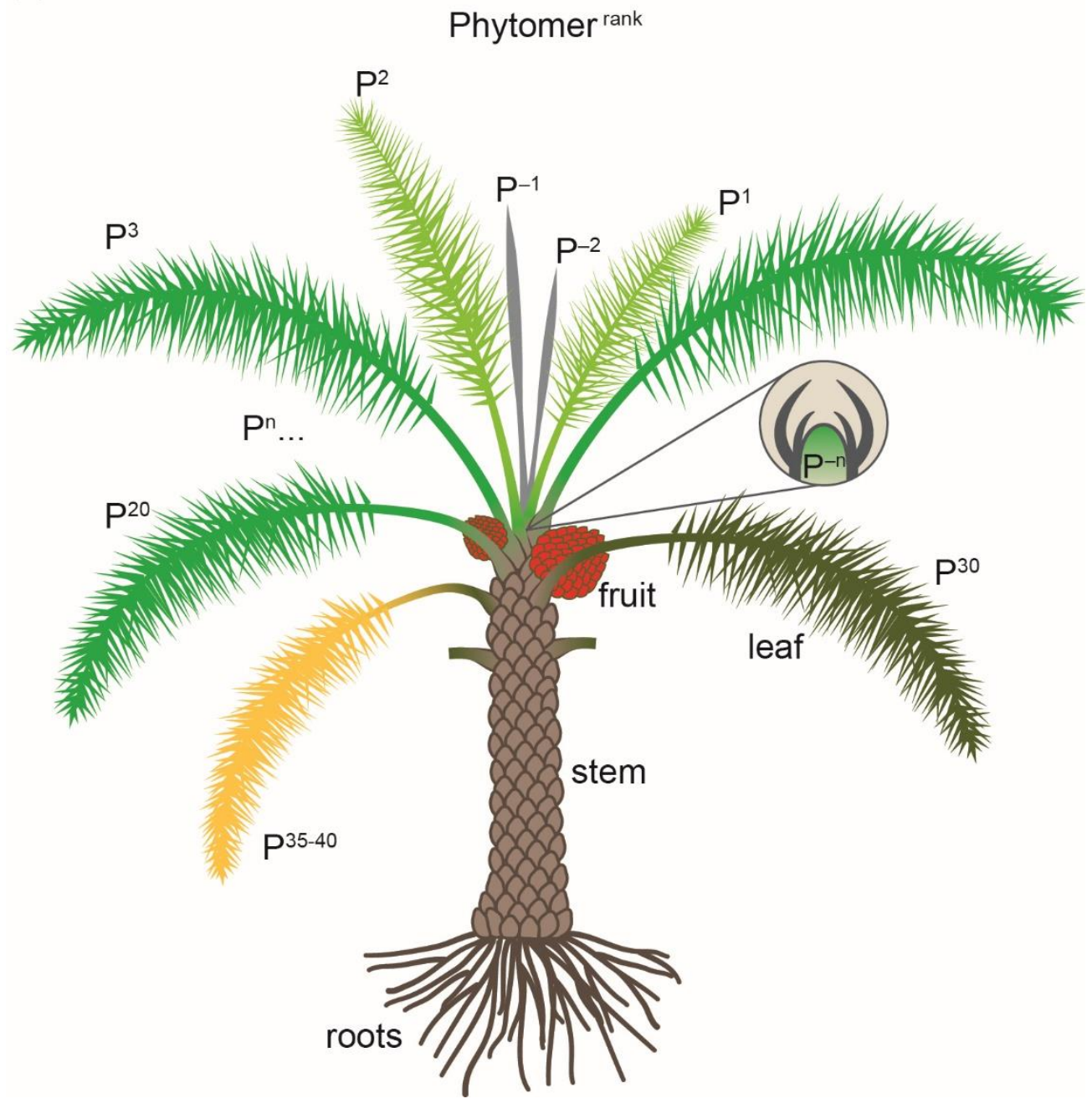




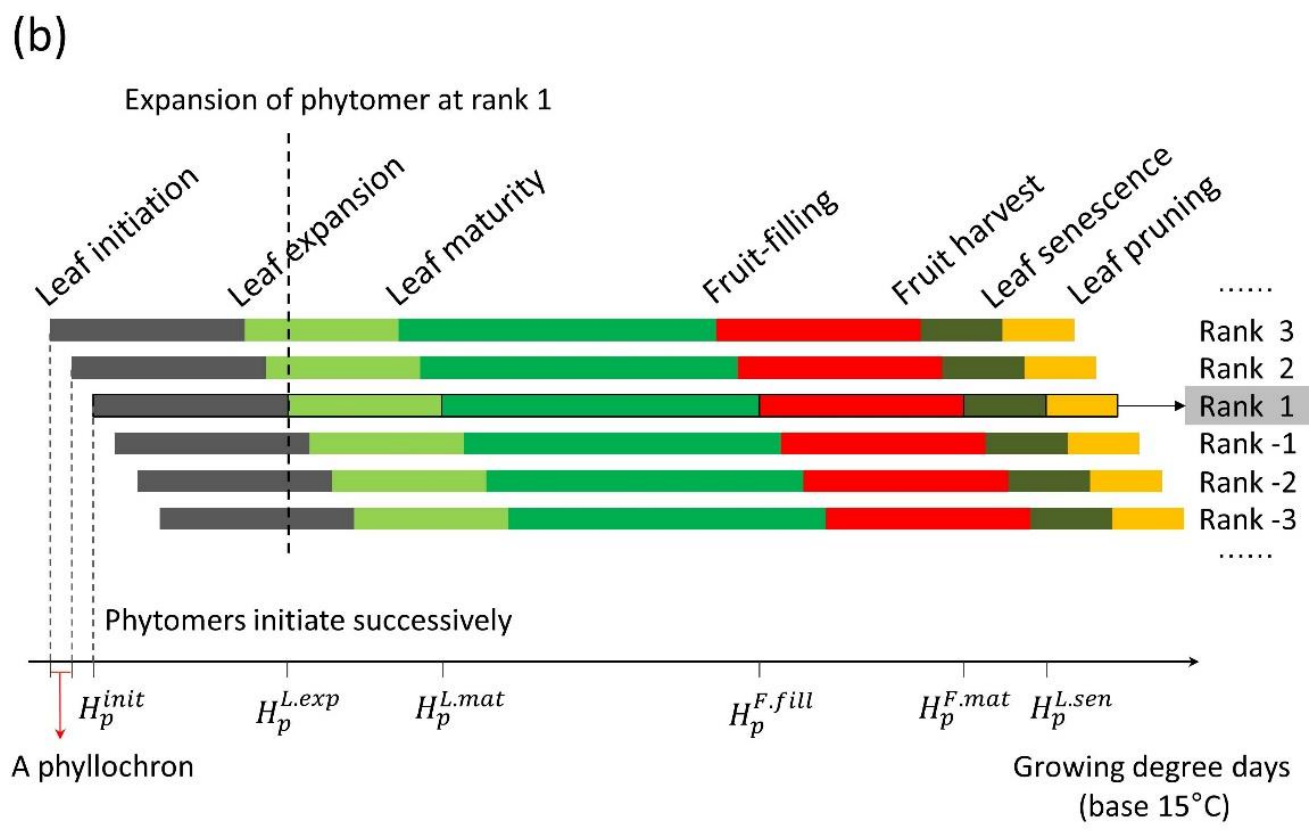

Figure 2.1. (a) New sub-canopy phytomer structure of CLM-Palm. $\mathrm{P}^{1}$ to $\mathrm{P}^{\mathrm{n}}$ indicate expanded phytomers and $\mathrm{P}^{-1}$ to $\mathrm{P}^{-\mathrm{n}}$ at the top indicate unexpanded phytomers packed in the bud. Each phytomer has its own phenology, represented by different colors corresponding to: (b) the phytomer phenology: from initiation to leaf expansion, to leaf maturity, to fruit-fill, to harvest, to senescence and to pruning. Phytomers initiate successively according to the phyllochron (the period in heat unit between initiations of two subsequent phytomers). Detailed phenology description is in Supplementary materials.

Here we describe only the new phenology, allocation and agricultural management functions developed for the oil palm. Photosynthesis, respiration, water and $\mathrm{N}$ cycles and other biogeophysical processes already implemented in CLM4.5 (Oleson et al., 2013) are not modified (except $\mathrm{N}$ retranslocation scheme) for the current study. The following diagram shows the new functions and their coupling with existing modules within the CLM4.5 framework (Fig. 2.2). 


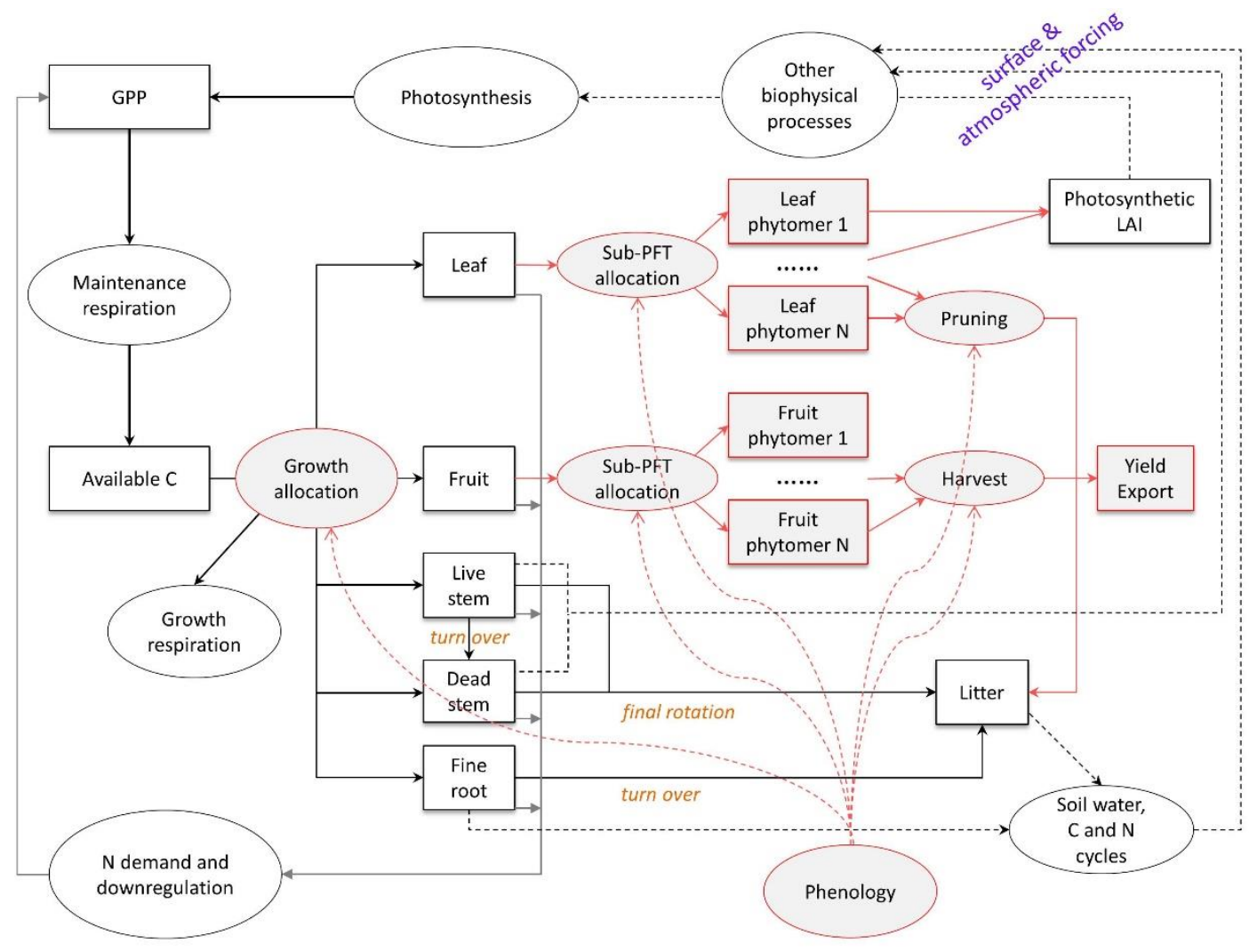

Figure 2.2. Original and modified structure and functions for developing CLM-Palm in the framework of CLM4.5. Original functions from CLM4.5 are represented in black or grey. New functions designed for CLM-Palm are represented in red, including phenology, allocation, pruning, fruit harvest and export, as well as the sub-canopy (sub-PFT) structure.

\subsubsection{Phenology}

Establishment of the oil palm plantation is implemented with two options: seed sowing or transplanting of seedlings. In this study, the transplanting option is used. We design 7 postplanting phenological steps for the development of each phytomer: 1) leaf initiation; 2) start of leaf expansion; 3) leaf maturity; 4) start of fruit-fill; 5) fruit maturity and harvest; 6) start of leaf senescence; and 7) end of leaf senescence and pruning (Fig. 2.1b). The first two steps differentiate pre-expansion (heterotrophic) and post-expansion (autotrophic) leaf growth phases. The other steps control leaf and fruit developments independently so that leaf growth and maturity could be finished well before fruit-fill, and leaf senescence could happen after fruit harvest according to field observations. The modified phenology subroutine controls the life cycle of each phytomer (sub-PFT level) as well as the planting, stem and root turnover, vegetative maturity (start of fruiting) and final rotation (replanting) of the whole plant (PFT level). 
All phytomers are assumed to follow the same phenological steps, where the thermal length for each phase is measured by growing degree-days (GDD; White et al., 1997). For oil palm, a new GDD variable with $15^{\circ} \mathrm{C}$ base temperature and 25 degree-days daily maximum (Corley and Tinker, 2016; Goh, 2000; Hormaza et al., 2012) is accumulated from planting (denoted GDD 15 ). The phenological phases are signaled by respective GDD requirements, except that pruning is controlled by the maximum number of expanded phytomers according to plantation management. Other processes in the model such as $\mathrm{C}$ and $\mathrm{N}$ allocation for growth of new tissues respond to this phenology scheme at both PFT level and phytomer level. Detailed description of oil palm phenology is as follows. The main phenological parameters are in Appendix (section 2.7, Table A 2.1).

\section{Planting and leaf initiation}

Planting is implemented in the similar way as in the CLM4.5 crop phenology except that GDD 15 (growing degree-days with $15^{\circ} \mathrm{C}$ base temperature) is tracked since planting and an option of transplanting is enabled. An initial phytomer emergence threshold $\left(G D D_{\text {init }}\right)$ is prescribed for attaining the first leaf initiation after planting (Table A 2.1). When $G D D_{\text {init }}$ is zero, it implies transplanting from nursery instead of seed sowing in the field. Oil palm seedlings usually grow in nursery for 1-2 year before being transplanted into the field. Therefore, in this study $G D D_{\text {init }}$ is set to zero and the first new phytomer is assumed to initiate immediately after transplanting in the field. An initial total leaf area index (LAI) of 0.15 is assigned to the existing expanded phytomers, whose leaf sizes are restricted to be within $10 \%$ of the maximum phytomer LAI $\left(P L A I_{\max }\right)$ (Table A 2.2 in Appendix 2.7).

The oil palm phytomers initiate as leaf primordia in the apical bud and then appear as leaves on the stem successively according to relatively stable intervening periods, termed plastochron (the duration in terms of heat unit (GDD) between successive leaf initiation events) and phyllochron (the rate of leaf emergence from the apical bud). Here for simplicity, the phyllochron is assumed equal to the plastochron. As the apical buds in palms usually do not start to accumulate dry mass immediately after physiological initiation but wait until several phyllochrons before expansion (Navarro et al., 2008), we define leaf initiation as the start of active accumulation of leaf $\mathrm{C}$ in this model, so that the phenological steps and $\mathrm{C}$ and $\mathrm{N}$ allocation process can be at the same pace.

A parameter phyllochron is prescribed with an initial value of 130 degree-days at planting with reference to $\mathrm{GDD}_{15}$ and it increases linearly to 1.5 times at 10-year old (Huth et al., 2014). Given $G D D_{\text {init }}$ and phyllochron, a heat unit index $H_{p}^{\text {init }}$ for triggering leaf initiation can be calculated for each new phytomer when a preceding phytomer initiates: 


$$
\begin{gathered}
H_{1}^{\text {init }}=G D D_{\text {init }} \\
H_{p+1}^{\text {init }}=H_{p}^{\text {init }}+\text { phyllochron }
\end{gathered}
$$

where subscripts $p$ and $p+l$ refer to successive phytomers and $l$ refers to the first new phytomer initiated after planting.

As the GDD accumulates since planting, new phytomers will be turned on in sequence when $G D D_{15}>H_{p}^{\text {init }}$, and will enter the 7-step life cycle one by one. The timing of later phenological steps for each new phytomer is determined at the time of initiation by adding the length of a corresponding phase period (Table A 2.1). Each newly initiated phytomer is assigned a negative rank of $-N$ and remains packed in the bud until the next phase of leaf expansion is triggered. The oldest unexpanded phytomer (spear leaf), right before expansion, has a rank of -1 . The GDD period between leaf initiation and expansion is used to calculate the number of bud phytomers that have already initiated before transplanting, i.e. $N=\frac{G D D_{\text {exp }}}{\text { phyllochron }}$.

\section{Leaf expansion}

During the phase from initiation to leaf expansion, leaf $\mathrm{C}$ already starts to build-up in the bud or spear leaf but it remains photosynthetically inactive. The thermal threshold for leaf

expansion is calculated by $H_{p}^{\text {exp }}=H_{p}^{\text {init }}+G D D_{\text {exp }}$. Only when $G D D_{15}>H_{p}^{\text {exp }}$ for a phytomer ranked -1 , the leaf starts to expand and becomes photosynthetically active. Its rank changes to a positive value of 1 , while the ranks of other phytomers all increase by 1 at the same time. The expansion phase lasts for roughly 5-6 phyllochrons until leaf maturity (Legros et al., 2009).

Hereafter, the pre-expansion and post-expansion growth periods, distinguished by negative and positive ranks, are treated separately so as to differentiate non-photosynthetic and photosynthetic increases in leaf $\mathrm{C}$. The following post-expansion phases and their thresholds are determined with reference to $H_{p}^{\text {exp }}$.

\section{Leaf maturity}

Another phenological step is added for the timing of leaf maturing so as to control the period of post-expansion leaf growth for each phytomer. An oil palm leaf usually reaches maturity well before fruit-fill starts on the same phytomer. Therefore, we set the parameter $G D D_{L \text { mat }}$ to be smaller than $G D D_{F . f i l}$ (Table A 2.1) so that post-expansion leaf growth continues for 2-3 
months (5-6 phyllochrons) and stops around 6 months before fruit-fill. The phenological threshold $H_{p}^{L . m a t}$ is calculated as $H_{p}^{\text {L.mat }}=H_{p}^{e x p}+G D D_{\text {L.mat }}$.

\section{Fruit filling}

Fruit-fill starts on a phytomer when $\mathrm{GDD}_{15}$ exceeds a heat unit index $H_{p}^{F . f i l l}$. This threshold is calculated by $H_{p}^{F . f i l l}=H_{p}^{\text {exp }}+G D D_{F . f i l l}$. At this point, the phytomer enters reproductive growth. Growth allocation increases gradually for the fruit component while leaf $\mathrm{C}$ and LAI remain constant on the mature phytomer until senescence. Due to the fact that most inflorescences on the initial phytomers within 2 years after planting are male (Corley and Tinker, 2016), another threshold $G D D_{\min }$ is used to control the beginning of first fruiting on the palm. Only when $G D D_{15}>G D D_{\min }$, the mature phytomers are allowed to start fruit-filling.

\section{Fruit harvest and output}

Fruit harvest occurs at one time step when a phytomer reaches fruit maturity, measured by a heat unit index $H_{p}^{F . m a t}=H_{p}^{e x p}+G D D_{F . m a t}$. Since GDD build-up is weather dependent and phyllochron increases through aging, the harvest interval is not constant. New variables track the flow of fruit $\mathrm{C}$ and $\mathrm{N}$ harvested from each phytomer to PFT-level crop yield output pools. The fruit $\mathrm{C}$ and $\mathrm{N}$ outputs are isolated and are not involved in any further processes such as respiration and decomposition, although their fate is uncertain (largely exported as oil products and consumed by humans).

\section{Litter fall}

For oil palm, leaf litter-fall is performed in two phases: senescence and pruning. Senescence is simulated as a gradual reduction in photosynthetic leaf $\mathrm{C}$ and $\mathrm{N}$ on the bottom phytomers when $G D D_{15}>H_{p}^{\text {L.sen }}$, where $H_{p}^{\text {L.sen }}=H_{p}^{\text {exp }}+G D D_{\text {L.sen }}$. These phytomers are allowed to stay on the palm until pruning is triggered. Their senescence rates are calculated as the inverse of the remaining time until the end of a phytomer's life cycle $\left(G D D_{\text {end }}\right)$. Leaf $\mathrm{C}$ removed during this phase is not put into the litter pool immediately but saved in a temporary pool $C_{\text {leaf }}^{\text {senescent }}$ until pruning, while the photosynthetic LAI of senescent phytomers are updated at every time step. The reason to do this is that each oil palm frond is a big leaf attached tightly to the stem and its leaflets do not fall to the ground during senescence unless the whole frond is pruned. Thus, the dynamics of soil litter pool and decomposition process could be represented better with this function. Nitrogen from senescent phytomers is remobilized to a separate $\mathrm{N}$ retranslocation pool that contributes to photosynthetic $\mathrm{N}$ demand of other phytomers and avoids supplying 
excessive amount of $\mathrm{N}$ to the litter. The proportion of $\mathrm{N}$ remobilized from senescent leaves before pruning is adjusted by the length of senescent period $\left(G D D_{\text {end }}-G D D_{L . s e n}\right)$ with a given pruning frequency, and the rest $\mathrm{N}$ goes to the litter pool.

Pruning is conducted at one time step if the number of expanded phytomers (including senescent ones) exceeds the maximum number allowed on a palm (mxlivenp). All senescent phytomers are subject to pruning at the time of harvest and their remaining $\mathrm{C}$ and $\mathrm{N}$ together with the temporary $C_{\text {leaf }}^{\text {senescent }}$ pool are moved to the litter pool immediately. The frequency and intensity of pruning is determined through the combination of mxlivenp, $G D D_{L . s e n}$ and phyllochron. A larger mxlivenp gives lower pruning frequency and a smaller $G D D_{\text {L.sen }}$ results in more senescent leaves being pruned at one time. Besides, since phyllochron increases by age, the rate of phytomer emergence decreases and thus pruning frequency also decreases when the plantation becomes older.

\section{Stem, roots and rotation}

Unlike other crops, the oil palm stem is represented by two separate pools for live and dead stem tissues (Fig. 2.1a). Although the stem of oil palm is not truly woody, field observations have found that the stem section below the lowest phytomer only contains less than $6 \%$ of live tissues in the core of trunk for transporting assimilates to the roots (Van Kraalingen et al., 1989). This is similar to the stem of most woody trees that largely consists of functionally dead lignified xylem. Therefore, conversion from live to dead stem for oil palm follows the CLM4.5 stem turnover function for trees, except that the turnover rate is slightly adjusted to be the inverse of leaf longevity (in seconds), such that when a leaf is dead the stem section below it will mostly become dead. Leaf longevity is around 1.6 years measured from leaf expansion to the end of senescence. The oil palm fine-root turnover follows the CLM4.5 scheme for trees and crops which also uses a turnover rate as the inverse of leaf longevity. When the maximum plantation age (usually 25 years) of oil palm is reached and a new rotation cycle starts, the whole PFT is turned off and all $\mathrm{C}$ and $\mathrm{N}$ of the leaves, stem and roots go to litter. Existing fruit $\mathrm{C}$ and $\mathrm{N}$ of mature phytomers go to the fruit output pools. The PFT is then replanted in the next year and enters new phenological cycles.

\subsection{2. $\mathrm{C}$ and $\mathrm{N}$ allocation}

In CLM, the fate of newly assimilated $\mathrm{C}$ from photosynthesis is determined by a coupled $\mathrm{C}$ and $\mathrm{N}$ allocation routine. Potential allocation for new growth of various plant tissues is calculated based on allocation coefficients and their allometric relationship (Table A 2.2). 
A two-step allocation scheme is designed for the sub-canopy phytomer structure and according to the new phenology. First, available $\mathrm{C}$ (after subtracting respiration costs) is partitioned to the root, stem, overall leaf, and overall fruit pools with respect to their relative demands by dynamic allocation functions according to PFT-level phenology. The C:N ratios for different tissues link $\mathrm{C}$ demand and $\mathrm{N}$ demand so that a $\mathrm{N}$ downregulation mechanism is enabled to rescale GPP and $\mathrm{C}$ allocation if $\mathrm{N}$ availability from soil mineral $\mathrm{N}$ pool and retranslocated $\mathrm{N}$ pool does not meet the demand. Then, the actual $\mathrm{C}$ and $\mathrm{N}$ allocated to the overall leaf or fruit pools are partitioned between different phytomers at the sub-PFT level (Fig. 2.2). Details are described below.

\section{PFT level allocation}

$\mathrm{C}$ and $\mathrm{N}$ allocation at the PFT level is treated distinctly before and after oil palm reaches vegetative maturity. At the juvenile stage before fruiting starts (i.e. $G D D_{15}<G D D_{\min }$ ) all the allocation goes to the vegetative components. The following equations are used to calculate the allometric ratios for partitioning available $\mathrm{C}$ and $\mathrm{N}$ to the leaf, stem, and root pools.

$$
\begin{array}{r}
A_{\text {root }}=a_{\text {root }}^{i}-\left(a_{\text {root }}^{i}-a_{\text {root }}^{f}\right) \frac{D P P}{A g e_{\text {max }}} \\
A_{\text {leaf }}=f_{\text {leaf }}^{i} \times\left(1-A_{\text {root }}\right) \\
A_{\text {stem }}=1-A_{\text {root }}-A_{\text {leaf }}
\end{array}
$$

where $\frac{D P P}{A g e_{\max }} \leq 1, D P P$ is the days past planting, and $A g e_{\max }$ is the maximum plantation age ( 25 years). $a_{\text {root }}^{i}$ and $a_{\text {root }}^{f}$ are the initial and final allocation coefficients for roots and $f_{\text {leaf }}^{i}$ is the initial leaf allocation coefficient before fruiting (Table A 2.2). Root and stem allocation ratios are calculated with Eqs. 2.1 and 2.3 for all ages and phenological stages of oil palm.

After fruiting begins, the new non-linear function is used for leaf allocation:

$$
A_{\text {leaf }}=a_{\text {leaf }}^{2}-\left(a_{\text {leaf }}^{2}-a_{\text {leaf }}^{f}\right)\left(\frac{D P P-D P P_{2}}{A g e_{\text {max }} \times d_{\text {mat }}-D P P_{2}}\right)^{d_{\text {alloc }}^{\text {leaf }}}
$$

where $a_{\text {leaf }}^{2}$ equals the last value of $A_{\text {leaf }}$ calculated right before fruit-fill starts and $D P P_{2}$ is the days past planting right before fruit-fill starts. $d_{\text {mat }}$ controls the age when the leaf allocation ratio approaches its final value $a_{\text {leaf }}^{f}$, while $d_{\text {alloc }}^{\text {leaf }}$ determines the shape of change (convex when $d_{\text {alloc }}^{\text {leaf }}<1$; concave when $\left.d_{\text {alloc }}^{\text {leaf }}>1\right)$. A $A_{\text {leaf }}$ stabilizes at $a_{\text {leaf }}^{f}$ when $D P P \geq$ $A g e_{\text {max }} d_{\text {mat }}$. The equations reflect changed vegetative allocation strategy that shifts resources 
to leaf for maintaining LAI and increasing photosynthetic productivity when fruiting starts. The three vegetative allocation ratios $A_{\text {leaf }}, A_{\text {stem }}$ and $A_{\text {root }}$ always sum to 1 .

At the reproductive phase a fruit allocation ratio $A_{\text {fruit }}$ is introduced, which is relative to the total vegetative allocation unity. To represent the dynamics of reproductive allocation effort of oil palm, we adapt the stem allocation scheme for woody PFTs in CLM, in which increasing NPP results in increased allocation ratio for the stem wood (Oleson et al., 2013). A similar formula is used for reproductive allocation of oil palm so that it increases with increasing NPP:

$$
A_{\text {fruit }}=\frac{2}{1+e^{-b\left(N P P \text { month }^{-100)}\right.}}-a
$$

where $N P P_{\text {month }}$ is the monthly sum of NPP from the previous month calculated with a runtime accumulator in the model. The number $100\left(\mathrm{~g} \mathrm{C} \mathrm{m}^{-2} \mathrm{month}^{-1}\right)$ is the base monthly NPP when the palm starts to yield (Kotowska et al., 2015). Parameters $a$ and $b$ adjust the base allocation rate and the slope of change, respectively (Table A 2.2). This function generates a dynamic curve of $A_{\text {fruit }}$ increasing from the beginning of fruiting to full vegetative maturity, which is used in the allocation allometry to partition assimilates between vegetative and reproductive pools (Fig. 2.3).

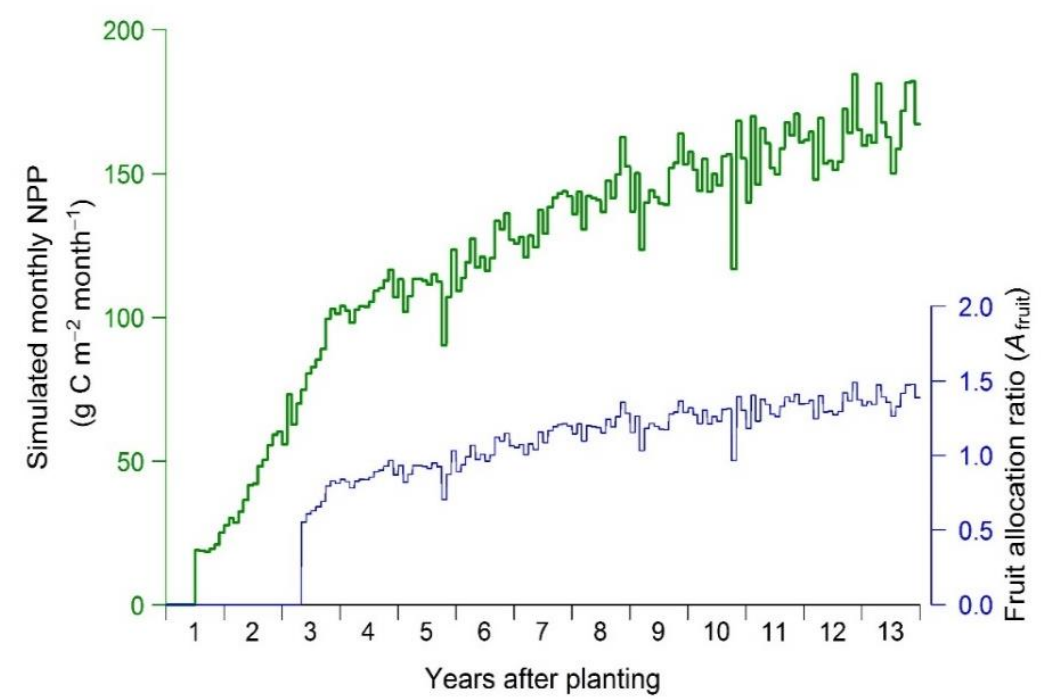

Figure 2.3. Time course of reproductive allocation rate (blue line) in relation to monthly NPP from the previous month (NPP ${ }_{\text {mon }}$, green line) according to Eq. (2.6). $A_{\text {fruit }}$ is relative to the vegetative unity $\left(A_{\text {leaf }}+A_{\text {stem }}+A_{\text {root }}=1\right.$ and $\left.0 \leq A_{\text {fruit }} \leq 2\right)$. The data shown here were simulated with calibrated parameters for the PTPN-VI site. 
Total leaf and fruit allocations are partitioned to the different phytomers according to their phenological stages. Fruit allocation per phytomer is calculated with a sink size index:

$$
S_{p}^{\text {fruit }}=\frac{G D D_{15}-H_{p}^{F . f i l l}}{H_{p}^{F . m a t}-H_{p}^{F . f i l l}},
$$

where $p$ stands for the phytomer number, $H_{p}^{F . f i l l}$ and $H_{p}^{F . m a t}$ are the phenological indices for the start of fruit-fill and fruit maturity (when $H_{p}^{F . f i l l} \leq G D D_{15} \leq H_{p}^{F . m a t}$ ). $S_{p}^{\text {fruit }}$ increases from zero at the beginning of fruit-fill to the maximum of 1 right before harvest for each phytomer. This is because the oil palm fruit accumulates assimilates at increasing rate during development until the peak when it becomes ripe and oil synthesis dominates the demand (Corley and Tinker, 2016). The sum of $S_{p}^{\text {fruit }}$ for all phytomers gives the total reproductive sink size index. Each phytomer receives a portion of fruit allocation by $\frac{s_{p}^{\text {fruit }}}{\sum_{p=1}^{n} s_{p}^{\text {fruit }}} \times A_{\text {fruit }}$, where $A_{\text {fruit }}$ is the overall fruit allocation by Eq. (2.6).

An important allocation strategy for leaf is the division of displayed versus storage pools for the pre-expansion and post-expansion leaf growth phases. These two types of leaf $\mathrm{C}$ and $\mathrm{N}$ pools are distinct in that only the displayed pools contribute to LAI growth, whereas the storage pools support the growth of unexpanded phytomers, i.e. bud \& spear leaves, which remain photosynthetically inactive. Total $\mathrm{C}$ and $\mathrm{N}$ allocation to the overall leaf pool is divided to the displayed and storage pools by a fraction $l f_{\text {disp }}$ (Table A 2.2) according to the following equation:

$$
\begin{gathered}
A_{\text {leaf }}^{\text {display }}=l f_{\text {disp }} \times A_{\text {leaf }} \\
A_{\text {leaf }}^{\text {storage }}=\left(1-l f_{\text {disp }}\right) \times A_{\text {leaf }}
\end{gathered}
$$

The plant level $A_{\text {leaf }}^{\text {display }}$ and $A_{\text {leaf }}^{\text {storage }}$ are then distributed evenly to expanded and unexpanded phytomers, respectively, at each time step. When a phytomer enters the leaf expansion phase, $\mathrm{C}$ and $\mathrm{N}$ from its leaf storage pools transfer gradually to the displayed pools during the expansion period. Therefore, a transfer flux is added to the real-time allocation flux and they together contribute to the post-expansion leaf growth.

LAI is calculated only for each expanded phytomer according to a constant specific leaf area (SLA) and prognostic amount of leaf $\mathrm{C}$ accumulated by phytomer $n$. In case it reaches the prescribed maximum $\left(P L A I_{\max }\right)$, partitioning of leaf $\mathrm{C}$ and $\mathrm{N}$ allocation to this phytomer becomes zero. 


\subsubsection{Other parameterizations}

$\mathrm{N}$ retranslocation is performed exclusively during leaf senescence and stem turnover. A part of $\mathrm{N}$ from senescent leaves and from the portion of live stem that turns dead is remobilized to a separate $\mathrm{N}$ pool that feeds plant growth or reproductive demand. $\mathrm{N}$ of fine roots is all moved to the litter pool during root turnover. We do not consider $\mathrm{N}$ retranslocation from live leaves, stem and roots specifically during grain-fill that is designed for annual crops (Drewniak et al., 2013) because oil palm has continuous fruit-fill year around at different phytomers.

The fertilization scheme for oil palm is adapted to the plantation management generally carried out in our study area, which applies fertilizer biannually, starting only 6 years after planting, assuming each fertilization event lasts one day. Currently the CLM-CN belowground routine uses an unrealistically high denitrification rate under conditions of $\mathrm{N}$ saturation, e.g. after fertilization, which results in a $50 \%$ loss of any excess soil mineral $\mathrm{N}$ per day (Oleson et al., 2013). This caused the simple biannual regular fertilization nearly useless because peak $\mathrm{N}$ demand by oil palm is hard to predict given its continuous fruiting and vegetative growth and most fertilized $\mathrm{N}$ is thus lost in several days. The high denitrification factor has been recognized as an artifact (Drewniak et al., 2013; Tang et al., 2013). According to a study on a banana plantation in the tropics (Veldkamp and Keller, 1997), around 8.5\% of fertilized $\mathrm{N}$ is lost as nitrogen oxide $\left(\mathrm{N}_{2} \mathrm{O}\right.$ and $\left.\mathrm{NO}\right)$. Accounting additionally for a larger amount of denitrification loss to gaseous $\mathrm{N}_{2}$, we modified the daily denitrification rate from 0.5 to 0.001 , which gives a $30 \%$ annual loss of $\mathrm{N}$ due to denitrification that matches global observations (Galloway et al., 2004).

The irrigation option is turned off because oil palm plantations in the study area are usually not irrigated. Other input parameters for oil palm such as its optical, morphological, and physiological characteristics are summarized in Table A 2.3. Most of them are generalized over the life of oil palm.

\subsection{Model evaluation}

\subsubsection{Site data}

Two oil palm plantations in the Jambi province of Sumatra, Indonesia provide data for calibration. One is a mature industrial plantation at PTPN-VI (01 ${ }^{\circ} 41.6^{\prime} \mathrm{S}, 103^{\circ} 23.5^{\prime} \mathrm{E}, 2186$ ha) planted in 2002, which provides long-term monthly harvest data (2005 to 2014). Another is a 2-year young plantation at a nearby smallholder site Pompa Air $\left(01^{\circ} 50.1^{\prime} \mathrm{S}, 103^{\circ} 17.7^{\prime} \mathrm{E}\right.$, 
$5.7 \mathrm{ha})$. The leaf area and dry weight at multiple growth stages were measured by sampling leaflets of phytomers at different ranks $(+1$ to +20$)$ on a palm and repeating for 3 different ages within the two plantations. The input parameter SLA (Table A 2.2) was derived from leaf area and dry weight (excluding the heavy rachis). The phytomer-level LAI was estimated based on the number of leaflets (90-300) per leaf of a certain rank and the PFT-level LAI was estimated by the number of expanded leaves (35-45) per palm of a certain age. In both cases, a planting density of 156 palms per hectare $(8 \mathrm{~m} \times 8 \mathrm{~m}$ per palm) was used according to observation.

Table 2.1. Site conditions and $\mathrm{N}$ fertilization records at the calibration and validation plots.

\begin{tabular}{|c|c|c|c|c|c|c|}
\hline \multirow[t]{2}{*}{ Site } & \multirow[t]{2}{*}{$\begin{array}{l}\text { Year of } \\
\text { planting }\end{array}$} & \multirow[t]{2}{*}{$\begin{array}{l}\text { Precipitation } \\
\qquad\left(\mathrm{mm} \mathrm{yr}^{-1}\right)\end{array}$} & \multirow[t]{2}{*}{ Soil type } & \multicolumn{2}{|c|}{$\begin{array}{l}\text { Fertilization } \\
\left(\mathrm{kg} \mathrm{N} \mathrm{ha}^{-1} \mathrm{yr}^{-1}\right)\end{array}$} & \multirow[t]{2}{*}{ Comments } \\
\hline & & & & amount & period & \\
\hline $\begin{array}{l}\text { PTPN- } \\
\text { VI }\end{array}$ & 2002 & 2567 & $\begin{array}{c}\text { loam } \\
\text { Acrisol }\end{array}$ & 456 & $2008-2014$ & $\begin{array}{c}\text { industrial plantation; } \\
\text { others are } \\
\text { smallholders }\end{array}$ \\
\hline $\begin{array}{l}\text { Pompa } \\
\text { Air }\end{array}$ & 2012 & 2567 & $\begin{array}{c}\text { loam } \\
\text { Acrisol }\end{array}$ & - & - & $\begin{array}{l}\mathrm{N} \text { fertilization from } \\
\text { 6-year old onward }\end{array}$ \\
\hline HO1 & 1997 & 2567 & $\begin{array}{c}\text { loam } \\
\text { Acrisol }\end{array}$ & 96 & $2003-2014$ & regular fertilization \\
\hline $\mathrm{HO} 2$ & 1999 & 2567 & $\begin{array}{c}\text { loam } \\
\text { Acrisol }\end{array}$ & 96 & $2005-2014$ & regular fertilization \\
\hline $\mathrm{HO} 3$ & 1996 & 2567 & $\begin{array}{c}\text { loam } \\
\text { Acrisol }\end{array}$ & 96 & $2002-2014$ & regular fertilization \\
\hline $\mathrm{HO} 4$ & 2003 & 2567 & $\begin{array}{c}\text { loam } \\
\text { Acrisol }\end{array}$ & 96 & $2009-2014$ & regular fertilization \\
\hline $\mathrm{BO} 2$ & 2000 & 2902 & clay Acrisol & 24 & 2006-2012 & reduced fertilization \\
\hline $\mathrm{BO} 3$ & 2001 & 2902 & clay Acrisol & 24 & $2007-2012$ & reduced fertilization \\
\hline BO4 & 2002 & 2902 & clay Acrisol & 24 & $2008-2012$ & reduced fertilization \\
\hline BO5 & 2004 & 2902 & clay Acrisol & 24 & $2010-2012$ & reduced fertilization \\
\hline
\end{tabular}


Additionally, LAI, yield and NPP measurements from eight independent smallholder oil palm plantations $(50 \mathrm{~m} \times 50 \mathrm{~m}$ each) were used for model validation (Table 2.1). Four of these sites ( $\mathrm{HO} 1, \mathrm{HO} 2, \mathrm{HO} 3, \mathrm{HO} 4)$ are located in the Harapan region nearby PTPN-VI, and another four $(\mathrm{BO} 2, \mathrm{BO} 3, \mathrm{BO} 4, \mathrm{BO})$ are in Bukit Duabelas region $\left(02^{\circ} 04^{\prime} \mathrm{S}, 102^{\circ} 47^{\prime} \mathrm{E}\right)$, both in Jambi, Sumatra. Fresh bunch harvest data were collected at these sites for a whole year in 2014. Harvest records from both PTPN-VI and the 8 validation sites were converted to harvested C $\left(\mathrm{g} \mathrm{C} / \mathrm{m}^{2}\right)$ with mean dry/wet weight ratio of $58.65 \%$ and $\mathrm{C}$ content $60.13 \%$ per dry weight according to C:N analysis (Kotowska et al., 2015). The oil palm monthly NPP and its partitioning between fruit, leaf, stem and root were estimated based on measurements of fruit yield (monthly), pruned leaves (monthly), stem increment (every 6 month) and fine root samples (once in a interval of 6-8 month) at the eight validation sites (Kotowska et al., 2016).

The amount of fertilization at the industrial plantation PTPN-VI was $456 \mathrm{~kg} \mathrm{~N} \mathrm{ha}^{-1} \mathrm{yr}^{-1}$, applied regularly twice per year since 6-year old. The smallholder plantations in Harapan (H plots) and Bukit Duabelas (B plots) used much less fertilizer. From interview data, the $\mathrm{H}$ plots had roughly regular $\mathrm{N}$ fertilization (twice per year), whereas among the B plots only BO3 indicated one fertilization event per year but the amount was unclear (applied chicken manure in 2013) and the other plots had no N fertilization in 2013 and 2014 due to financial difficulty. Fertilization history prior to 2013 is unavailable for all the smallholder plantations. Given the limited information, we consider two levels of fertilization for $\mathrm{H}$ plots (regular: $96 \mathrm{~kg} \mathrm{~N} \mathrm{ha}^{-1} \mathrm{yr}^{-1}$, from 6-year old until 2014) and B plots (reduced: $24 \mathrm{~kg} \mathrm{~N} \mathrm{ha}^{-1} \mathrm{yr}^{-1}$, from 6-year old until 2012), respectively (Table 2.1).

The mean annual rainfall (the Worldclim database: http://www.worldclim.org (Hijmans et al., 2005); average of 50 years) of the two investigated landscapes in Jambi Province was 2567 $\mathrm{mm} \mathrm{y}^{-1}$ in the Harapan region (including PTPN-VI) and $\sim 2902 \mathrm{~mm} \mathrm{y}^{-1}$ in the Bukit Duabelas region. In both areas, May to September represented a markedly drier season (30\% less precipitation) in comparison to the rainy season between October and April. Air temperature is relatively constant throughout the year with an annual average of $26.7^{\circ} \mathrm{C}$. In both landscapes, the principal soil types are Acrisols: in the Harapan landscape loam Acrisols dominate, whereas in Bukit Duabelas the majority is clay Acrisol. Soil texture such as sand/silt/clay ratios and soil organic matter $\mathrm{C}$ content were measured at multiply soil layers (down to $2.5 \mathrm{~m}$ ) (Allen et al., 2015). They were used to create two sets of surface input data for the two regions separately.

\subsubsection{Model setup}

The model modifications and parameterizations were implemented according to CLM4.5 standards. A new sub-PFT dimension called phytomer was added to all the new variables so 
that the model can output history tapes of their values for each phytomer and prepare restart files for model stop and restart with bit-for-bit continuity. Simulations were set up in point mode (a single $0.5 \times 0.5$ degree grid) at every 30 -min time step. A spin-up procedure (Koven et al., 2013) was followed to get a steady-state estimate of soil C and N pools, with the CLM-CN decomposition cascade and broadleaf evergreen tropical forest PFT. The soil $\mathrm{C}$ and $\mathrm{N}$ pools were rescaled to match the average field observation at two reference lowland rainforest sites in Harapan and Bukit Duabelas regions (Allen et al., 2015; Guillaume et al., 2015), which serve as the initial conditions. The forest was replaced with the oil palm at a specific year of plantation establishment (2002 for PTPN-VI and 1996, 1997, 1999, 2000, 2001, 2002, 2003, 2004 for $\mathrm{HO} 3, \mathrm{HO} 1, \mathrm{HO} 2, \mathrm{BO} 2, \mathrm{BO} 3, \mathrm{BO} 4, \mathrm{HO} 4, \mathrm{BO} 5$, respectively). The oil palm functions were then turned on and simulations continued until 2014. The 3-hourly ERA Interim climate data (Dee et al., 2011) were used as atmospheric forcing.

\subsubsection{Calibration of key parameters}

A simulation from 2002 to 2014 at the PTPN-VI site was used for model calibration. Both the PFT level and phytomer level LAI development were calibrated with field observations in 2014 from a chronosequence approach (space for time substitution) using oil palm samples of three different age and multiple phytomers of different rank. Simulated yield outputs (around twice per month) were calibrated with monthly harvest records of PTPN-VI plantation from 2005 to 2014. Cumulative yields were compared because the timing of harvest in the plantations was largely uncertain and varied depending on weather and other conditions.

To simplify model calibration, we focused on parameters related to the new phenology and allocation processes. Phenological parameters listed in Table A 2.1 were determined according to field observations and existing knowledge about oil palm growth phenology (Combres et al., 2013; Corley and Tinker, 2016) as well as plantation management in Sumatra, Indonesia. Allocation coefficients in Table A 2.2 were more uncertain and they were the key parameters to optimize in order to match observed LAI and yield dynamics according to the following sensitivity analysis. Measurements of oil palm NPP and its partitioning between fruit, canopy, stem, and root from the eight sites were used as a general reference when calibrating the allocation coefficients.

Leaf C:N ratio and SLA were determined by field measurements. Other C:N ratios and optical and morphological parameters in Table A 2.3 were either fixed by field observations or adjusted in-between trees and crops. 


\subsubsection{Sensitivity analysis}

Performing a full sensitivity analysis of all parameters used in simulating oil palm (more than 100 parameters, though a majority are shared with natural vegetation and other crops) would be a challenging work. As with calibration, we limited the sensitivity analysis to a set of parameters introduced for the specific PFT and model structure designed for oil palm. Among the phenological parameters, mxlivenp (maximum number of expanded phytomers) and phyllochron (Table A 2.1) are closely related to pruning frequency but they should not vary widely for a given oil palm breed and plantation condition. Therefore, they were fixed at the average level for the study sites in Jambi, Sumatra. Parameter $P L A I_{\max }$ is only meant for error controlling, although in our simulations phytomer-level LAI never reached $P L A I_{\max }$ (see Fig. 2.5 in results) because environmental constraints and $\mathrm{N}$ downregulation already limited phytomer leaf growth well within the range. $G D D_{\text {init }}$ was kept to zero because only the transplanting scenario was considered for seedling establishment.

We tested two hypotheses of phytomer level leaf development based on the other phenological parameters: 1) considering the leaf storage growth period, that is, the bud \& spear leaf phase is explicitly simulated with the GDD parameters in Table A 2.1 and $l f_{d i s p}=0.3$ in Table A 2.2;2) excluding the storage growth period by setting $G D D_{\exp }=0$ and $l f_{\text {disp }}=1$ so that leaf expands immediately after initiation and leaf $\mathrm{C}$ and $\mathrm{N}$ allocation all goes to the photosynthetic active pools.

The sensitivity of allocation and photosynthesis parameters in Table A 2.2 were tested by adding or subtracting $10 \%$ or $30 \%$ to the baseline values (calibrated) one-by-one and calculating their effect on final cumulative yield at the end of simulation (December 2014). In fact, all the allocation parameters are interconnected because they co-determine photosynthesis capacity and respiration costs as partitioning to the different vegetative and reproductive components varies. This simple approach provides a starting point to identify sensitive parameters, although a more sophisticated sensitivity analysis is needed in the future.

\subsubsection{Validation}

In this study, we only validated the model structure and model behavior on simulating aboveground $\mathrm{C}$ dynamics and partitioning as represented by LAI, fruit yield and NPP. Independent leaf measurement, yield and monthly NPP data collected in 2014 from the eight mature oil palm sites ( $\mathrm{H}$ and $\mathrm{B}$ plots) were compared with the eight simulations using the same model settings and calibrated parameters, except that two categories of climate forcing, surface 
input data (for soil texture) and fertilization (regular vs. reduced) were prescribed for the $\mathrm{H}$ plots and B plots, respectively.

\subsection{Results}

\subsubsection{Calibration with LAI and yield}

In calibration with the industrial PTPN-VI plantation, the PFT-level LAI dynamics simulated by the model incorporating the pre-expansion phase matches well with the LAI measurements for three different ages (Fig. 2.4). Simulated LAI for the PFT increases with age in a sigmoid relationship. The dynamics of LAI is also impacted by pruning and harvest events because oil palms invest around half of their assimilates into fruit yield. Oil palms are routinely pruned by farmers to maintain the maximum number of expanded leaves around 40. Hence, when yield begins 2-3 years after planting, LAI recurrently shows an immediate drop after pruning and then quickly recovers. The pruning frequency decreases with age because the phyllochron increases to 1.5 times at 10-year old (Table A 2.1). Simulations without the pre-expansion storage growth phase show an unrealistic fast increase of LAI before 3 years old, much higher than observed in the field. At older age after yield begins, LAI drops drastically and recovers afterwards. Although the final LAI could stabilize at a similar level, the initial jump and drop of LAI at young stage do not match field observations and cannot be solved by adjusting parameters other than $G D D_{\text {exp. }}$. Hereafter, all simulations were run using the pre-expansion phase.

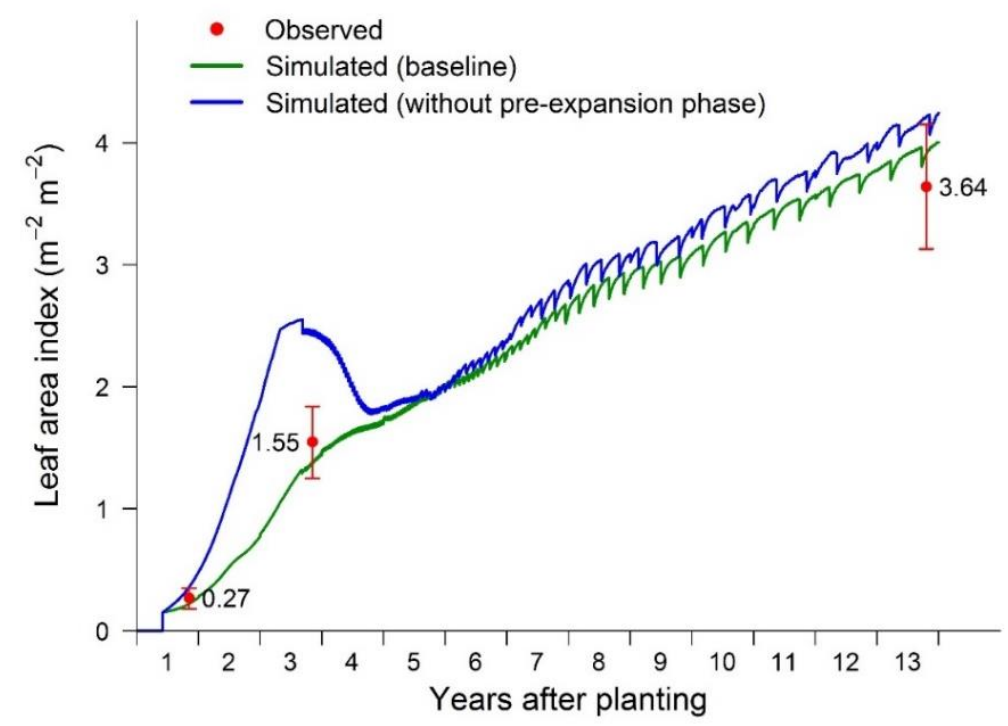

Figure 2.4. PFT-level LAI simulated by CLM-Palm, with and without the pre-expansion growth phase in the phytomer phenology and compared to field measurements used for 
calibration. The initial sudden increase at year 1 represents transplanting from nursery. The sharp drops mark pruning events.

The phytomer level LAI development is comparable with leaf samples from the field (Fig. 2.5). The two leaf samples at rank $5(\mathrm{LAI}=0.085)$ and rank $20(\mathrm{LAI}=0.122)$ of a mature oil palm in PTPN-VI (the two black crosses for 2014) are slightly lower than simulated values $(0.089$ and 0.138 , respectively). The other sample at rank 25 (LAI $=0.04$, for 2004) of a young oil palm in Pompa Air is slightly higher than the simulated value (0.036). Each horizontal color bar clearly marks the post-expansion leaf phenology cycle, including gradual increment of photosynthetic LAI during phytomer development and gradual declining during senescence. The pre-expansion phase is not included in the figure but model outputs show that roughly 60$70 \%$ of leaf $\mathrm{C}$ in a phytomer is accumulated before leaf expansion, which is co-determined by the allocation ratio $l f_{\text {disp }}$ and the lengths of two growth phases set by $G D D_{\exp }$ and $G D D_{\text {L.mat. }}$. This is comparable to observations on coconut palm that dry mass of the oldest unexpanded leaf accounts for $60 \%$ of that of a mature leaf (Navarro et al., 2008). Only when the palm becomes mature, phytomer LAI could come closer to the prescribed $P L A I_{\max }(0.165)$. However, during the whole growth period from 2002 to 2014 none of the phytomers have reached $P L A I_{\max }$, which is the prognostic result of the $\mathrm{C}$ balance simulated by the model.

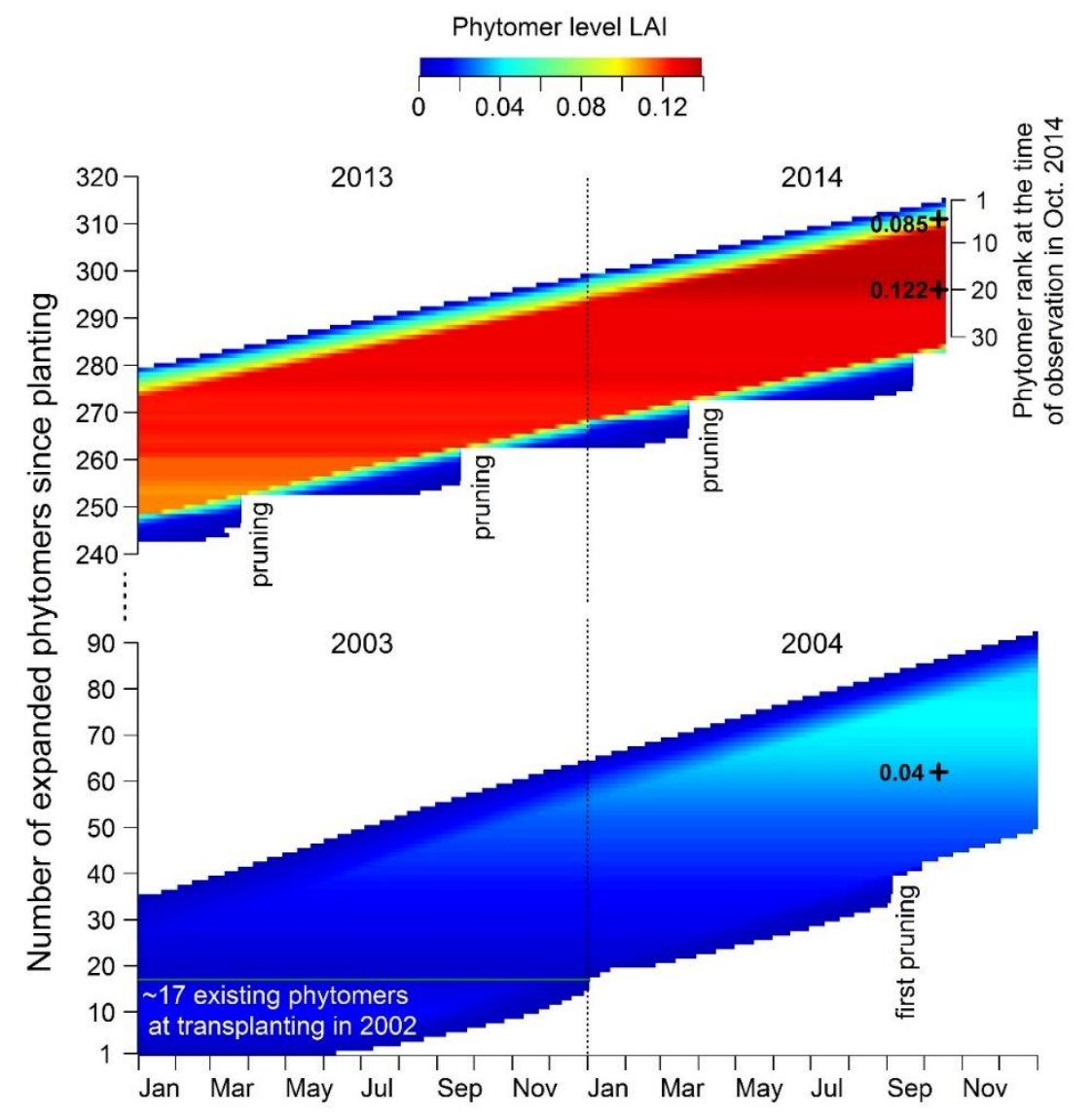


Figure 2.5. Simulated phytomer level LAI dynamics (horizontal color bar) compared with field observations (black crosses with measured LAI values). A phytomer in the model is only meant to represent the average condition of an age-cohort of actual oil palm phytomers across the whole plantation landscape. The newly expanded phytomer at a given point of time has a rank of 1. Each horizontal bar represents the life cycle of a phytomer after leaf expansion. Phytomers emerge in sequence and the $y$-axis gives the total number of phytomers that have expanded since transplanting in the field. Senescent phytomers are pruned.

The cumulative yield of baseline simulation has overall high consistency with harvest records (Fig. 2.6). The mean percentage error (MPE) is only $3 \%$. The slope of simulated curve increases slightly after 2008 when the LAI continues to increase and NPP reaches a high level (Fig. 2.3). The harvest records also show the same pattern after 2008 when heavy fertilization began (456 $\left.\operatorname{kg~N~ha-1~} \mathrm{yr}^{-1}\right)$.

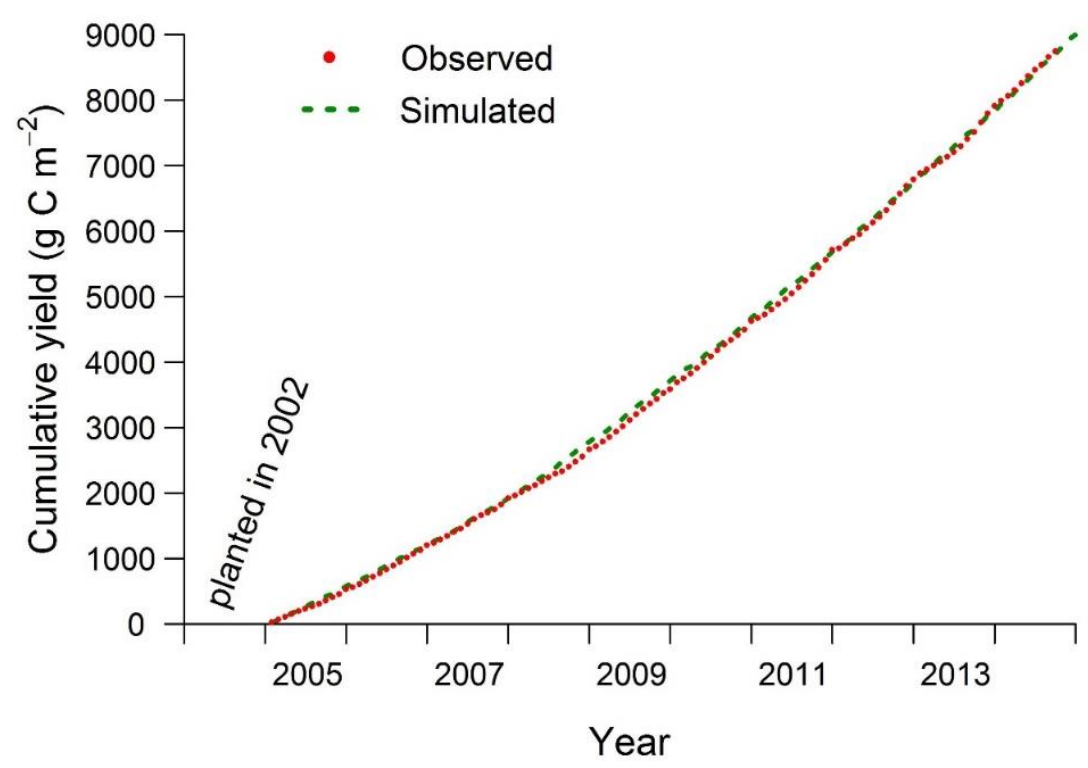

Figure 2.6. Simulated PFT-level yield compared with monthly harvest data (2005-2014) from the calibration site PTPN-VI in Jambi, Sumatra. CLM-Palm represents multiple harvests from different phytomers (about twice per month). The cumulative harvest amounts throughout time are compared.

The per-month harvest records exhibit strong zig-zag pattern (Fig. 2.7). One reason is that oil palms are harvested every 15-20 days and summarizing harvest events by calendar month would result in uneven harvest times per month, e.g. two harvests fall in a previous month and only one in the next month. Yet it still shows that harvests at PTPN-VI plantation dominated from October to December whereas in the earlier months of each year harvest amounts were significantly lower. The simulated monthly yield has less seasonal fluctuation, but it corresponds to the general pattern of precipitation (Fig. 2.7). A significant positive linear 
correlation exists between simulated yield (detrended to minimize phenological effects) and the accumulative precipitation of a 120-day period (the main fruit-filling and oil synthesis period) before each harvest event (Pearson's $r=0.32, p$-value $<1 \mathrm{E}-06$ ). Examining the longer term year-to-year variability, a clear increasing trend of yield with increasing plantation age is captured by the model, largely matching field records since the plantation began to yield in 2005 .

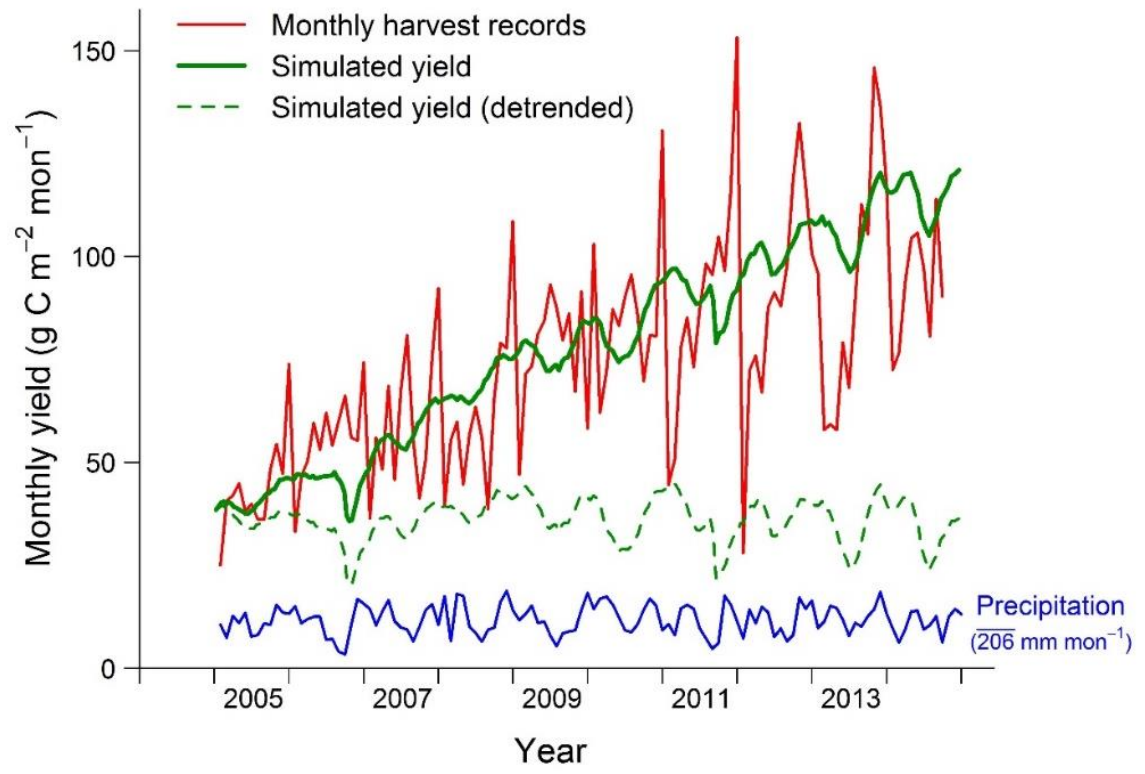

Figure 2.7. Comparison of simulated and observed monthly yield at PTPN-VI. The modeled yield outputs are per harvest event (every 15-20 days depending on the phyllochron), while harvest records are the summary of harvest events per month. The model output is thus rescaled to show the monthly trend of yield that matches the mean of harvest records, given that the cumulative yields are almost the same between simulation and observation as shown in Fig. 2.6. The detrended curve is to facilitate comparison with the dynamics of monthly mean precipitation.

\subsubsection{Sensitivity analysis}

The leaf $\mathrm{N}$ fraction in Rubisco $\left(F_{L N R}\right)$ is shown to be the most sensitive parameter (Fig. 2.8), because it determines the maximum rate of carboxylation at $25{ }^{\circ} \mathrm{C}\left(V_{c \max 25}\right)$ together with $S L A$ (also sensitive), foliage $\mathrm{N}$ concentration ( $C N_{\text {leaf }}$, Table A 2.3$)$ and other constants. Given the fact that $F_{L N R}$ should not vary widely in nature for a specific plant, we constrained this parameter within narrow boundaries to get a $V_{c \max 25}$ around 100.7 , the same as that shared by all other crop PFTs in CLM. We fixed SLA to 0.013 by field measurements. The value is only representative of the photosynthetic leaflets. The initial root allocation ratio $\left(a_{\text {root }}^{i}\right)$ has considerable influence on yield because it modifies the overall respiration cost along the gradual declining trend of 
fine root growth across 25 years (Eq. 2.2). The final ratio $\left(a_{\text {root }}^{f}\right)$ has limited effects because its baseline value $(0.1)$ is set very low and thus the percentage changes are insignificant. The leaf allocation coefficients $\left(f_{\text {leaf }}^{i}, a_{\text {leaf }}^{f}\right)$ are very sensitive parameters because they determine the magnitudes of LAI and GPP and consequently yield. The coefficients $d_{\text {mat }}$ and $d_{\text {alloc }}^{\text {leaf }}$ control the nonlinear curve of leaf development (Eq. 2.5) and hence the dynamics of NPP and that partitioned to fruits. Increased $F_{\text {stem }}^{\text {live }}$ results in higher proportion of live stem throughout life, given the fixed stem turnover rate, and therefore it brings higher respiration cost and lower yield. The relative influence of fruit allocation coefficients $a$ and $b$ on yield is much lower than the leaf allocation coefficients because of the restriction of $A_{\text {fruit }}$ by NPP dynamics (Eq. 2.6). Parameters $l f_{d i s p}$ and transplant have negligible effects. $l f_{d i s p}$ has to work together with the phenological parameter $G D D_{\text {exp }}$ to give a reasonable size of spear leaves before expansion according to field observation. The sensitivity of $G D D_{\exp }$ is shown in Fig. 2.4. Varying the size of seedlings at transplanting by $10 \%$ or $30 \%$ does not alter the final yield, likely because the initial LAI is still within a limited range (0.1 0.2) given the baseline value 0.15.

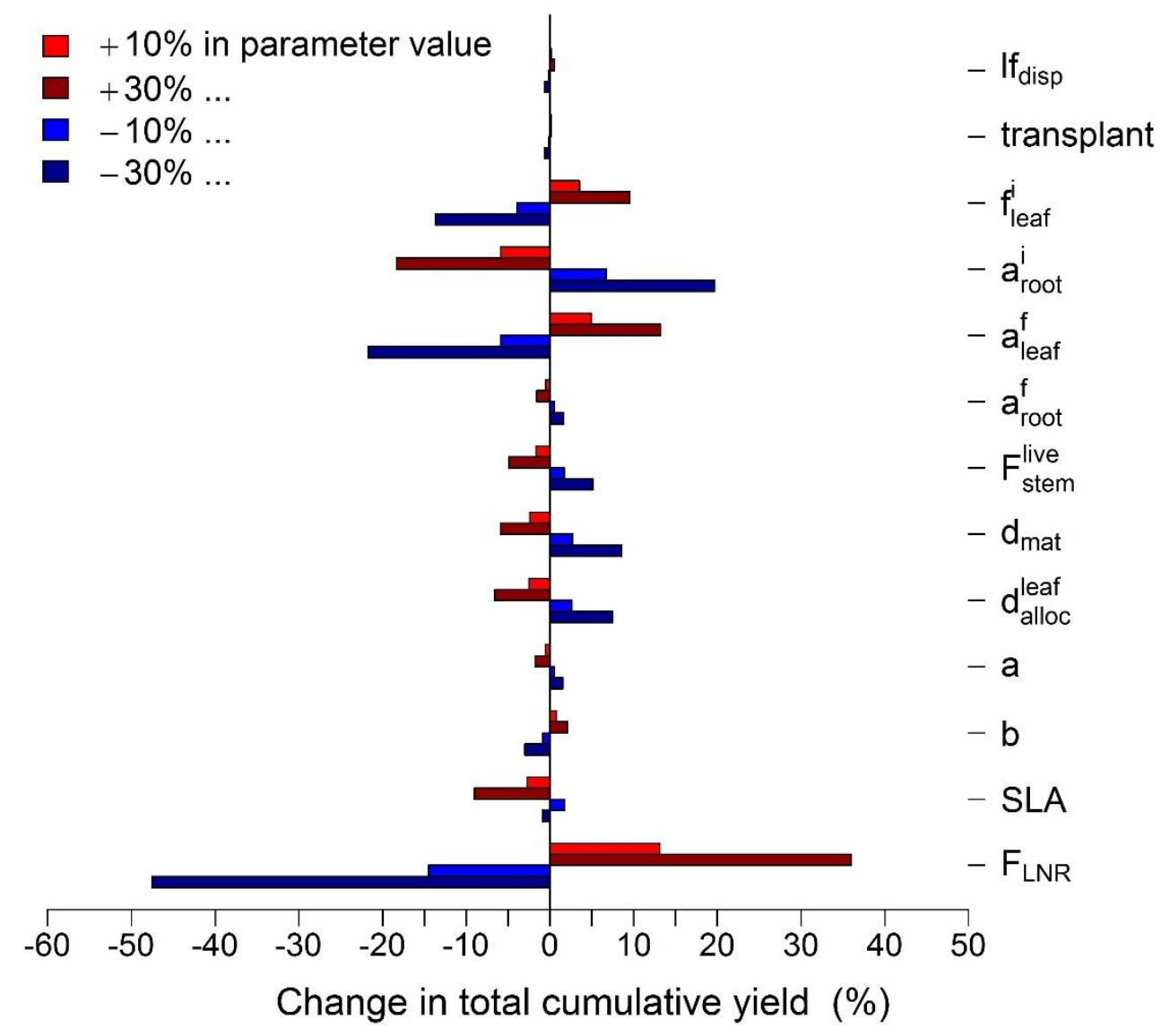

Figure 2.8. Sensitivity analysis of key allocation parameters in regard of the cumulative yield at the end of simulation, with two magnitudes of change in the value of a parameter one-byone while others are hold at the baseline values in Table A 2.2. 


\subsubsection{Model validation with independent dataset}

The LAI development curves for the eight oil palm sites follow similar patterns since field transplanting in different years, except that the $\mathrm{B}$ plots $(\mathrm{BO} 2, \mathrm{BO} 3, \mathrm{BO} 4)$ are restrained in LAI growth after 11 years old because of reduced fertilization (Fig. 2.9a). The field data in 2014 also shows the check by $\mathrm{N}$ limitation and even exhibits a decreasing trend of LAI with increasing plantation age at B plots except BO5 which is under 10 years old (Fig. 2.9b). In general, the modelled LAI has a positive relationship with plantation age under regularly fertilized condition and it stabilizes after 15-year old (site HO3) as controlled by $d_{\text {mat }}$ (Eq. 2.5). This age-dependent trend is observed in the field with a notable deviation by site HO1. The average LAI of the eight sites from the model is comparable with field measurement in $2014($ MPE $=13 \%)$. There are large uncertainties in field LAI estimates because we did not measure LAI at the plot level directly but only sampled leaf area and dry weight of individual phytomers and scaled the values up.

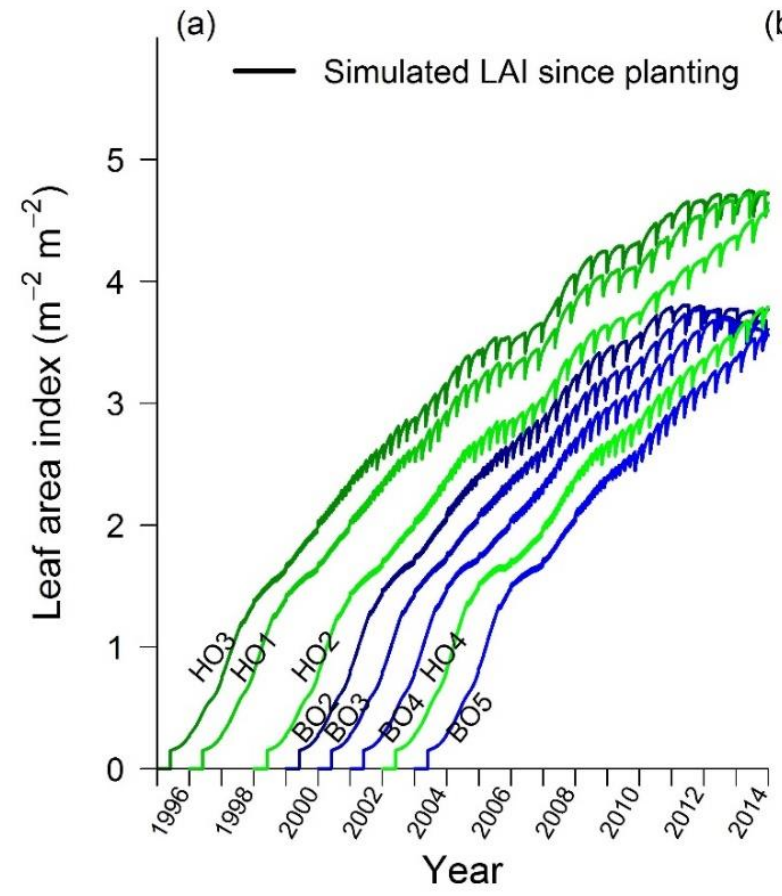

(b) - Measured LAI March 2014
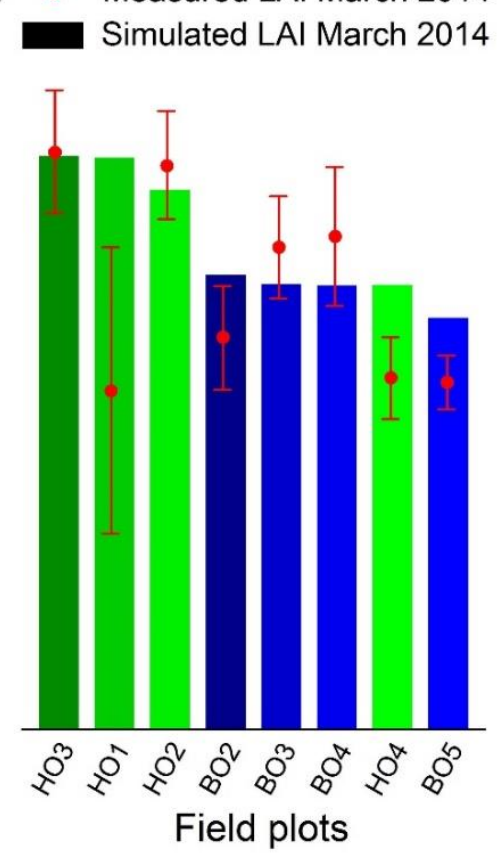

Figure 2.9. Validation of LAI with eight independent oil palm sites (sequence in plantation age) from the Harapan (regular fertilization) and Bukit Duabelas (reduced fertilization) regions: (a) shows the LAI development of each site simulated by the model since planting; (b) shows the comparison of field measured LAI in 2014 with model. 


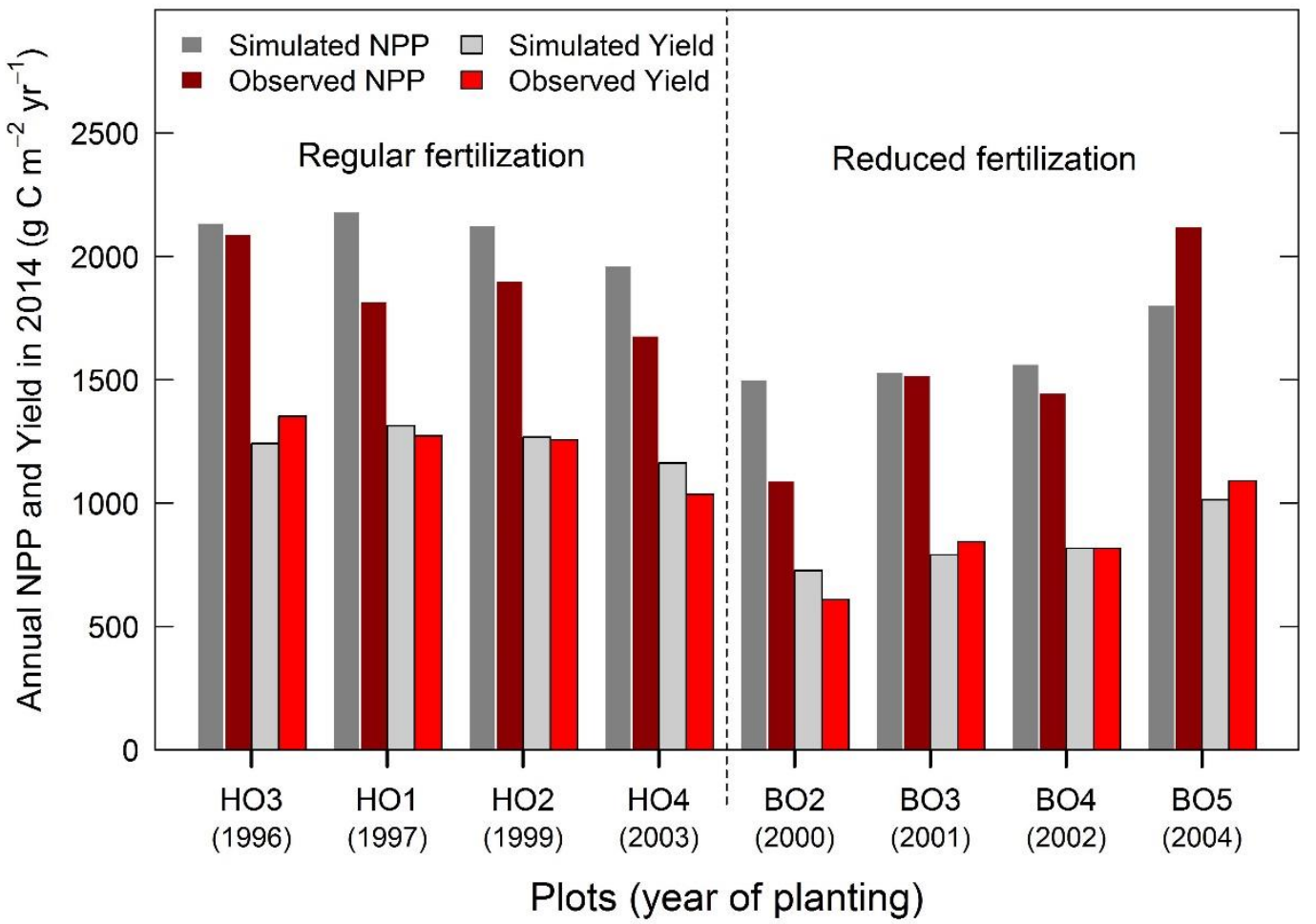

Figure 2.10. Validation of yield and NPP with eight independent oil palm sites from the Harapan $(\mathrm{H})$ and Bukit Duabelas $(\mathrm{B})$ regions with different fertilization treatments. Field data were collected in 2014.

The simulated annual yields match closely with field observations in 2014 at both the H plots $(\mathrm{MPE}=2 \%)$ and B plots (MPE $=2 \%$; Fig. 2.10). With regular fertilization in the H plots, both the modelled and observed yield are slightly higher in the older plantations (HO2, HO1, and HO3) than the younger one (HO4) but stabilize around $1280 \mathrm{~g} \mathrm{C} \mathrm{m}^{-2} \mathrm{yr}^{-1}$ past the age of 15 years. In contrast, the B plots have significantly lower yield because of reduced $\mathrm{N}$ input and the model is able to capture the N limitation effect on both NPP and yield, i.e. the declining trend with increasing age, which is consistent with field observation. The model simulates slightly higher NPP than field estimates at 7 smallholder sites (MPE $=10 \%)$ using the input parameters calibrated and optimized only for LAI and yield at the industrial PTPN-VI plantation. It needs to be noted that field measured NPP at the validation sites does not consider the growing size of canopy (i.e. increasing LAI) which could partly explain the lower observed than simulated NPP at most sites. 


\subsection{Discussion}

Calibration and validation with multiple site data demonstrate the utility of CLM-Palm and its sub-canopy structure for simulating the growth and yield of the unique oil palm plantation system within a land surface modeling context.

The pre-expansion phenological phase is proved necessary for simulating both phytomer-level and PFT-level LAI development in a prognostic manner. The leaf $\mathrm{C}$ storage pool provides an efficient buffer to support phytomer development and maintain overall LAI during fruiting. It also avoids an abnormally fast increase of LAI in the juvenile stage when $\mathrm{C}$ and $\mathrm{N}$ allocation is dedicated to the vegetative components. Without the leaf storage pool, the plant's canopy develops unrealistically fast at young age and then enters an emergent drop once fruit-fill begins (Fig. 2.4). This is because the plant becomes unable to sustain leaf growth just from its current photosynthetic assimilates when a large portion is allocated to fruits.

The model well simulates year-to-year variability in yield (Fig. 2.7), in which the increasing trend is closely related to the fruit allocation function (Fig. 2.3) and LAI development (Fig. 2.4). The seasonal variability in simulated yield corresponds to precipitation, which is involved in the coupled stomatal conductance and photosynthesis and other hydrological processes in the model. But it is difficult to interpret the difference from monthly harvest records due to the artificial zig-zag pattern. The harvest records from plantations do not necessarily correspond to the amount of mature fruits along a phenological time scale due to varying harvest arrangements, e.g. fruits are not necessarily harvested when they are ideal for harvest, but when it is convenient. Observations of mature fruits on a tree basis (e.g. Navarro et al., 2008 on coconut) would be more suitable to compare with modeled yield, but such data are not available at our sites. Some studies have also demonstrated important physiological mechanisms on oil palm yield including inflorescence gender determination and abortion rates that both respond to seasonal climatic dynamics although with a time lag (Combres et al., 2013; Legros et al., 2009). The lack of representation of such physiological traits might affect the seasonal dynamics of yield simulated by our model, but these mechanisms are rarely considered in a land surface modeling context. Nevertheless, the results correspond generally to the purpose of our modeling which is focused on the long-term climatological effects of oil palm agriculture. The correct representation of multi-year trend of $\mathrm{C}$ balance which we did reach is more important than the correct prediction of each yield event. For latter the more agriculturallyoriented models should be used. 
Resource allocation patterns for perennial crops are more difficult to simulate than annual crops. For annuals, the LAI is often assumed to decline during grain-fill (Levis et al., 2012). However, the oil palm has to sustain a rather stable leaf area while partitioning a significant amount of $\mathrm{C}$ to the fruits. The balance between reproductive and vegetative allocations is crucial. The dynamics of $A_{\text {fruit }}$ as a function of monthly NPP is proved useful to capture the increasing yield capacity of oil palms during maturing at favorable conditions (Figs. 2.6, 2.7) and also able to adjust fruit allocation and shift resources to the vegetative components under stress conditions (e.g. N limitation, Figs. 2.9, 2.10). The value of $A_{\text {fruit }}$ increased from 0.5 to 1.5 (Fig. 2.3), resulting more than a half partitioning of NPP to the reproductive pool at mature stage which matched closely with field observations (Kotowska et al., 2015; Kotowska et al., 2016). Our experiments (not shown here) confirmed that the dynamic function is more robust than a simple time-dependent or vegetation-size-dependent allocation function.

The phenology and allocation processes in land surface models are usually aimed to represent the average growth trend of a PFT at large spatial scale (Bonan et al., 2002; Drewniak et al., 2013). We made a step forward by comparing point simulations with multiple specific site observations. The model predicts well the average LAI development and yield as well as NPP of mature plantations across two different regions. Site-to-site variability in yield and NPP at the Harapan and Bukit Duabelas plots under contrasting conditions (regular vs. reduced fertilization) is largely captured by the model. The decreasing trend of yield and pause of LAI growth in B plots after 10 years old (Figs. 2.9,2.10) reflect reduced $\mathrm{N}$ availability observed in the clay Acrisol soil in Bukit Duabelas (Allen et al., 2015) with very limited C and N return from leaf litter because of the pruning and piling of highly lignified leaves (Guillaume et al., 2015). Yet there remains small-scale discrepancy in LAI, NPP or yield in some sites which is possibly due to the fact that microclimate, surface input data and the amount and timing of fertilization were only prescribed as two categories for $\mathrm{H}$ and $\mathrm{P}$ plots, respectively. Field data show the proportion of NPP allocated to yield is significantly higher in plot HO1 (70\%) than in other plots (50\% to $65 \%$ ) which could explain the low LAI of HO1. This is not reflected in the model as the same parameters are used in the fruit allocation function (Eq. 2.6) across sites. The deviation in allocation pattern is likely due to differences in plantation management (e.g. harvest and pruning cycles), which has been shown to be crucial for determining vegetative and reproductive growth (Euler, 2015). Other factors such as insects, fungal infection, and possibly different oil palm progenies could also result in difference in oil palm growth and productivity, but they are typically omitted in land surface models. Generalized input parameterization across a region is usually the case when modeling with a PFT, although a more complex management scheme (e.g. dynamic fertilization) could be devised and evaluated thoroughly with additional field data, which we lack at the moment. 
Overall, the sub-canopy phytomer-based structure, the extended phenological phases for a perennial crop PFT and the two-step allocation scheme of CLM-Palm are distinct from existing functions in land surface models. The phytomer configuration is similar to the one already implemented in other oil palm growth and yield models such as the APSIM-Oil Palm model (Huth et al., 2014) or the ECOPALM yield prediction model (Combres et al., 2013). But the implementation of this sub-canopy structure is the first attempt among land surface models. CLM-Palm incorporates the ability of an agricultural model for simulating growth and yield, beside that it allows the modeling of biogeophysical and biogeochemical processes as a land model should do, e.g. what is the whole fate of $\mathrm{C}$ in plant, soil and atmosphere if land surface composition shifts from a natural system to the managed oil palm system? In a following study, a fuller picture of the $\mathrm{C}, \mathrm{N}$, water and energy fluxes over the oil palm plantation are examined with CLM-Palm presented here and evaluated with eddy covariance flux observation data. We develop this palm sub-model in the CLM framework as it allows coupling with climate models so that the feedbacks of oil palm expansion to climate can be simulated in future steps.

\subsection{Conclusions}

The development of CLM-Palm including canopy structure, phenology, and $\mathrm{C}$ and $\mathrm{N}$ allocation functions was proposed for modeling an important agricultural system in the tropics. This chapter demonstrates the ability of the new palm module to simulate the inter-annual dynamics of vegetative growth and fruit yield from field planting to full maturity of the plantation. The sub-canopy-scale phenology and allocation strategy are necessary for this perennial evergreen crop which yields continuously on multiple phytomers. The pre-expansion leaf storage growth phase is proved essential for buffering and balancing overall vegetative and reproductive growth. Average LAI, yield and NPP are satisfactorily simulated for multiple sites, which fulfills the main mission of a land surface model, that is, to represent the average conditions and dynamics of processes governing land-atmosphere interactions. On the other hand, simulating small-scale site-to-site variation $(50 \mathrm{~m} \times 50 \mathrm{~m}$ sites $)$ requires detailed input data on site conditions (e.g. microclimate) and plantation managements that are often not available thus limiting the applicability of the model at small scales. Nevertheless, the CLM-Palm model sufficiently represents the significant region-wide variability in oil palm NPP and yield driven by nutrient input and plantation age in Jambi, Sumatra. The point simulations here provide a starting point for calibration and validation at large scales.

To run CLM-Palm on a regional or global grid, the age class structure of plantations needs to be taken into account. This can be achieved by setting multiple replicates of the PFT for oil palm, each planted at a point of time at a certain grid. As a result, a series of oil palm cohorts 
developing at different grids could be configured with a transient PFT distribution dataset, which allows for a quantitative analysis of the effects of land-use changes, specifically rainforest to oil palm conversion, on $\mathrm{C}$, water and energy fluxes. This will contribute to the land surface modeling community for simulating this structurally unique, economically and ecologically sensitive, and fast expanding land cover type. 


\subsection{Appendix}

Table A 2.1. Summary of new phenological parameters introduced for the phenology subroutine of CLM-Palm. The default values were determined by calibration and with reference to field observations and literatures on oil palm (Combres et al., 2013; Corley and Tinker, 2016; Hormaza et al., 2012; Legros et al., 2009).

\begin{tabular}{|c|c|c|c|c|}
\hline Parameter & Default & Min & Max & Explanation (Unit) \\
\hline$G D D_{\text {init }}$ & 0 & 0 & 1500 & $\begin{array}{l}\text { GDD needed from planting to the first phytomer } \\
\text { initiation ( }{ }^{\circ} \text { days). Initiation refers to the start of } \\
\text { active accumulation of leaf C. A value } 0 \text { implies } \\
\text { transplanting. }\end{array}$ \\
\hline$G D D_{\exp }$ & 1550 & 0 & 8000 & $\begin{array}{l}\text { GDD needed from leaf initiation to start of leaf } \\
\text { expansion for each phytomer (pre-expansion) } \\
\left({ }^{\circ} \text { days) }\right.\end{array}$ \\
\hline$G D D_{\text {L.mat }}$ & 1250 & 500 & 1600 & $\begin{array}{l}\text { GDD needed from start of leaf expansion to leaf } \\
\text { maturity for each phytomer (post-expansion) ( }{ }^{\circ} \text { days) }\end{array}$ \\
\hline$G D D_{F . f i l l}$ & 3800 & 3500 & 4200 & $\begin{array}{l}\text { GDD needed from start of leaf expansion to } \\
\text { beginning of fruit-fill for each phytomer }\left({ }^{\circ} \text { days }\right)\end{array}$ \\
\hline$G D D_{F \cdot m a t}$ & 5200 & 4500 & 6500 & $\begin{array}{l}\text { GDD needed from start of leaf expansion to fruit } \\
\text { maturity and harvest for each phytomer }\left({ }^{\circ} \text { days }\right)\end{array}$ \\
\hline$G D D_{L . s e n}$ & 6000 & 5000 & 8000 & $\begin{array}{l}\text { GDD needed from start of leaf expansion to } \\
\text { beginning of senescence for each phytomer }\left({ }^{\circ} \text { days }\right)\end{array}$ \\
\hline$G D D_{\text {end }}$ & 6650 & 5600 & 9000 & $\begin{array}{l}\text { GDD needed from start of leaf expansion to end of } \\
\left.\text { senescence for each phytomer ( }{ }^{\circ} \text { days }\right)\end{array}$ \\
\hline$G D D_{\min }$ & 7500 & 6000 & 10000 & $\begin{array}{l}\text { GDD needed from planting to the beginning of first } \\
\left.\text { fruit-fill ( }{ }^{\circ} \text { days }\right)\end{array}$ \\
\hline$A g e_{\max }$ & 25 & 20 & 30 & $\begin{array}{l}\text { Maximum plantation age (productive period) from } \\
\text { planting to final rotation /replanting (years) }\end{array}$ \\
\hline$P L A I_{\max }$ & 0.165 & 0.1 & 0.2 & Maximum LAI of a single phytomer $\left(\mathrm{m}^{2} \mathrm{~m}^{-2}\right)$ \\
\hline mxlivenp & 40 & 30 & 50 & $\begin{array}{l}\text { Maximum number of expanded phytomers } \\
\text { coexisting on a palm }\end{array}$ \\
\hline
\end{tabular}


phyllochron $130 \quad 100 \quad 160 \quad$ Initial phyllochron (=plastochron): the period in heat unit between the initiations of two successive phytomers. The value increases to 1.5 times, i.e. 195 , at 10 -year old ( ${ }^{\circ}$ days $)$

Table A 2.2. Summary of parameters involved in $\mathrm{C}$ and $\mathrm{N}$ allocation. The default values were determined by calibration and with reference to field measurements (Kotowska et al., 2015).

\begin{tabular}{|c|c|c|c|c|}
\hline Parameter & Defaults & Min & $\operatorname{Max}$ & Explanation (Unit) \\
\hline$* l f_{\text {disp }}$ & 0.3 & 0.1 & 1 & $\begin{array}{l}\text { Fraction of } \mathrm{C} \text { and } \mathrm{N} \text { allocated to the displayed leaf } \\
\text { pool }\end{array}$ \\
\hline *transplant & 0.15 & 0 & 0.3 & $\begin{array}{l}\text { Initial total LAI assigned to existing expanded } \\
\text { phytomers at transplanting. Value } 0 \text { implies planting } \\
\text { as seeds. }\end{array}$ \\
\hline$f_{\text {leaf }}^{i}$ & 0.15 & 0 & 1 & $\begin{array}{l}\text { Initial value of leaf allocation coefficient before the } \\
\text { first fruit-fill }\end{array}$ \\
\hline$a_{\text {root }}^{i}$ & 0.3 & 0 & 1 & $\begin{array}{l}\text { Initial value of root allocation coefficient before the } \\
\text { first fruit-fill }\end{array}$ \\
\hline$a_{\text {leaf }}^{f}$ & 0.28 & 0 & 1 & $\begin{array}{l}\text { Final value of leaf allocation coefficient after } \\
\text { vegetative maturity }\end{array}$ \\
\hline$a_{\text {root }}^{f}$ & 0.1 & 0 & 1 & $\begin{array}{l}\text { Final value of root allocation coefficient after } \\
\text { vegetative maturity }\end{array}$ \\
\hline$F_{\text {stem }}^{\text {live }}$ & 0.15 & 0 & 1 & $\begin{array}{l}\text { Fraction of new stem allocation that goes to live stem } \\
\text { tissues, the rest to metabolically inactive stem tissues }\end{array}$ \\
\hline$d_{\text {mat }}$ & 0.6 & 0.1 & 1 & $\begin{array}{l}\text { Factor to control the age when the leaf allocation } \\
\text { ratio stabilizes at } a_{\text {leaf }}^{f} \text { according to Eq. (2.5) }\end{array}$ \\
\hline$d_{\text {alloc }}^{\text {leaf }}$ & 0.6 & 0 & 5 & $\begin{array}{l}\text { Factor to control the nonlinear function in Eq. (2.5). } \\
\text { Values }<1 \text { give a convex curve and those }>1 \text { give a } \\
\text { concave curve. Value } 1 \text { gives a linear function. }\end{array}$ \\
\hline
\end{tabular}




\begin{tabular}{|c|c|c|c|c|}
\hline$* a$ & 0.2 & 0 & 1 & $\begin{array}{l}\text { Parameter } a \text { for fruit allocation coefficient } A_{\text {fruit }} \text { in } \\
\text { Eq. (2.6) }\end{array}$ \\
\hline$* b$ & 0.02 & 0 & 1 & $\begin{array}{l}\text { Parameter } b \text { for fruit allocation coefficient } A_{\text {fruit }} \text { in } \\
\text { Eq. (2.6) }\end{array}$ \\
\hline$S L A$ & 0.013 & 0.01 & 0.015 & Specific leaf area $\left(\mathrm{m}^{2} \mathrm{~g}^{-1} \mathrm{C}\right)$ \\
\hline$F_{L N R}$ & 0.1005 & 0.05 & 0.1 & $\begin{array}{l}\text { Fraction of leaf } \mathrm{N} \text { in Rubisco enzyme. Used together } \\
\text { with } S L A \text { to calculate } V_{c \max 25}\left(\mathrm{~g} \mathrm{~N} \text { Rubisco } \mathrm{g}^{-1} \mathrm{~N}\right)\end{array}$ \\
\hline
\end{tabular}

* New parameters introduced for oil palm. Others are existing parameters in CLM4.5 but mostly are redefined or used in changed context.

Table A 2.3. Other optical, morphological, and physiological parameters used in CLM-Palm.

\begin{tabular}{|c|c|c|c|}
\hline Parameter & Value & Definition (Unit) & Comments \\
\hline$C N_{\text {leaf }}$ & 33 & Leaf C:N ratio $\left(\mathrm{g} \mathrm{C} \mathrm{g}^{-1} \mathrm{~N}\right)$ & By leaf $\mathrm{C}: \mathrm{N}$ analysis \\
\hline$C N_{\text {root }}$ & 42 & Root $\mathrm{C}: \mathrm{N}$ ratio $\left(\mathrm{g} \mathrm{C} \mathrm{g}^{-1} \mathrm{~N}\right)$ & Same as all other PFTs \\
\hline$C N_{\text {livewd }}$ & 50 & Live stem C: $\mathrm{N}$ ratio $\left(\mathrm{g} \mathrm{C} \mathrm{g}^{-1} \mathrm{~N}\right)$ & Same as all other PFTs \\
\hline$C N_{\text {deadwd }}$ & 500 & Dead stem C:N ratio $\left(\mathrm{g} \mathrm{C}^{-1} \mathrm{~N}\right)$ & Same as all other PFTs \\
\hline$C N_{\text {lflit }}$ & 60 & Leaf litter C:N ratio $\left(\mathrm{g} \mathrm{C} \mathrm{g}^{-1} \mathrm{~N}\right)$ & Same as other tree PFTs \\
\hline$C N_{\text {fruit }}$ & 75 & Fruit $\mathrm{C}: \mathrm{N}$ ratio $\left(\mathrm{g} \mathrm{C} \mathrm{g}^{-1} \mathrm{~N}\right)$ & $\begin{array}{l}\text { Higher than the value } 50 \text { for } \\
\text { other crops because of high } \\
\text { oil content in palm fruit }\end{array}$ \\
\hline$r_{v i s / n i r}^{\text {leaf }}$ & $0.09 / 0.45$ & $\begin{array}{l}\text { Leaf reflectance in the visible (VIS) or } \\
\text { near-infrared (NIR) bands }\end{array}$ & $\begin{array}{l}\text { Values adjusted in- } \\
\text { between trees and crops }\end{array}$ \\
\hline$r_{\text {vis } / \text { nir }}^{\text {stem }}$ & $\begin{array}{l}0.16 / \\
0.39\end{array}$ & $\begin{array}{l}\text { Stem reflectance in the visible or near- } \\
\text { infrared bands }\end{array}$ & $\begin{array}{l}\text { Values adjusted in- } \\
\text { between trees and crops }\end{array}$ \\
\hline$\tau_{\text {vis } / \text { leaf }}^{\text {lir }}$ & $0.05 / 0.25$ & $\begin{array}{l}\text { Leaf transmittance in the visible or } \\
\text { near-infrared bands }\end{array}$ & $\begin{array}{l}\text { Values adjusted in- } \\
\text { between trees and crops }\end{array}$ \\
\hline$\tau_{\text {vis/nir }}^{\text {stem }}$ & $\begin{array}{l}0.001 / \\
0.001\end{array}$ & $\begin{array}{l}\text { Stem transmittance in the visible or } \\
\text { near-infrared bands }\end{array}$ & $\begin{array}{l}\text { Values adjusted in- } \\
\text { between trees and crops }\end{array}$ \\
\hline
\end{tabular}


$\chi_{L} \quad-0.4 \quad$ Leaf angle distribution index for Estimated by field radiative transfer $(0=$ random leaves; 1 observation. In CLM,

$=$ horizontal leaves; $-1=$ vertical $-0.4 \leq \chi_{L} \leq 0.6$ leaves)

taper $50 \quad$ Ratio of stem height to radius-at- Field observation. Used breast-height together with stocking and dwood to calculate canopy top and bottom heights.

stocking $\quad 150 \quad$ Number of palms per hectare (stems Field observation. $\left.\mathrm{ha}^{-2}\right)$

dwood $\quad 100000 \quad$ Wood density $\left(\mathrm{gC} \mathrm{m}^{-3}\right)$ Similar as coconut palm (O. Roupsard, personal communication, 2015)

$R_{z 0 m} \quad 0.05 \quad$ Ratio of momentum roughness length $\mathrm{T}$. June, personal to canopy top height communication, 2015

$R_{d} \quad 0.76 \quad$ Ratio of displacement height to canopy T. June, personal top height communication, 2015 


\section{CHAPTER 3}

Implementation of a dynamic multilayer radiative transfer scheme 


\subsection{Introduction}

The interactions between solar radiation and vegetation canopies are central to the land surface energy balance. The absorption and scattering of radiative fluxes within the canopy drives photosynthesis and energy exchanges. The absorption and reflectance by canopy and ground define surface albedo, which determines the land surface energy budget and temperature. The specification and integration of scattering, transmission and absorption of incident solar radiation by vegetation elements and the ground surface are modeled by various radiative transfer schemes (Goel, 1988). Land surface models (e.g. CLM, LPJ-mL, JULES) often assume a one-layered big-leaf or sunlit/shaded two-big-leaf canopy (Dai et al., 2004; Ryu et al., 2011) in order to simplify the solution of radiative transfer equations, whereas plant canopy models (e.g. CANOAK) commonly represent the canopy as discrete multilayers and solve radiative transfer and absorption for each layer specifically (Baldocchi, 1997).

In Chapter 2, a CLM-Palm sub-model was developed within the framework of the Community Land Model (CLM4.5) for simulating a palm PFT with sub-canopy-scale phenology and allocation. The term sub-canopy refers to the individual layers and layer-specific processes within the canopy. The new parameterizations allow multiple phytomers (each carrying a large leaf and a fruit bunch) to develop simultaneously but according to their different phenological steps (leaf growth, fruit-filling and leaf senescence) at different canopy layers. This multilayer structure was proved useful for simulating canopy development and productivity in terms of leaf area index (LAI), fruit yield and net primary production (NPP). Vegetative and reproductive growths regulate above and belowground carbon stocks and nutrient cycling. They also provide direct feedbacks to land surface energy and water fluxes through radiative transfer, photosynthesis and stomatal conductance. The oil palm's monopodial and hierarchical canopy structure allows not only sub-canopy phenology and allocation but is also suitable for representing layer-specific radiation and photosynthesis-related processes.

Although the canopy-integrated parameterization is computationally efficient, it limits the ability to simulate diverse canopy properties and sub-canopy processes. The CLM4.5 model uses the one-layered two-big-leaf canopy and the two-stream approximation scheme as the defaults for radiative transfer (Fig. 3.1a, Meador and Weaver, 1980; Dickinson, 1983; Sellers, 1985). In this scheme, the upward and downward direct and diffuse radiative fluxes per unit incident flux are solved in a closed-form (without iterations) for an integrated canopy. A single leaf angle distribution (LAD) is assumed for the whole canopy, characterized by the $\chi_{\mathrm{L}}$ index that adjusts the average departure of leaf orientations from the spherical leaf angle distribution (Ross, 1975). However, some plant canopies, such as that of oil palm, have naturally formed 
discrete canopy layers, each having unique development pattern in leaf dimension (i.e. LAI) and leaf inclination angle (i.e. LAD) through growth and senescence. It has been shown that the common assumption of a spherical LAD is invalid for most of the broadleaf tree species (Pisek et al., 2013). Considering different LADs also has significant implications for $\mathrm{CO}_{2}$ exchange, latent and sensible heat fluxes (Baldocchi et al., 2002) in the context of land surface modeling.

Plant photosynthesis is more efficient under diffuse irradiance conditions (Knohl and Baldocchi, 2008; Mercado et al., 2009). When diffuse radiation makes up a large proportion of the incoming radiation, the discrepancy between one-layered and multilayer models is elevated in simulating processes in biosphere-atmosphere exchange (Knohl and Baldocchi, 2008). The deficiency of one-layered (big-leaf or sunlit/shaded two-big-leaf) model is related to the overestimation of diffuse light absorption by shaded leaves (Bonan et al., 2012). The tropical Indonesia, especially our study areas in Sumatra and Sulawesi, have frequent cloudy and fireinduced smoky conditions (Davison, 2004; Langmann, 2007) and thus the shortcomings in radiative transfer modeling associated with diffuse fluxes needs to be recognized and addressed.

This chapter aims to implement a dynamic multilayer canopy structure and radiative transfer scheme and adapt canopy-level calculations of radiation, photosynthesis, stomatal conductance, and respiration to the sub-canopy level, so that they can be closely linked with sub-canopy phenology and other vertical variations in leaf traits. This could be potentially applicable to other PFTs with naturally structured canopies. Chapter 2 implemented and validated the subcanopy phenology and allocation functions in CLM-Palm, while the radiative transfer scheme and photosynthesis calculation still followed the CLM4.5 default one-layered two-big-leaf model. Although Bonan et al. (2012) proposed a statistical derivative multilayer model in CLM, their radiative transfer scheme still followed the canopy-integrated method of two-stream approximation but additionally derived absorbed radiative fluxes as functions of cumulative LAI. This method is numerically efficient but is restricted to evenly stratified canopy layers with vertically uniform LAI and LAD (Fig. 3.1b). It, therefore, remains meaningful to test a flexible multilayer canopy model with explicit considerations of layer thickness, leaf angle changes or other vertical gradients in the canopy. Moreover, the advancement of modern computing facilities encourage the use of classic iterative multilayer radiative transfer schemes, which could offer higher accuracy.

In this chapter, a series of adaptations are implemented in CLM-Palm, most of which are applicable to the natural forest PFTs too. First, CLM-Palm's canopy structure is stratified into non-uniform layers of changing LAI (Fig. 3.1c). Second, each layer has its unique range of leaf 
inclination angle and light extinction coefficient. Third, the classic multilayer radiative transfer scheme from Norman (1979) is incorporated into CLM-Palm (and also CLM4.5) for calculating radiative fluxes and absorption per layer. Furthermore, photosynthesis (e.g. $V_{c m a x}$ ) and related canopy processes are adapted to the dynamic multilayer structure and performed for each layer. The one-layered and multilayer canopy models and different leaf trait options are compared with reference to the $\mathrm{CO}_{2}$ flux and sensible/latent heat fluxes by eddy covariance measurements from a mature oil palm plantation in Sumatra, Indonesia. Similar model experiments are also applied to a mountainous tropical rainforest in Central Sulawesi, Indonesia. This chapter also serves to validate CLM-Palm in simulating carbon, water and energy fluxes at fine time step and in different site conditions.

\subsection{Model description}

The CLM-Palm canopy structure consists of multiple vertically ranked phytomers, each carrying a large leaf and an inflorescence bunch. A maximum of 40 expanded leaves are usually maintained in plantations with senescent ones at the bottom removed routinely by pruning management. The expanded leaves form a natural multilayer canopy and contribute to photosynthesis. Each phytomer has prognostic leaf growth and fruit yield according to its own phenology and allocation steps (see details in Chapter 2 or Fan et al., 2015). The leaf angle changes from being vertical at the top right after leaf expansion to being largely horizontal when the phytomer position is progressively moved to the bottom (covered by upper younger ones) during the phenological cycle. CLM-Palm models the whole fate of carbon and nitrogen throughout the canopy according to sub-canopy phenology. The vertical structure of foliage also allows resolving light competition, radiative transfer and photosynthesis. These new aspects are described in the following sections.

\subsubsection{Canopy stratification}

Oil palm's phytomer-based structure and phenology requires appropriate treatments of subcanopy radiative profile and photosynthesis. The large mature leaves of the vertically ranked phytomers resemble canopy layers, and LAI is calculated for each phytomer individually in CLM-Palm. Moreover, leaf phenology including senescence and leaf pruning operates on each phytomer so that the decrease in photosynthetic capacity at the bottom senescent layers is recognized.

Following oil palm's monopodial morphology and sequential phenology from the top to bottom phytomers, the canopy can be stratified as either 40 layers by considering each phytomer as a 
layer, or 5 layers considering every 8 phytomers encircling the stem at similar heights as a canopy layer. A dynamic and non-uniform multilayer canopy structure is thus established for radiative transferring through layers with varying LAI and LAD (Fig. 3.1c) and for photosynthesis calculation according to layer-specific light and nitrogen profiles. This contrasts the canopy stratification in the multilayer option of CLM4.5 which uses a fixed LAI per layer (i.e. total LAI divided by the number of canopy layers) and the same optical properties such as LAD from the canopy top to bottom (Fig. 3.1b).

\subsubsection{Multilayer radiative transfer}

Our multilayer radiative transfer scheme has explicit representation of leaf angle distribution (LAD) and LAI at different layers (Fig. 3.1c). Variation in leaf inclination per layer is considered by the LAD function, which determines leaf mean projection (the $G$ function, Eqs. A 3.2-5) and light extinction coefficient (the $K$ parameter, Eq. A 3.1). For oil palm, layerspecific LAD function is calculated by the two-parameter Beta distribution (Goel and Strebel, 1984) considering different mean leaf inclination angles for different canopy layers. Details on the derivation of LAD, the $\mathrm{G}$ function and extinction coefficient are in Appendix (section 3.7).

These parameters are used in the Norman multilayer radiative transfer scheme which is implemented here in CLM-Palm as an alternative to its default one-layered two-stream approximation scheme and the statistical derivative multilayer two-stream solution by Bonan et al. (2012). The equations for radiative transfer of direct and diffuse fluxes are performed similarly for visible (PAR) and near-infrared (NIR) bands except that sunlit and shaded leaves are differentiated when calculating the radiation absorption in the visible band. This new scheme is applicable to both oil palm and other PFTs in CLM4.5 such as broadleaf evergreen tropical trees (BET). Details on the implementation of Norman multilayer radiative transfer scheme are in Appendix 3.7.

The codes for $G$ function and Norman radiative transfer used in the CANOAK model (Baldocchi and Harley, 1995) were partly modified and fit into the CLM4.5 model structure (see major equations in Appendix 3.7). The calculation of sunlit fraction of canopy layers (Eq. A 3.13) and the absorption of direct and diffuse radiation (Eqs. A 3.16, 3.17) are different from CANOAK methods. 

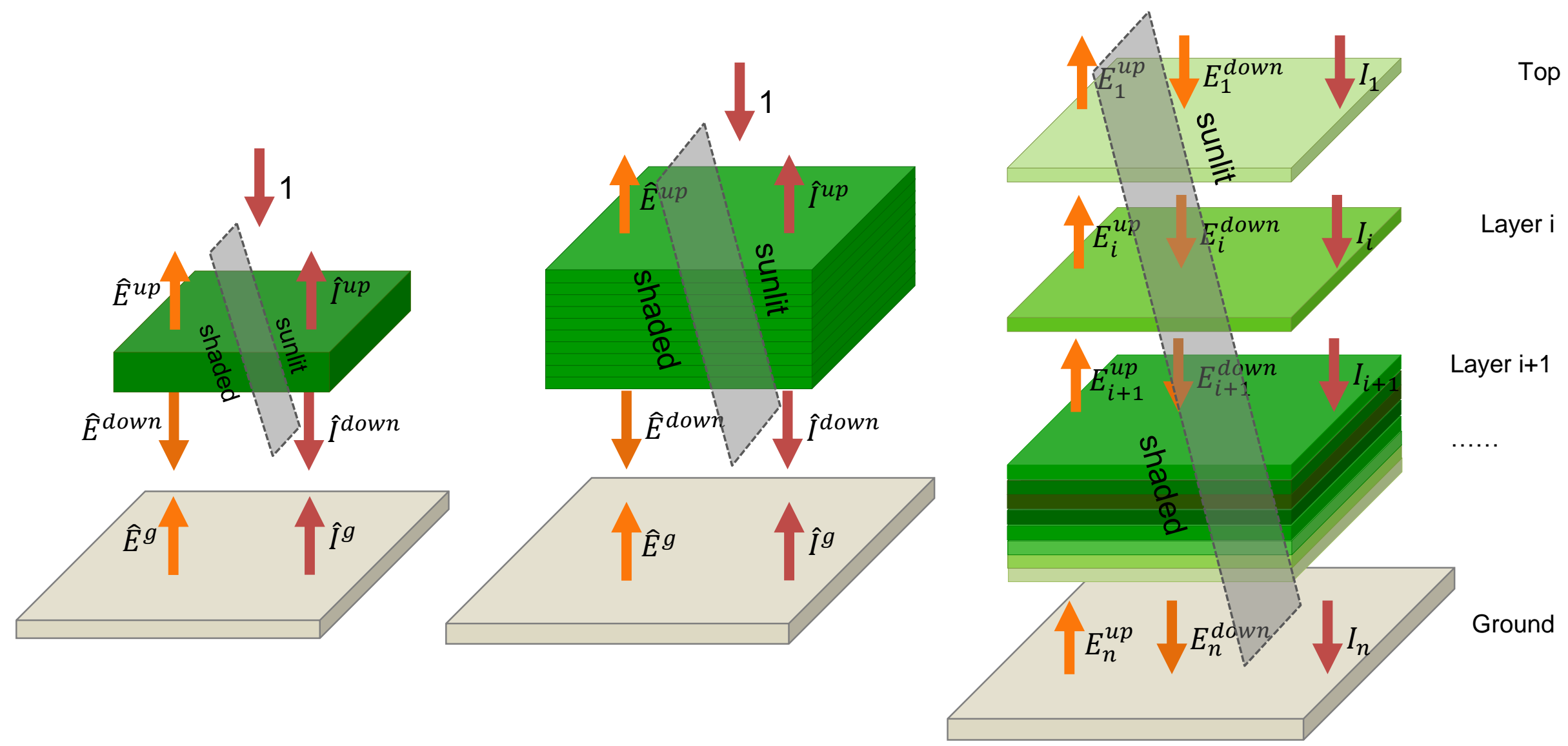

Figure 3.1. Three alternative radiative transfer schemes: (a) CLM4.5 default big-leaf two-stream approximation; (b) CLM4.5 optional statistical multilayer derivative solution of two-stream approximation, with uniform canopy stratification; and (c) the Norman multilayer radiative transfer scheme with dynamic canopy stratification in CLM-Palm. E represents diffuse radiation and $I$ represents direct beam (visible and near-infrared bands are performed separately). The hat denotes per unit incident direct or diffuse flux. In (a) and (b), $\hat{E}$ includes both up- and downward fluxes resulting from the transimission, reflection and scattering of incident direct beam and diffuse radiation above the canopy, while $\hat{I}$ is only sourced from direct beam. $\hat{E}^{g}$ and $\hat{I}^{g}$ are the ground albedo of diffuse and direct radiation. In (c) each layer has unique LAI. $I_{i}$ only considers downward incident direct beam per layer while $E_{i}^{u p}$ and $E_{i}^{\text {down }}$ are the up- and downward diffuse fluxes per layer resulting from both incident direct beam and diffuse radiation. Fluxes are partitioned for sunlit and shaded fractions of each canopy layer. 


\subsubsection{Sub-canopy photosynthesis and related processes}

Now that radiative transfer and absorption are resolved for sub-canopy layers, it is also feasible to resolve photosynthesis and related processes (e.g. stomatal conductance, respiration, etc.) in CLM-Palm in order to avoid scale mismatch problem. Land surface models with multilayer canopy normally prescribe the carboxylation rate at the canopy top (i.e. $V_{\mathrm{cmax} 25}^{0}$ ) and then use a $\mathrm{N}$ scaling factor $\left(K_{n}\right)$ to drive the layer-specific photosynthetic profile with an exponential function (Bonan et al., 2012; Krinner et al., 2005):

$$
\mathrm{V}_{\mathrm{cmax} 25}^{i}=\mathrm{V}_{\mathrm{cmax} 25}^{0} \times e^{-K_{n} \sum_{z=1}^{i} L A I_{z}},
$$

where $\sum_{z=1}^{i} L A I_{z}$ is the cumulative LAI from the canopy top to layer $i . \mathrm{V}_{\mathrm{cmax} 25}^{0}$ is specified through the PFT parameters the top of canopy specific leaf area $\left(S L A_{0}\right)$ and leaf C:N ratio together with other constants (Table A 2.2 in Chapter 2). The factor $K_{n}$ represents the possible gradient in leaf $\mathrm{N}$ concentration $\left(L N C_{i}\right)$ and therefore photosynthetic rate, but the actual foliage $\mathrm{N}$ pool size is not explicitly calculated per layer in the current model due to the fixed $\mathrm{C}: \mathrm{N}$ ratios. The CLM4.5 default background leaf litter-fall function does not update the LAI and leaf C and $\mathrm{N}$ pools per layer either, because it is a canopy-averaged function. Thus, PFTs other than oil palm in CLM4.5 have to rely on the statistical downscaling with Eq. (3.1). $K_{n}$ can be either prescribed as a PFT-specific constant or related to $V_{\mathrm{cmax} 25}^{0}$ by an exponential function according to Lloyd et al. (2010).

For oil palm's multilayer structure, leaf phenology operates on each phytomer unit, which results in discrete LAI and leaf $\mathrm{C}$ and $\mathrm{N}$ pool sizes across layers (Fig. 3.1c). Given that all plant tissues have to maintain fixed C:N ratios for the strictly coupled $\mathrm{C}$ and $\mathrm{N}$ cycles, CLM-Palm has to use a phytomer-specific senescence function that decreases leaf $\mathrm{C}$ and $\mathrm{N}$ pools simultaneously in order to maintain the leaf $\mathrm{C}: \mathrm{N}$ ratio but allow reducing the effective LAI and photosynthetic capacity of senescent phytomers. During this process, the overall leaf $\mathrm{N}$ concentration (including live and dead tissues) is effectively reduced at the lower canopy layers although live foliage $L N C_{i}$ is constant (more details in Chapter 2). Photosynthesis downscaling via senescence is only limited to the bottom layers of old leaves, whereas the upper young leaves could still consider additional $\mathrm{N}$ gradient, if any in the green foliage. Many oil palm studies have done leaf nutrient analysis (Chapman and Gray, 1949; Fairhurst, 1998; Tan and Rajaratnam, 1978), but no usable data have yet been found on the exact $\mathrm{N}$ gradient in oil palm's canopy, i.e. the trend of leaf $\mathrm{N}$ concentration from the top to bottom leaves. In Chapter 2 the CLM4.5 default $K_{n}$ value 0.3 for all PFTs was applied to oil palm too. To evaluate whether the senescence function in CLM-Palm is sufficient for scaling down photosynthesis at bottom 
canopy layers or additional leaf $\mathrm{N}$ gradient is necessary for the whole canopy, a $K_{n}$ of 0 was compared with the default value 0.3 for oil palm.

The statistically derived layer-specific $V_{c m a x 25}^{i}$ and the absorbed radiation $A P A R_{i}^{s u n}$ and $A P A R_{i}^{\text {shade }}$ (Eq. A 3.18) calculated from the multilayer radiative transfer model together determine gross photosynthetic rates for sunlit and shaded fractions per layer. The base rate for leaf maintenance respiration at $25^{\circ} \mathrm{C}$ is directly related to the leaf $\mathrm{N}$ concentration by $R_{d 25}^{i}=$ $0.2577 L N C_{i}\left(\mu \mathrm{mol} \mathrm{CO} \mathrm{g}^{-1} \mathrm{~N} \mathrm{~s}^{-1}\right)$, which is then adjusted for canopy temperature for sunlit and shaded portions of each layer respectively. Stomatal conductance is related to net photosynthesis per canopy layer according to the Ball-Berry conductance model (Collatz et al., 1991; Sellers et al., 1996) which accounts for the relative humidity and $\mathrm{CO}_{2}$ concentration at the leaf surface as well as soil water stress. Net photosynthesis is the subtraction of leaf respiration from the gross photosynthesis. Both stomatal conductance and photosynthesis calculations are solved for sunlit and shaded fractions of each layer respectively. Details of respiration calculations and the coupled photosynthesis-stomatal conductance model implemented in CLM4.5 are described in Bonan et al. (2011) or Oleson et al. (2013). Currently, leaf temperature, relative humidity, $\mathrm{CO}_{2}$ concentration and wind profiles in the canopy are not resolved per layer and not distinguished between sunlit and shaded leaves, which is typically so in land surface models but could be improved in the future.

\subsection{Model evaluation}

\subsubsection{Eddy covariance flux data}

Two eddy covariance flux towers provided data for validation of the model. One is installed in a 12-year-old mature oil palm plantation (PTPN-VI, 01 ${ }^{\circ} 41.6^{\prime} \mathrm{S}, 103^{\circ} 23.5^{\prime} \mathrm{E}$ ) in the province of Jambi, Sumatra, Indonesia and another in a mountainous tropical rainforest (Bariri, $01^{\circ} 39^{\prime} \mathrm{S}$, $120^{\circ} 10^{\prime} \mathrm{E}, 1427 \mathrm{~m}$ a.s.l) in Central Sulawesi, Indonesia. The flux towers provide continuous measurements of half-hourly fluxes of energy, water vapor and $\mathrm{CO}_{2}$ using the eddy covariance (EC) technique (Baldocchi, 2003) as well as necessary environmental variables (e.g. radiation, air temperature and humidity, precipitation, soil moisture and temperature, etc.). Measured net $\mathrm{CO}_{2}$ fluxes were partitioned into gross primary productivity (GPP) and ecosystem respiration (R) according to (Reichstein et al., 2005). The Jambi oil palm site provides 8-month data of EC flux and meteorological measurements (see Meijide et al., 2016). The Bariri forest site provides 4-year EC flux and meteorological data from 2004 to 2007 (Olchev et al., 2015). The CLMPalm model was already calibrated against LAI, yield and NPP in Chapter 2. 


\subsubsection{Model setup}

A series of simulations were conducted with the oil palm PFT. For reference, the new radiative transfer model is also applied to the rainforest represented by a broadleaf evergreen tropical tree (BET) PFT. All the simulations were all set up in the point mode with CLM-SP (satellite phenology) option that uses prescribed LAI without invoking the full carbon-nitrogen biogeochemistry module so that different canopy structure and radiative transfer model options can be compared with the same baseline vegetation conditions. For the rainforest, the default MODIS-derived monthly LAI used in CLM4.5 was extracted to the Bariri site and prescribed in the surface input data. The CLM-Palm model was also technically adapted to allow run in CLM-SP mode and prescription of monthly LAI at both the canopy scale and sub-canopy scale (denoted LAI_Z for layer-specific LAI) at different age. Multidimensional data of the calibrated and validated LAI and LAI_Z developments from Chapter 2 were used as inputs in the surface data for oil palm. Soil initial conditions of the oil palm plantation prior to the simulation year were the same as in Chapter 2, which described the modelling procedure (including spin-up) that also applies to this chapter. A 1-year continuing run in 2014 was conducted for the PTPNVI site from 12 years old (planted in 2002). Soil conditions at both sites have already been spin up to equilibrium state. The model has been technically adapted to enable restarting a simulation from a previous run with changed canopy and radiative transfer mode.

Site-specific meteorological forcing was used in all simulations. For the oil palm site, direct and diffuse shortwave radiation were both measured and used as forcing data during 2014. For the forest site, only the total shortwave radiation data was available as input during 2004 to 2007 and CLM4.5 automatically diagnoses direct and diffuse components using empirical partitioning functions for visible and near-infrared bands (Lawrence et al., 2011).

\subsubsection{Model experiments and analysis}

The three options for radiative transfer: 1) CLM4.5 default one-layered two-stream approximation scheme (1L-2S), 2) the statistical derivative multilayer solution based on twostream approximation (ML-2S), and 3) the classic Norman multilayer radiative transfer scheme (ML-NM) were implemented for the mature oil palm plantation PTPN-VI and Bariri (BET forest) sites, respectively. Each radiative transfer option comes with a choice of canopy stratification, LAD function, and LAI and nitrogen profiles. The 1L-2S and ML-2S simulations use the CLM4.5 default LAD controlled by a single $\chi_{\mathrm{L}}$ parameter (denoted $\chi_{\mathrm{L}}$, see Eq. A 3.20). The ML-NM simulations at oil palm sites use a two-parameter beta distribution of LAD specifically designed for the palm PFT (denoted Beta, see Eq. A 3.6). For the BET PFT, given 
that its canopy structure is different from that of oil palm, two alterative LAD functions were used for the ML-NM simulation at the forest site. One is the canopy-integrated LAD function using the $\chi_{\mathrm{L}}$ parameter like in $1 \mathrm{~L}-2 \mathrm{~S}$ and ML-2S (denoted ML-NM-Xl). Another is a dynamic LAD function adopted from the CANOAK model (denoted ML-NM-DL). CANOAK LAD assumes a mean leaf inclination of $45^{\circ}$ for top layers and decreases leaf angle exponentially (from $45^{\circ}$ to $10^{\circ}$ ) towards the bottom layer of canopy once cumulative LAI exceeds 2.6.

Each LAD function can be prescribed with different mean leaf inclination (by $\chi_{\mathrm{L}}$.or $\overline{\theta_{\mathrm{L}}}$ ). Here the term leaf inclination refers to the mean zenithal tilt angle of all leaflets within a leaf. The actual number of simulations expands with the specification of LAD and its mean leaf inclination. The general categories of simulations are listed in Table 3.1.

Table 3.1. Model options and description for different radiative transfer schemes.

\begin{tabular}{|c|c|c|c|c|c|c|c|}
\hline PFT & Simulation & $\begin{array}{l}\text { Radiative } \\
\text { transfer }\end{array}$ & Canopy & LAI & LAD & $\begin{array}{l}\mathrm{N} \\
\text { profile }\end{array}$ & Description \\
\hline Palm & $1 \mathrm{~L}-2 \mathrm{~S}$ & $\begin{array}{l}\text { two- } \\
\text { stream }\end{array}$ & one layer & integrated & $\chi_{\mathrm{L}}$ & $\begin{array}{l}K_{n}=0 \\
\text { or } 0.3\end{array}$ & $\begin{array}{l}\text { Integrated LAD } \\
\text { and LAI (Fig. 3.1a) }\end{array}$ \\
\hline Palm & ML-2S & $\begin{array}{l}\text { two- } \\
\text { stream }\end{array}$ & multilayer & $\begin{array}{l}\text { Non- } \\
\text { uniform }\end{array}$ & $\chi_{\mathrm{L}}$ & $\begin{array}{l}K_{n}=0 \\
\text { or } 0.3\end{array}$ & $\begin{array}{l}\text { Uniform LAD but } \\
\text { dynamic LAI } \\
\text { across layers (Fig. } \\
\text { 3.1b) }\end{array}$ \\
\hline Palm & ML-NM & Norman & multilayer & $\begin{array}{l}\text { Non- } \\
\text { uniform }\end{array}$ & Beta & $\begin{array}{l}K_{n}=0 \\
\text { or } 0.3\end{array}$ & $\begin{array}{l}\text { Dynamic LAI and } \\
\text { LAD with different } \\
\theta_{\mathrm{L}} \text { per layer (Fig. } \\
3.1 \mathrm{c})\end{array}$ \\
\hline BET & $1 \mathrm{~L}-2 \mathrm{~S}$ & $\begin{array}{l}\text { two- } \\
\text { stream }\end{array}$ & one layer & integrated & $\chi_{\mathrm{L}}$ & $\begin{array}{l}K_{n}= \\
0.3\end{array}$ & Fig. 3.1a \\
\hline BET & ML-2S & $\begin{array}{l}\text { two- } \\
\text { stream }\end{array}$ & multilayer & uniform & $\chi_{\mathrm{L}}$ & $\begin{array}{l}K_{n}= \\
0.3\end{array}$ & $\begin{array}{l}\text { Uniform LAI and } \\
\text { LAD (Fig. 3.1b) }\end{array}$ \\
\hline BET & $\begin{array}{l}\text { ML-NM- } \\
\text { Xl }\end{array}$ & Norman & multilayer & uniform & $\chi_{\mathrm{L}}$ & $\begin{array}{l}K_{n}= \\
0.3\end{array}$ & $\begin{array}{l}\chi_{\mathrm{L}} \text { function adapted } \\
\text { to Norman model; } \\
\text { uniform LAI and } \\
\text { LAD }\end{array}$ \\
\hline BET & $\begin{array}{l}\text { ML-NM- } \\
\text { DL }\end{array}$ & Norman & multilayer & uniform & CANOAK & $\begin{array}{l}K_{n}= \\
0.3\end{array}$ & $\begin{array}{l}\text { Dynamic LAD } \\
\text { from CANOAK }\end{array}$ \\
\hline
\end{tabular}


First, six experiments were performed with the mature oil palm using the ML-2S and ML-NM options, each prescribed with 3 levels of mean leaf inclination, to compare the two radiative transfer schemes with respect to absorbed photosynthetically active radiation (APAR) and within-canopy photosynthesis profile. Both sunny and cloudy conditions are considered. For ML-NM, the Beta function was prescribed with three different mean leaf inclinations by parameter $\overline{\theta_{\mathrm{L}}}$ : a flatter $\left(\overline{\theta_{\mathrm{L}}}=20^{\circ}\right)$, a medium $\operatorname{LAD}\left(\overline{\theta_{\mathrm{L}}}=45^{\circ}\right)$, and a more vertical LAD $\left(\overline{\theta_{\mathrm{L}}}=60^{\circ}\right) \cdot \overline{\theta_{\mathrm{L}}}$ and the overall range of leaf angle $\left(90^{\circ}-0^{\circ}\right)$ from canopy top to bottom codetermine the LAD function for each layer according to Eq. (A 3.6). For ML-2S, three $\chi_{\mathrm{L}}$ values were used to mimic the different levels of leaf inclination from very flat $\left(\chi_{\mathrm{L}}=0.6\right)$ to medium or spherical $\left(\chi_{\mathrm{L}}=0\right)$, and to very vertical $\left(\chi_{\mathrm{L}}=-0.4\right)$. In CLM4.5 $\chi_{\mathrm{L}}$ is limited to the range of -0.4 to 0.6 .

Second, the three model options 1L-2S, ML-2S and ML-NM were all compared at the mature oil palm site with reference to observed ecosystem-scale photosynthesis-light response curves from the flux tower data. This aims to further compare the alternative radiative transfer schemes and their sensitivity to leaf angle distribution. The effects of within-canopy $\mathrm{N}$ profile is also analyzed with two $K_{n}$ values, given the reason mentioned earlier.

Third, applying the four different model options to the BET forest PFT was aimed to disentangle the contribution of LAD function from the effect of radiative transfer scheme. One shortcoming of this experiment was that the incident diffuse radiation for the Bariri site was diagnosed by the CLM model using the empirical partitioning functions in Lawrence et al. (2011) but the resulting diffuse component only accounts for an average fraction 30\% of global radiation. Therefore, the very high diffuse radiation condition of Indonesia might not be reflected in this experiment and the model comparison only provides a general guide.

Lastly, the baseline model selected from the above experiments was used to simulate GPP, and sensible and latent heat fluxes. They were compared with eddy covariance flux measurements in order to validate the CLM-Palm model for simulating the biogeophysical functions of oil palm.

\subsection{Results}

\subsubsection{Radiative transfer and leaf angle distribution}

The simulated APAR and photosynthesis profiles are both sensitive to different radiative transfer models and LAD functions (Fig. 3.2). Under sunny conditions, the difference between 
ML-2S and ML-NM is clear at the sunlit portion of canopy layers. APAR dominates at the top layers for ML-2S and decrease dramatically towards the bottom layers, whereas ML-NM allows more PAR penetrating to the middle and lower layers. The influence of leaf angle is more apparent for ML_NM because it uses distinct LADs across layers while ML-2S assumes a constant and uniform LAD throughout the canopy. This explains why the ML-2S simulations have more smooth curves compared to ML-NM, which is an artificial result of the uniform LAD in ML-2S (Fig. 3.1b). For ML_NM, the higher mean leaf angle yields more evenly distributed APAP throughout the canopy which is reasonable given the highly vertical leaves at the top of oil palm. The high APAR simulated by ML_2S at the canopy top is unrealistic given that the young oblique oil palm leaves emerged at the top have limited relative projected area along the sun beam. Difference in the diffuse radiation absorption by shaded leaves is relatively small between simulations but still distinguishable for the upper canopy layers ( 1 to 20 ), where the two-stream method generally yields higher APAR (shaded). When leaf surfaces tend to be flat (e.g. $\chi_{\mathrm{L}}=0.6$ and $\overline{\theta_{\mathrm{L}}}=20^{\circ}$ ), the shaded APAR profile is more comparable between the two models.

Under cloudy or hazy conditions when diffuse radiation dominates, the contrast in APAR for shaded leaves becomes larger between the ML_2S and ML_NM methods while the opposite is true for sunlit portion of leaves. ML_2S simulates substantially higher APAR at the upper layers and the proportion absorbed by shaded leaves can exceed that by sunlit leaves at the middle to lower layers. 

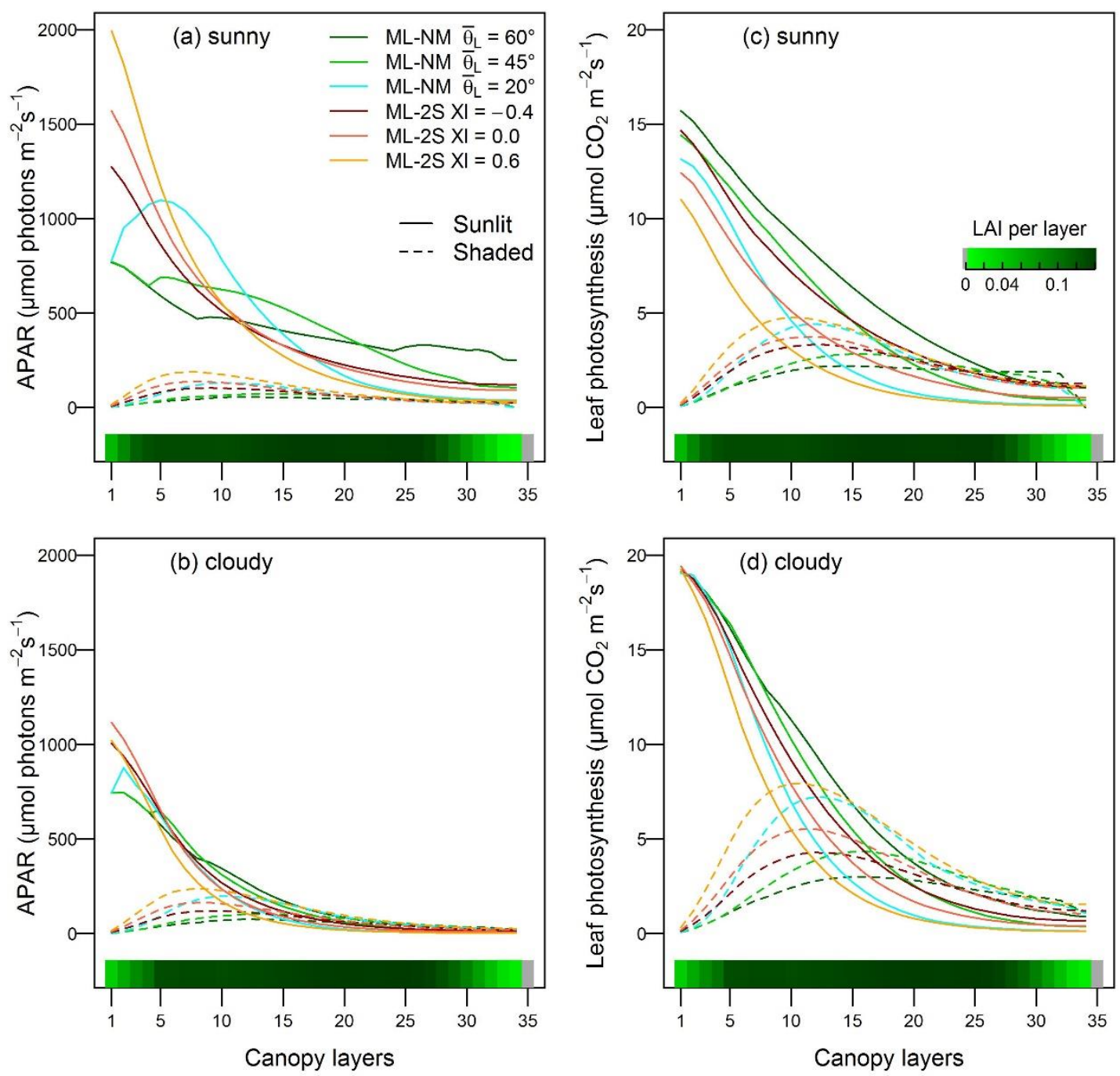

Figure 3.2. Sub-canopy profile of absorbed photosynthetically active radiation (APAR) and photosynthesis at noon time (12:00) simulated with two radiative transfer schemes: the multilayer derivative two-stream approximation by Bonan et al. (2012) and the discrete multilayer radiative transfer scheme by Norman (1979), and with different LAD functions. (a) and (c) are under sunny condition: the incident photon flux density at the top of canopy is 2400 $\mu \mathrm{mol} \mathrm{m} \mathrm{m}^{-2} \mathrm{~s}^{-1}$, and the diffuse fraction is 0.28 . (b) and (d) are under cloudy condition: the incident photon flux density at the top of canopy is $1200\left(\mu \mathrm{mol} \mathrm{m}^{-2} \mathrm{~s}^{-1}\right)$, and the diffuse fraction is 0.9 . The fluxes are per unit leaf area (sunlit + shaded) so that the different model options are comparable because they calculate different sunlit/shaded profiles per layer. The sum of sunlit and shaded fluxes per layer multiplied by layer-specific LAI value ( $\mathrm{x}$-axis legend) gives the total flux per layer per ground area. Layer 1 indicates canopy top. Data shown here are selected from October 2014 with sun zenith $10^{\circ}$.

The photosynthesis profiles have similar patterns and exhibit clearer contrast between ML_2S and ML_NM models, in which the former generally simulates higher photosynthesis rate for shaded leaves but lower for sunlit leaves compared to the latter (Fig. 3.2c, d). When mean leaf angle becomes flat, ML_2S behaves more similar to ML_NM. It needs to be noted that 
ML_NM considers oil palm leaf angle always ranging from $90^{\circ}$ at the canopy top to $0^{\circ}$ at the bottom although the mean is adjustable by $\overline{\theta_{\mathrm{L}}}$. From Fig. 3.2c and 3.2d, the ML_2S with $\chi_{\mathrm{L}}=-0.4$ generates most similar photosynthesis curves to that simulated by ML_ML with $45^{\circ}$ mean leaf angle. All models have higher leaf photosynthesis rate under cloudy than sunny conditions for both sunlit and shaded leaves at most canopy layers. Canopy integrated values show that the total APAR is 2143 vs. $1068 \mu \mathrm{mol}$ photons $\mathrm{m}^{-2} \mathrm{~s}^{-1}$ for sunny and cloudy conditions, whereas the canopy total photosynthesis is in the opposite order: 21 vs. $34 \mu \mathrm{mol}$ $\mathrm{CO}_{2} \mathrm{~m}^{-2} \mathrm{~s}^{-1}$ for the selected sunny and cloudy days, respectively.

Comparing the alternative radiative transfer options for simulating photosynthesis-light response in oil palm plantation, the big-leaf model (1L-2S) estimates substantially higher rate of photosynthesis than the multilayer models (ML-2S, ML-NM), although the overestimation by $1 \mathrm{~L}-2 \mathrm{~S}$ is largely reduced when a $\mathrm{N}$ downscaling parameter $K_{n}$ of 0.3 is enforced (Fig. 3.3). When $K_{n}=0.3$, the ML-NM with $45^{\circ}$ and $60^{\circ}$ mean leaf angles have best predictions compared to observed photosynthesis rate derived from eddy covariance measurements (Fig. 3.3g, h). The mean leaf angle $45^{\circ}$ with boundaries $0-90^{\circ}$ conforms best to field measurements of leaf inclination from mature oil palms at PTPN-VI and is also similar to that of coconut palm ( $43^{\circ}$; Roupsard et al., 2008). The multilayer models ML-2S and ML-NM are comparable at median to low leaf angles. The maximum $\chi_{L}$ value 0.6 (flat leaves) in ML-2S gives nearly the same response curves as $\overline{\theta_{\mathrm{L}}}=20^{\circ}$ does in ML-NM (Fig. 3.3f, i). The lower boundary of $\chi_{\mathrm{L}},-0.4$, which signifies plagiophile or oblique leaves in ML-2S has comparable meaning and results with $\overline{\theta_{\mathrm{L}}}=45^{\circ}$ in ML-NM (Fig. 3.3d, h).

When $K_{n}=0$, all the simulations overestimate the photosynthesis rate, which is due to fact that the prescribed LAI and LAI_Z were simulated with $1 \mathrm{~L}-2 \mathrm{~S}$ and $K_{n}=0.3$ from Chapter 2. Without $\mathrm{N}$ downscaling, the model could achieve similar levels of photosynthesis-light response with a lower LAI or a higher $C N_{\text {leaf }}^{0}$ or when assuming extremely flat leaf inclination in the multilayer models (Fig. 3.3f, i). The Norman method using a $\mathrm{LAD}$ from $\overline{\theta_{\mathrm{L}}}=20^{\circ}$ to $60^{\circ}$ already represents a wider range of photosynthesis than the two-stream approximation methods (1L-2S, ML-2S) with a full range of LAD from $\chi_{\mathrm{L}}=0.6$ to -0.4 . As indicated by the RMSEs the difference between the big-leaf (1L-2S) and multilayer models (ML-2S, ML-NM) are minimized when a high $\mathrm{N}$ downscaling factor $\left(K_{n}=0.3\right)$ is used. However, in this condition the big leaf model becomes no longer sensitive to different leaf inclinations angles. The Norman method in general allows simulating a larger variability of leaf angle distribution and associated effects on photosynthesis under the same radiation conditions. 

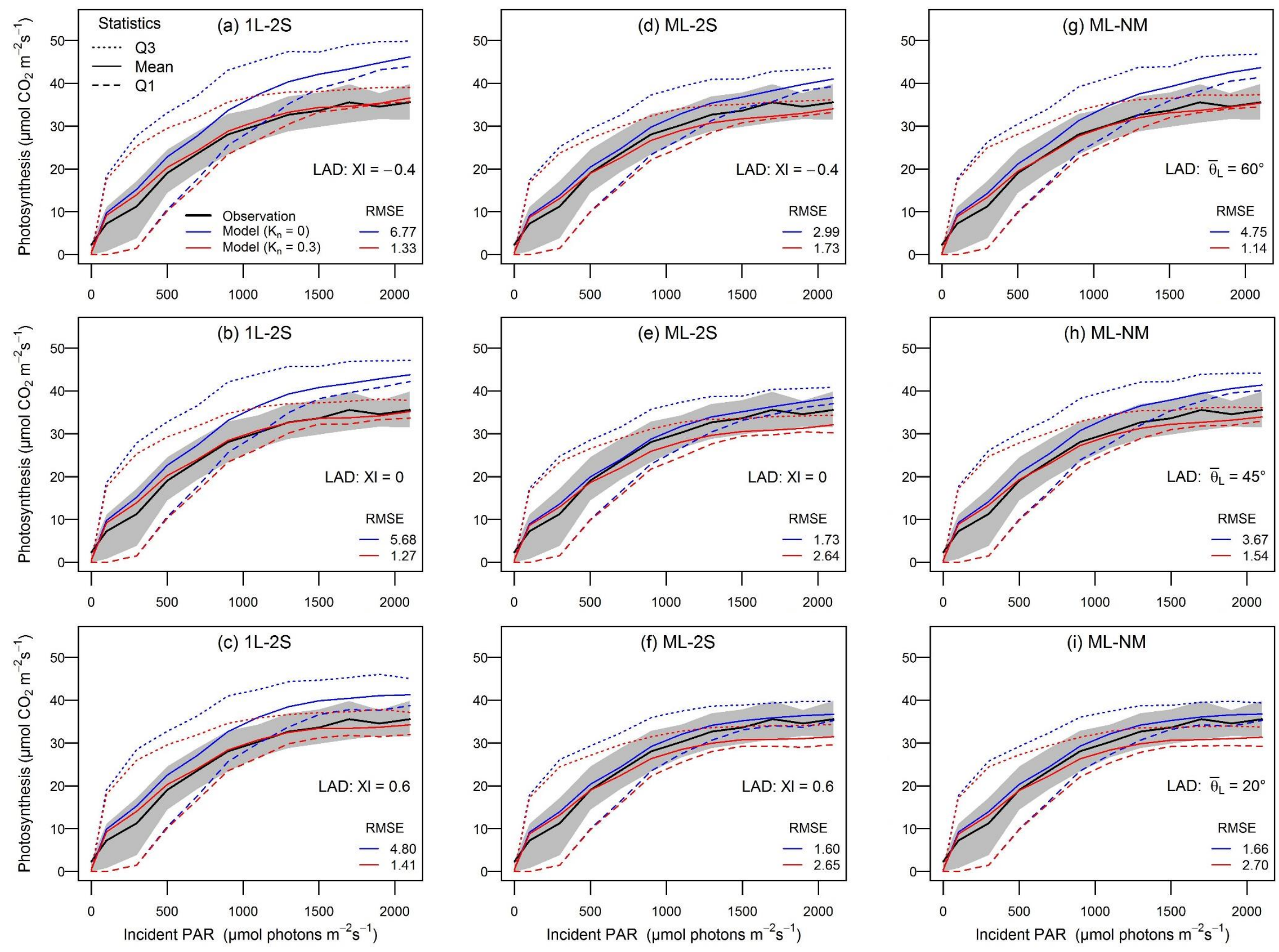
Figure 3.3. Canopy photosynthesis rate in relation to incident PAR at the top of canopy simulated with three radiative transfer schemes (Norman method: ML-NM; Two-stream approximations: $1 \mathrm{~L}-2 \mathrm{~S}, \mathrm{ML}-2 \mathrm{~S}$ ) and with different LAD functions at the mature oil palm site. Data shown here are selected from Oct.-Dec. 2014, which is the rain season with high fraction of diffuse radiation (FSDSdif). Locally measured direct beam (FSDSdir) and FSDSdif are used in atmospheric forcing.

(a) $1 \mathrm{~L}-2 \mathrm{~S}$

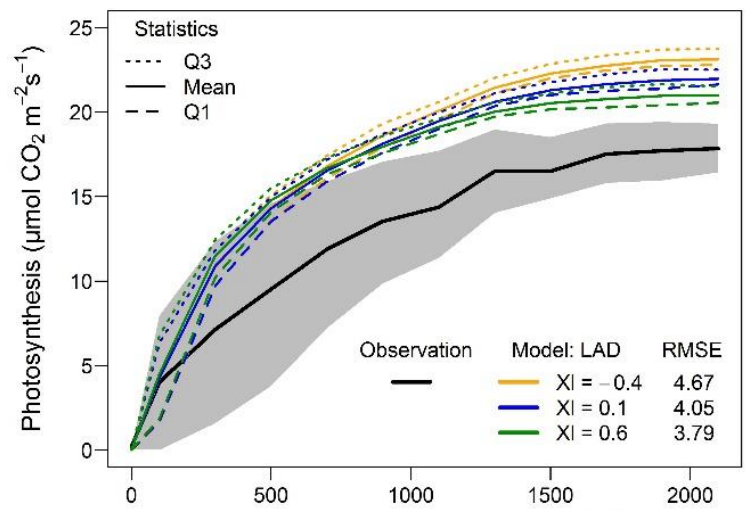

(c) ML-NM-XI

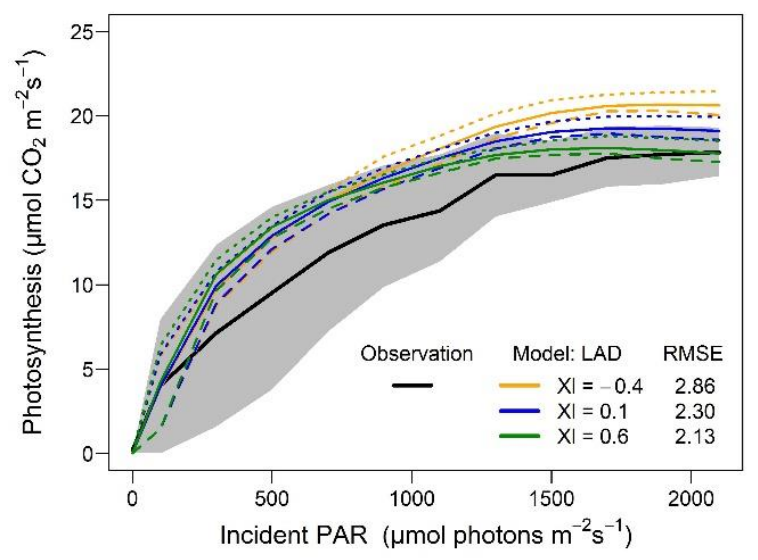

(b) ML-2S

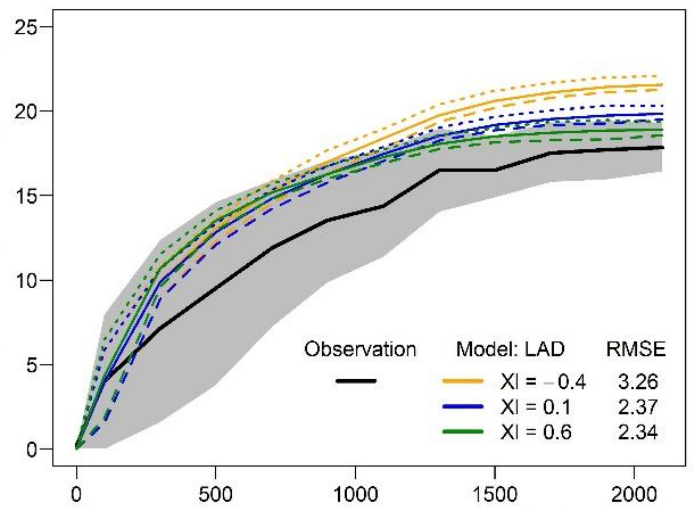

(d) ML-NM-DL

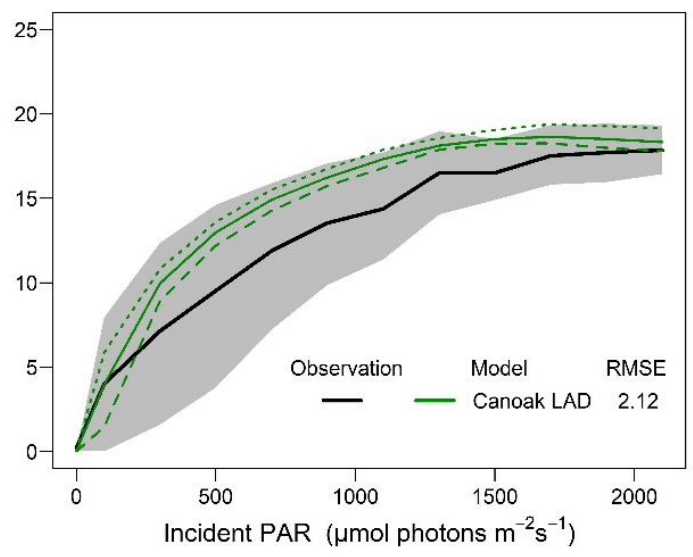

Figure 3.4. Observed and simulated canopy photosynthesis light response curves at the rainforest site (BET PFT) using different model settings. The ML-NM-Xl and ML-NM-DL are both based on the Norman multilayer radiative transfer scheme but are differentiated by a canopy-integrated LAD and a layer-specific LAD (details in Table 3.1). The atmospheric forcing only includes global radiation (FSDS). Data shown here are selected from Nov.-Dec. of 2004 to 2007. Statistics is based on 4-year mean values of each time step (30-min) within the two months.

Simulations at the rainforest site are aimed to dissect the model differences to the portion attributed by LAD functions and that from the radiative transfer models themselves. The BET forest PFT is usually assumed to have evenly distributed canopy layers with uniform LAI and LAD. When this assumption is applied to the Norman multilayer radiative transfer scheme by using the same LAD function with the $\chi_{\mathrm{L}}$ parameter, the ML-NM-Xl simulations have slightly 
improved photosynthesis-light responses than ML-2S (Fig. 3.4b, c). The two-stream approximation generally yields higher photosynthesis rate than the Norman model, which is very likely linked to the higher APAR profile of shaded leaves simulated by the two-stream method (Fig. 3.2b), when the fraction of diffuse radiation is high year-round in Indonesia. The one-layered big-leaf model simulates significantly higher photosynthesis rate than other model options and compared to eddy covariance data for the forest (Fig. 3.4a). The CANOAK dynamic LAD function combined with the Norman model yield the best result among all forest simulations (Fig. 3.4d).

\subsubsection{Carbon and energy fluxes}

From the above model comparisons, the Norman multilayer radiative transfer scheme implemented in CLM-Palm showed improved accuracy and strong adaptability in simulating the photosynthesis of oil palm and forest PFTs with distinct canopy characteristics. The MLNM model with a LAD of medium to high leaf inclination (e.g. $\overline{\theta_{L}}$ of $45^{\circ}$ or $60^{\circ}$ ) can be used as baseline configuration for future simulations on oil palm. When comparing the ML-NM $\left(\overline{\theta_{\mathrm{L}}}=60^{\circ}\right), 1 \mathrm{~L}-2 \mathrm{~S}$ and ML-2S $\left(\chi_{\mathrm{L}}=-0.4\right)$ models for simulating GPP, all of them produce satisfactory results with reference to observations but the ML-NM model slightly outperforms the others by its highest $\mathrm{R}^{2}$ (Fig. 3.5).

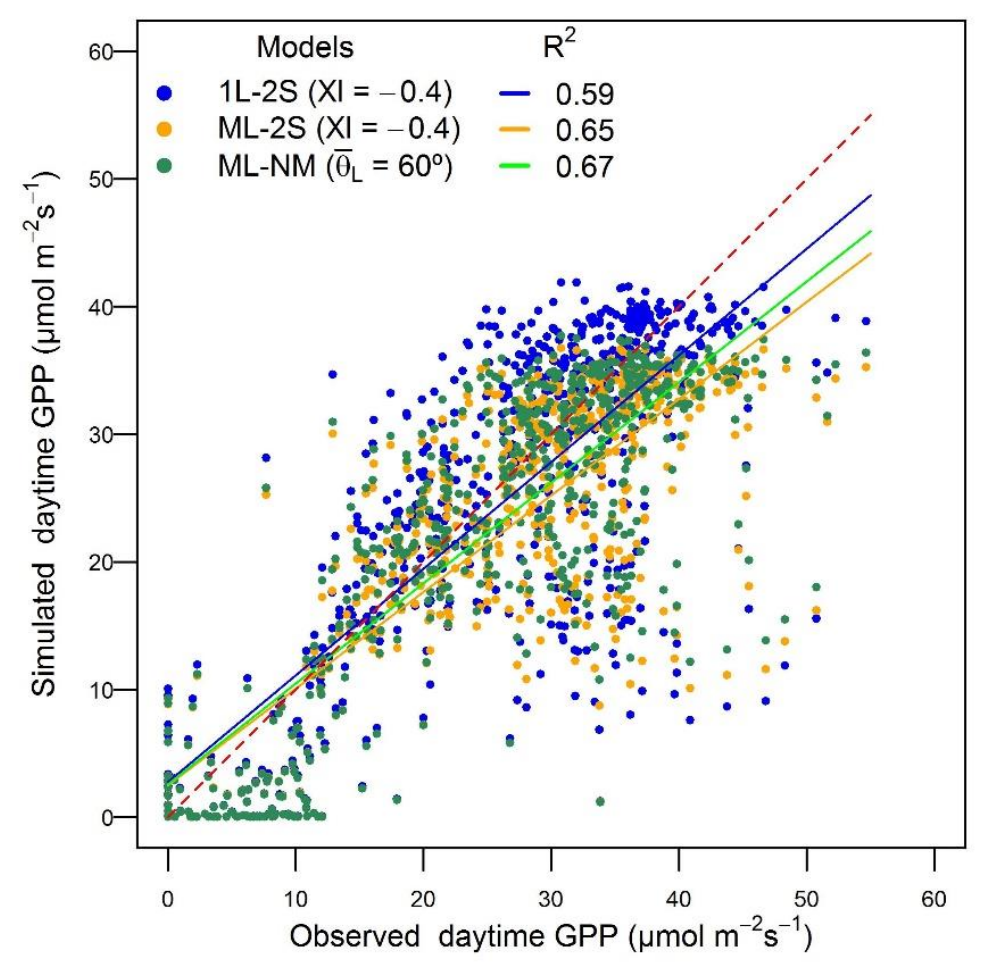

Figure 3.5. Correlation of observed and simulated GPP during daytime in October 2014. 
Further validation on the diurnal trends of carbon and energy fluxes show that the three models using median-high leaf inclination all produced comparable half-hourly fluxes with reference to eddy covariance measurements (Fig. 3.6). The Norman multilayer model (ML-NM) has the lowest RMSE in GPP. As observed earlier, the big-leaf model (1L-2S) gives relatively high photosynthesis-light response (Fig. 3.3) and thus overestimates diurnal C flux (Fig. 3.6a). On the contrary, the big-leaf model has the least bias in energy fluxes (Fig. 3.6b). All the models significantly underestimate latent heat flux especially around morning and midday and overestimate sensible heat flux especially in the afternoon (RMSEs $>20$, mean $\mathrm{H}$ is $28 \mathrm{~W} \mathrm{~m}^{-2}$ ).
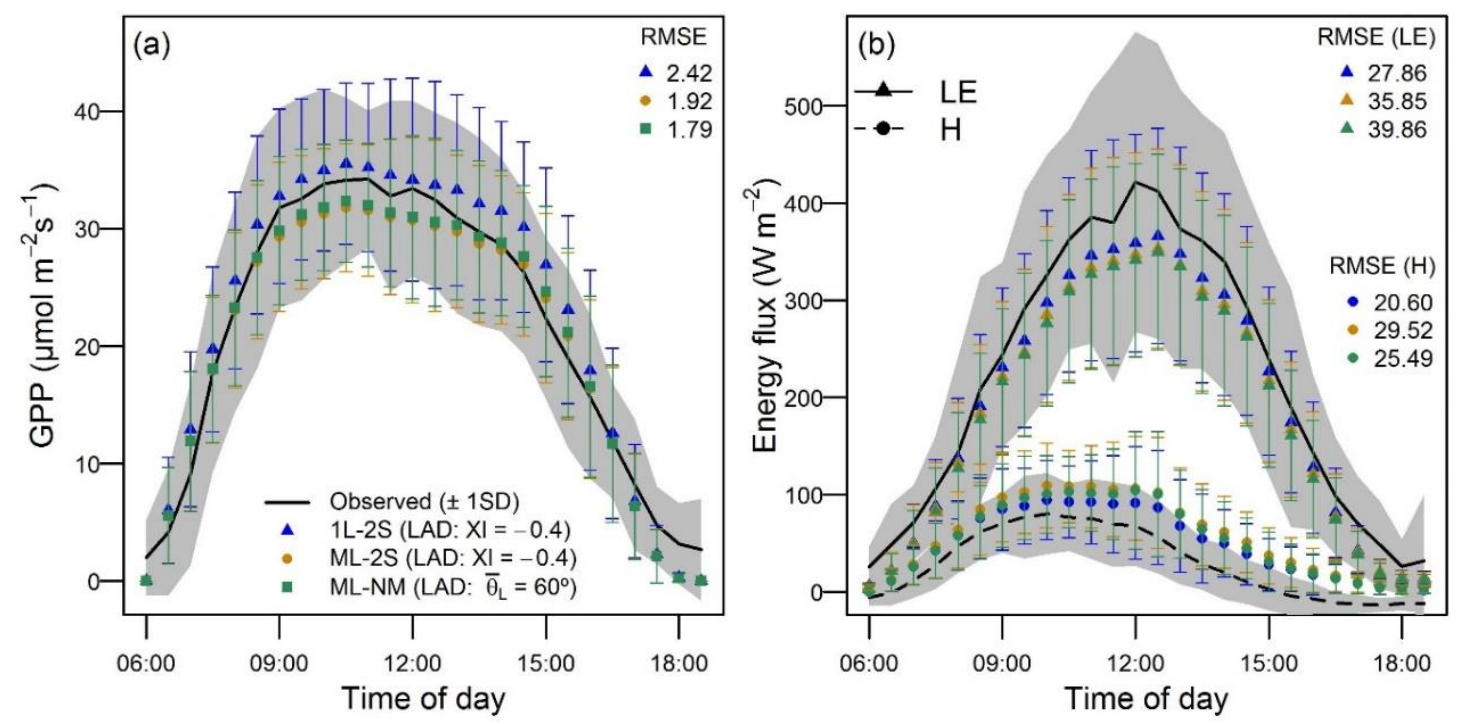

Figure 3.6. Comparison of observed and simulated GPP, latent heat and sensible heat fluxes for the mature oil palm plantation PTPN-VI in Jambi, Sumatra. Mean diurnal cycle are averaged over the period from October to December 2014 with least gaps. The gray area and error bars represent one standard deviation from the mean.

\subsection{Discussion}

\subsubsection{Radiation and photosynthesis profiles}

In general, the Norman multilayer scheme slightly improves over the two-stream scheme for simulating APAR profile and photosynthesis-light response under the premise of comparable model settings. This improvement is largely attributable to more realistic representation of $\mathrm{LAD}$, which is crucial for radiative transfer and distribution of PAR among the canopy layers with changing leaf traits. The dynamic multilayer structure (Fig. 3.1c) is especially suitable for oil palm's canopy which consists of many inclined larges leaves (with long rachis) spanning the hemisphere. ML_NM simulations are able to distribute PAR more evenly along the canopy 
depth using layer-specific LAD and G functions (Fig. 3.2). Difference in light absorption simulated by the Norman and two-stream models is most remarkable at the upper canopy layers for both direct and diffuse radiation. The oil palm's newly expanded erectophile leaves at the top of canopy allow sufficient light penetrating to lower layers, which should make higher radiation use efficiency than canopies dominated by horizontally arranged leaves according to canopy light interception and photosynthesis theories by de Wit (1965) (as cited in Corley and Tinker, 2016). It can be seen that when mean leaf inclination increases to medium or high angles the ML_NM model can simulate more APAR from the middle towards the base of the canopy than ML_2S does (Fig. 3.2a). This could explain why the simulations with more oblique LAD predict higher photosynthesis rate across all layers under sunny conditions (Fig. 3.2c). Breure (1988) also showed that older oil palms have improved light distribution and light use efficiency due to increased light penetration to lower layers by the more erectophile leaf arrangement, compared to the intermediate leaf inclination (plagiophile) of juvenile palms (Corley, 1976). Still in situ measurements of APAR from the oil palm plantations in Jambi are needed to validate the APAR distributions simulated by the all the models for the study area under its specific climate and plantation management (e.g. planting density and pruning).

Validation with available eddy covariance flux data suggests that the commonly assumed spherical leaf angle distribution $\left(\chi_{\mathrm{L}}=0\right.$ or 0.1$)$ used by many PFTs might not be the perfect choice for oil palm and rainforest in the tropics. Results prove that higher inclination angles (e.g. $\overline{\theta_{\mathrm{L}}}=60^{\circ}$ ) should be more realistic LAD for oil palm, whereas flatter leaf angles fit better with the rainforest in Sulawesi. Although the ML_2S model can produce similar photosynthesis profiles when its $\chi_{\mathrm{L}}$ parameter corresponds to an appropriate mean leaf angle used in ML_NM, this canopy-integrated parameter only represents a relatively narrow range of leaf angle ( $45^{\circ}$ to $20^{\circ}$ ) compared to that represented by the two-parameter beta distribution $\left(90^{\circ}\right.$ to $\left.0^{\circ}\right)$. Thus, the LAD used in ML_2S might not be sufficient for those species that have more dramatically changing leaf inclinations among the different canopy layers.

The statistical derivative multilayer solution by Bonan et al. (2012) effectively reduces the bias of the big-leaf model by downscaling the canopy profile of radiation absorption using an exponential function of cumulative leaf area from canopy top to bottom. However, it still has to rely on an implicit parameter $\chi_{\mathrm{L}}$ to describe canopy-integrated leaf angle distribution. It could diagnose the non-linearity of light profile to a certain degree with reference to canopyintegrated radiative fluxes, but the use of the same LAD and LAI across canopy layers are not correct representation of the canopy profile of natural vegetation. This inductive approach requires calibration of $\chi_{\mathrm{L}}$ against canopy-integrated radiation measurements but cannot be verified by sub-canopy-scale radiative profiles. One may simply calibrate $\chi_{\mathrm{L}}$ against canopy 
photosynthesis, which could be confounded due to the covariate effects of other canopy scalers, such as $K_{n}$, for relating leaf level photosynthesis to the canopy level. Overall, the accuracy of $\chi_{\mathrm{L}}$ is not physically measureable but could be easily biased or over-corrected by other inaccurate parameters used in radiative and photosynthetic processes or even from the meteorological forcing data. In contrast, the realistic Norman multilayer solution is based on a posteriori knowledge of leaf angle distribution at each canopy layer. The accuracy of $\overline{\theta_{\mathrm{L}}}$ parameter could be referenced to field leaf angle observation. The sunlit/shaded profile and radiative absorption of each canopy layer derived from layer-specific LAD and LAI could also be verified with canopy light measurements. Although in this study a full validation dataset with APAR profile is not available, the canopy mean $\theta_{\mathrm{L}}$ and layer-specific LAD and LAI can be empirically prescribed for the oil palm plantations based on field observation in the study area.

All the models predicted increased photosynthesis rate by oil palm under cloudy than sunny conditions (Fig. 3.2c, d), which is consistent with widely observed phenomena that plant photosynthesis is more efficient under diffuse irradiance conditions (Mercado et al., 2009). Oil palm leaves can achieve high photosynthesis rate per unit leaf area in cloudy conditions provided only a half of incident PAR compared to sunny conditions. This is because the incident photon flux density $1200 \mu \mathrm{mol} \mathrm{m}{ }^{-2} \mathrm{~s}^{-1}$ at noon in the selected cloudy day was still well above the light saturation point (Chazdon, 1986). The canopy integrated photosynthesis at noon for the selected sunny day is $62 \%$ of the cloudy day although the former has twice absorbed PAR. This implies a strong downregulation of photosynthesis in sunny conditions especially at the chosen noon time (for data shown in Fig. 3.2) when the stomatal conductance could be scaled down by a low relative humidity at leaf surface or soil water stress according to Sellers et al. (1996). Other studies on forest canopies also show increased carbon uptake efficiency under conditions with high fraction of diffuse radiation (Baldocchi et al., 1997; Gu, 2003; Jenkins et al., 2007). Knohl and Baldocchi, (2008) used the multilayer canopy model CANOAK to reveal high sensitivity of photosynthesis to increasing diffuse radiation especially for clumped canopies with high leaf inclination angles which allow stronger radiation transfer into lower canopy layers. This matches well with the multilayer simulation (Fig. 3.2d). The increased overall photosynthesis is largely contributed by shaded leaves at middle to lower canopy layers that can absorb significant amount of diffuse radiation (Fig. 3.2b). Alton et al. (2007) suggested that global land surface models that don't use an explicit multilayer canopy structure may exaggerate the "diffuse fertilization effects" and lead to overestimation of GPP about 10\% globally and up to $25 \%$ regionally. This is especially true if the big-leaf model is used with a low $K_{n}$ value which could significantly overestimate photosynthesis with a RMSE twice as high as that of multilayer models (Figs. 3.3, 3.4). Given the especially frequent diffuse radiative 
conditions in the tropical Indonesia, applying the dynamic multilayer radiative transfer scheme could potentially improve the accuracy of surface energy and carbon balance.

\subsubsection{Carbon and energy fluxes}

The one-layered radiation model with an oblique $\operatorname{LAD}\left(\chi_{\mathrm{L}}=-0.4\right)$ produced satisfactory APAR and photosynthesis profiles (Figs. 3.2, 3.3) and the settings were used in Chapter 2 for calibration and validation of CLM-Palm with observed LAI, yield and NPP (carbon fluxes). The new model comparison in this chapter shows that the multilayer models with medium to high LAD can simulate GPP that better correlates with observations. The Norman multilayer model consistently yielded the best carbon fluxes although the improvements were marginal. However, the one-layered big-leaf model gave the best results in energy fluxes (LE, H). In fact, all the models substantially underestimate LE and overestimate $\mathrm{H}$. The one-layered radiation model likely compensates the biases in CLM's water and energy cycles by its overestimation of photosynthesis (Figs. 3.3, 3.6a) which enhances stomatal conductance and transpiration. The higher transpiration could explain the reduced underestimation in LE and reduced overestimation in $\mathrm{H}$ by the one-layered model. The statistical derivative multilayer solution by Bonan et al. (2012) indeed significantly improves over the one-layered model on carbon fluxes and have similar performance with the Norman multilayer model. But the statistical method is based on canopy-integrated radiative fluxes calculated with the same two-stream approximation approach as the one-layered model. This is still theoretically different from the classic multilayer radiative transfer schemes such as Goudriaan (1977) and Norman (1979) that calculates the absorption, transmission and reflection of radiative fluxes among different layers iteratively. As discussed earlier, the canopy-integrated LAD and $\mathrm{G}$ function does not represent varying leaf characteristics along the canopy depth and restricts its ability to simulate light competition among dynamically growing or declining phytomers of oil palms. The Norman model allows a realistic representation of oil palm's canopy features and thus improves simulations of carbon fluxes. It is also useful for rainforests as shown in the photosynthesislight response curves (Fig. 3.4).

The Norman model implemented in CLM-Palm is also applicable to PFTs other than oil palm, as long as appropriate LAD functions are available to describe their canopy structure. Numerical experiments suggest that the iterative multilayer radiative transfer solution usually converges within 7 iterations and does not bring significantly higher computing cost. With the advance of modern computing capacity, the numerical efficiency of big-leaf models should not prevent the use of more sophisticated and realistic canopy models that are able to simulate a larger variety of canopy structures and within-canopy processes. The multilayer models should 
be at least considered as alternatives to the big-leaf model. Given the limited field data in this study, advantages of the Norman multilayer radiative transfer model are not fully exhibited. APAR measurements at multiple canopy depth and detailed radiation and energy properties such as longwave radiation, surface albedo and temperature from the sites are necessary to examine the overall effects of radiative transfer models on energy balance.

Apart from the difference in radiative transfer schemes, the significant underestimation of LE and overestimation of $\mathrm{H}$ for simulating oil palm plantation are very likely related to deficiencies in the other parts of CLM-Palm and CLM4.5 such as stomatal control on transpiration and hydrological parameterizations including canopy water interception and evaporation. A reduced stomatal conductance since noon could induce a lower photosynthesis and a lower latent heat flux together with a higher sensible heat flux in the afternoon. However, field measurements did not show any soil water limitation for the simulation period (October to December) which was within the rainy season. Thus, the biases in simulated LE and $\mathrm{H}$ are not likely caused by reduction in stomatal conductance due to soil water stress. The diurnal energy fluxes for the rainforest site also shows similar bias in LE and $\mathrm{H}$ as compared to eddy covariance measurements (data not shown). It is thus more likely that other hydrological mechanisms are insufficiently parameterized. For example, the oil palm plantation could have intercepted sufficient rainwater in the canopy during the rainy season (including the period of data in Fig. 3.6) which could have contributed to higher amount of evaporation from wet leaf surfaces especially around noon time. Higher evaporation could sustain higher level of latent heat flux and bring down sensible heat in the afternoon as shown in the field data, which is not captured by the model. The next chapter explores this hypothesis by adapting the canopy hydrological processes in the CLM4.5 model such as canopy rainfall interception and evaporation that are closely linked to energy fluxes.

\subsection{Conclusions}

Overall, the Norman multilayer radiative transfer scheme is a realistic representation of oil palm's multilayer canopy and it allows flexible parameterizations of the amount and distribution of leaf elements at each layer. This scheme is also applicable to natural forest PFTs such as the broadleaf evergreen tropical forest. The spatial and temporal patterns of the green mosaic covered on land surface are defined by dynamic canopy properties such as canopy structure, phenology, and leaf distribution and optical properties, which co-determine radiative transfer and absorption through the canopy down to the ground. Simulations with the Norman methods generally improve carbon flux estimation, especially reducing the significant overestimation by the big-leaf model. Given that the same baseline vegetation condition and 
photosynthesis model are used, this suggests a positive contribution of improving canopy radiative transfer on estimating carbon fluxes. On the other hand, biases in simulating latent and sensible heat fluxes can be to a large degree due to incomplete representation of oil palm's stomatal physiology and water use strategy or biased parameterization of the hydrological processes including soil and canopy evaporation that all have important impacts on surface energy fluxes. 


\subsection{Appendix}

\section{Leaf angle distribution and extinction coefficient}

The light extinction coefficient $K$ is related to a $G$ function through

$$
K(\theta, \varnothing)=\frac{G(\theta, \varnothing)}{\cos \theta}
$$

where the $\mathrm{G}$ function $G(\theta, \varnothing)$ defines the mean relative projected area of vegetative elements (leaf and stem) in the direction of incident radiation, and $\cos \theta$ accounts for increased path length with increasing incidence zenith angle (Lemeur, 1973). The G function can be formed as (Nilson, 1971, Ross, 1981, Wang et al., 2007b):

$$
G(\theta, \varnothing)=\frac{1}{2 \pi} \int_{0}^{2 \pi} \int_{0}^{\pi / 2} f\left(\theta_{L}, \phi_{L}\right)|\cos \delta| \sin \theta_{L} d \theta_{L} d \emptyset_{L}
$$

where $f\left(\theta_{L}, \phi_{L}\right)$ is a combined probability distribution function of the inclination angle $\theta_{L}$ and azimuth $\phi_{L}$ of leaf or phytoelements (hereafter only mention leaf). It determines the fraction of leaf area per unit solid angle $\Delta \Omega$ (i.e. $\Delta \Omega=\sin \theta_{L} d \theta_{L} d \emptyset_{L}$ ) within which the normals of such leaves are oriented. $|\cos \delta|$ calculates the projection of unit leaf area in the radiation direction and its mean value for all possible leaf orientations yields $G(\theta, \varnothing)$.

$$
\cos \delta=\cos \theta \cos \theta_{L}+\sin \theta \sin \theta_{L} \cos \left(\phi_{L}-\varnothing\right)
$$

When assuming symmetric leaf azimuth distribution, the $\mathrm{G}$ function can be simplified as (Wang et al., 2007b),

$$
G(\theta)=\int_{0}^{\pi / 2} A\left(\theta, \theta_{L}\right) f\left(\theta_{L}\right) d \theta_{L},
$$

where $A\left(\theta, \theta_{L}\right)$ is given by,

$$
A\left(\theta, \theta_{L}\right)=\left\{\begin{array}{c}
\cos \theta \cos \theta_{L}, \text { when }\left|\cot \theta \cot \theta_{L}\right|>1 \\
\cos \theta \cos \theta_{L}[1+(2 / \pi)(\tan \varphi-\varphi)], \quad \text { otherwise }
\end{array},\right.
$$

where $\varphi=\cos ^{-1}\left(\cot \theta \cot \theta_{L}\right)$.

For oil palm, the G function is calculated for each canopy layer depending on layer specific leaf angle distribution (LAD, i.e. $\left.f\left(\theta_{L}\right)\right)$. Each layer $i$ has a mean leaf inclination angle $\overline{\theta_{L}^{l}}(0 \sim \pi / 2)$, 
defined as the angle between leaf surface normal and zenith direction. Field measurements show that the inclination of oil palm frond (a big leaf) ranges from $\pi / 2$ at the canopy top (vertical at rank 1) to zero at the bottom (horizontal at lower senescent layers). Individual leaflets on each frond have certain degrees of departure from the overall frond inclination. CLM-Palm allows the prescription of a mean leaf inclination angle for the whole canopy denoted $\overline{\theta_{L}}$ (expressed in degrees as a PFT parameter). The model then automatically diagnoses the mean leaf inclination angle $\overline{\theta_{L}^{\imath}}$ for each layer according to the boundary angles ( $\pi / 2$ to 0 from canopy top to bottom) and the overall canopy-average $\overline{\theta_{L}}$.

Finally, the LAD probability density function per canopy layer follows the two-parameter beta distribution by Goel and Strebel (1984):

$$
f\left(\theta_{L}\right)_{i}=\frac{2}{\pi} \frac{\Gamma(\mu+v)}{\Gamma(\mu) \Gamma(v)}\left(1-2 \theta_{L} / \pi\right)^{\mu-1}\left(2 \theta_{L} / \pi\right)^{v-1}
$$

where $\Gamma$ is the Gamma function computed with GNU Scientific Library (Gough, 2009). For each canopy layer $i$ the two parameters $\mu, v$ are related to its mean leaf inclination angle $\overline{\theta_{L}^{\imath}}$ and its standard deviation $\sigma_{i}$ (set to constant 20 degrees or $\pi / 9$ radians) by:

$$
\begin{gathered}
\overline{\theta_{L}^{\imath}}=\frac{\pi}{2} \frac{v}{\mu+v} \\
\sigma_{i}^{2}=\left(\frac{\pi}{2}\right)^{2} \frac{v(v+1)}{(\mu+v)(\mu+v+1)}
\end{gathered}
$$

The probability density function (Eq. A 3.6) is solved with 9 angle classes between 0 and $\pi / 2$, including leaves or leaflets with their normals facing down. The integrals of $f\left(\theta_{L}\right)_{i}$, with $0 \leq \theta_{L} \leq \frac{\pi}{2}$, are all close to 1 . 
Table A 3.1. Symbols used in the derivation of radiative transfer functions.

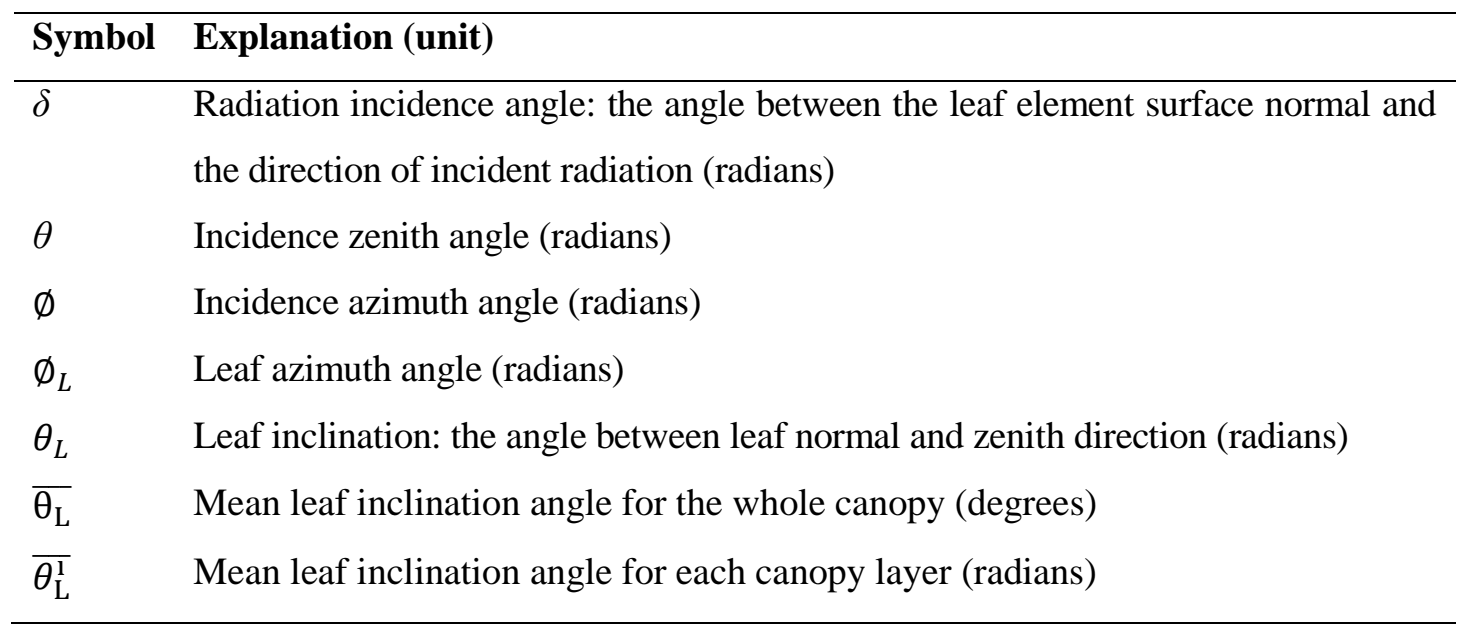

\section{Norman multilayer radiative transfer}

The probability of direct solar beam penetration through a single layer with a given incident zenith direction is calculated as:

$$
P_{i}^{\text {beam }}=\exp \left(-\mathrm{LAI}_{\mathrm{i}} \frac{G(\theta)_{i}}{\cos \theta}\right)
$$

Integrated probability of diffuse sky radiation penetration through the hemisphere of each canopy layer:

$$
P_{i}^{s k y}=\sum_{z=1}^{9}\left[2 \Delta \theta_{z} \sin \theta_{z} \cos \theta_{z} \exp \left(-L A I_{i} \frac{G\left(\theta_{z}\right)_{i}}{\cos \theta_{z}}\right)\right]
$$

where $\Delta \theta_{z}$ equals $10^{\circ}$ or $\frac{\pi}{18}$ rad when the sky is divided to 9 zenith sectors ( $\mathrm{z}=1$ to 9 ).

The upward and downward diffuse fluxes above each layer are expressed as:

$$
\begin{aligned}
E_{i}^{u p} & =\bar{\rho}_{l} E_{i}^{\text {down }}+\bar{\tau}_{l} E_{i+1}^{u p}+I_{i}\left(1-P_{i}^{\text {beam }}\right) \rho \\
E_{i+1}^{\text {down }} & =\bar{\rho}_{l} E_{i+1}^{\text {up }}+\bar{\tau}_{l} E_{i}^{\text {down }}+I_{i}\left(1-P_{i}^{\text {beam }}\right) \tau
\end{aligned}
$$

where $\bar{\rho}_{l}=\rho\left(1-P_{i}^{s k y}\right)$, and $\bar{\tau}_{l}=\tau\left(1-P_{i}^{s k y}\right)+P_{i}^{s k y}$, which are the diffuse radiation reflectance and transmittance of a canopy layer, related to the vegetation element reflectance and transmittance, $\rho$ and $\tau$, respectively. $I_{i}$ is the incident beam radiation on each canopy layer, calculated by: 


$$
I_{i}=I_{1} \prod_{n=1}^{i-1} P_{n}^{\text {beam }}
$$

where $I_{1}$ is the incident direct beam radiation above the top layer. $\prod_{n=1}^{i-1} P_{n}^{\text {beam }}$ is the product of beam penetration factors (Eq. A 3.8) of all layers above the layer $i$. This variable can be used to derive the sunlit and shaded fraction for each canopy layer:

$$
f_{\text {sun }}^{i}=\frac{\prod_{n=1}^{i-1} P_{n}^{\text {beam }}-\prod_{n=1}^{i} P_{n}^{\text {beam }}}{\mathrm{LAI}_{\mathrm{i}} G(\theta)_{i} / \cos \theta}
$$

where the dividend of the equation gives the ratio of intercepted beam by layer $i$ because the probability of beam penetration is attenuated along canopy depth (from layer $i-1$ to $i$ ). Dividing the interception ratio by the mean projection of layer $i$ along beam direction $\left(G(\theta)_{i} / \cos \theta\right)$ then yields the sunlit leaf area for this specific layer.

An iterative approach is used to solve Eqs. (A 3.10, 3.11) as described in (Norman, 1979) and Goel (1988). First assume $I_{i}$ all equal zero. Divide both sides of Eq. (A 3.10) by $E_{i}^{\text {down }}$ and those of Eq. (A 3.11) by $E_{i+1}^{\text {down }}$, and multiply the two equations by the left and right, respectively, one gets the ratio of up/down diffuse radiation for each layer:

$$
R_{i}=\frac{R_{i+1} \bar{\tau}_{l} \bar{\tau}_{l}}{\left(1-R_{i+1} \overline{\rho_{l}}\right)}+\overline{\rho_{l}}
$$

One also gets the ratio of downward diffuse fluxes in successive layers from Eq. (A 3.11):

$$
\frac{E_{i+1}^{\text {down }}}{E_{i}^{\text {down }}}=\frac{\overline{\tau_{l}}}{\left(1-R_{i+1} \overline{\rho_{l}}\right)}
$$

Starting from soil layer, calculate $R_{i}$ successively using Eq. (A 3.14), and then starting from the sky, solve downward diffuse fluxes successively with Eq. (A 3.15). $E_{1}^{\text {down }}$ is above the top canopy layer and is the incoming diffuse sky radiation. Now one has an initial guess for all the up- and down-ward diffuse fluxes when assuming zero beam fluxes. When direct beam is on, substitute these fluxes to the right side of Eq. (A 3.9) to recalculate downward diffuse fluxes from canopy top to bottom and then use Eq. (A 3.8) to recalculate upward diffuse fluxes from canopy bottom to top. Since upward fluxes are all adjusted, downward diffuse fluxes may need to be adjusted again. Recalculation with Eqs. (A 3.10, 3.11) repeats until the up/down diffuse fluxes converges at a given threshold. An iteration of 2 to 7 rounds is usually enough to converge at $1 \mathrm{e}-6 \mathrm{~W} / \mathrm{m}^{2}$ precision for up/down diffuse fluxes within all canopy layers. 
Once the transmitted fluxes are known, the absorbed fluxes by sunlit and shaded leaves of each canopy layer can be then derived in order to drive photosynthesis and energy exchanges. The absorbed direct beam flux by sunlit leaves per layer is:

$$
\hat{I}_{i}^{\text {sun }}=I_{i}\left(1-P_{i}^{\text {beam }}\right)(1-\rho-\tau)
$$

where the term $\left(1-P_{i}^{\text {beam }}\right)(1-\rho-\tau)$ represents the direct beam absorptance of a canopy layer after accounting for beam penetration and reflectance and transmittance of intercepted beam by vegetation elements. Shaded leaves receive no direct beam flux and thus $\hat{I}_{i}^{\text {shade }}=0$.

The absorbed diffuse radiation by sunlit and shaded leaves per layer is:

$$
\begin{gathered}
\hat{E}_{i}^{\text {sun }}=f_{\text {sun }}^{i}\left(E_{i}^{\text {down }}+E_{i+1}^{\text {up }}\right)\left(1-P_{i}^{\text {sky }}\right)(1-\rho-\tau) \\
\hat{E}_{i}^{\text {shade }}=\left(1-f_{\text {sun }}^{i}\right)\left(E_{i}^{\text {down }}+E_{i+1}^{u p}\right)\left(1-P_{i}^{\text {sky }}\right)(1-\rho-\tau)
\end{gathered}
$$

where the term $\left(1-P_{i}^{s k y}\right)(1-\rho-\tau)$ represents the diffuse radiation absorptance of a canopy layer. It only includes the portion of intercepted and absorbed diffuse radiation received on the top and bottom of a layer.

The above transmitted and absorbed fluxes are calculated for both visible (PAR) and nearinfrared bands (NIR). Absorbed flux in the visible band is so-called APAR (absorbed photosynthetically active radiation), and it is separated to sunlit and shaded leaves per layer by Eq. (A 3.18) for photosynthesis calculation. Radiation absorption in the NIR band is only calculated for the whole canopy per unit direct or diffuse flux.

$$
\begin{gathered}
A P A R_{i}^{\text {sun }}=\hat{I}_{i}^{\text {sun }}+\hat{E}_{i}^{\text {sun }} \\
A P A R_{i}^{\text {shade }}=\hat{E}_{i}^{\text {shade }}
\end{gathered}
$$

\section{The multilayer derivative of two-stream approximation}

Bonan et al. (2012) implemented a statistical multilayer solution in CLM to derive the vertical profile of absorbed radiative fluxes for sunlit and shaded leaves at different canopy layers. It is still based on the canopy-integrated radiative fluxes calculated with the one-layered two-stream approximation radiative transfer scheme (Dickinson, 1983; Sellers, 1985; Dai et al., 2004; Oleson et al., 2013). The statistical solution derives, from the canopy-integrated radiative fluxes, the profile of radiative absorption (direct and diffuse) per canopy layer with respect to cumulative plant area index (i.e. the sum of LAI and stem area index; here only LAI is 
mentioned for simplicity). These fluxes are then partitioned to the sunlit and shaded fractions at canopy depths by:

$$
f_{\text {sun }}^{i}=e^{-K \sum_{i=1}^{n} L A I_{i}},
$$

where $K$ is the direct beam extinction coefficient as in Eq. (A 3.1). However, in this multilayer mode $K$ is only calculated for a whole canopy based on a semi-empirical $\mathrm{G}$ function from Goudriaan (1977):

$$
\begin{gathered}
\beta=0.5-0.633 \chi_{L}-0.33 \chi_{L}^{2}, \quad-0.4<\chi_{L}<0.6 \\
G(\theta)=\beta+0.877(1-2 \beta) \cos \theta
\end{gathered}
$$

where $\chi_{\mathrm{L}}$ is the canopy-integrated LAD index from Ross (1975). It describes the average departure of leaf angles from a spherical distribution (when $\chi_{\mathrm{L}}=0$ ), with positive numbers $\left(\chi_{\mathrm{L}}>\right.$ 0 ) indicating tendency towards a horizontal LAD and negative numbers $\left(\chi_{\mathrm{L}}<0\right)$ towards a vertical distribution. $\chi_{\mathrm{L}}$ is limited to the range of -0.4 to 0.6 , which works well for the canopy of a large range of natural PFTs. However, rare LADs such as planophile (mostly horizontal), erectophile (mostly vertical), and plagiophile (mostly oblique leaves) are hard to fit with this equation. Moreover, some canopies, like that of oil palm, have stratified LAD that varies from an erectophile one at the canopy top to a nearly planophile one at the bottom, for which the canopy-integrated $\chi_{\mathrm{L}}$ index and the corresponding G function (Eq. A 3.20) are hard to describe. 


\section{CHAPTER 4}

Reconciling canopy hydrological parameterization and observed water and energy fluxes 


\subsection{Introduction}

Plant's life cycle and its interaction with soil, water, and the atmosphere is the key regulator of terrestrial biogeochemical and biogeophysical processes. Plant's canopy plays a central role in these processes by assimilating and releasing $\mathrm{CO}_{2}$, by absorbing solar radiation and transforming energy, and by transpiring, intercepting and evaporating water (Bonan, 2008). While the terrestrial water fluxes are dominated by transpiration through the stomata of leaves (80 to $90 \%$ of evapotranspiration; Jasechko et al., 2013), the large cumulative surface area of leaves and stems of vegetation is also an important physical pool for intercepting precipitation and contributing to surface evaporation. Correct parameterization of canopy hydrology is critical for modeling water fluxes and also for partitioning of available energy into latent (LE) and sensible heat $(\mathrm{H})$. However, there lacks consistency in the fraction of intercepted precipitation and its effects on leaf gas exchange among major ecosystem models, even for the same vegetation type under the same climatic condition (De Kauwe et al., 2013). The canopy hydrological parameterization of the older CLM model (CLM3) was evaluated by Wang et al. (2007a), which showed severe overestimation of annual rainfall interception ratio for tropical areas (18-70\% simulated vs. 16-42\% observed). On the contrary, in a model evaluation by De Kauwe et al. (2013) CLM4 gave a range of 3.5-5.1\% rainfall interception for the temperate forest and tree plantation sites, which were considerably underestimated compared to field measured values (16-27\%; Oishi et al., 2008; Schäfer et al., 2003). It needs to be noted that CLM4 used different water interception parameters from CLM3 (Lawrence et al., 2007). CLM4.5 has the same water interception parameterization as CLM4, in which uniform water interception efficiency and storage capacity are used by all PFTs without taking into account the potential morphological difference among species, even between boreal and tropical forests and between forest and crops. Biases in canopy water interception could directly propagate to transpiration and evapotranspiration calculations in CLM4.5 because the intercepted precipitation will decrease transpiration by reducing the fraction of dry canopy that is allowed to transpire (Lawrence et al., 2007).

Overall, the hydrological mechanisms concerning canopy water interception vary strongly among the land surface models (De Kauwe et al., 2013) and even between different versions of a model (e.g. CLM3 and CLM4). The validation of CLM-Palm with eddy covariance flux data in Chapter 3 showed its strong capacity for simulating $\mathrm{C}$ fluxes. However, the modeled water fluxes and energy partitioning were biased which might be related to unrealistic canopy water interception. In this chapter, I will reevaluate the canopy hydrological parameterization in CLM4.5 (inherited by CLM-Palm) with specific consideration of the morphological traits of oil palm. The objectives are: 1) to recalibrate two key parameters of interception efficiency and 
interception storage capacity with field measured evapotranspiration and transpiration data; 2) to evaluate the influence of canopy water interception on energy fluxes (LE, H); and 3) to design a special interception mechanism that differentiates water storage capacity between leaf and stem surfaces according to field observation on oil palm.

\subsection{Model experiments}

\subsubsection{Description of canopy hydrology in CLM4.5}

CLM4.5 currently uses two hard-coded parameters controlling canopy interception of precipitation. The first is the water interception efficiency (fpi), which represents the fraction of precipitation intercepted by the canopy (and of 1-fpi, the fraction of throughfall; Lawrence et al., 2007). The other is the water film thickness dewmx (Dickinson et al., 1993), which is a measure of the maximum storage capacity for intercepted precipitation and dew on vegetation surfaces, i.e. per unit plant area index (PAI). PAI is the sum of leaf area index (LAI) and stem area index $(\mathrm{SAI})$, i.e. $\mathrm{PAI}=\mathrm{LAI}+\mathrm{SAI}$, where $\mathrm{SAI}$ is calculated in the model as the ratio 0.1 of LAI for certain crops (e.g. corn; Levis et al., 2012) and also for oil palm (Fan et al., 2015).

The interception efficiency fpi is a nonlinear function of PAI according to the following equation:

$$
f p i=f p i m x \times\left(1-e^{-0.5 \times P A I}\right),
$$

where the coefficient fpimx is a scaling factor that represents the maximal fpi when PAI tends to infinity. It has a default value 0.25 in CLM4.5 giving a range of fpi from 0.1 to 0.24 when PAI increases from 1 to 7.

The potential rainfall interception rate $\left(I_{c a n} ; \mathrm{mm} \mathrm{s}^{-1}\right)$ and storage $\left(Q_{c a n} ; \mathrm{mm}\right)$ for a given precipitation rate $\left(q_{\text {rain }} ; \mathrm{mm} \mathrm{s}^{-1}\right)$ is:

$$
\begin{aligned}
I_{\text {can }} & =f p i \times q_{\text {rain }}, \\
Q_{\text {can }} & =\sum I_{\text {can }} \times \Delta t
\end{aligned}
$$

where $\Delta t$ is the model time step. $Q_{c a n}$ represents the storage pool of intercepted water, which is simultaneously updated by interception gain $\left(I_{c a n}\right)$ and canopy evaporation loss. Canopy evaporation is not shown here but is described in Oleson et al. (2013).

The maximum storage capacity of intercepted water by the canopy $\left(Q_{c a n}^{m x} ; \mathrm{mm}\right)$ is: 


$$
Q_{\text {can }}^{m x}=\text { dewmx } \times P A I,
$$

where dewmx is set as a constant value 0.1 (mm per unit PAI). When $Q_{\text {can }}$ surpasses $Q_{\text {can }}^{m x}$, the excess water is partitioned to canopy runoff by the rate $R_{c a n}\left(\mathrm{~mm} \mathrm{~s}^{-1}\right)$ and $Q_{c a n}$ is reset to $Q_{c a n}^{m x}$.

$$
R_{c a n}=\left(Q_{c a n}-Q_{c a n}^{m x}\right) / \Delta t
$$

The actual accumulative interception $\left(I_{\text {can }}^{A} ; \mathrm{mm}\right)$ is tracked through time by:

$$
I_{\text {can }}^{A}=\sum\left(I_{\text {can }}-R_{\text {can }}\right) \times \Delta t
$$

During and following a rain event, the balance of intercepted water after adjusting canopy runoff and evaporation loss (denoted $\bar{Q}_{c a n}$ ) fills the leaf and stem surfaces equally to determine the fraction of canopy area which is wet $\left(f_{w e t}\right)$ and the fraction of foliage area which is dry $\left(f_{d r y}\right)$ according to:

$$
\begin{aligned}
& f_{\text {wet }}=\left[\frac{\bar{Q}_{\text {can }}}{Q_{c a n}^{m x}}\right]^{0.666} \\
& f_{\text {dry }}=\left(1-f_{\text {wet }}\right) \frac{L A I}{P A I}
\end{aligned}
$$

The above $f_{\text {wet }}$ is for all vegetation surfaces (i.e. PAI) including stem area which are wet and contribute to evaporation, whereas $f_{d r y}$ is only meant for the dry fraction of leaf area (i.e. LAI) because only leaves can transpire. $f_{\text {wet }}$ adjusts canopy evaporation rate which in turn updates the intercepted water pool continuously until the whole canopy becomes dry (i.e. $Q_{c a n}=0$ ). The canopy transpiration rate is adjusted by $f_{d r y}$ linearly. Details on the calculation of transpiration and evaporation are in Oleson et al. (2013).

\subsubsection{Rationale for new parameterization}

In the CLM4.5, fpimx and dewmx are fixed at default values and shared by all the PFTs including natural forests and crops. The same water film thickness (dewmx) is also assumed for leaf and stem surfaces. An apparent weakness of this uniform parameterization is that potential differences in water interception capacity of differently structured canopies or species under different climates (e.g. tropical vs. boreal zones) are not accounted for. Tropical plants are characterized by extremely dense canopies and diverse leaf morphologies. The current values of fpimx and dewmx might not be representative of oil palm's water interception and storage capacity. In fact, the original value of fpimx was 1.0 in the older version CLM3 (Oleson et al., 
2004), but Lawrence et al. (2007) reduced this value to 0.25 for fitting the partitioning of evapotranspiration (reducing the share of canopy evaporation) to global mean patterns.

In the previous chapter the validation of CLM-Palm with eddy covariance flux data showed biases in modeling the partitioning of $\mathrm{H}$ and LE for the mature oil palm plantation (see Fig. 3.6, Chapter 3) although the diurnal carbon flux was well simulated. The underestimation of LE especially in the morning is likely related to the hysteresis of transpiration and trunk water storage unrepresented in the model. However, oil palm's hydrodynamics such as trunk water storage and utilization mechanism is still unclear according to field research in the study area (Niu et al., 2015) and its connection to leaf water potential and stomatal functioning is complex to model.

During midday, LE is also systematically underestimated in the model. One potential explanation could be an underestimated canopy water interception. More intercepted precipitation in the canopy could have contributed to higher amount of evaporation from wet leaf surfaces especially around noon when radiation, vapor pressure deficit and temperatures are higher. The overestimation of $\mathrm{H}$ notably in the afternoon also suggests the ground or the canopy could have evaporated more water vapor to keep the surface cooler in reality than in the simulations. Because the dense canopy of tropical vegetation allows little solar radiation reaching the ground, the contribution of ground evaporation is relatively small as compared to the above canopy (Jordan and Heuveldop, 1981; Shuttleworth et al., 1984). Thus, I hypothesize that biases in LE and $\mathrm{H}$ can be reduced by modifying the canopy hydrological scheme to fit with oil palm's canopy traits.

\subsubsection{Experiment design}

Field observations from the same study area suggest that oil palm's large leaves and caved leaflets as well as the axils are noticeably easy to capture and store rainfall (Merten et al., 2016). The axils can hold water and remain wet long after a rainfall event. A series of experiments were thus conducted by increasing fpimx and dewmx stepwise. First, the original fpimx value 1.0 from CLM3 was adopted, which is the same as that in the CANOAK model (Baldocchi et al., 2002). The dewmx value 0.4 from CANOAK was used as the maximum reference value.

Additionally, a special experiment treated the canopy water storage capacity differently among leaflets, rachis and axils. The rachis and axils are modeled as stem (SAI) in CLM-Palm. Therefore, two dewmx parameters dewmxl and dewmx2 were set for the leaf (LAI) and stem (SAI), respectively. Based on field observation, oil palm's stem surfaces (esp. axils) are assumed to be able to hold much thicker water film (even pools of water) than leaf surfaces (i.e. 
dewmx $2>$ dewmx1). These two parameters are involved in partitioning the total intercepted water to leaf and stem and in calculating the fractions of wet and dry canopy $\left(f_{\text {wet }}, f_{d r y}\right)$ as follows.

Intercepted rainwater is stored in the leaf and stem pools separately as:

$$
\begin{aligned}
& Q_{\text {leaf }}=\sum f p i \times q_{\text {rain }} \times \Delta t \times \frac{L A I}{P A I}, \\
& Q_{\text {stem }}=\sum f p i \times q_{\text {rain }} \times \Delta t \times \frac{S A I}{P A I}
\end{aligned}
$$

where $Q_{\text {leaf }}+Q_{\text {stem }}=Q_{\text {can }}$. When the leaf pool is full, excess water drains to the stem pool:

$$
\begin{gathered}
Q_{\text {stem }}=Q_{\text {can }}-\text { dewmx } 1 \times L A I \\
Q_{\text {leaf }}=\text { dewmx } 1 \times L A I
\end{gathered} .
$$

When both the leaf and stem pools are full, excess water is then partitioned to canopy runoff.

$Q_{\text {leaf }}$ and $Q_{\text {stem }}$ are updated by the same rate of evaporation loss per unit surface area. The balances of interception gain and evaporation loss for two water storage pools (denoted $\bar{Q}_{\text {leaf }}$ and $\bar{Q}_{\text {stem }}$ ) are used to calculate the fractions of leaf and stem surfaces that are wet:

$$
\begin{aligned}
f_{\text {wet }}^{\text {leaf }} & =\left[\frac{\bar{Q}_{\text {leaf }}}{\text { dewm } x 1 \times L A I}\right]^{0.666} \\
f_{\text {wet }}^{\text {stem }} & =\left[\frac{\bar{Q}_{\text {stem }}}{\text { dewm } \times 2 \times S A I}\right]^{0.666}
\end{aligned}
$$

Once $f_{\text {wet }}^{\text {leaf }}$ and $f_{\text {wet }}^{\text {stem }}$ are obtained, the overall wet and dry fractions of canopy are derived as:

$$
\begin{aligned}
& f_{\text {wet }}=\left[f_{\text {wet }}^{\text {leaf }} \times L A I+f_{\text {wet }}^{\text {stem }} \times S A I\right] / P A I \\
& f_{\text {dry }}=\left[\left(1-f_{\text {wet }}^{\text {leaf }}\right) \times L A I\right] / P A I
\end{aligned}
$$

$f_{w e t}$ and $f_{d r y}$ are used in the coupled stomatal conductance and photosynthesis model (Oleson et al., 2013) . Only the dry fraction of foliage $\left(f_{d r y}\right.$ of LAI $)$ is considered in transpiration and photosynthesis, whereas both the wet fraction of foliage and stem area $\left(f_{\text {wet }}\right.$ of PAI) are considered for evaporation.

\subsubsection{Model evaluation}

The experiments on canopy water interception were evaluated with eddy covariance flux data (Meijide et al., 2016) and sap flux measurements (Röll et al., 2015) covering the period June to December 2014 from a mature oil palm plantation (PTPN-VI) in Jambi, Sumatra. Details on 
eddy covariance measurements were described in Chapter 3 according to Meijide et al. (2016). The sap flux measurements were carried out by Röll et al. (2015) using the approach designed for oil palms by Niu et al. (2015). Meteorological variables (e.g. radiation, air temperature and humidity, precipitation, soil microclimate) measured at the same time and location were used as input forcing data. The radiative transfer model follows the Norman multilayer scheme. All other model parameters follow the calibrated and validated values in Chapter 2.

The model evaluation was based on mean daily values of evapotranspiration (ET), transpiration $(T)$, canopy evaporation $\left(E_{C}\right)$, soil evaporation $\left(E_{S}\right)$, rainfall interception ratio $\left(\mathrm{I}_{\mathrm{C}}\right)$ and latent and sensible heat fluxes (LE, H) from all the experiments covering the same period of field data. The mean diurnal cycles of LE, H, ET and T with half-hourly time step were also analyzed for selected experiments. A preliminary check on ET and T with the default model parameters was first conducted for the dry days to verify that canopy transpiration is comparable with observation and that it should be the major component of evapotranspiration when the foliage is dry. The modified canopy water interception parameters and the new mechanism were then analyzed for their effects on water fluxes (ET, T) and energy partitioning (LE, H) during rainy days.

\subsection{Results and discussion}

The simulated annual interception ratio $\left(\mathrm{I}_{\mathrm{C}}\right)$ and 7-month mean daily values of $\mathrm{ET}, \mathrm{T}, \mathrm{E}_{\mathrm{C}}, \mathrm{E}_{\mathrm{S}}$, $\mathrm{LE}$, and $\mathrm{H}$ from a series of experiments described above are summarized in Table 4.1. Field data (ET, T, and LE, H) from the same period and reported value ranges of other variables $\left(\mathrm{E}_{\mathrm{C}}\right.$, $\left.E_{S}, I_{C}\right)$ from literature are used as reference. The results show that increased rainfall interception efficiency (fpimx) and storage capacity ( $($ ewmx $)$ by the canopy, including separate treatment of leaf and stem surfaces, progressively improve the magnitude of evapotranspiration and its components $\left(\mathrm{T}, \mathrm{E}_{\mathrm{C}}\right)$ as well as the partitioning of surface energy fluxes (LE, $\left.\mathrm{H}\right)$ compared to the reference values. The annual rainfall interception also becomes much closer to observed range. More interpretation and discussion on the results and remaining biases are presented in the following sections. 
Table 4.1 Mean daily water and energy fluxes summarized from June to December 2014 and the annual interception ratio of 2014 simulated by the series of experiments described in section 4.2. The total precipitation for the PTPN-VI site was $1680 \mathrm{~mm}$ in 2014.

\begin{tabular}{|c|c|c|c|c|c|c|c|c|}
\hline Experiment & & $\begin{array}{l}\mathbf{L E} \\
(\mathbf{W} \\
\left.\mathbf{m}^{-1}\right)\end{array}$ & $\begin{array}{c}\mathbf{H} \\
(\mathbf{W} \\
\left.\mathbf{m}^{-1}\right)\end{array}$ & $\begin{array}{c}\text { ET } \\
(\mathbf{m m} \\
\left.\text { day }^{-1}\right)\end{array}$ & $\begin{array}{c}\mathbf{T} \\
(\mathbf{m m} \\
\left.\operatorname{day}^{-1} ; \%\right)\end{array}$ & $\begin{array}{c}\mathrm{E}_{\mathrm{C}} \\
(\%)\end{array}$ & $\begin{array}{c}\mathrm{E}_{\mathrm{S}} \\
(\%)\end{array}$ & $\begin{array}{c}\mathbf{I}_{\mathbf{C}} \\
(\%)\end{array}$ \\
\hline fpimx $=0.25$ & dewmx $=0.1$ (default) & 98.7 & 27.2 & 3.41 & $3.10 ; 90.8$ & 5.2 & 4.0 & 3.7 \\
\hline fpimx $=0.5$ & dewmx $=0.2$ & 100.0 & 26.1 & 3.45 & $2.99 ; 86.7$ & 9.5 & 3.8 & 7.0 \\
\hline fpim $x=0.5$ & dewmx $=0.4$ & 101.6 & 24.8 & 3.51 & $2.84 ; 81.0$ & 15.4 & 3.6 & 11.1 \\
\hline fpimx $=0.5$ & dewmx $1 / 2=0.2 / 2$ & 101.9 & 24.6 & 3.52 & $2.90 ; 82.3$ & 14.1 & 3.6 & 10.3 \\
\hline fpim $x=0.5$ & dewmx $1 / 2=0.4 / 4$ & 104.2 & 22.7 & 3.60 & $2.71 ; 75.3$ & 21.4 & 3.3 & 15.3 \\
\hline fpim $x=1.0$ & dewmx $=0.2$ & 100.3 & 25.9 & 3.47 & $2.97 ; 85.6$ & 10.6 & 3.8 & 8.1 \\
\hline fpim $x=1.0$ & dewmx $=0.4$ & 102.1 & 24.3 & 3.53 & $2.79 ; 79.1$ & 17.4 & 3.5 & 13.1 \\
\hline fpimx $=1.0$ & dewmx $1 / 2=0.2 / 2$ & 102.4 & 24.1 & 3.54 & $2.85 ; 80.6$ & 15.9 & 3.5 & 12.1 \\
\hline fpimx $=1.0$ & dewmx $1 / 2=0.4 / 4$ & 105.1 & 21.9 & 3.63 & $2.64 ; 72.7$ & 24.2 & 3.1 & 18.5 \\
\hline \multirow[t]{2}{*}{ Reference } & observation/literature & 129.4 & 10.6 & 4.8 & $2.56 ; 53$ & $16-20$ & $8-16$ & $16-42$ \\
\hline & & \multicolumn{3}{|c|}{ eddy covariance } & sap flux & \multicolumn{3}{|c|}{ literature* } \\
\hline
\end{tabular}

* $\mathrm{E}_{\mathrm{C}}: 16 \%$ (global mean) in Dirmeyer et al. (2005) and 20\% for forest in Wilson et al. (2001); Es: 8-16\% in Wilson et al. (2001); IC: 16-42\% in Wang et al. (2007a)

\subsubsection{Water fluxes with default parameterization}

Preliminary check with the default canopy hydrological parameterization shows that the simulated transpiration is close to evapotranspiration when the foliage is dry (Fig. 4.1). However, the field measured fluxes indicate considerable difference between ET (eddy covariance flux) and $\mathrm{T}$ (sap flux) during dry days. The average daily $\mathrm{T}$ by sap flux measurements $\left(2.6 \mathrm{~mm} \mathrm{day}^{-1}\right)$ was only $54 \%$ of ET by eddy covariance measurements $(4.7 \mathrm{~mm}$ day $^{-1}$ ), although the model indicates very small component of evaporation during the dry period $(<10 \%)$. Another study by Roupsard et al. (2006) on coconut palm, a close relative of oil palm, shows a much higher $\mathrm{T}$ to ET ratio (68\%) with the same sap flux and eddy covariance techniques (but independent calibrations and experimental setup). The larger difference of ET and $\mathrm{T}$ for oil palm could be either contributed by ground or stem evaporation or by the transpiration of other vegetation (e.g. epiphytes) that were not included in sap flux measurements (Röll et al., 2015). Evaporation of intercepted rainfall, especially by the axils along the stem, could last for a certain period after rain events and contribute to the high measured ET of the selected dry days in Fig. 4.1. There is also methodological difference between the eddy covariance technique and sap flux measurements. According to Wilson et al. 
(2001), sap flux measurements may systematically underestimate transpiration because it only accounts for about $50 \%$ (similar to the above data) of annual evapotranspiration estimated by eddy covariance and catchment water balance techniques. The thermal dissipation probe (TDP) measurements (Granier, 1987) were conducted on oil palm's leaf petioles only to estimate sap fluxes of individual leaves (Niu et al., 2015; Röll et al., 2015). When scaling up the leaf fluxes to the transpiration of a whole stand, there are potential errors associated with the leaf sample size, spatial variability of stand conditions (Williams et al., 2004), and variations in vessel density within leaf petioles (Clearwater et al., 1999). Wilson et al. (2001) also showed for forest sites that ground (soil) evaporation explains only less than $16 \%$ of the difference between sap flux estimates of transpiration and eddy covariance estimates of evapotranspiration, and that the remaining discrepancy could be largely although not fully explained by evaporation of intercepted water.

Examining the rainy days, both measured and simulated ET become lower especially the peak value at noon. But the simulated ET and T still have similar magnitudes throughout the day, implying very limited evaporation loss of water even during rainy days. Transpiration is slightly reduced in simulation and in sap flux estimates. Field data show the daily average share of $\mathrm{T}$ in ET decreases slightly from $54.4 \%$ in dry days to $52.8 \%$ in wet days. The model simulates a sharper drop of the $\mathrm{T} / \mathrm{ET}$ ratio from $95.2 \%$ (dry) to $85.2 \%$ (wet). As mentioned earlier the model decreases transpiration when the foliage is wet (Eq. 4.6). Field measured T peaks earlier (around 10:00 AM) than that in the simulation (around noon) during both wet and dry days.
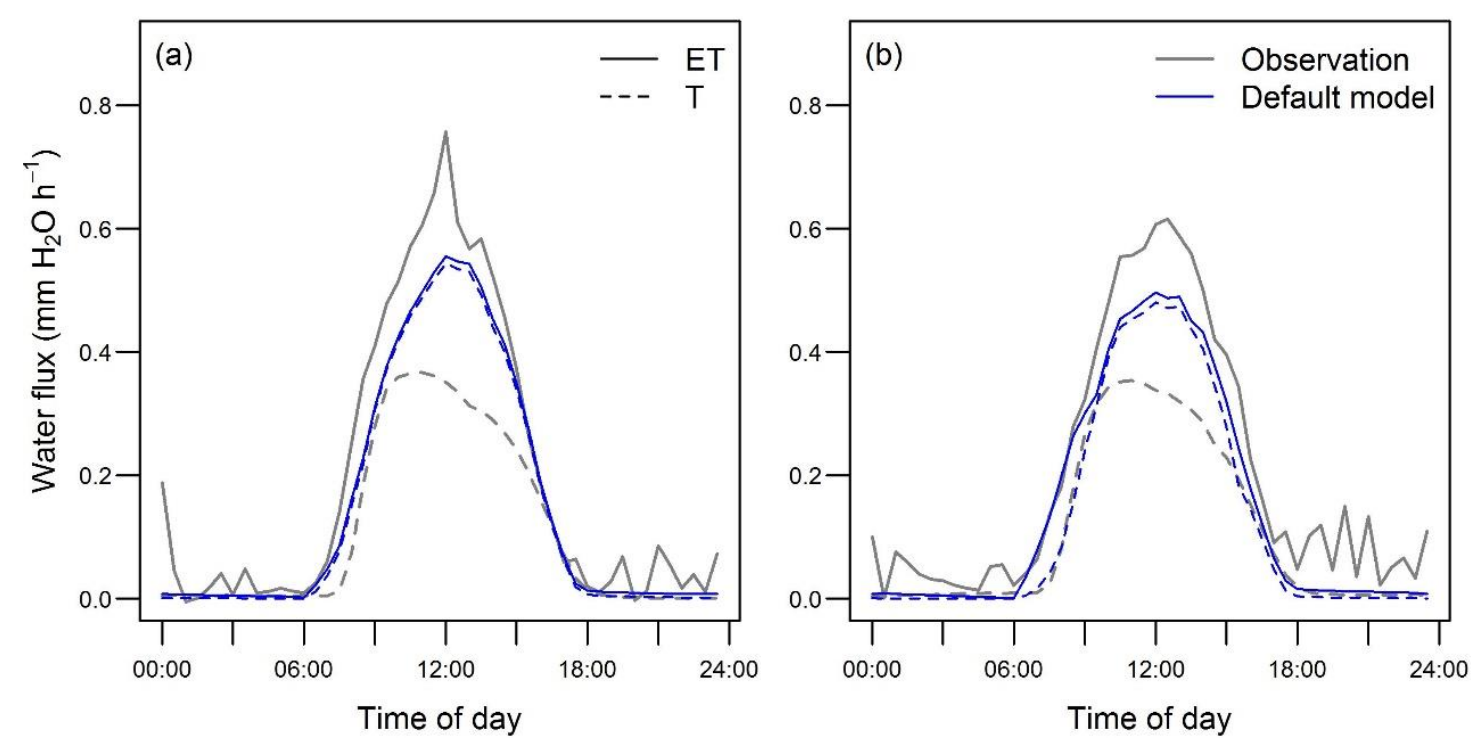

Figure 4.1. Simulated evapotranspiration (ET) and transpiration (T) during (a) dry and (b) rainy days compared to eddy covariance (ET) and sap flux (T) measurements. 
The difference in ET partitioning between the default simulation and field measurements in both dry and rainy days can be partly attributed to the potential underestimation of $\mathrm{T}$ by sap flux estimates and partly due to the overestimation of $\mathrm{T}$ by the model. The apparent overestimation of $\mathrm{T}$ in the default simulation ( $90.8 \%$ of ET) could result from potential biased or missing mechanisms related to soil water processes and the controls on stomatal conductance in the model. The relative contribution of canopy transpiration and soil evaporation in CLM4.5 can be adjusted by a turbulent transfer coefficient between the soil and the canopy air (Zeng et al., 2005). Lawrence et al. (2007) and Sakaguchi and Zeng (2009) evaluated this mechanism and the related under-canopy processes concerning ground evaporation. The coupled stomatal conductance and photosynthesis in CLM4.5 follows the Ball-Berry relationship and considers the influence of relative humidity and $\mathrm{CO}_{2}$ concentration at the leaf surface (Collatz et al., 1991). Soil moisture has direct control on stomatal conductance by multiplying the minimum conductance by a soil water stress function $\left(0<\beta_{t} \leq 1\right)$ related to soil water potential and PFT root distribution (Sellers et al., 1996). $\beta_{t}$ also influences stomatal conductance indirectly via $V_{c m a x}$ and respiration. This approach can effectively represent soil control on plant water uptake in the root zone and on long-term water budget, but it ignores much of the hydrodynamic processes from root to leaf, where in the end leaf water potential has more direct mechanistic control on stomatal conductance especially for intra-daily dynamics (Matheny et al., 2014). The missing processes between root and leaf may explain why CLM4.5 cannot capture the morning peak and early decline of $\mathrm{T}$ in the oil palm plantation (Fig. 4.1). However, these processes are difficult to model because they are linked to the natural variability of plant hydraulic and architecture characteristics, stem water storage capacity, and root-to-leaf water transport cost, etc. (Janott et al., 2011; Tuzet et al., 2003). They are not included in the model experiments in this study.

The simulated annual mean canopy evaporation ( $\mathrm{E}_{\mathrm{C}}: 5.9 \%$ ) and soil evaporation (Es: 4\%) as well as rainfall interception ratio $\left(\mathrm{I}_{\mathrm{C}}: 3.7 \%\right.$ ) by the default parameterization (Table 4.1$)$ are all likely underestimated compared to reference values from literature (e.g. $\mathrm{E}_{\mathrm{C}}$ : $16 \%$ (global mean) in Dirmeyer et al. (2005); $\mathrm{E}_{\mathrm{S}}$ : 8-16\% in Wilson et al. (2001); $\mathrm{I}_{\mathrm{C}}$ : 16-42\% in Wang et al. (2007a)). Although the exact shares of ground and stem evaporation and unmeasured transpiration are unknown due to limited water flux data for oil palm plantations, other studies (Williams et al., 2004; Wilson et al., 2001) have suggested the underestimation of $\mathrm{T}$ by the sap flux method and have indicated the stronger role of canopy water interception than soil evaporation on the ET-T discrepancy estimated by eddy covariance and sap flux. Thus, model evaluation and discussion are focused on canopy water interception and storage capacity in the following sections. 


\subsubsection{Effects of increased canopy interception}

The CLM4.5 default water interception parameters substantially underestimate ET and overestimate $\mathrm{T}$, resulting very limited contribution of evaporation to ET even during rainy days (Fig. 4.2a). The energy partitioning is similarly biased by the model with underestimation of LE and overestimation of $\mathrm{H}$ throughout the day (Fig. 4.2b). When the higher values of dewmx (0.4) and fpimx (1.0) from the CANOAK model are used, moderate improvements are observed on ET and T but are limited to the morning time (Fig. 4.2a). The mean daily $\mathrm{T}$ from the model $\left(2.44 \mathrm{~mm} \mathrm{day}^{-1}\right)$ and sap flux estimates $\left(2.55 \mathrm{~mm} \mathrm{day}^{-1}\right)$ become comparable during rainy days, although the overall mean is still higher in the model than the sap flux ( $2.71 \mathrm{vs} .2 .56 \mathrm{~mm} \mathrm{day}^{-1}$; Table 4.1). The RMSE does not change from the default to the modified parameters for simulating $\mathrm{T}$ because the diurnal pattern of $\mathrm{T}$ especially its early peak indicated by sap flux measurement is still not captured by the model. The underestimation of LE and overestimation of $\mathrm{H}$ are reduced (smaller RMSEs), notably for the morning (Fig. 4.2b). However, the biases remain at the same level in the afternoon.

The limited effects of canopy interception in the afternoon could be partly explained by the difference in the amount and intensity of rainfalls between the morning and afternoon. It is known that plant canopy has higher potential to intercept light rainfalls with smaller raindrops as compared to rainstorms (Calder, 1996). The meteorological data from Jambi shows that more rainfall happened in the morning (60\% measured by frequency). The $40 \%$ rainfall in the afternoon also has slightly higher intensity $(6.1 \mathrm{~mm}$ vs. $5.7 \mathrm{~mm}$ per event) and shorter length (76 min vs. $80 \mathrm{~min}$ per event) than in the morning. The heavier and shorter rains in the afternoon can result in less intercepted water over time given limited canopy water storage during a rain event (i.e. $Q_{c a n}^{m x}$; Eq. 4.3). Moreover, remaining rainfalls intercepted from the nighttime (after 18:00) likely contribute to the evaporation in the morning and the throughfalls at night could also promote soil water uptake and consequently enhance transpiration in the earlier part of a day. 

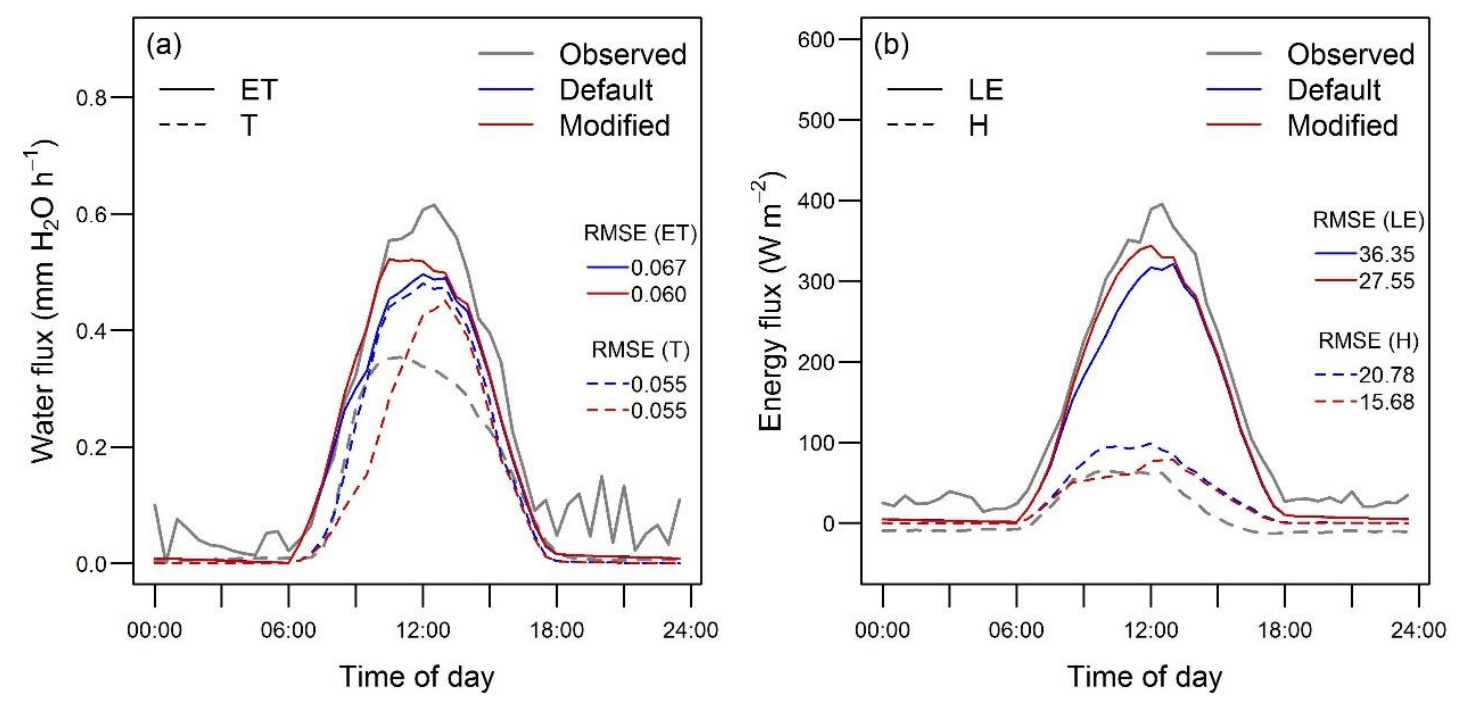

Figure 4.2. The effects of increased water interception on (a) water fluxes (ET, T) and (b) energy fluxes (LE, H). The experimental values for dewmx (0.4) and fpimx (1.0) are from the CANOAK model, which are both 4 times of the CLM4.5 default values. Flux data are selected from June to December 2014 for the rainy days only.

Among the two key parameters, fpimx adjusts the interception efficiency for a given canopy cover (PAI) while dewmx is the dominant parameter controlling the actual ratio of interception (IC) especially when short and heavy rainfalls could often surpass the immediate water storage capacity by the leaf and stem surfaces. Beside plant canopy traits, the regional climate pattern such as the frequency, intensity and length of precipitation is also the key controller of canopy water interception. Lawrence et al. (2007) decreased the canopy interception efficiency fpimx from 1.0 to 0.25 in CLM4 (same as CLM4.5) in order to match the global mean patterns of ET partitioning. However, the tropical forests especially those in Indonesia have been observed to have significantly higher water interception and ET than other forest locations (Dykes, 1997; Lockwood and Sellers, 1982). Considering the frequency and intensity of rainfall in Jambi (> $4 \mathrm{~mm}$ per event, 380 events per year), a fpimx of 0.25 allows too much throughfall (78\%; Eq. 4.1) while a dewmx of 0.1 only give a maximum interception of $0.4 \mathrm{~mm}$ per rain event $\left(Q_{c a n}^{m x}\right.$; Eq. 4.3). They result in an annual mean interception ratio as low as $3.7 \%$ (Table 4.1). Only if fpimx is larger than 0.5 and dewmx is larger than 0.4 (or considering additional storage by stem; see below) the interception ratio ( $\mathrm{I}_{\mathrm{C}}$, Table 4.1) could become comparable to the observed values for oil palm (21\%; Nelson et al., 2014) and for tropical forests (e.g. 18-20\% for Borneo, Dykes, 1997; 12.4\% for Amazon, Shuttleworth, 1988). Therefore, both fpimx and dewmx should be adapted to the regional climate condition and to the species-specific canopy traits.

Overall, the model experiments listed in Table 4.1 show that canopy water interception and storage capacity were indeed underrepresented in the original model. Higher fpimx and dewmx 
values within reasonable ranges enhance evapotranspiration and improve the partitioning of its components $\left(\mathrm{T}, \mathrm{E}_{\mathrm{C}}\right)$ for the oil palm plantation. An exception is that the underestimation of soil evaporation $\left(E_{S}\right)$ is slightly exacerbated. Given the mechanism behind soil evaporation discussed above, further investigations on the relative contribution of canopy transpiration and soil evaporation are needed to fully address the remaining biases. Nevertheless, the role of interception in land surface water and energy fluxes is remarkable. Increased interception by oil palm plantation is necessary to reconcile the simulated rainfall interception ratio and the observed range of values under the tropical climate conditions. A larger component of canopy evaporation also enhances the simulated energy partitioning by reducing the underestimation of LE and overestimation of $\mathrm{H}$.

\subsubsection{Special treatment of leaf and stem surfaces}

Increasing the canopy water storage capacity to a certain high level could eventually allow the canopy to intercept and store sufficient water for enhancing evaporation and reducing transpiration even into the afternoon. However, the interception capacity should not be overcalibrated to fit the level of $\mathrm{T}$ of sap flux measurements as the latter potentially underestimate $\mathrm{T}$ as discussed above. Therefore, the dewmx values tested in the experiments were firstly aimed to match the reported rainfall interception ratios for tropical vegetation as discussed above. Nevertheless, dewmx needs to be realistic according to the natural morphology of oil palm's foliage and stem.

Most models do not distinguish the interception capacity of leaf and stem surfaces. A single dewmx value between $0.1 \mathrm{~mm}$ and $0.4 \mathrm{~mm}$ is usually used (Lloyd et al., 1988; Baldocchi and Harley, 1995). Some has used a value of $0.135 \mathrm{~mm}$ for modeling 4-year old young oil palm (Henson and Harun, 2005). The canopy of mature industrial oil palm plantation does have higher interception capacity than forests according to measurements by Dufrêne et al. (1992) and the high interception ratio (21\%) reported by Nelson et al. (2014). Observations from the PTPN-VI plantation also revealed wet stem surfaces most of the time during field visits. Yet, the single dewmx value should not be increased even higher than $0.4(\mathrm{~mm})$ for oil palm's big leaves. CANOAK considers both sides of a leaf can be wet and thus it already doubles dewmx from the normal value 0.2 to 0.4 . In order to allow sufficiently high water interception and canopy evaporation into the afternoon, the potential large water storage capacity of oil palm' stem (Merten et al., 2016) needs to be considered.

A special experiment is designed to test the hypothesis that oil palm's stem surfaces such as its axils could store more intercepted water than leaves (thicker water film on stem surfaces: e.g. dewmx $2=4$ ). The maximal water film thickness allowed for leaf is the CANOAK value 
$($ dewmxl $=0.4)$. Results show that the water fluxes and energy partitioning are all improved significantly compared to the CLM4.5 default parameterization (Fig. 4.3). In this experiment, the intercepted rainwater is stored in the leaf and stem pools separately and when the leaf surface is full the excess water drains to the stem pool (Eqs. 4.7, 4.8). The canopy has to decrease transpiration when the leaf surface is wet. The stem pool allows longer lasting evaporation because of its small surface area $(\mathrm{SAI}=0.1 \times \mathrm{LAI})$. With the values fpimx $=1$, dewmx $1=0.4$ and dewmx $2=4$ the annual rainfall interception ratio (18.5\%) increases to be within the observed range (16-42\%). The simulated mean daily magnitudes of ET and T (3.63 and 2.64) are closest to the measured values (4.8 and 2.56; Table 4.1). The diurnal curves also show better agreement with field data (smaller RMSEs) than the default model and other experiments with a single dewmx (Fig. 4.3). Yet the diurnal pattern of $\mathrm{T}$ from the sap flux data is still not reflected by the model. Notably, the separate treatment of leaf and stem surfaces for canopy water storage further improves morning fluxes of LE and $\mathrm{H}$ and even extends the positive effects into the afternoon (Fig. 4.3b).
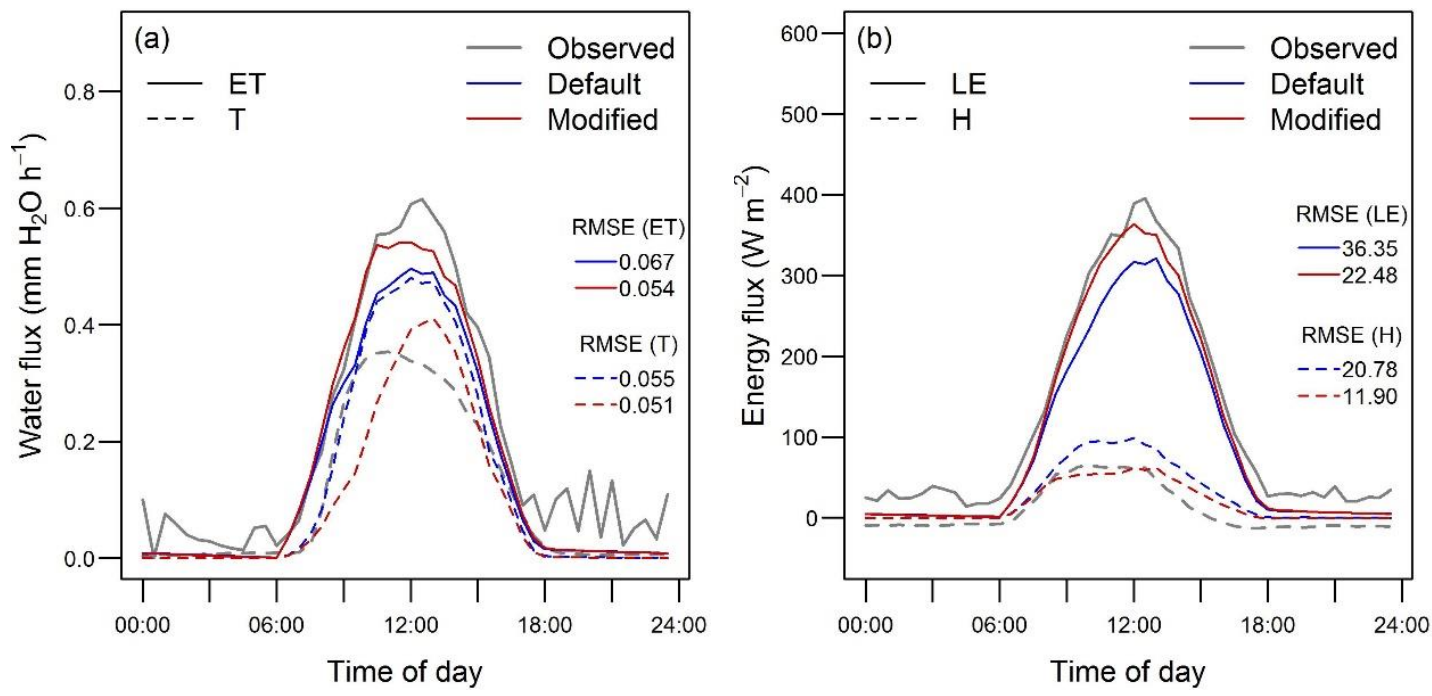

Figure 4.3. Special treatment of canopy water storage by leaf and stem surfaces. Two values for dewmx are used: dewmx $1=0.4$ for leaf and dewmx $2=4.0$ for stem (rachis and axils). fpimx still uses the value 1.0.

Distinguishing leaf and stem surfaces significantly improved the water fluxes and energy partitioning throughout the day. The combination of dewmxl $(0.4 \mathrm{~mm})$ and dewmx2 $(4 \mathrm{~mm})$ allows more realistic water film thickness on leaf surfaces and probes into the possibility that oil palm's special morphology (e.g. caved leaflets and axils, hairy stem surfaces) could allow higher water storage capacity (Merten et al., 2016). Oil palm's axils including the leftover part after leaf pruning provide spacious and rough surfaces around the stem according to field 
observation. A $4 \mathrm{~mm}$ water film thickness was used for stem so that it accounts for a half of the overall water storage capacity given that SAI is 0.1 of LAI and dewmx2 is 10 times of dewmx1. Observation by Herwitz (1985) also showed the water storage capacity of stem surfaces (bark) of tropical trees often exceeds $50 \%$ of the total interception storage. Results from the special treatment conform to the hypothesis that increased water storage by the oil palm axils with limited surface area allows longer lasting evaporation after rain events, which further improved the afternoon energy fluxes compared to using a single dewmx by assuming the same water film thickness on leaf and stem surfaces. However, quantitative measurements of water film thickness, stem flow and axils water storage of oil palm are still lacking to verify the experimental values.

\subsubsection{Remaining uncertainty in water and energy fluxes}

The phase shift of transpiration is still not solved, likely due to the missing mechanism of oil palm hydrodynamics and its water utilization strategy in the model. A time gap between depletion of water storage in the leaves and recharge of water through the root-stem-leaf continuum is commonly found in plant hydrodynamics (Sperry et al., 2002; Zhang et al., 2014). This time lag contributes to the hysteretic phenomena in transpiration, i.e. more water is transpired during the morning than in the afternoon (Matheny et al., 2014; Zhang et al., 2014). This missing mechanism in most land surface models has been verified to cause biased diurnal patterns of transpiration (Matheny et al., 2014) that matches exactly the underestimation of transpiration during morning and the overestimation in the afternoon in the above model-data comparison (Figs. 4.2, 4.3). The hysteretic transpiration can also explain the phase shift of LE and $\mathrm{H}$ fluxes from morning to afternoon because transpiration accounts for the majority of evapotranspiration and thus LE flux in terrestrial ecosystems (Jasechko et al., 2013). Other studies (Verbeeck et al., 2007; Zhang et al., 2014) also demonstrated the hysteresis of diurnal transpiration due to the early consumption of water storage in the stem and its depletion in the afternoon. The studies by Niu et al. (2015) and Meijide et al. (2016) both suggest, though not confirmed, that oil palm may have large water storage in the trunk accumulated from soil water uptake during night which could lead to concentrated water consumption and peak of transpiration in the morning followed by early closure of stomatal before noon. This trunk water storage function may explain the remaining biases in simulated transpiration and $\mathrm{H}$ and LE fluxes after being adapted to the new canopy interception parameterization. 


\subsection{Conclusions}

A series of model experiments and analyses were conducted to evaluate CLM4.5's default canopy water interception and storage parameters with reference to the climate condition (frequency, intensity and length of rainfalls) in the study area of Jambi and measured water fluxes (evapotranspiration and transpiration) and energy fluxes (LE, H). Higher fpimx and dewmx values allow the canopy to capture and store more intercepted water and provide longer lasting evaporation that helps balance the partitioning of evapotranspiration and surface energy fluxes during most part of a day. A special treatment of canopy water interception and storage was considered by differentiating leaf and stem surfaces given oil palm's special morphological traits. The modified canopy hydrological parameterization, especially the significantly higher canopy water storage capacity by stem surface, indeed improved water and energy fluxes compared to field measurements for oil palm. The remaining biases in diurnal patterns of transpiration, LE and $\mathrm{H}$ are very likely due to the typical hysteresis of transpiration and hydrodynamics from root to stem and to leaf that are not represented in CLM4.5's current stomatal conductance model. A modification of the existing soil moisture stress function in CLM4.5 or adding hydraulic parameterization for oil palm (e.g. trunk water storage and utilization) are not feasible in the scope of this study due to the requirement of extensive knowledge and field data on oil palm's physiology.

Nevertheless, the more feasible canopy hydrology experiments do provide insights into the water and energy cycles of this new palm PFT. For a land surface modeling approach, the water interception efficiency and capacity should be modeled as PFT dependent parameters instead of being set as uniform for all PFTs regardless of their canopy structure and leaf traits. The experiments in CLM-Palm suggest that mature oil palm plantations do have much higher water interception capacity per leaf and stem area than forests. Oil palm's special morphology of leaf and axils could intercept and store sufficient amount of precipitation to balance water and energy fluxes throughout the day under the tropical climate. 


\section{Chapter 5}

A dynamic nitrogen scheme for simulating fertilization effects in agriculture 


\subsection{Introduction}

Nitrogen is one of the most important nutrients giving direct feedbacks to global $\mathrm{C}$ cycling through controls on plant photosynthesis and respiration as well as on decomposition of organic matter in litter and soil (Reich et al., 1997; Vitousek and Howarth, 1991). The N cycle also leverages the long-term effects of rising atmospheric $\mathrm{CO}_{2}$ on terrestrial ecosystems through the close C-N coupling (Finzi et al., 2007; Luo et al., 2004). Without appropriate treatment of N availability and $\mathrm{C}-\mathrm{N}$ interaction, the estimate of terrestrial $\mathrm{C}$ sequestration under the changing climate can be considerably biased (Oren et al., 2001; Hungate, 2003). The inputs of biologically available $\mathrm{N}$ into the natural ecosystems have been greatly altered by human activities including the use of artificial $\mathrm{N}$ fertilizers in agriculture and $\mathrm{N}$ emission and deposition via fossil fuel and biofuel burning (Galloway et al., 2004). The significance of $\mathrm{N}$ in terrestrial ecosystem functioning and in nitrogen-carbon-climate interactions has been widely recognized (Gruber and Galloway, 2008; Zaehle et al., 2010), so that N cycling becomes more commonly implemented in Earth system models (Gerber et al., 2010; Zaehle and Friend, 2010) including the rather complete $\mathrm{N}$ treatment in CLM4.5 (also named CLM-CN; Thornton et al., 2007).

However, an important shortcoming was observed in the N scheme of CLM4.5 during the fertilization tests in Chapter 2. CLM4.5 currently uses fixed C:N ratios for plant tissues which limit the effects of $\mathrm{N}$ fertilization on crop productivity and $\mathrm{N}$ cycling. A plant species naturally has its range of adaptability to the nutrient status in soils and other sources (e.g. atmospheric $\mathrm{N}$ deposition), and could adjust its photosynthetic and respiration rates accordingly (White et al., 2000). Using fixed $\mathrm{C}: \mathrm{N}$ ratios for different tissue types per PFT is a convenient way to simulate the stoichiometry of $\mathrm{C}$ and $\mathrm{N}$ allocation for new growth and $\mathrm{N}$ resorption during litter-fall in land surface models, but it may overlook the influences of spatial and temporal dynamics of $\mathrm{N}$ availability on photosynthetic capacity, autotrophic and heterotrophic respirations and nutrient use efficiency, and ultimately on the dynamics of $\mathrm{C}$ cycling. Other terrestrial biosphere models take into account the variability in C:N ratios (Wang et al., 2010; Zaehle and Friend, 2010). The agriculture model APSIM-Oil Palm (Huth et al., 2014) also considers dynamic foliage N concentration and its effect on photosynthesis.

Furthermore, the CLM4.5 parameterization of C-N biogeochemistry has two other limitations. First at the canopy level, the $\mathrm{N}$ downregulation on GPP is applied after the $V_{\text {cmax }}$ calculation (Eq. 3.1, Chapter 3) and thus there is no direct effect of $\mathrm{N}$ availability on the coupled photosynthesis-stomatal conductance processes (Bonan et al., 2012). Although the N-regulated prognostic leaf growth can provide indirect limitation on light capture and stomatal 
conductance on longer time scales, there is an inevitable lag between the direct and indirect downregulation mechanisms. Second, at the sub-canopy level, there is an inconsistence between upscaling photosynthetic capacity from leaf to canopy and updating true foliage $\mathrm{N}$ concentration across canopy layers. The inconsistence and scale mismatch between different processes might influence the real-time status of plant and soil $\mathrm{N}$ pools and $\mathrm{N}$ cycling that is critical for carbon flux and even water and energy fluxes.

Until now CLM-Palm has inherited the full feature and potential shortcomings of the static $\mathrm{N}$ scheme of CLM4.5. The derivation of canopy photosynthesis from leaf-level calculations also takes the integrative canopy upscaling approach, without taking the full advantage of CLMPalm's multilayer canopy structure. Given the central role of $\mathrm{N}$ fertilization in agriculture systems including oil palm plantations, it worth re-evaluating the current $\mathrm{C}-\mathrm{N}$ coupling mechanism in CLM4.5 and implementing a dynamic $\mathrm{N}$ scheme in CLM-Palm where foliage $\mathrm{N}$ concentration and $\mathrm{C}: \mathrm{N}$ ratios in live tissues could adjust automatically in response to $\mathrm{N}$ availability. Such a scheme could be valuable for simulating $\mathrm{N}$ fertilization effects on $\mathrm{C}$ fluxes in this study and potentially applicable to other agriculture systems.

This chapter documents the implementation of a new N scheme into CLM-Palm (and CLM4.5 in general) including: 1) a dynamic $\mathrm{N}$ uptake and allocation mechanism; 2) variability of C:N ratios in live tissues; 3 ) adjustments of photosynthesis calculation; and 4) a dynamic foliage $\mathrm{N}$ profile for the multilayer structure. The different $\mathrm{N}$ schemes were compared on simulating $\mathrm{C}$ flux and $\mathrm{N}$ balance during long-term oil palm cultivation. Modeled leaf $\mathrm{C}: \mathrm{N}$ ratio, plantation growth and yield were compared with field measurements from a mature oil palm plantation in Sumatra, Indonesia. Implications on nitrogen use efficiency (NUE) was also presented.

\subsection{Model description}

CLM4.5 uses fixed C:N ratios for all plant tissues in order to couple $\mathrm{C}$ and $\mathrm{N}$ fluxes (Fig. 5.1a). The demand of $\mathrm{N}$ for vegetative and reproductive growth is linked to the amount of available $\mathrm{C}$ for allocation. When the total $\mathrm{N}$ demand is not met, the GPP and $\mathrm{C}$ allocation are then scaled down after the photosynthesis calculation. This approach is numerically simple but cannot simulate the direct effects of $\mathrm{N}$ availability on other biogeophysical and biogeochemical processes because the statistical method does not change foliage $\mathrm{N}$ content (determining $V_{\text {cmax }}$ ) and the downregulation is only applied after the coupled photosynthesis-stomatal conductance processes (Bonan et al., 2012). The fixed leaf C:N ratio also does not allow directly resolving layer specific $\mathrm{N}$ content and $V_{\text {cmax }}$ for the multilayer canopy. Thus, photosynthesis has to be calculated at the canopy-scale with a top-of-canopy leaf $\mathrm{C}: \mathrm{N}$ ratio which is then scaled down 
using a $\mathrm{N}$ scaling factor $\left(K_{n}\right)$ to represent the usually decreasing trend of $\mathrm{N}$ concentration from the top to the bottom of canopy. However, the actual $\mathrm{N}$ pool in the canopy is still not updated by the statistical approach which may cause bias in $\mathrm{N}$ balance. Synchronizing the canopy vertical gradient of Rubisco-limited photosynthetic capacity with the actual foliage $\mathrm{N}$ profile across layers could improve overall $\mathrm{N}$ dynamics and conservation that was proved crucial for global carbon cycle simulation (Alton et al., 2007). Moreover, the fixed C:N scheme also prohibits parsimonious representations of plant-soil interaction and $\mathrm{N}$ fertilization effects which are important determinants of plant $\mathrm{N}$ distribution and its related biogeochemical processes. An improved $\mathrm{N}$ scheme is especially needed for modeling agricultural systems such as oil palm plantations which are routinely fertilized.

\subsubsection{Original and the new dynamic nitrogen schemes}

In CLM-Palm, the multilayer prognostic leaf growth and fruit yield capacity according to layerspecific phenology and allocation is referred to as sub-PFT processes. $\mathrm{C}$ and $\mathrm{N}$ allocation operates at the PFT level for all tissue types and at sub-PFT level for leaf and fruit, where $\mathrm{N}$ demand is linked to potential $\mathrm{C}$ allocation though fixed C:N ratios of each tissue type (Fig. 5.1a). Soil water limitation and $\mathrm{N}$ availability influence overall net photosynthesis via statistical downregulation. The final available $\mathrm{C}$ and $\mathrm{N}$ fluxes for allocation are partitioned in two steps, first at the PFT level and then at the sub-PFT level to different phytomers. The sub-PFT phenology and allocation scheme allows modeling photosynthesis dynamics of the different canopy layers with consideration of light competition among layers with different LAIs as well as the vertical gradient of foliage $\mathrm{N}$ content. Chapter 3 introduced the dynamic canopy stratification, leaf angle distribution and light extinction across multiple layers. Here a new $\mathrm{N}$ scheme is implemented to be compatible with CLM-Palm's multilayer structure and the subPFT processes (Fig. 5.1b). 
(a)

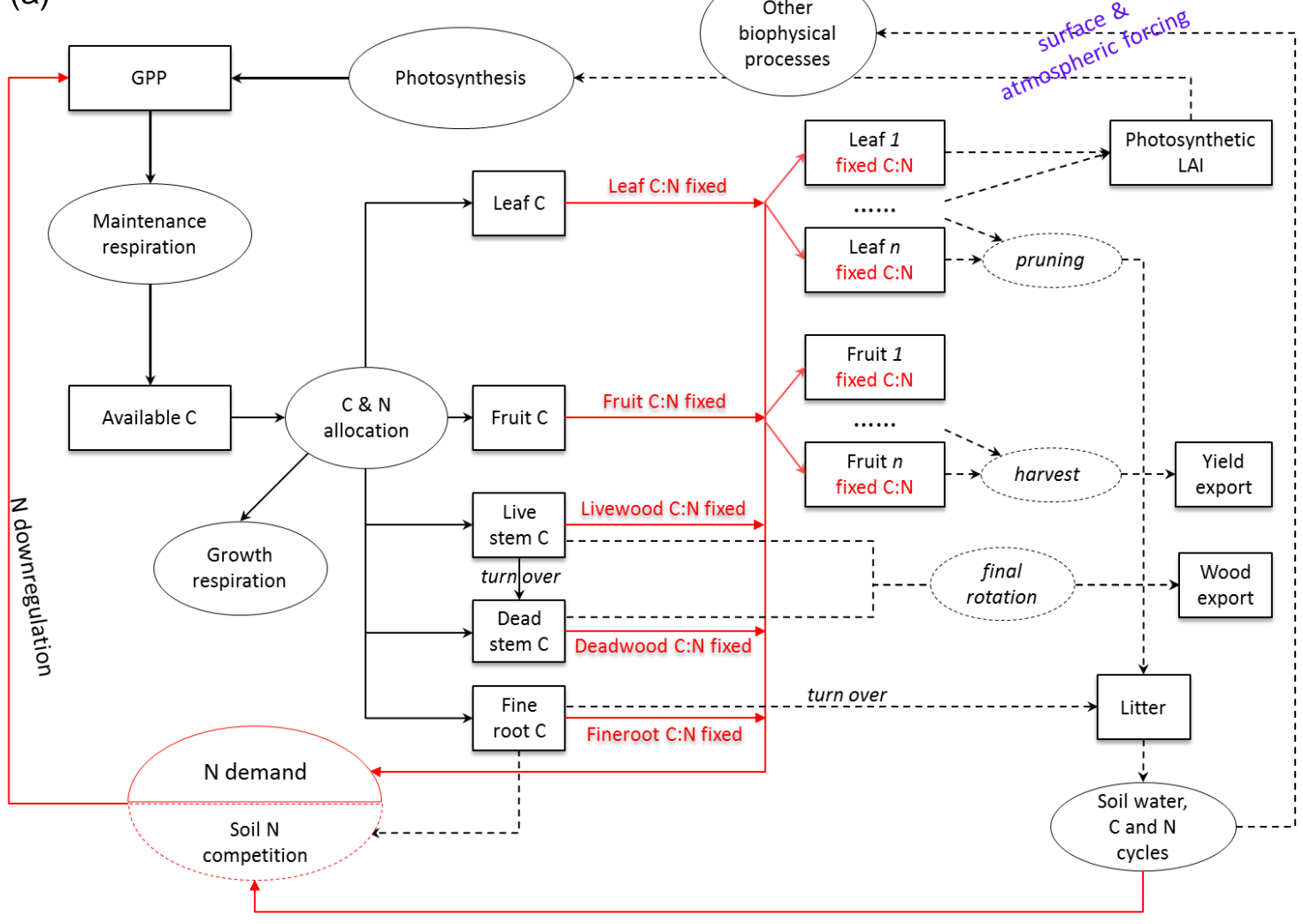

(b)

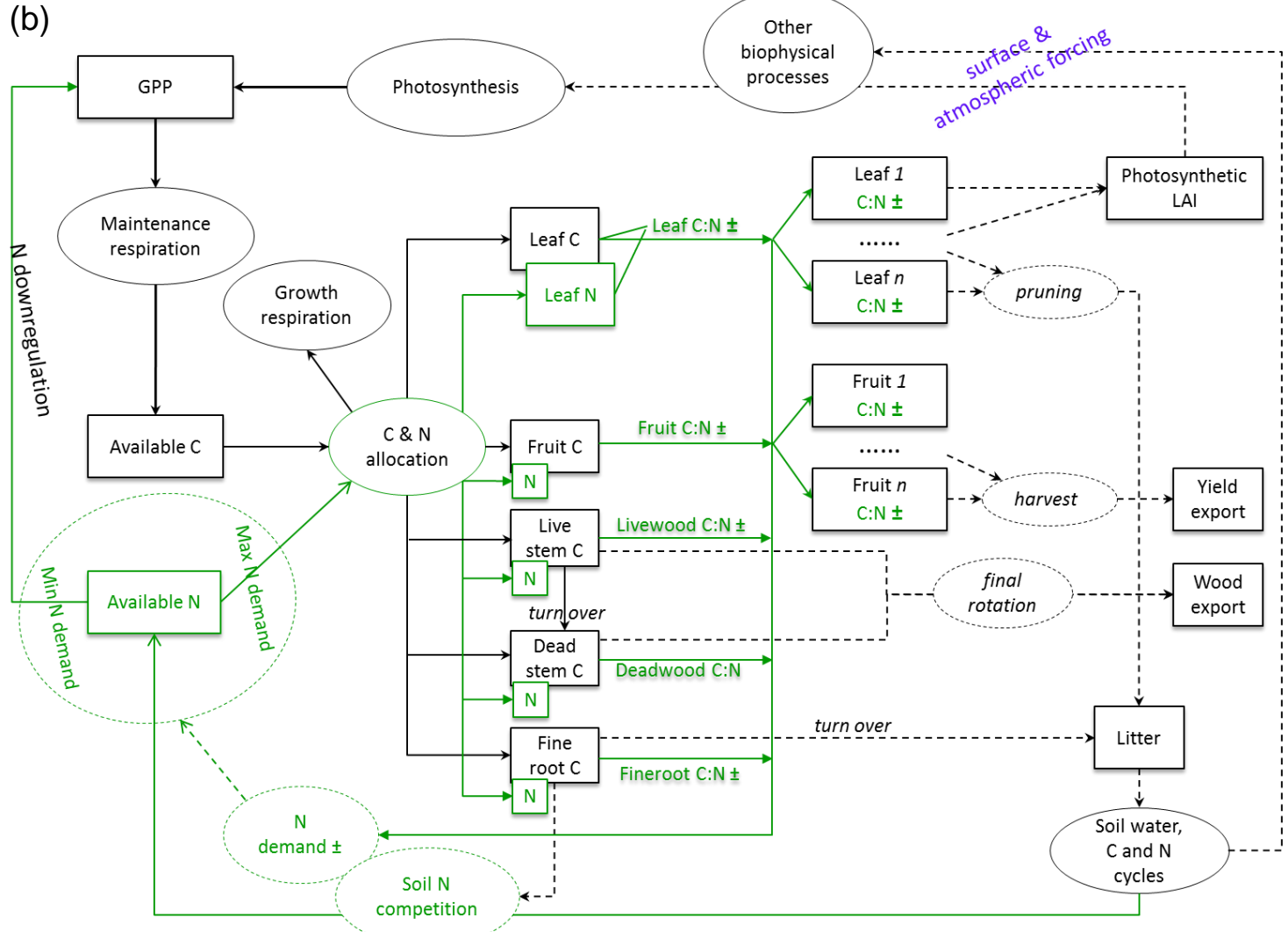

Figure 5.1. (a) The CLM4.5 default coupled $C \& N$ cycles with fixed C: $N$ ratios and (b) The new independent $\mathrm{N}$ paths with dynamic $\mathrm{C}: \mathrm{N}$ ratios and dynamic $\mathrm{N}$ uptake and allocation. 
In this new dynamic $\mathrm{N}$ scheme, $\mathrm{C}: \mathrm{N}$ ratios of all vegetative components including the leaf $\mathrm{C}: \mathrm{N}$ ratio of each canopy layer are allowed to vary in response to changing $\mathrm{N}$ availability and demand. The dynamic $\mathrm{N}$ uptake mechanism is adopted from Wang et al. (2010) which is based on the assumption that the potential $\mathrm{N}$ uptake above the minimal demand is proportional to the maximal $\mathrm{N}$ demand for a given NPP, where the proportion is determined by the range of $\mathrm{C}: \mathrm{N}$ ratios in plant tissues, the soil $\mathrm{N}$ availability and the competition with soil $\mathrm{N}$ immobilization. This demand and uptake mechanism is adapted to CLM's column and PFT structures and its soil decomposition model which assumes an equal competition between plant $\mathrm{N}$ uptake and soil $\mathrm{N}$ immobilization. This is different from the original mechanism in Wang et al. (2010) that soil $\mathrm{N}$ immobilization takes absolute priority over plant $\mathrm{N}$ uptake. The realized $\mathrm{N}$ uptake is then allocated to the PFT and sub-PFT components in CLM-Palm. Now that N uptake and allocation are both dynamic and do not conform to the fixed C:N stoichiometry, an independent $\mathrm{N}$ cycle is added so that all the $\mathrm{N}$ fluxes associated with phenology and allocation processes can be calculated separately. In contrast, within the CLM4.5 default strictly coupled C-N cycles, N fluxes are always derived from $\mathrm{C}$ fluxes using fixed C:N ratios (Fig. 5.1a). The dynamic N uptake and allocation mechanisms are well adapted to the multilayer structure and functions in CLM-Palm so that each canopy layer gets dynamic leaf C:N ratio and $\mathrm{N}$ concentration in response to soil $\mathrm{N}$ availability, which has a controlling role in photosynthesis calculation (Fig. 5.1b). Detailed steps of the adapted N scheme are described below and in Appendix (section 5.6).

The range of variability in live tissue C: $N$ ratios is prescribed to be within $\pm 20 \%$ (adjustable parameter, Table 5.1) departure from the default values, whereas dead tissues (e.g. leaf litter, dead stem and soil organic matter) use fixed C:N ratios. The dynamic $\mathrm{N}$ scheme works at the following steps:

1) Calculate the minimal and maximal $\mathrm{N}$ demands for a potential $\mathrm{C}$ flux to new growth at a given potential GPP (Eqs. A 5.1, 5.2).

2) Deploy the retranslocated $\mathrm{N}$ pool to support plant $\mathrm{N}$ demand (Eq. A 5.3).

3) Recalculate plant $\mathrm{N}$ demand from soil after utilizing available retranslocated $\mathrm{N}$; the remaining potential $\mathrm{N}$ uptake depends on soil mineral $\mathrm{N}$ availability (Eqs. A 5.4, 5.5) and competes with the $\mathrm{N}$ immobilization demand from soil heterotrophs (Eq. A 5.6); the result of competition gives the actual plant $\mathrm{N}$ uptake from soil (Eq. A 5.7).

4) Rescale the $\mathrm{C}: \mathrm{N}$ stoichiometric relationship for growth allocation according to the total actual $\mathrm{N}$ obtained by plant above its minimum requirement (Eqs. A 5.8-10); if the minimum $\mathrm{N}$ demand is not achieved, then reduce the potential 
GPP and recalculate $\mathrm{C}$ allocation flux according to the actual allocated $\mathrm{N}$ flux (Eqs. A 5.11-13).

5) Use the updated $\mathrm{C}: \mathrm{N}$ stoichiometry for allocation of $\mathrm{C}$ and $\mathrm{N}$ fluxes to new growth (Eqs. A 5.14-16).

6) Update the $\mathrm{C}$ and $\mathrm{N}$ pools of all tissues after growth allocation and other phenological steps; recalculate the average leaf C:N ratio (Eq. A 5.17) which is used in the photosynthesis-stomatal conductance model; the updated $\mathrm{N}$ contents in different pools are used to calculate respiration cost and $\mathrm{N}$ retranslocation during senescence and live-dead wood turnover.

7) Enter the next time step and repeat the above procedures.

More detailed description is in Appendix 5.6.

\subsubsection{Canopy photosynthesis calculation}

In CLM4.5, leaf photosynthesis of $C_{3}$ plants is based on the model of Farquhar et al. (1980), but with updated calculation of leaf-scale APAR for the sunlit and shaded fractions from Dai et al. (2004). The leaf photosynthesis rate corresponds to the minimum of Rubisco-limited, light-limited, and product-limited rates of carboxylation (Oleson et al., 2013). After accounting for respiration $\left(R_{d}\right)$, it gives leaf net photosynthesis. Among the three types of carboxylation rates, the Rubisco-limited rate relies on a parameter $V_{c m a x}$, i.e. the maximum rate of carboxylation, after adjusting for leaf temperature from the reference rate $\mathrm{V}_{\mathrm{cmax} 25}$ at $25^{\circ} \mathrm{C}$, which is calculated as:

$$
\mathrm{V}_{\mathrm{cmax} 25}^{0}=\frac{1}{C N_{\text {leaf }} S L A_{0}} F_{L N R} F_{N R} a_{R 25},
$$

where the nomenclature is listed in Table 5.1.

Here the $\mathrm{V}_{\mathrm{cmax} 25}$ for oil palm is adjusted to 55 which is the same as the broadleaf evergreen tropical tree PFT and very close to field measurements from two oil palm plantations in Jambi, Sumatra (Meijide et al., 2016). The slope of the Ball-Berry stomatal conductance model (Ball et al., 1987; Collatz et al., 1991) is also adjusted from 9 to be 10.5, which better matches the $V_{c \max }$ value 55 according to the optimization experiments in Bonan et al. (2014). Given the significantly lower $\mathrm{V}_{\text {cmax25 }}$ value than previously used (100, Chapter 2) and the adapted $\mathrm{N}$ scheme, the key allocation parameters are recalibrated to match simulated LAI and yield with long-term observation data from Chapter 2. The new parameterization in Table 5.1 is only limited to the scope of this chapter. 
Table 5.1. Summary of parameters used in the dynamic nitrogen scheme.

\begin{tabular}{|c|c|c|}
\hline Parameter & Value & Explanation (Unit) \\
\hline$f_{\text {leaf }}^{i}$ & 0.25 & Initial value of leaf allocation coefficient before the first fruit-fill \\
\hline$a_{\text {root }}^{i}$ & 0.3 & Initial value of root allocation coefficient before the first fruit-fill \\
\hline$a_{\text {leaf }}^{f}$ & 0.45 & Final value of leaf allocation coefficient after vegetative maturity \\
\hline$a_{\text {root }}^{f}$ & 0.2 & Final value of root allocation coefficient after vegetative maturity \\
\hline$C N_{\text {leaf }}$ & 33 & $\begin{array}{l}\text { The base leaf carbon-to-nitrogen ratio, either fixed during a } \\
\text { simulation for the default } \mathrm{N} \text { scheme or used as the baseline value } \\
\text { together with } F_{C N} \text { for the dynamic } \mathrm{N} \text { scheme }\left(\mathrm{g} \mathrm{C} \mathrm{g}^{-1} \mathrm{~N}\right)\end{array}$ \\
\hline$F_{C N}$ & 0.2 & $\begin{array}{l}\text { The fraction of departure of maximum and minimum } \mathrm{CN} \text { ratios } \\
\text { from the baseline value (for leaf, live stem, fine root and fruit) }\end{array}$ \\
\hline$k n_{u p}$ & 2 & $\begin{array}{l}\text { Empirical constant for plant-soil nitrogen competition ( } \mathrm{g} \mathrm{N} \mathrm{m-2)} \\
\text { use zero to turn off the competition. }\end{array}$ \\
\hline$F_{L N R}$ & 0.055 & Fraction of leaf nitrogen in Rubisco enzyme \\
\hline$F_{N R}$ & 7.16 & Mass ratio of total Rubisco molecular mass to nitrogen in Rubisco \\
\hline$a_{R 25}$ & 60 & Specific activity of Rubisco $\left(\mu \mathrm{mol} \mathrm{CO} \mathrm{CO}^{-1}\right.$ Rubisco s$\left.{ }^{-1}\right)$ \\
\hline$V_{\mathrm{cmax} 25}^{0}$ & 55 & $\begin{array}{l}\text { Maximum top of canopy carboxylation at } 25^{\circ} \mathrm{C} \text {, calculated based } \\
\text { on } F_{L N R}, S L A_{\text {top }}, C N_{\text {leaf }} \text {, and other constants }\left(\mu \mathrm{mol} \mathrm{CO}_{2} \mathrm{~m}^{-2} \mathrm{~s}^{-1}\right)\end{array}$ \\
\hline$K_{N}$ & 0.3 & Leaf nitrogen decay coefficient for leaf to canopy scaling \\
\hline
\end{tabular}

\subsubsection{Foliage nitrogen profile}

In order to avoid scale mismatch the key canopy processes such as photosynthesis, stomatal conductance and leaf respiration should be resolved at each canopy layer together with leaf phenology and allocation and radiative absorption in the CLM-Palm multilayer structure. The similar $\mathrm{N}$ downscaling approach on photosynthesis-related processes using the $K_{n}$ coefficient and the exponential function (Bonan et al., 2012; Krinner et al., 2005) is followed from Chapter 3 (Eq. 3.1). The difference here is that the dynamic $\mathrm{N}$ scheme introduced above provides layer- 
specific leaf $\mathrm{C}: \mathrm{N}$ ratio and explicitly reduces the foliage $\mathrm{N}$ concentration $\left(L N C_{i}\right)$ at lower canopy layers with the follow equation.

$$
L N C_{i}=\frac{1}{C N_{\text {leaf }}^{0} S L A_{0}} e^{-K_{n} \sum_{z=1}^{i} L A I_{z}}
$$

where $\sum_{z=1}^{i} L A I_{z}$ is the cumulative LAI from the canopy top to layer i. $C N_{\text {leaf }}^{0}$ and $S L A_{0}$ are the top of canopy leaf $\mathrm{C}: \mathrm{N}$ ratio and specific leaf area. The implementation of $K_{n}$ parameter and its effects on canopy photosynthesis was thoroughly studied in Bonan et al. (2012).

It needs to be noted that although the above statistical solution is a measure of foliage $\mathrm{N}$ profile along canopy depth, the CLM4.5 default $\mathrm{N}$ scheme does not have real-time adjustment for leaf $\mathrm{N}$ pool at different canopy layers. A constant $C N_{\text {leaf }}$ ratio is used for the live foliage of the whole canopy regardless of root $\mathrm{N}$ uptake, $\mathrm{N}$ deposition and fertilization. Even though the litter-fall subroutines move a fraction of dead foliage $\mathrm{N}$ to soil (and reabsorb the rest), they operate at a constant rate year-around on a canopy basis which does not reflect foliage $\mathrm{N}$ dynamics at the sub-canopy scale.

With the dynamic $\mathrm{N}$ scheme (Fig. 5.1b), each canopy layer can obtain changing $\mathrm{N}$ concentration through time. Because the top of canopy leaf $\mathrm{C}: \mathrm{N}$ ratio is also changing and not known beforehand, a new inverse approach is taken to drive the $\mathrm{N}$ concentration for each layer from the canopy mean (see Appendix 5.6, Eqs. A 5.19-23). When the new $\mathrm{N}$ scheme is applied to oil palm's multilayer structure, the dynamic foliage $\mathrm{N}$ concentration across layers is either the sole outcome of the phytomer-specific growth allocation and senescence function (when $K_{n}=0$ ) or the combined result with additional $\mathrm{N}$ downscaling from canopy top to bottom (when $K_{n} \neq$ 0 ). Independent $\mathrm{C}$ and $\mathrm{N}$ cycles operate at the PFT level and on each phytomer unit, giving non-uniform leaf $\mathrm{C}$ and $\mathrm{N}$ pool sizes across layers. The fluctuation of leaf $\mathrm{C}: \mathrm{N}$ ratio according to $F_{C N}$ is consistent at both the canopy and sub-canopy scales.

Once layer-specific and dynamic leaf $\mathrm{N}$ concentration $\left(L N C_{i}\right)$ is obtained, all the nitrogenrelated canopy processes such as photosynthesis, stomatal conductance and autotrophic respiration can also be performed at the sub-canopy scale. For example, one of the key photosynthetic parameters, the maximum rate of carboxylation at $25^{\circ} \mathrm{C}$ per layer is:

$$
V_{\text {cmax } 25}^{i}=L N C_{i} F_{L N R} F_{N R} a_{R 25}
$$

where $F_{L N R}$ is the fraction of leaf nitrogen in Rubisco enzyme, prescribed per PFT. $F_{N R}$ and $a_{R 25}$ are PFT-independent constants regarding Rubisco activity. Other photosynthetic

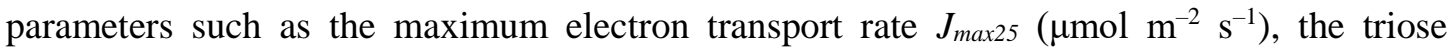


phosphate utilization rate $T P U_{25}\left(\mu \mathrm{mol} \mathrm{m} \mathrm{m}^{-2} \mathrm{~s}^{-1}\right)$, and leaf respiration rate $R_{d 25}\left(\mu \mathrm{mol} \mathrm{CO} \mathrm{Cm}^{-2} \mathrm{~s}^{-}\right.$ $\left.{ }^{1}\right)$ are all related to $V_{c \max 25}$ with respective equations and thus scaled similarly (Oleson et al., 2013).

The dynamic $\mathrm{N}$ investment in tissues within permitted boundaries will allow quick adjustment of $\mathrm{C}$ and $\mathrm{N}$ sinks to tissue growth, as well as gradual acclimation of photosynthetic and respiration rates in response to changing soil $\mathrm{N}$ availability and foliage $\mathrm{N}$ concentration (Zaehle and Friend, 2010). Only when the minimum $\mathrm{N}$ concentration in tissues cannot be met, the $\mathrm{N}$ downregulation mechanism is turned on. A larger $F_{C N}$ will give wider ranges of variability in

plant tissue $\mathrm{N}$ concentrations $\left(C N_{\text {leaf }}^{\max }, C N_{\text {leaf }}^{\max }, C N_{\text {root }}^{\max }, C N_{\text {root }}^{\max }\right.$, etc. in Eq. A 5.2) and allow a majority of $\mathrm{N}$ effects to exert via the gradual adjustment of photosynthesis $\left(V_{c \max }\right)$ and respiration, whereas narrower ranges or constant $\mathrm{C}: \mathrm{N}$ ratios will make the model more relying on the immediate effect of $\mathrm{N}$ downregulation on GPP which occurs outside of the photosynthesis-stomatal conductance model. The sensitivity of $F_{C N}$ is examined in the following fertilization experiments.

\subsection{Model evaluation}

The new dynamic $\mathrm{N}$ scheme was compared with the CLM4.5 standard $\mathrm{N}$ scheme on carbon fluxes and nitrogen profiles with reference to available field data. LAI, yield, gross primary production (GPP), net ecosystem exchange (NEE) and dynamics of $\mathrm{N}$ pools for a full course of oil palm cultivation in Jambi, Sumatra from 2002 to 2027 (one rotation cycle) were analyzed. Nitrogen use efficiency was also calculated and compared for analyzing the efficiency of $\mathrm{N}$ fertilizer utilization in crop production.

\subsection{Results and discussion}

\subsubsection{Effects on diurnal carbon flux}

The dynamic $\mathrm{N}$ scheme shows improved diurnal estimates of NEE with reference to observations because of enchancement in photosynthetic rates in the day time and slightly increased maintenance respiration in night time (Fig. 5.2). The enhancement effect could be explained by increased $\mathrm{N}$ concentration in leaf and other tissues due to $\mathrm{N}$ fertilization so that both the $V_{\text {cmax }}$ (Eq. 5.3) and respiration rates (linked to C:N ratio in each tissue) are higher, whereas the default $\mathrm{N}$ scheme holds $\mathrm{C}: \mathrm{N}$ ratios constant regardless of fertilization and soil conditions and is thus inert to increased $\mathrm{N}$ availablity. Although the PFT parameters such as allocation ratios, C:N ratios or $V_{\text {cmax }}$ could be recalibrated to match better with the observed 
fluxes, they should be fixed during a simualtion with the default $\mathrm{N}$ scheme. Therefore, even with recalibrated $\mathrm{C}: \mathrm{N}$ ratios the default model will not be able to reflect the variability in photosynthesis and respiration rates with changing $\mathrm{N}$ availability. Nevertheless, the values of PFT parameters in Table 5.1, especially the base $C N_{\text {leaf }}$ of 33, were chosen based on field measurements and should not be subject to overfitting. The dynamic $\mathrm{N}$ scheme allows simulating the variabilty of $C N_{\text {leaf }}$ and $V_{\text {cmax }}$ in a progonstic manner driven by the dynamics of environmental conditions. The following results from fertiliation tests provide more support to this argument.

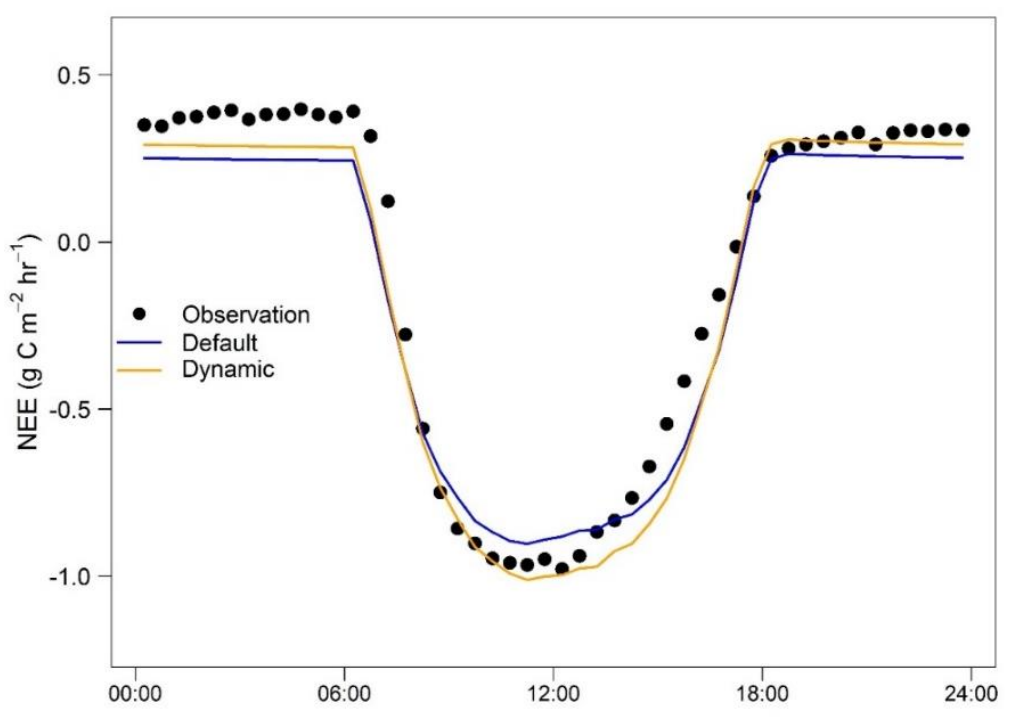

Figure 5.2. The mean diurnal curve of net ecosystem exchange (NEE) between the default $N$ scheme and the dynamic $\mathrm{N}$ scheme with reference to eddy covariance observation from June to December 2014.

\subsubsection{Fertilization effects on growth and yield}

The dynamic $\mathrm{N}$ scheme is able to reflect a range of variability in growth (Fig. 5.3) and yield (Fig. 5.4) under different levels of $\mathrm{N}$ fertilization. The default $\mathrm{N}$ scheme cannot reflect the enhancement effects of fertilization because the photosynthetic rate $V_{\text {cmax }}$ is fixed by the static leaf C:N ratio (Eq. 5.1), although it can still simulate the $\mathrm{N}$ limitation effects with the statistical downregulation function (Fig. 5.1a). The stop of LAI development and drop in yield under reduced $\mathrm{N}$ availability were also observed in multiple smallholder oil palm plantations in the Bukit Duabelas region (Figs. 2.9, 2.10 in Chapter 2). Industrial oil palm plantations in Indonesia are often heavily fertilized (e.g. $400 \mathrm{~kg} \mathrm{~N} \mathrm{ha}^{-1} \mathrm{yr}^{-1}$ in PTPN-VI). Although the modeled LAI and yield could be calibrated to observation data under a certain level of fertilization by the allocation parameters (Table A 2.2 in Chapter 2), these parameters are fixed during simulations 
and thus cannot simulate the effects of increasing fertilization and $\mathrm{N}$ availability on growth and yield when the default $\mathrm{N}$ scheme is used.

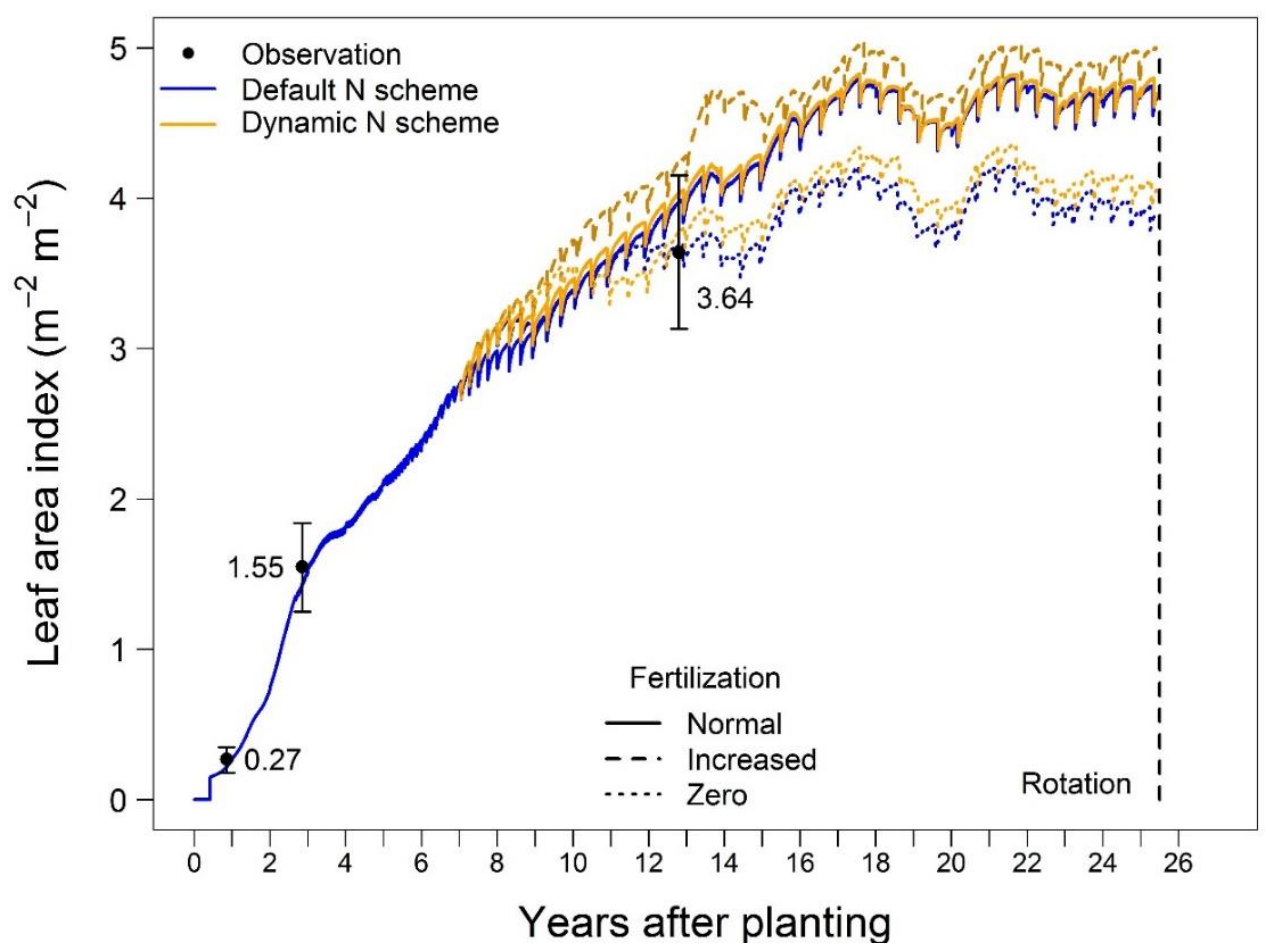

Figure 5.3. The simulated LAI development from plantation establishment till final rotation by the default $\mathrm{N}$ scheme and the dynamic $\mathrm{N}$ scheme under different fertilization treatment (normal: $400 \mathrm{~kg} \mathrm{~N} \mathrm{ha}^{-1} \mathrm{yr}^{-1}$, increased: $800 \mathrm{~kg} \mathrm{~N} \mathrm{ha}^{-1} \mathrm{yr}^{-1}$, zero: $0 \mathrm{~kg} \mathrm{~N} \mathrm{ha}^{-1} \mathrm{yr}^{-1}$ ) with reference to field observations on three different ages of palms.

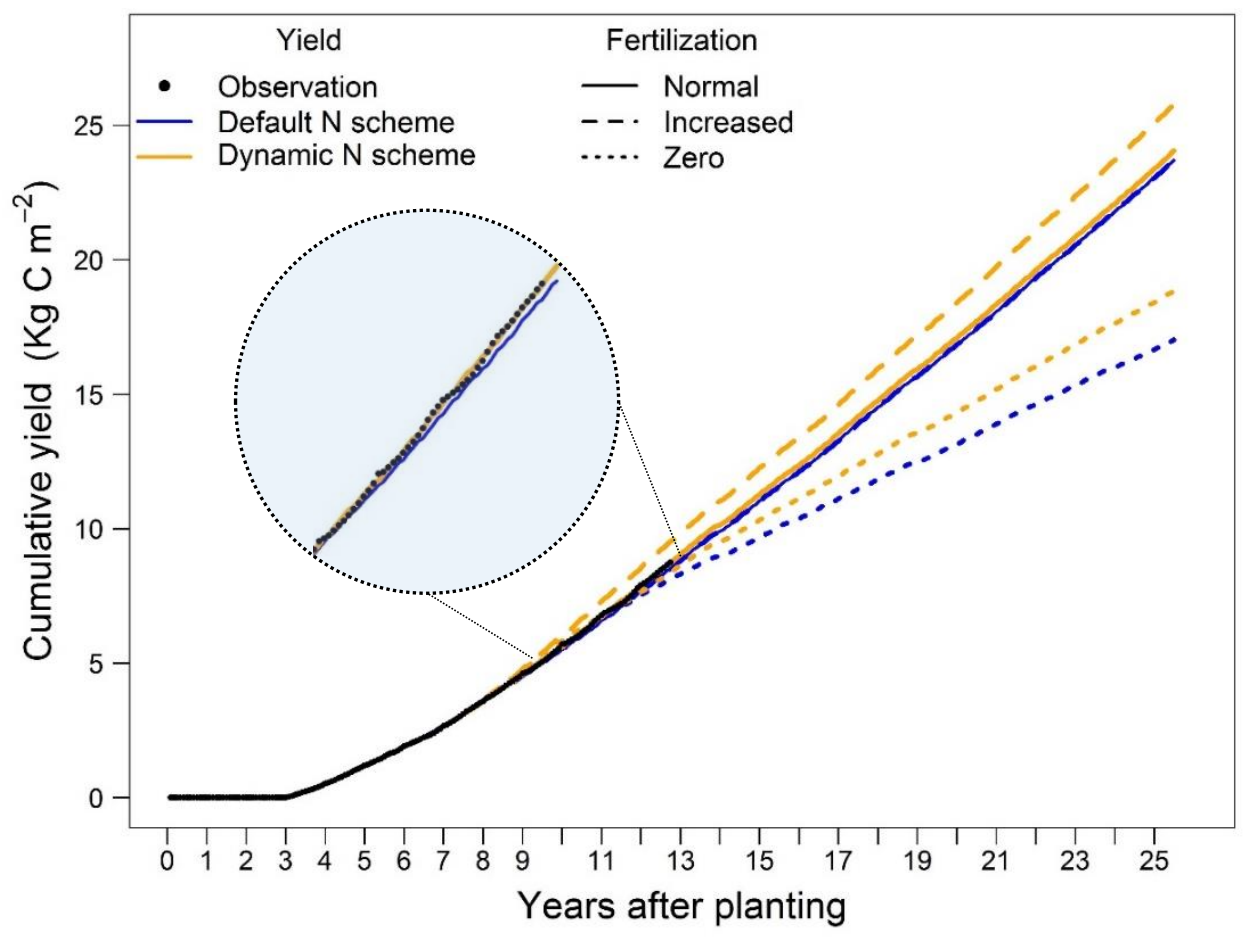


Figure 5.4. The simulated yield from plantation establishment till final rotation ( 25 year old) by the default $\mathrm{N}$ scheme and the dynamic $\mathrm{N}$ scheme with different $\mathrm{N}$ fertilization treatments (same as above). Observed yield is available from 3 to 13 years old from PTPN-VI plantation.

\subsubsection{Leaf $C: N$ ratio and nitrogen use efficiency}

A series of model experiments with different fertilization treatments show that in the dynamic $\mathrm{N}$ scheme canopy mean leaf C:N ratio can quickly (within two years) adapt to enhanced soil mineral $\mathrm{N}$ conditions, while reduced $\mathrm{N}$ fertilization of $200 \mathrm{~kg} \mathrm{~N} \mathrm{ha}^{-1} \mathrm{yr}^{-1}$ will just be enough to sustain the level of soil mineral $\mathrm{N}$ concentration and leaf $\mathrm{N}$ concentration (Fig. 5.5). A $F_{C N}$ value of 0.2 in the dynamic $\mathrm{N}$ scheme can represent most of the variability in leaf $\mathrm{C}: \mathrm{N}$ ratio measured in the field, in both dry and rainy seasons, from different ages of palms and across site conditions of different fertilization treatments (data from Kotowska et al., 2016). When fertilization drops to $100 \mathrm{~kg} \mathrm{~N} \mathrm{ha}^{-1} \mathrm{yr}^{-1}$ and below, both soil mineral $\mathrm{N}$ and leaf $\mathrm{N}$ concentrations will decrease to the level below the initial conditions in the long run. However, $100 \mathrm{~kg} \mathrm{~N} \mathrm{ha}^{-1} \mathrm{yr}^{-1}$ fertilization can still meet the high yield demand of oil palm as shown in Fig. 5.6. At this level of fertilization, the NUE is above 100\%, suggesting taking up of extra soil mineral $\mathrm{N}$ by the plant to compensate the deficiency in fertilizer supply. This matches the trend of depleting soil mineral $\mathrm{N}$ near the end of a rotation cycle ( 25 years, Fig. 5.5$)$. If the amount of fertilization keeps at the level of $100 \mathrm{~kg} \mathrm{~N} \mathrm{ha}^{-1} \mathrm{yr}^{-1}$, the total and average yield over the 25 years period is undistinguishable compared to the current practice of using much more fertilizer (400 $\mathrm{kg} \mathrm{N} \mathrm{ha}^{-1} \mathrm{yr}^{-1}$ ) at the study site PTPN-VI (Fig. 5.6). Although the soil becomes less fertile within 25 years of cultivation, the purpose of oil palm fruit production is sufficiently met by the high NUE. Soil fertility could be restored or enhanced by appropriate $\mathrm{N}$ fertilization or using organic fertilizer as an alternative, either during the gap period before next rotation cycle or in the beginning of new plantation establishment when the young palms' $\mathrm{N}$ demand is significantly lower. 


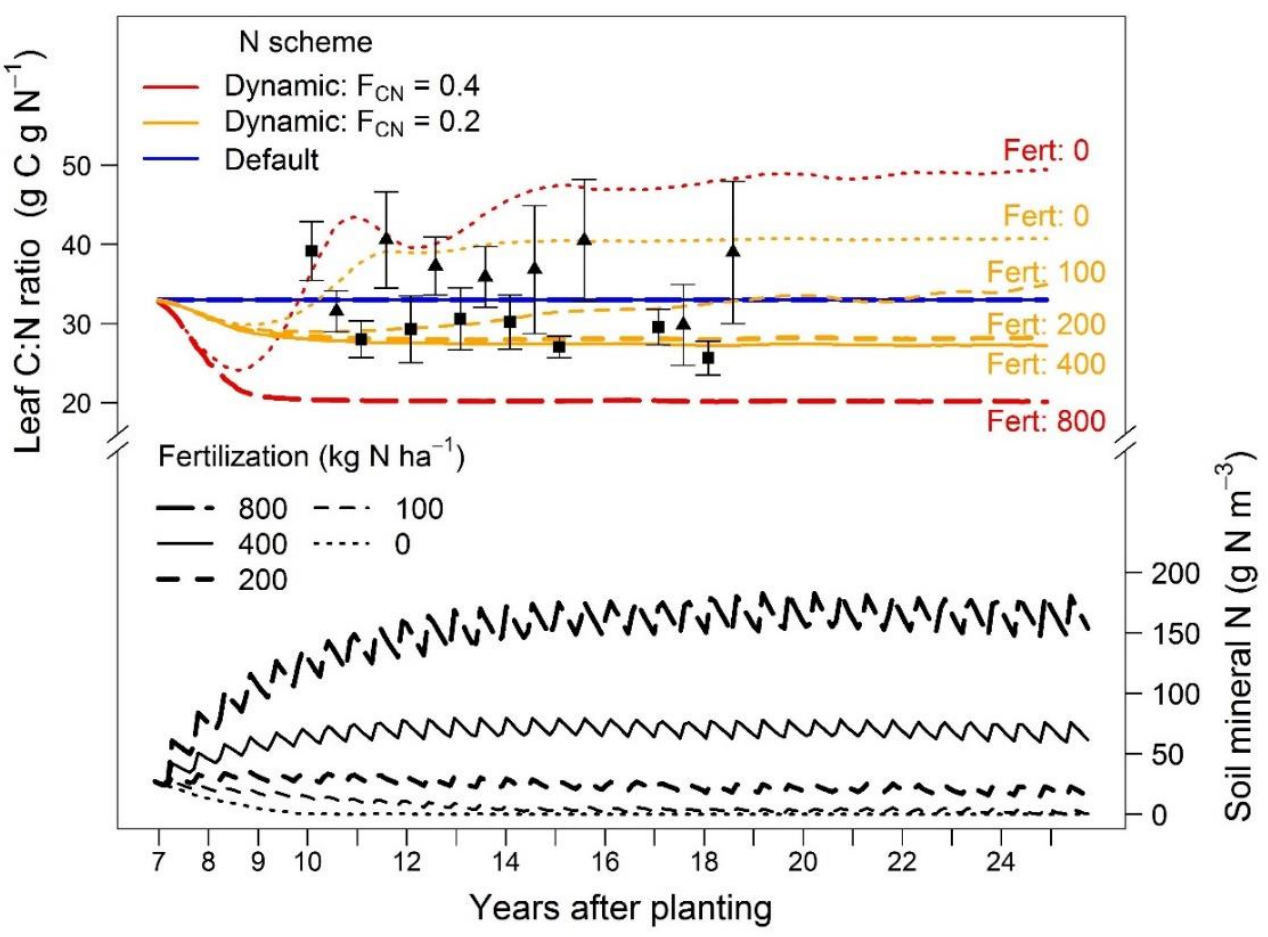

Figure 5.5. Leaf C:N ratio (upper panel) by the default $\mathrm{N}$ scheme and the dynamic $\mathrm{N}$ scheme with different $\mathrm{N}$ fertilization treatments $\left(400 \mathrm{~kg} \mathrm{~N} \mathrm{ha}^{-1} \mathrm{yr}^{-1}\right.$ is the normal practice in PTPN-VI). The $F_{C N}$ values set the maximum allowed fraction of departure of C:N ratios from the standard $\mathrm{C}: \mathrm{N}$ in the dynamic $\mathrm{N}$ scheme (Table 5.1). The points and error bars are field measured leaf $\mathrm{C}: \mathrm{N}$ ratio (mean and standard deviation) from different ages of palms (square for rainy season, triangle for dry season). Fertilization frequency is every 6 months. The tip of each zig-zag curve of the soil mineral $\mathrm{N}$ content (lower panel) marks a fertilization event.

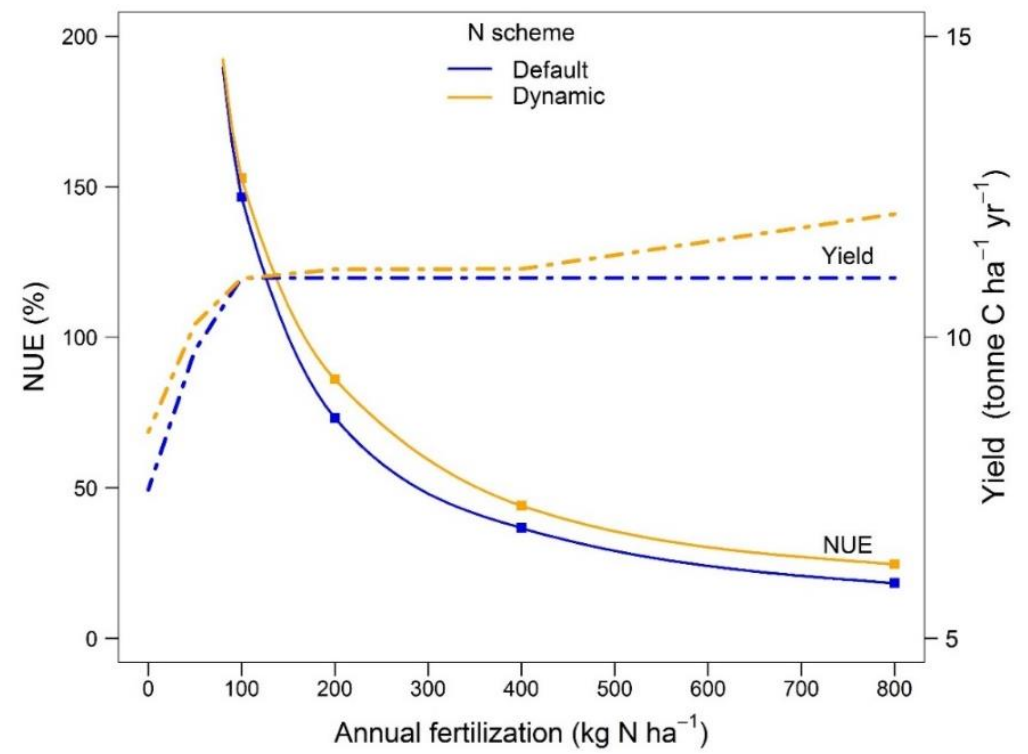

Figure 5.6. Nitrogen use efficiency (NUE) and productivity in yield simulated by the default $\mathrm{N}$ scheme and the dynamic $\mathrm{N}$ scheme. NUE is defined by the ratio between $\mathrm{N}$ export with harvest and the amount of fertilizer $\mathrm{N}$ applied per year. Yield is the annual average during a full cultivation cycle ( 25 years). 
On the contrary, further increasing fertilization to $800 \mathrm{~kg} \mathrm{~N} \mathrm{ha}^{-1} \mathrm{yr}^{-1}$ from the current practice, the yield could only slightly increase (8\%). But the drop of NUE to $20 \%$ indicates a much lower efficiency of fertilizer utilization. The $80 \%$ excess fertilizer in the soil will potentially increase GHG emission including nitrous oxide $\left(\mathrm{N}_{2} \mathrm{O}\right)$, and/or leaching of nitrate, which is significant contributor to global warming and/or local and regional water quality problems (Brumme and Beese, 1992; Dowdell et al., 1979; Goulding et al., 2000).

Combining fertilization experiments by the model and field records from other smallholder plantations which apply much lower fertilizer (Chapter 2), it suggests that the current fertilization in PTPN-VI is overly applied. Using less than half of fertilizer (100 to $200 \mathrm{~kg} \mathrm{~N}$ $\mathrm{ha}^{-1} \mathrm{yr}^{-1}$ ) would have been the most economical (with similarly high yield and lower fertilizer cost) and most sustainable (in regard of soil fertility and GHG emission) fertilization management.

Overall, the new dynamic $\mathrm{N}$ scheme allows to simulate $\mathrm{N}$ fertilization effects on the growth and yield as well as plant-soil $\mathrm{N}$ balance in the oil palm monoculture system. It can improve the adaptability of CLM-Palm and CLM4.5 to a wider range of soil nutrient conditions and fertilization practice. For the application of the dynamic $\mathrm{N}$ scheme on agricultural systems, the modeled trend of NUE together with yield variability with different levels of fertilization in the industrial oil palm plantation has comparable patterns with those observed in field fertilization experiments on winter wheat (Brentrup and Pallière, 2010) or other crops (e.g. rice and oat) or pasture (de Wit, 1992). In contrast, the CLM4.5 default $\mathrm{N}$ scheme with fixed C:N ratios does not fit well for modeling agricultural systems that are highly fertilized. The static $\mathrm{N}$ scheme is only able to simulate a limited range of fertilization effects under $\mathrm{N}$ shortage, relying heavily on the $\mathrm{N}$ downregulation mechanism on GPP which is a flawed approach due to its disconnectedness with the photosynthesis-stomatal conductance model (Bonan et al., 2012). This scheme cannot simulate fertilization enhancement effects, which is, however, useful information for agricultural management and planning.

Beyond this, nutrient availability has been found to be the key regulator of net ecosystem production (NEP) and therefore $\mathrm{C}$ sequestration of forested landscape (Fernández-Martínez et al., 2014). It is critical to consider the change of nutrient availability induced by human activities (e.g. $\mathrm{N}$ deposition and fertilization) together with climate change factors (e.g. rising atmospheric $\mathrm{CO}_{2}$ ) when quantifying the trend of terrestrial $\mathrm{C}$ sequestration by both natural and managed ecosystems (De Vries and Posch, 2011; Luo et al., 2004). The ability to simulate realistic $\mathrm{N}$ cycle and its interaction with $\mathrm{C}$ cycle should be emphasized in Earth system models (Piao et al., 2013; Zaehle and Friend, 2010; Zaehle et al., 2010). This study shows that the 
traditional strictly coupled C-N model with static C:N ratios should be improved with a relaxed and more realistic relationship between $\mathrm{C}$ and $\mathrm{N}$ cycling that can reflect the regulating effects of nutrient availability on both photosynthesis and heterotrophic respiration as well as $\mathrm{C}$ allocation pattern.

\subsection{Conclusion}

The advantages and utility of the new dynamic $\mathrm{N}$ scheme implemented in CLM-Palm are demonstrated by the comparison of NEE, LAI and yield with observations and by the various fertilization experiments on leaf $\mathrm{C}: \mathrm{N}$ ratio and nitrogen use efficiency. The results provide meaningful information for agricultural planning. For example, the level of $\mathrm{N}$ fertilization between 100 and $200 \mathrm{~kg} \mathrm{~N} \mathrm{ha}^{-1} \mathrm{yr}^{-1}$ should be recommended to both new oil palm plantations for the preparation of fertilization or to mature ones to rectify the often overly fertilized management to achieve the highest yield and NUE at the same time. The modeling experiments in this study are on the basis of strict calibration and validation of CLM-Palm (Fan et al., 2015) and successful application of the similar dynamic N scheme in other models (Wang et al., 2010). Allowing $\mathrm{N}$ concentration in plant tissues to vary in response to $\mathrm{N}$ demand and $\mathrm{N}$ availability is thus a meaningful parameterization which should be advocated in C-N biogeochemical models (Wang et al., 2010; Zaehle and Friend, 2010), especially for simulating

agricultural systems. CLM-Palm with the adapted $\mathrm{N}$ scheme has improved capacity for modeling the $\mathrm{C}$ and $\mathrm{N}$ dynamics and crop productivity in oil palm monoculture which is also applicable to other crop PFTs in the CLM4.5. 


\subsection{Appendix}

\section{Dynamic N scheme}

At each time step (half-hourly) after calculation of potential photosynthesis given the current LAI, leaf $\mathrm{N}$ concentration, absorbed radiation and other environmental variables for a PFT, its minimal and maximal $\mathrm{N}$ demands for new growth allocation are calculated as $\left(N F_{\text {plant_demand }}\right)$ :

$$
\begin{aligned}
& N F_{\text {plant_demand }}^{\max }=C F_{\text {pot_alloc }} \frac{N_{\text {allometry }}^{\max }}{C_{\text {allometry }}} \\
& N F_{\text {plant_demand }}^{\text {min }}=C F_{\text {pot_alloc }} \frac{N_{\text {allometry }}^{\text {min }}}{C_{\text {allometry }}}
\end{aligned}
$$

where $C F_{\text {pot_alloc }}$ is the potential $\mathrm{C}$ flux from photosynthesis that can be allocated to new growth after accounting for maintenance respiration. Maintenance respiration cost is determined according to the $\mathrm{C}$ amount and $\mathrm{N}$ concentration in plant tissues, and temperature at the preceding time step. More details can be found in Oleson et al. (2013). $C F_{\text {pot_alloc }}$ also includes a constant proportion $\left(f_{g}\right)$ dedicated to growth respiration cost. $C_{\text {allometry }}$ is the sum of indices for $\mathrm{C}$ allocation allometry that partition $\mathrm{C}$ flux between different tissue types at a given phenological step. $N_{\text {allometry }}^{\min }$ and $N_{\text {allometry }}^{\max }$ are the minimal and maximal sum of indices for $\mathrm{N}$ allocation allometry, using two sets, the maximum and minimum possible $\mathrm{C}: \mathrm{N}$ ratios of different tissues, respectively.

$$
\begin{gathered}
C_{\text {allometry }}=\left(1+f_{g}\right)\left(A_{\text {leaf }}+A_{\text {root }}+A_{\text {fruit }}+A_{\text {stem }}\left(1+F_{\text {stem }}^{\text {croot }}\right)\right) \\
\left.N_{\text {allometry }}^{\text {min }}=\frac{A_{\text {leaf }}}{C N_{\text {leaf }}^{\text {max }}}+\frac{A_{\text {root }}}{C N_{\text {root }}^{\text {max }}}+\frac{A_{\text {fruit }}}{C N_{\text {fruit }}^{\text {max }}}+\frac{A_{\text {stem }} \times F_{\text {stem }}^{\text {live }} \times\left(1+F_{\text {stem }}^{\text {croot }}\right)}{C N_{\text {livewd }}^{\text {max }}}+\frac{A_{\text {stem }} \times\left(1-F_{\text {stem }}^{\text {live }}\right) \times\left(1+F_{\text {stem }}^{\text {croot }}\right)}{C N_{\text {deadwd }}}\right) \\
N_{\text {allometry }}^{\text {max }}=\frac{A_{\text {leaf }}}{C N_{\text {leaf }}^{\text {min }}}+\frac{A_{\text {root }}}{C N_{\text {root }}^{\text {min }}}+\frac{A_{\text {fruit }}}{C N_{\text {fruit }}^{\text {min }}}+\frac{A_{\text {stem }} \times F_{\text {stem }}^{\text {live }} \times\left(1+F_{\text {stem }}^{\text {croot }}\right)}{C N_{\text {livewd }}^{\text {min }}}+\frac{A_{\text {stem }} \times\left(1-F_{\text {stem }}^{\text {live }}\right) \times\left(1+F_{\text {stem }}^{\text {croot }}\right)}{C N_{\text {deadwd }}}
\end{gathered}
$$

where the allocation indices $\left(A_{\text {leaf }}, A_{\text {root }}, A_{\text {stem }}\right.$ and $\left.A_{\text {fruit }}\right)$ controls the growth rates and allometry among different tissues according to the phenology cycle (Fan et al., 2015). $A_{\text {fruit }}$ is only used for crop PFTs.. $F_{\text {stem }}^{\text {croot }}$ is only used for woody PFTs. The maximum and minimum C:N ratios of live tissues are set as $1 \pm F_{C N}$ of the baseline values. The ratio $C_{\text {allometry }} / N_{\text {allometry }}$ defines the overall C:N stoichiometry for new growth allocation, where $N_{\text {allometry }}$ is variable between $N_{\text {allometry }}^{\min }$ and $N_{\text {allometry }}^{\max }$, depending on the updated C:N ratios. 
A plant first utilizes its retranslocated $\mathrm{N}$ pool for new growth. For perennial PFTs (incl. oil palm), the allocation flux of available retranslocated $\mathrm{N}\left(N F_{\text {avail_retrans }}\right)$ follows a demandbased annual cycle which results in a complete turnover of the retranslocated $\mathrm{N}$ pool in about one-year (Oleson et al., 2013). For annual crop PFTs, they pull from retranslocated N pool as much as possible only during grain-fill. This flux is not greater than the maximum $\mathrm{N}$ demand:

$$
N F_{\text {retrans_alloc }}=\min \left(N F_{\text {plant_demand }}^{\max }, N F_{\text {avail_retrans }}\right)
$$

The remaining demand drives root uptake of $\mathrm{N}$ from soil. A similar assumption is made as in Wang et al. (2010) that the potential $\mathrm{N}$ uptake above the minimal demand for each PFT depends on the soil mineral $\mathrm{N}$ availability in the whole column. When soil $\mathrm{N}$ is abundant, root uptake potential of each PFT can be achieved up to its maximum $\mathrm{N}$ demand. Otherwise, its potential uptake is rescaled to be a proportion of the maximum demand. The rescaling is carried out with an empirical constant $k n_{u p}$ by the equation:

$$
\begin{gathered}
N F_{\text {sminn_demand }}=\frac{N_{\text {smin,tot }}}{N_{\text {smin,tot }}+k n_{\text {up }}}\left(N F_{\text {plant_demand }}^{\max }-N F_{\text {plant_demand }}^{\min }\right)+ \\
\left(N F_{\text {plant_demand }}^{\text {min }}-N F_{\text {retrans_alloc }}\right)
\end{gathered}
$$

when $N F_{\text {retrans_alloc }}>N F_{\text {plant_demand }}^{\min }$,

$$
N F_{\text {Sminn_demand }}=\frac{N_{\text {smin,tot }}}{N_{\text {smin, }, \text { tot }}+k n_{u p}}\left(N F_{\text {plant_demand }}^{\max }-N F_{\text {retrans_alloc }}\right)
$$

The soil mineral N pool is shared by all PFTs that are in the same soil column and also the soil heterotrophic community. Thus, the combined uptake demand from all PFTs $\left(\sum_{p f t=1}^{n} N F_{\text {sminn_demand }}\right)$ competes with the $\mathrm{N}$ immobilization demand $\left(N F_{\text {immob_demand }}\right)$ by soil heterotrophs. The latter is calculated independently in the soil model.

$$
f_{\text {plant_demand }}=f_{\text {immob_demand }}=\frac{N_{\text {smin }, \text { tot }}}{\Delta t\left(\sum_{p f t=1}^{n} N F_{\text {sminn_demand }}+N F_{\text {immob_demand }}\right)}
$$

The demand-based competition yields a ratio $f_{\text {plant_demand }}$ that is applied to each PFT to calculate its actual $\mathrm{N}$ uptake from soil:

$$
N F_{\text {Sminn_alloc }}=f_{\text {plant_demand }} N F_{\text {Sminn_demand }}
$$

Wang et al. (2010) did not consider an equal competition between plant $\mathrm{N}$ uptake and soil $\mathrm{N}$ immobilization like CLM4.5 does. Rather, soil N immobilization takes absolute priority over plant $\mathrm{N}$ uptake in their model. Although given this difference, the Eqs. (A 5.4, 5.5) allows a 
pre-control of plant $\mathrm{N}$ demand, which reflects plant's adjustment of $\mathrm{N}$ investment strategy in any given soil environment.

The total actual $\mathrm{N}$ flux allocated to plant is the sum of actual $\mathrm{N}$ uptake from soil and the restranslocated $\mathrm{N}$ flux:

$$
N F_{\text {alloc }}=N F_{\text {Sminn_alloc }}+N F_{\text {retrans_alloc }}
$$

The percentage of extra $\mathrm{N}$ allocation above the minimum requirement can be used to rescale the $\mathrm{C}: \mathrm{N}$ stoichiometric relationship for growth allocation to different tissues.

When $N F_{\text {alloc }}>N F_{\text {plant_demand }}^{\text {min }}$,

$$
\begin{gathered}
C F_{\text {alloc }}=C F_{\text {pot_alloc }} \\
C n^{r}=\frac{N F_{\text {alloc }}-N F_{\text {plant_demand }}^{\text {min }}}{N F_{\text {plant_demand }}^{\text {max }}-N F_{\text {plant_demand }}^{\text {min }}}
\end{gathered}
$$

where the rescaling factor $c n^{r} \leq 1 . C F_{\text {alloc }}$ is the actual $\mathrm{C}$ flux allocated for new growth (from full potential photosynthesis).

When $N F_{\text {alloc }}<N F_{\text {plant_demand }}^{\text {min }}$, that is, $\mathrm{N}$ is limited,

$$
\begin{gathered}
C F_{\text {alloc }}=N F_{\text {alloc }} \frac{C_{\text {allometry }}}{N_{\text {allometry }}^{\text {min }}} \\
c n^{r}=0
\end{gathered}
$$

where the actual $\mathrm{C}$ flux allocation is in relation to the actual $\mathrm{N}$ flux using the stoichiometry calculated with the minimum $\mathrm{C}: \mathrm{N}$ ratios (Eq. A 5.2). In this $\mathrm{N}$ limited situation, the downregulation mechanism is turned on, which rescales the potential photosynthetic $\mathrm{C}$ flux by the ratio:

$$
f_{\text {dreg }}=1-\frac{C F_{\text {pot_alloc }}-C F_{\text {alloc }}}{C F_{\text {pot_GPP }}}
$$

The total allocated carbon flux $C F_{\text {alloc }}$ is partitioned to the different tissue pools by the allocation allometry: 


$$
\begin{aligned}
C F_{\text {alloc }, \text { leaf }} & =C F_{\text {alloc }} \frac{A_{\text {leaf }}}{C_{\text {allometry }}} \\
C F_{\text {alloc, froot }} & =C F_{\text {alloc }} \frac{A_{\text {root }}}{C_{\text {allometry }}} \\
C F_{\text {alloc,livestem }} & =C F_{\text {alloc }} \frac{A_{\text {stem }} F_{\text {stem }}^{\text {live }}}{C_{\text {allometry }}} \\
C F_{\text {alloc,deadstem }} & =C F_{\text {alloc }} \frac{A_{\text {stem }}\left(1-F_{\text {stem }}^{\text {live }}\right)}{C_{\text {allometry }}} \\
C F_{\text {alloc,fruit }} & =C F_{\text {alloc }} \frac{A_{\text {fruit }}}{C_{\text {allometry }}}
\end{aligned}
$$

The updated C:N stoichiometric relationship for allocation to different tissues are determined by $c n^{r}$ using the following equations.

$$
\begin{gathered}
C N_{\text {leaf }}^{\text {alloc }}=C N_{\text {leaf }}^{\max }-\left(C N_{\text {leaf }}^{\max }-C N_{\text {leaf }}^{\text {min }}\right) c n^{r} \\
C N_{\text {root }}^{\text {alloc }}=C N_{\text {root }}^{\text {max }}-\left(C N_{\text {root }}^{\text {max }}-C N_{\text {root }}^{\text {min }}\right) c n^{r} \\
C N_{\text {livewd }}^{\text {alloc }}=C N_{\text {livewd }}^{\text {max }}-\left(C N_{\text {livewd }}^{\text {max }}-C N_{\text {livewd }}^{\text {min }}\right) c n^{r} \\
C N_{\text {fruit }}^{\text {alloc }}=C N_{\text {fruit }}^{\text {max }}-\left(C N_{\text {fruit }}^{\text {max }}-C N_{\text {fruit }}^{\text {min }}\right) c n^{r}
\end{gathered}
$$

where the $\mathrm{C}: \mathrm{N}$ ratios for allocation are conceptually different from the real-time $\mathrm{C}: \mathrm{N}$ ratios in each tissue pool. They are used to allocate corresponding $\mathrm{N}$ fluxes to each tissue type (except $C N_{\text {deadwd }}$ is constant):

$$
\begin{aligned}
N F_{\text {alloc,leaf }} & =\frac{C F_{\text {alloc,leaf }}}{C N_{\text {leaf }}^{\text {alloc }}} \\
N F_{\text {alloc,froot }} & =\frac{C F_{\text {alloc,froot }}}{C N_{\text {root }}^{\text {alloc }}} \\
N F_{\text {alloc,livestem }} & =\frac{C F_{\text {alloc,livestem }}}{C N_{\text {livewd }}^{\text {alloc }}} \\
N F_{\text {alloc,deadstem }} & =\frac{C F_{\text {alloc,deadstem }}}{C N_{\text {deadwd }}} \\
N F_{\text {alloc,fruit }} & =\frac{C F_{\text {alloc,fruit }}}{C N_{\text {fruit }}^{\text {alloc }}}
\end{aligned}
$$

After growth allocation of $\mathrm{C}$ and $\mathrm{N}$ fluxes and phenological updates (e.g. senescence), the realtime $\mathrm{C}: \mathrm{N}$ ratios in live tissues is recalculated, e.g. for leaf:

$$
C N_{\text {leaf }}=\frac{C_{\text {leaf }}}{N_{\text {leaf }}}
$$

The dynamic $C N_{\text {leaf }}$ (leaf $\mathrm{N}$ concentration) is used for photosynthesis, stomatal conductance and respiration calculations in the next time step. The dynamic $\mathrm{N}$ concentration in other live tissues are also involved in respiration and $\mathrm{N}$ retranslocation processes. 


\section{Derive sub-canopy leaf $N$ concentration}

For those PFTs that do not have layer-specific leaf $\mathrm{C}$ and $\mathrm{N}$ pools with the multilayer option (i.e. uniform LAI per layer, see Fig. 3.1b in Chapter 3), an exponential function is usually used to attenuate the leaf $\mathrm{N}$ concentration from canopy top to bottom, if the top of canopy leaf C:N ratio $\left(C N_{\text {leaf }}^{\text {top }}\right)$ and specific leaf area $\left(S L A_{\text {top }}\right)$ are given:

$$
L N C_{i}=\frac{e^{-K_{N} L A I_{\text {cum }, i}}}{C N_{\text {leaf }}^{\text {top }} S L A_{\text {top }}}
$$

where $L A I_{\text {cum }, i}$ is cumulative LAI from the canopy top to layer $i . K_{N}$ is the $\mathrm{N}$ scaling factor that is often used to drive the gradients of photosynthesis, stomatal conductance and respiration across canopy depth. The CLM4.5 model also uses this approach to scale down photosynthesisrelated processes but it does not actually recalculate leaf $\mathrm{N}$ concentration and $\mathrm{C}: \mathrm{N}$ ratio per canopy layer, whereas in this study they are explicitly calculated at each time step.

When the dynamic $\mathrm{N}$ scheme is turned on, the top of canopy leaf $\mathrm{C}: \mathrm{N}$ ratio $\left(C N_{\text {leaf }}^{\text {top }}\right)$ is also changing and not known beforehand, the above equation (Eq. A 5.18) does not work and a new procedure has to be used to drive the $\mathrm{N}$ concentration for each layer. First, the mean $V_{c \max }$ can be obtained for the whole canopy:

$$
V_{\text {cmax } 25}^{\text {mean }}=L N C_{\text {mean }} F_{L N R} F_{N R} a_{R 25}
$$

where $L N C_{\text {mean }}$ is the mean leaf $\mathrm{N}$ concentration by:

$$
L N C_{\text {mean }}=\frac{1}{C N_{\text {leaf }} S L A}
$$

where $C N_{\text {leaf }}$ is the canopy average leaf C:N ratio calculated at every half-hourly time step by Eq. (A 5.17). The $\mathrm{N}$ scaling factor $K_{N}$ can be then derived from $V_{c m a x 25}^{\text {mean }}$ using the empirical relationship from (Lloyd et al., 2010):

$$
K_{N}=e^{\left(0.00963 V_{c m a x 25}^{\text {mean }}-2.43\right)}
$$

An inverse approach is then used to derive the top of canopy $\mathrm{N}$ concentration from the canopy mean:

$$
L N C_{\text {top }}=\frac{L N C_{\text {mean }}}{\sum_{i=1}^{n}\left(e^{\left.-K_{N} L A I_{\text {cum }, i}\right) / n_{\text {layer }}}\right.}
$$


where the divisor is the mean of the scaling factors (in Eq. A 5.18) across the number of canopy layers $\left(n_{\text {layer }}\right)$.

Finally, the leaf $\mathrm{N}$ concentration for each layer is obtained:

$$
L N C_{i}=L N C_{t o p} \times e^{-K_{N} L A I_{\text {cum }, i}}
$$

For the oil palm multilayer structure with the dynamic $\mathrm{N}$ scheme, calculating $L N C_{i}$ is straightforward because layer-specific $\mathrm{C}$ and $\mathrm{N}$ pools are updated at each time step with the sub-canopy phenology and allocation functions in CLM-Palm (Fig. 5.1b). The area-based leaf $\mathrm{N}$ concentration ( $\mathrm{g} \mathrm{N} \mathrm{m}-2$ leaf area) at each canopy layer is calculated as:

$$
L N C_{i}=\frac{1}{C N_{\text {leaf }, i} S L A}
$$

where $S L A$ is the average specific leaf area for a given PFT. $C N_{\text {leaf }, i}$ is the average leaf C:N ratio for canopy layer $i$ :

$$
C N_{\text {leaf }, i}=\frac{\sum_{i} C_{\text {leaf }}}{\sum_{i} N_{\text {leaf }}}
$$

where $\sum_{i} C_{\text {leaf }}$ and $\sum_{i} N_{\text {leaf }}$ are the sums of $\mathrm{C}$ and $\mathrm{N}$, respectively, from the phytomers within canopy layer $i$. If a foliage $\mathrm{N}$ gradient $\left(K_{N} \neq 0\right)$ is enforced on oil palm like other PFTs, the same inverse approach (Eqs. A 5.19-23) could be used to derive $L N C_{i}$ from the canopy mean. 


\section{CHAPTER 6}

Simulating the effects of rainforest to oil palm conversion on carbon, water and energy fluxes and carbon stocks 


\subsection{Introduction}

Land transformation from natural rainforests to managed agricultural systems such as oil palm (Elaeis guineensis) plantations has significant implications on the land-atmosphere carbon, water and energy cycles (Fargione et al., 2008; Kotowska et al., 2015; Nogueira et al., 2015), through altering photosynthesis, evapotranspiration, and surface albedo as well as other processes related to the distinct PFTs and their dynamics (Bonan, 2008).

In the past two decades, more than 10 million ha of oil palm plantations have been newly established in Indonesia, of which nearly 50\% was at the expense of intact rainforests and $40 \%$ on logged or agro-forests (Carlson et al., 2012; Gunarso et al., 2013). The island of Sumatra is the hotspot of oil palm industry with the highest absolute rate of expansion $\left(\sim 190,000 \mathrm{ha} \mathrm{yr}^{-1}\right)$ in Indonesia (Gunarso et al., 2013). In order to investigate regional climatic effects of such transformation and quantify energy, water and carbon fluxes of the oil palm monoculture system, both field observations such as using eddy covariance flux measurements and land surface modeling experiments have been set up in Sumatra, Indonesia.

In the preceding chapters, the CLM-Palm sub-model with multilayer phytomer-based structure was developed for simulating the new palm PFT within the framework of CLM4.5 which is embedded in the Community Earth System Model (CESM) that allows simulating the interactions between land and atmosphere from regional to global scales (Gent et al., 2011). CLM-Palm retains all the features of CLM4.5 with extra functions for the palm PFT. Therefore, it is well-suited for simulating the effects of forest to oil palm conversion. As the first step, this study looks at the effects of conversion happening at the local scale on land-atmosphere energy and material cycling using a point simulation assuming a homogenous landscape spanning a multiyear period of forest clear-cut, plantation establishment and maturing. When large scale land-use and land-cover change data set is available as input, the CLM-Palm model can upscale the simulations to understand regional to global impacts of tropical land-use transformation driven by oil palm expansion.

Before the first application of CLM-Palm, it is helpful to recap all the model developments in this dissertation. First of all, CLM-Palm has a sub-canopy phenological and physiological parameterization, in which multiple leaf and fruit components develop (growth, senescence and/or yield) simultaneously but according to their different phenological steps separated by a thermal period called phyllochron. CLM-Palm adds one more dimension below PFT that is called "sub-PFT" for both carbon and nitrogen pools and the phenological steps. Agricultural practices including transplanting, fertilization, and leaf pruning are also represented. Second, a 
classic multilayer radiative transfer scheme is implemented in order to improve or ensure CLM's energy cycle. In this scheme, oil palm's special canopy morphology such as its highly vertical young leaves and changing leaf angles are all considered. Third, $\mathrm{N}$ fluxes are calculated independently for all the PFT-level and sub-PFT-level pools instead of being derivatives from the $\mathrm{C}$ fluxes based on fixed C:N ratios in CLM4.5. There is still relaxed coupling between $\mathrm{N}$ and $\mathrm{C}$ cycles but the new scheme allows variation in $\mathrm{C}: \mathrm{N}$ ratios and plant $\mathrm{N}$ use efficiency (the ratio of $\mathrm{N}$ use to $\mathrm{C}$ use) in different vegetative components in response to $\mathrm{N}$ availability and competition between plant and soil microorganisms. The revised dynamic $\mathrm{N}$ cycle feedbacks to the $\mathrm{C}$ cycle and improve the overall biogeochemical processes of the agricultural system. Overall, CLM-Palm combines the ability of an agricultural model for simulating growth and yield of oil palm (Chapter 2), beside that it allows the modeling of biogeophysical (Chapters 3 , 4) and biogeochemical (Chapter 5) processes as a land model should do.

This chapter aims to quantify the impacts of forest to oil palm conversion by applying all the above model developments to answer questions regarding the fates of $\mathrm{C}$, water, and energy fluxes in plant, soil and atmosphere when the land surface shifts from an undisturbed forest to a managed oil palm plantation.

\subsection{Methods}

\subsubsection{Experiment design}

Two simulations each spanning 15 years from 2001 to 2015 with all the new model features introduced in the preceding chapters were set up for the Harapan region of Jambi, Sumatra. One is a reference simulation representing a stable tropical lowland rainforest. Another simulates a dynamic land surface that has undergone land-use transformation from rainforest to oil palm plantation. The Harapan site is characterized by loam Acrisols and moderate rainfall $\left(\sim 2567 \mathrm{~mm} \mathrm{y}^{-1}\right)$. An old growth rainforest, represented by the broadleaf evergreen tropical tree (BET) PFT, is hypothesized to exist in both simulations until 2000. In 2001, the BET forest PFT in the dynamic simulation was turned off (representing clear-cut) and the land was left open for 1 year before the plantation establishment in 2002. The oil palms were transplanted to the field (palm PFT turned on) and managed with standard practice (including fertilization) like the PTPN-VI industrial plantation from 2002 to 2015, representing the historical period, and from 2016 to 2052, representing the future business-as-usual scenario. The dynamic simulation spanned two complete rotation periods which tried to represent the history and future of the PTPN-VI site provided abundant field data for validation. But given the fact that the pre-2002 site condition of PTPN-VI was not always forested, it is only possible to hypothesize an 
immediate land-use transformation from forest to oil palm plantation. The reference simulation aimed to model the protected old-growth rainforest which has rather natural site conditions although minor logging has been going on.

Similar to the model settings in Chapter 2, the initial conditions of starting year 2000 were provided by a standard spin-up (600 years) procedure that gives a pre-industrial era (1850) steady-state estimate of soil C and N pools with the BET forest PFT, followed by continuing simulation until 2000 with dynamic $\mathrm{CO}_{2}$ concentration in the atmosphere. The top 1-m soil C and $\mathrm{N}$ pools at the end of spin-up (2000) are within $-6 \%$ departure from the average field observation at the reference lowland rainforest sites in Harapan (Allen et al., 2015; Guillaume et al., 2015). The 3-hourly ERA Interim climate data (Dee et al., 2011) were used as atmospheric forcing for the historical period from 2000 to 2015. The same forcing data was cycled over for the future simulation from 2016 to 2052.

\subsubsection{Statistical analysis}

Two eddy covariance flux towers installed in oil palm plantations in the province of Jambi, Sumatra, Indonesia (Meijide et al., 2016) provided data for validating the simulation of oil palm plantation at young and mature stages. The sites were a 2-year old juvenile oil palm plantation (Pompa Air, 01 ${ }^{\circ} 50.1^{\prime} \mathrm{S}, 103^{\circ} 17.7^{\prime} \mathrm{E}$ ) and a mature 12-year-old plantation (PTPN-VI, 01 ${ }^{\circ} 41.6^{\prime}$ $\left.\mathrm{S}, 103^{\circ} 23.5^{\prime} \mathrm{E}\right)$. These flux towers provide continuous measurements of daily and half-hourly fluxes of energy, water vapor and $\mathrm{CO}_{2}$. GPP was derived from NEE following the same procedure in Chapter 3. However, there is no eddy covariance flux data for the Harapan rainforest in Jambi. The simulated BET forest PFT under the same climate forcing is meant to provide a baseline of biogeophysical and biogeochemical characters of old-growth rainforest, against which a comparison of the dynamic oil palm simulation was made. Using the available eddy covariance data from the young and mature oil palm plantations and remote sensing derived ground temperature (TG) for all three sites including the forest, a comparison was first made with simulated results in 2014 on a daily and seasonal basis to examine the intrinsic differences in carbon flux (GPP, NEE) and biogeophysical properties (e.g. evapotranspiration (ET), sensible heat flux (H) and TG) between the three land cover types. This comparison provides a starting point for the following analysis of long term land-use change effects.

Output from the land cover change simulation was used to showcase the long term dynamics of above- and below-ground $\mathrm{C}$ stocks from the initial forested condition to the following 50 years of oil palm cultivation. Statistics shows how the site's capacity of $\mathrm{C}$ assimilation and storage could have been dropped or enhanced by the transforming land cover and intensive plantation management in the long term. 


\subsection{Results}

\subsubsection{Comparison of diurnal carbon, water and energy flux}

Comparing the diurnal $\mathrm{C}$ fluxes between the three land cover types, it shows that the mature oil palm plantation has substantially higher productivity in regard of GPP compared to the oldgrowth rainforest and the young oil palm plantation that just starts to yield (Fig. 6.1a). The daily mean C assimilation rate of mature oil palm is $126 \%$ of the rainforest and $204 \%$ of the young oil palm. The old growth forest only shows $60 \%$ higher GPP than the 2-year old oil palm plantation although the forest has 4 times LAI of that of the young palm.
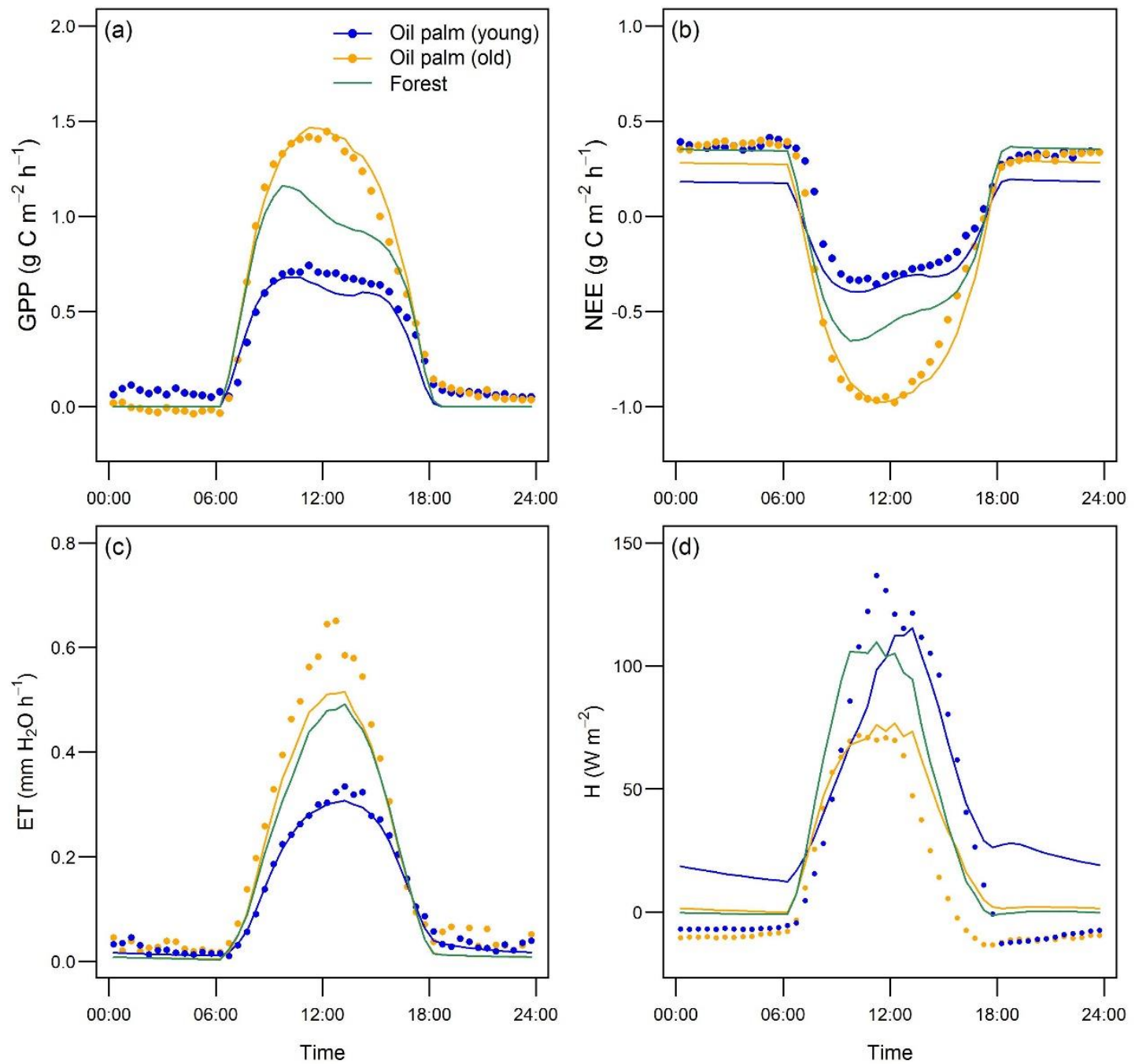

Figure 6.1. Comparison of mean diurnal fluxes of: (a) GPP, (b) NEE, (c) evapotranspiration (ET) and (d) sensible heat flux $(\mathrm{H})$ between young oil palm (2-year old, LAI $=1.0)$, mature oil palm (12-year old, $\mathrm{LAI}=3.7$ ) and old-growth rainforest $(\mathrm{LAI}=4.3)$, with reference to available eddy covariance flux data (points) for young and mature oil palm from Jambi, Sumatra. 
Similar gradients in daytime NEE were observed among the forest and the oil palms (Fig. 6.1b). The mature oil palm plantation sequesters significantly higher amount of $\mathrm{C}$ (NEE: $-3.77 \mathrm{~g} \mathrm{C}$ $\mathrm{m}^{-2}$ day $\left.^{-1}\right)$ than the young oil palm $\left(-0.66 \mathrm{~g} \mathrm{C} \mathrm{m}^{-2}\right.$ day $\left.^{-1}\right)$ and forest $\left(-0.14 \mathrm{~g} \mathrm{C} \mathrm{m}^{-2} \mathrm{day}^{-1}\right)$ on a daily basis. The mature plantation is the strongest carbon sink due to its fast vegetative growth and high fruit yield (see Chapter 2). In contrast, the forest has even lower net $\mathrm{C}$ uptake than the young oil palm although there lacks field data in Jambi for validating the NEE of forest. The simulated forest was continuing growing slowly under the 20th century climate trend after the spin-up equilibrium state. Its slight $\mathrm{C}$ sink on one hand is driven by $\mathrm{CO}_{2}$ fertilization and $\mathrm{N}$ deposition and on the other hand is limited by the high maintenance cost of its standing biomass (simulated $15540 \mathrm{~g} \mathrm{C} \mathrm{m}^{-2}$ of forest vs. 904 and $5060 \mathrm{~g} \mathrm{C} \mathrm{m}^{-2}$ of young and mature oil palms) and the respiration of large amount of belowground soil organic matter (SOM, $5960 \mathrm{~g} \mathrm{C} \mathrm{m}^{-2}$ simulated average).

The young oil palm plantation has significantly lower ET and higher $\mathrm{H}$ than the mature oil palm and rainforest. The difference between simulated sensible heat flux and eddy covariance estimates for the young planation is large at noon and night. The simulated $\mathrm{H}$ of the rainforest is substantially higher than the mature oil palm although their ET are not very different.

\subsubsection{Seasonal trends of $\mathrm{C}$ flux and biogeophysical variables}

Comparing the seasonal trends, it also shows that young and mature oil palms are different in carbon (GPP, NEE) and water (ET) fluxes and ground temperature (TG, defined in the model as top of soil temperature) and they are both inherently different from the rainforest (Fig. 6.2). The dynamic phenology and allocation mechanisms during palm development give a clear increasing trend of GPP for the young palm that is maturing (increasing LAI) and starting to yield, although its NEE shows a declining trend (Fig. 6.2a, b). The mature oil palm plantation has the highest rate of $\mathrm{C}$ sequestration as indicated by the NEE (Fig. 6.2b). The static parameters used by the forest PFT give a rather stable level of GPP $\left(9.5 \pm 1.3 \mathrm{~g} \mathrm{C} \mathrm{m}^{-2} \mathrm{day}^{-1}\right)$ throughout the year when the old-growth rainforest site is largely in an equilibrium state as indicated by the low NEE (-0.14 $\mathrm{g} \mathrm{C} \mathrm{m}^{-2}$ day $^{-1}$; Fig. 6.2b) and small variation in LAI $(4.3 \pm 0.14)$. The mature oil palm has more similar levels of biophysical dynamics such as ET (Fig. 6.2c) and TG (Fig. 6.2d) compared with the rainforest, while the young palm plantation releases much less water to the air and has higher ground temperature. Compared to the rainforest and young palm, the mature oil palm exhibits stronger seasonal variation in GPP, NEE and ET especially the striking responses to a severe drought period in March (13 $\mathrm{mm}$ rainfall month ${ }^{-1} \mathrm{vs}$. annual mean $140 \mathrm{~mm}$ month $\left.^{-1}\right)$ and a heatwave in May $\left(27^{\circ} \mathrm{C}\right.$ vs. $26.3{ }^{\circ} \mathrm{C}$ annual mean; precipitation 141 
$\mathrm{mm}$ in May). The modeled pattern of TG among the three sites matches well with remote sensing derived surface temperature (Sabajo et al., 2016).
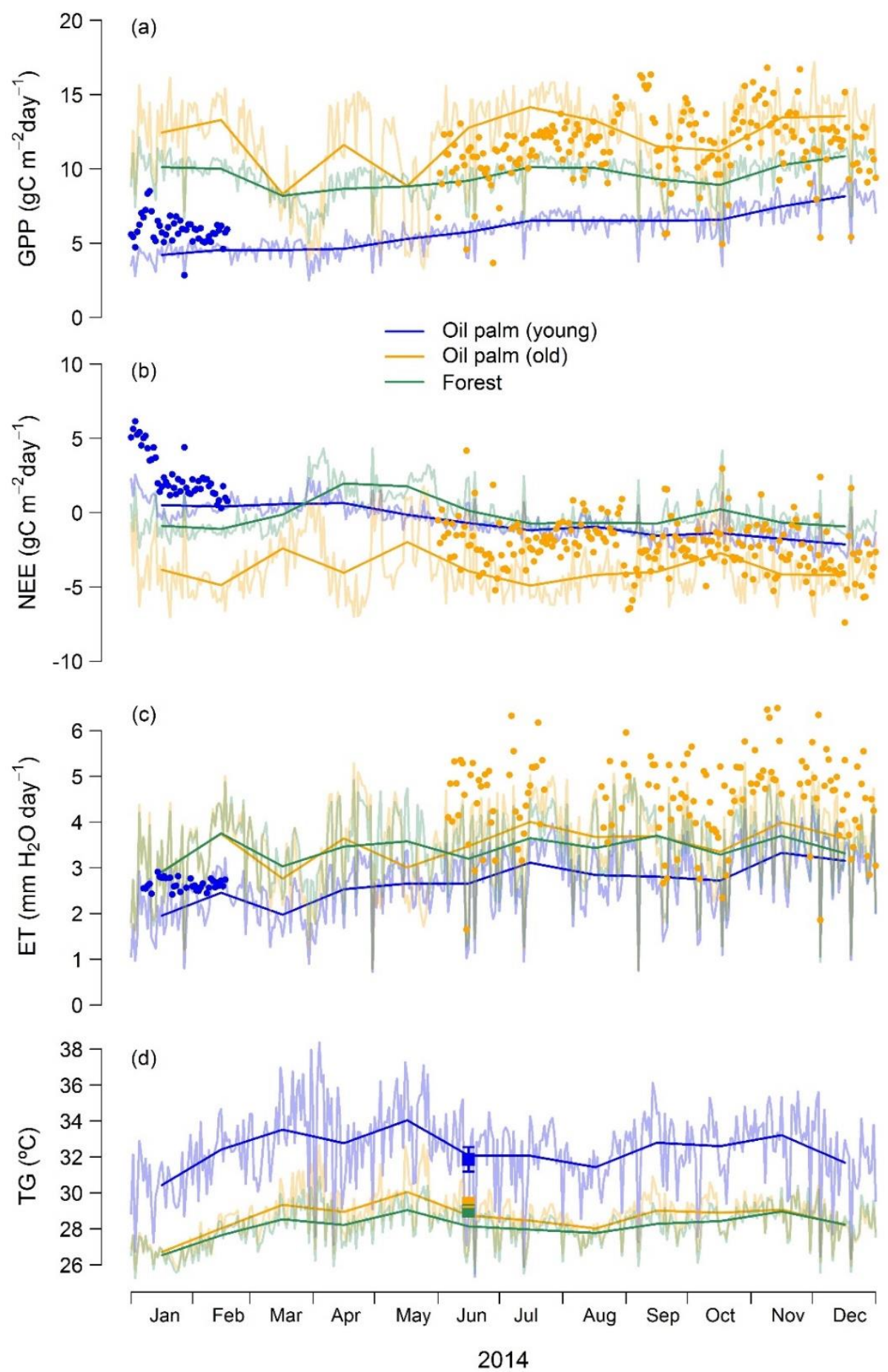

Figure 6.2. Observed (points) and simulated (lines) GPP, NEE, evapotranspiration (ET) and ground surface temperature (TG) between young and mature oil palm plantations and oldgrowth rainforest. Data gaps in the observed ET were filled with the mean value per time step before being summarized to daily value. In (a) to (c) the thick lines are monthly mean and the thin lines are daily sum. In (d) the simulated values reflect daily or monthly 10-11 a.m. means and the squares are satellite derived surface temperature in the same time window (10-11 a.m.). 


\subsubsection{Dynamics of $\mathrm{C}$ pools following forest to oil palm conversion}

The transient simulation from forest clear-cut to the establishment of oil palm plantation shows that the rainforest contains significantly higher amount of $\mathrm{C}$ than the managed oil palm plantation (Fig. 6.3). After clear-cut, most of the aboveground $\mathrm{C}$ stock is lost while the belowground carbon is largely retained in the soil. The establishment of oil palm plantation rapidly restores a part of the aboveground $\mathrm{C}$ stock with a linear increasing trend but most of the replenishment is gone due to the export of harvested fruit. Oil palm grows fast during the first 3 years after being transplanted to the field and then starts to yield (see the beginning of green and yellow lines, Fig. 6.3). The simulated monthly NPP of the mature oil palm plantation ( 150 $\mathrm{g} \mathrm{C} \mathrm{m}^{-2}$ ) is comparable to field measured total NPP estimated from aboveground litter production, woody biomass production and fine root litter production (Kotowska et al., 2015). However, more than a half of NPP is partitioned to fruit (see Chapter 2 on allocation) which is not retained on site. Compared to the rainforest, oil palm's aboveground $\mathrm{C}$ pool accounts for a smaller portion of total $\mathrm{C}$ pool. Thus the overall on-site ecosystem $\mathrm{C}$ only slightly increases along with the gradually growing biomass stock (majorly aboveground). During the plantation development, soil $\mathrm{C}$ pool is declining gradually due to very limited return of aboveground litter to soil because of the pruning and piling of highly lignified palm leaves (discussed in Chapter 2).

The trends of below-ground and aboveground (on-site) $\mathrm{C}$ stocks remain similar even after another rotation of 25 years into the future (Fig. 6.4). At the beginning (0-5 years) of the second rotation period the total ecosystem $\mathrm{C}$ stock even drops, which is due to the respiration cost of the exported stem wood biomass and the remaining root and leaf litter biomass left in the soil after the clear-cut at rotation. The oil palm plantation accumulates a large amount of stem biomass after 25 years of cultivation. The harvest routine of the CLM-Palm model has been adapted to export oil palm stem biomass at the time of rotation to a 10-year wood product pool in the same way as the wood harvest function for tree PFTs. The 10-year wood product pool is subject to a slow decay function that will result a loss of $90 \%$ harvested wood $\mathrm{C}$ in 10 years (Oleson et al., 2013). This special treatment prevents the overconsumption of soil mineral $\mathrm{N}$ pools for the decomposition of large amount of litter biomass if all the stem $\mathrm{C}$ is immediately merged to the soil litter pool like the annual crop harvest function does. Additional model experiments have proved that the wood harvest function is a necessary treatment for oil palm's stem $\mathrm{C}$ pool at rotation after many years of cultivation. Overall, the aboveground $\mathrm{C}$ stocks of the oil palm plantation largely repeat the pattern of $\mathrm{C}$ accumulation through fast growth and $\mathrm{C}$ loss through yield export at multiple cultivation cycles. The soil $\mathrm{C}$ stock is degrading continuously while the accumulated harvested fruit $\mathrm{C}$ can surpass the total on-site ecosystem $\mathrm{C}$ 
stock of the plantation itself and even of the rainforest, although the fruit $\mathrm{C}$ is consumed by humans soon and will return as $\mathrm{CO}_{2}$ back into the atmosphere.

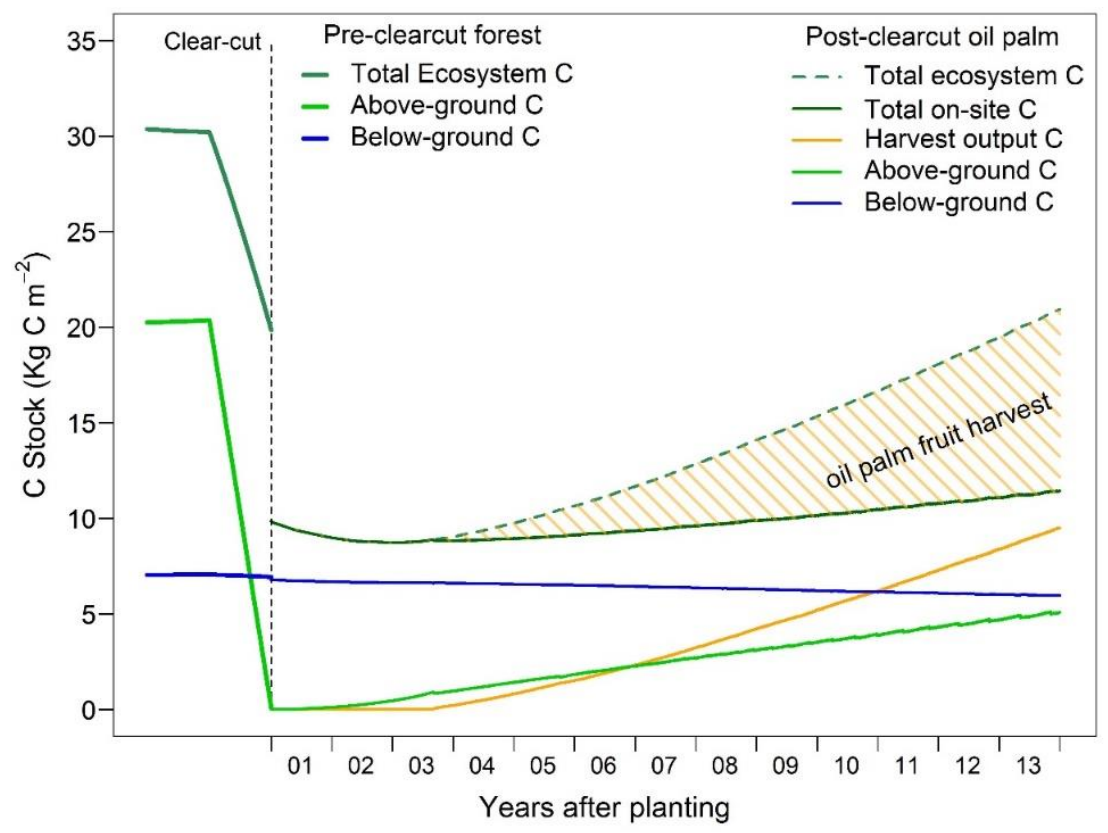

Figure 6.3. Trajectory of carbon stocks above- and below-ground following forest clear-cut and land cover transformation to oil palm plantation. The harvested $\mathrm{C}$ is the cumulated value through time. The oil palm site condition is representative of the PTPN-VI industrial plantation in the planting period of 2002 to 2014.

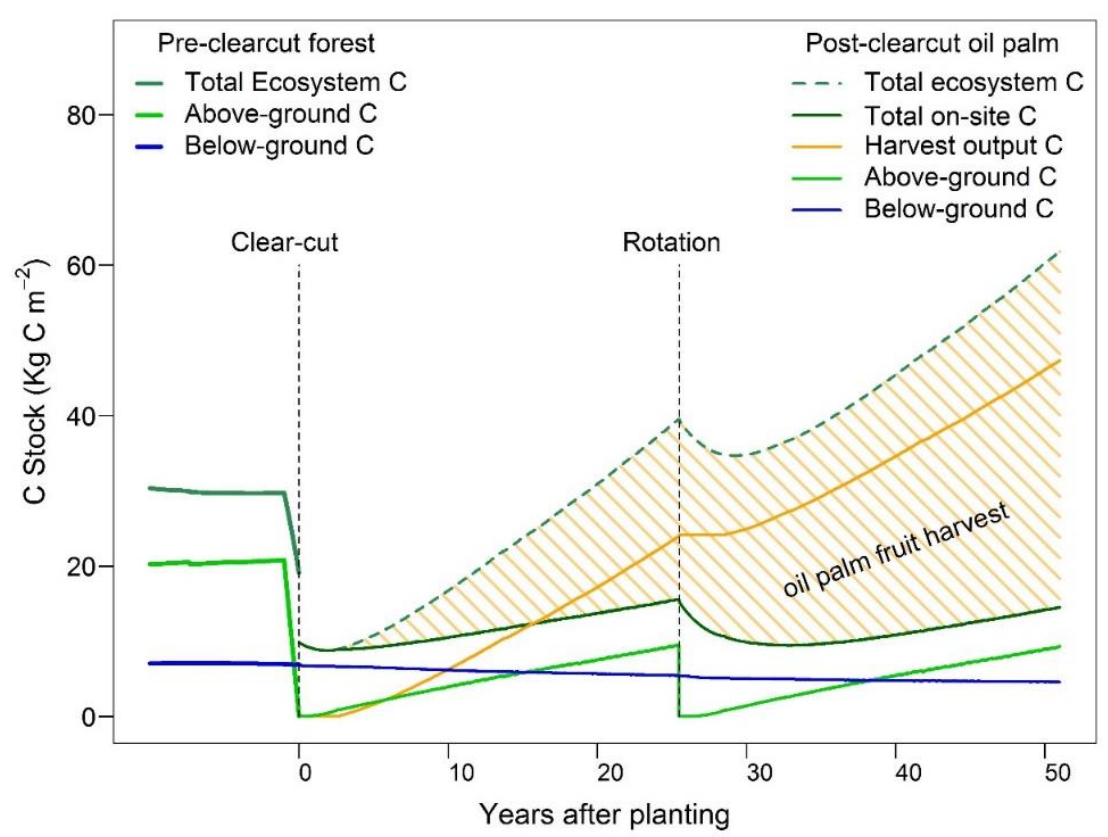

Figure 6.4. Trajectory of carbon stocks above- and below-ground through long term oil palm cultivation including plantation rotation (replanting) during 50 years. The simulation assumes the climatic conditions and fertilization management remain the current trend observed during 2002 to 2014 in the PTPN-VI plantation. 


\subsection{Discussion}

The comparison of young and mature oil palms with the old-growth rainforest suggests that unmanaged and managed vegetation have different $\mathrm{C}$ assimilation rates (GPP) and net ecosystem exchange (NEE) as well as different water and energy use strategies through time. Oil palm plantations have higher GPP and NEE (absolute value) than the old growth rainforest even when the former has similar or lower level of LAI. The high $\mathrm{N}$ fertilization rate in oil palm plantations contributes to the palm's high GPP per unit LAI as suggested in Chapter 5. The GPP of a 2-year-old oil palm plantation can catch up with the simulated rainforest within one year under the same climate in Jambi, Sumatra (Fig. 6.2). It suggests that the oil palm plantations have high $\mathrm{C}$ sequestration capacity by virtue of their fast growth and/or high yield, while the NEE and $\mathrm{C}$ stocks of the old growth rainforest only slightly increase due to $\mathrm{CO}_{2}$ fertilization and $\mathrm{N}$ deposition if not considering logging activities and forest disturbance. Nevertheless, when dramatic $\mathrm{C}$ loss from deforestation for plantation establishment is taken into account, the $\mathrm{C}$ sequestration and storage capacity of the oil palm plantations has to be reevaluated as shown with the land cover change simulation (Fig. 6.4).

Compared to the relatively stable $\mathrm{C}$ and water fluxes of the young oil palm and rainforest, the mature oil palm's stronger seasonal variation in GPP, NEE and evapotranspiration in response to drought or high temperature is likely related to its very high fraction of resource allocation to fruit yield (>50\% of NPP, Chapter 2). The higher GPP and yield export demand higher amount of water because of the coupled relationship between photosynthesis, stomatal conductance and transpiration in the model (Collatz et al., 1991; Sellers et al., 1996). This could explain the sensitivity of $\mathrm{C}$ and water fluxes to seasonal climate variability that is majorly driven by precipitation in Jambi, Sumatra. The high sensitivity of yield to drought events is also evident in other crops especially under the warming climate (Li et al., 2009; Lobell and Field, 2007; Lobell et al., 2014).

The discrepancy between modeled and measured nocturnal NEE and sensible heat flux for the young oil palm plantation indicates either errors in eddy covariance measurements at night due to low turbulence and/or strong advection conditions or points to biases in model parameterization and surface input setup especially when the vegetation cover of young oil palm is low. Future simulations could consider the mixture of ground vegetation in young oil palm plantations or the common under canopy stem epiphytes in mature oil palm plantations to improve the simulated carbon, water and energy fluxes through time. This would require substantial technical adaptations of the model because the current CLM sub-grid configuration does not allow co-existence of a natural PFT (e.g. grass) and a crop PFT (e.g. oil palm) in a 
single soil column and does not consider competition among PFTs for solar radiation. Moreover, the rainforest and mature oil palm plantation have similar levels of evapotranspiration but significantly different sensible heat flux. This is likely due to the fact that the oil palm simulations have applied the revised canopy hydrological parameterization (higher canopy rainfall interception) from Chapter 4 but the rainforest retains the default parameters. A higher share of canopy evaporation in ET reduces sensible heat flux for oil palm (see Fig. 4.3, Chapter 4). The simulated ET and H for the rainforest with the default canopy interception (uniform among all PFTs) likely face the same over- and under-estimation issues shown in Chapter 4 (see more discussion in that chapter).

The overall energy balance which controls surface temperature shows different magnitudes, though similar seasonal patterns of TG, among the three land cover types. The young oil palm plantation has significantly warmer ground surface (top of soil) than the mature oil palm plantation and the rainforest according to both modeled and remote sensing data. This is likely the result of the competing biophysical effects of evapotranspiration and albedo. The young plantation has lower ET (Fig. 6.2c) but higher surface albedo (modeled or according to remote sensing data from Sabajo et al. (2016)) than the other two sites. The higher albedo could have made the young oil palm plantation cooler due to less net radiation available for heating up the surface. However, the reduced cooling effects associated with water fluxes due to the young palm's much lower ET could offset and outcompete the albedo effects (Li et al., 2015) and thus results in the relatively warmer TG compared to the forest and mature oil palm. The biophysical differences between the mature oil palm and rainforest in surface temperature, ET and albedo (mature oil palm > forest) are more difficult to interpret given their similar magnitudes but different seasonal dynamics. More data are needed to verify the pattern of modeled ET, especially of the rainforest which currently lacks field measurement for validation. More comparison of modeled and observed ET for oil palm is available in Chapter 4.

The transient simulations suggest that oil palm has the potential to rapidly restore a part of predeforestation total ecosystem $\mathrm{C}$ by its high $\mathrm{C}$ assimilation rate. After being transplanted onto a clear-cut site, the oil palm plantation accumulates aboveground vegetative $\mathrm{C}$ in a linearly increasing trend and starts to output reproductive $\mathrm{C}$ from 2-3 years old in an even higher increasing trend. However, most of the assimilated $\mathrm{C}$ is not retained on the site but instead exported as oil products (e.g. biofuels, cosmetics, and edible oil) which are likely consumed and reverted to $\mathrm{CO}_{2}$ very quickly. The turnover rates of plant tissues including both vegetative biomass and the fruits that are consumed decide the vegetation $\mathrm{C}$ residence time, which has been found to dominate the uncertainty in vegetation dynamics and terrestrial $\mathrm{C}$ balance and transition under changing climate (Friend et al., 2014). Field data from the same study area 
show that the $\mathrm{C}$ residence time of oil palm is as low as $10 \%$ of that of natural forests (Kotowska et al., 2015). The total increase in a plantation's on-site C stock thus only parallels that of its aboveground $\mathrm{C}$, which is only a quarter of the aboveground $\mathrm{C}$ stock of an old-growth rainforest. It is known that tropical forests are the hotspots of biodiversity (Myers et al., 2000) and contain higher biomass C stocks compared to most other ecosystems (Dixon et al., 1994). Conversion of tropical forests to oil palm plantations significantly reduces the $\mathrm{C}$ stocks and $\mathrm{C}$ sequestration potential of tropical lands as proved by field comparison (Kotowska et al., 2015) and as projected in the long-term transient simulation presented here. Management of oil palm plantation (e.g. leaf pruning) also restricts the return of leaf litter $\mathrm{C}$ to the soil and thus results in slight decline of soil organic matter $\mathrm{C}$ pool through time. Overall, the oil palm monoculture does offer high rate of short-term $\mathrm{C}$ sequestration and economic revenues but only limited ecosystem service in regard of long-term $\mathrm{C}$ storage. 


\section{CHAPTER 7}

Synopsis 
Rainforests have immense value for cycling water, storing carbon and nourishing biodiversity. However, these precious ecosystems are increasingly being converted to oil palm plantations at unprecedented rates in tropical countries, especially Indonesia. In order to investigate the climatic effects of such land use transformation and better understand the oil palm monoculture system across time and space, I developed the CLM-Palm model to simulate a new perennial crop PFT for oil palm in this study. CLM-Palm combines the ability of an agriculture model for simulating palm's growth and yield and the capacity of a land surface model for predicting the whole fate of carbon, water and energy cycles between plant, soil and atmosphere. Aspects of model development have covered the major areas of biogeophysical and biogeochemical processes in the CLM4.5 land surface modeling framework that can be summarized by Fig. 7.1. They include new phenology and allocation functions for growth and yield, a multilayer radiative transfer scheme for the energy cycle, revised canopy hydrology for the water cycle, and a dynamic nitrogen scheme for the biogeochemical cycle. Towards the main objective of this study, I applied all these developments in CLM-Palm to quantify the effects of tropical land use change, specifically rainforest to oil palm conversion, on $\mathrm{C}$, water and energy fluxes and $\mathrm{C}$ sequestration capacity of the tropical land.

\subsection{CLM-Palm is developed for simulating oil palm monoculture}

CLM-Palm introduces a sub-canopy phenological and physiological parameterization in which each phytomer has its own prognostic leaf growth and fruit yield capacity but with shared stem and root components. Phenology (lower-right circle, Fig. 7.1) and $\mathrm{C}$ and $\mathrm{N}$ allocation (upperright in Fig. 7.1) operate on the different phytomers in parallel but at unsynchronized steps, separated by a thermal period. An important phenological phase was identified for the oil palm - the storage growth period of bud and "spear" leaves which are photosynthetically inactive before expansion. Agricultural practices such as transplanting, fertilization, and leaf pruning are also represented in the model.

Fig. 7.1. The schematics of CLM-Palm including new functions (in color) for phenology, radiation, hydrology and biogeochemistry as well as the land use change capacity. The gray texts represent the existing functions and processes in the original CLM4.5 (see Fig. 1.1). 


\section{Energy}

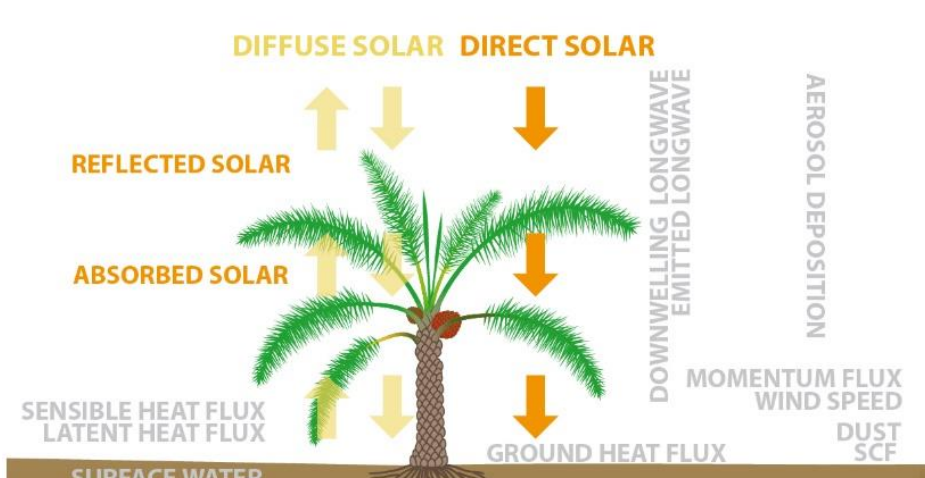

\section{Hydrology}

PRECIPITATION
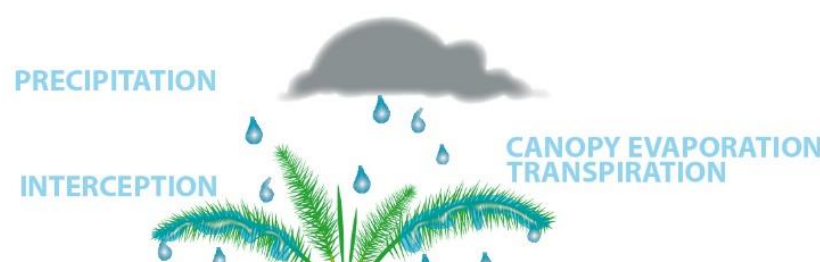

THROUGHFALL' (2) SUBLIMATION
SNOW MEIT

SOIL SATURATED FRACTION

SOIL (SAND, CLAY, ORGANIC)

\section{Biogeochemistry}

PHOTOSYNTHESIS
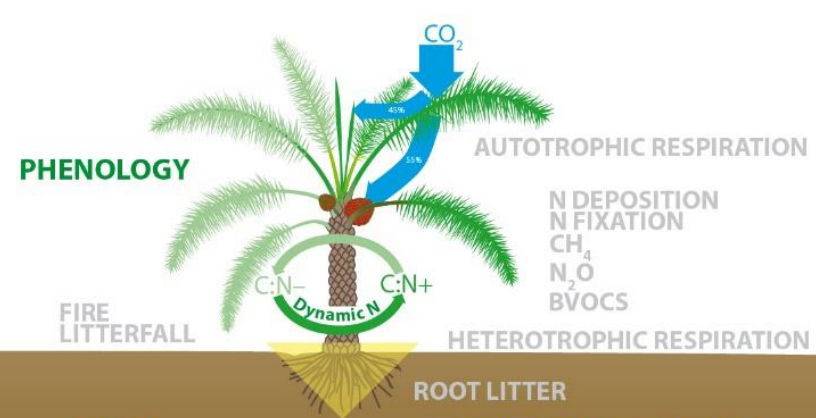

SOIL C/N
N MINERALIZATION

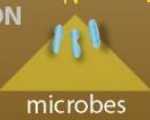

\section{CLM-Palm}

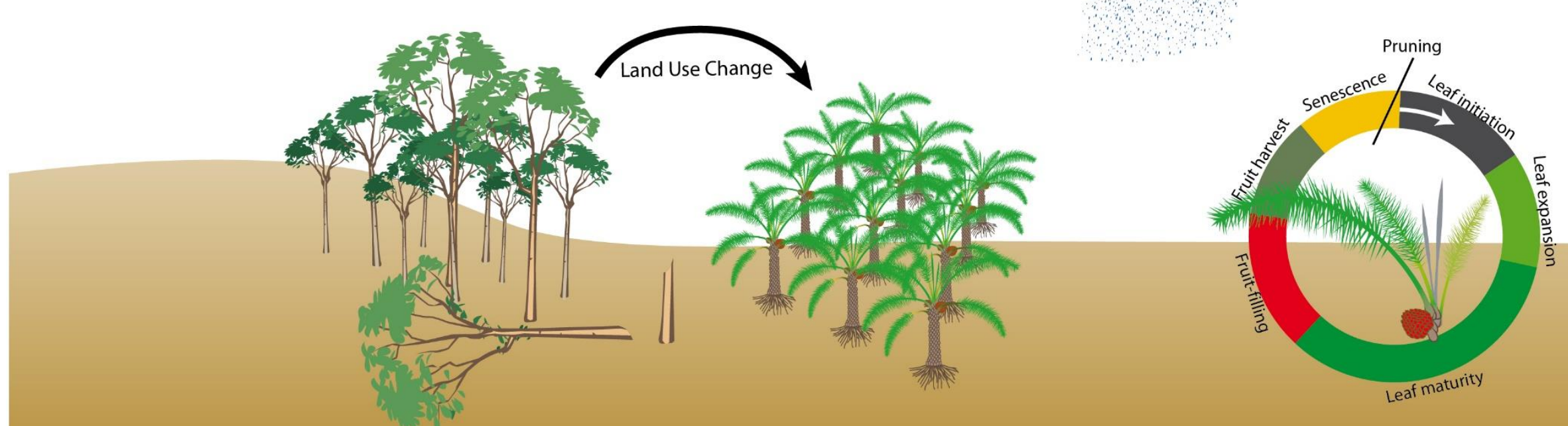


Parameters introduced for the oil palm especially on phenology and allocation were calibrated and validated with field measurements of LAI, yield and NPP from Sumatra, Indonesia. Simulated inter-annual dynamics of PFT-level and phytomer-level LAI were both within the range of field measurements. Cumulative yield was perfectly calibrated to 12 years harvest records by the dynamic physiological parameterization considering the age-dependent variation in leaf initiation and litter turnover rates and resource allocation patterns. Validation from eight independent oil palm sites shows the ability of the model to adequately predict the average leaf growth and fruit yield across sites and sufficiently represent the significant nitrogen- and agerelated site-to-site variability in NPP and yield. Results also indicate that seasonal dynamics of yield and remaining small-scale site-to-site variability of NPP are driven by processes not yet implemented in the model or reflected in the input data.

The new sub-canopy structure, phenology and allocation functions in CLM-Palm form the basis for further model developments and application in the Chapters 3-6. The palm PFT was tested on oil palm only but is meant of generic interest for other palm crops (e.g. coconut and date palms). CLM-Palm retains the full capacity of CLM4.5 for simulating other PFTs including forests and annual crops. It can also be coupled to atmospheric models or climate models within the CESM framework. Beside the small-scale application in simulating a rainforest to oil palm conversion showed in Chapter 6, CLM-Palm also allows exploring the effects of large-scale land-use change, from natural ecosystems to oil palm plantations, on carbon, water and energy cycles and regional climate.

\subsection{Energy fluxes}

Modeling the biogeophysical functions of oil palm is an important step to quantify the climatic effects of rainforest to oil palm conversion. The canopy traits of oil palm put forward the development of a dynamic multilayer scheme for radiative transfer and photosynthesis, so that these processes can be synchronized with the sub-canopy structure and phenology (upperleft, Fig. 7.1). The radiative and metabolic heterogeneity from canopy top to bottom is widely recognized. Discrete representation of radiation and photosynthesis-related processes for different canopy layers are thus a meaningful modeling approach.

In the initial version of CLM-Palm, the radiative absorption and photosynthesis calculations still followed the CLM4.5 default sunlit/shaded two-big-leaf canopy representation. In order to reconcile canopy and sub-canopy processes, some new features were implemented and evaluated in CLM-Palm including 1) non-uniform canopy stratification where each layer has dynamic LAI; 2) dynamic and specific leaf angle distribution from canopy top to bottom; 3) 
implementation of the classic Norman multilayer radiative transfer scheme which is applicable to both palm and forest PFTs in CLM.

These model adaptations exhibit comparable or slightly better performance than CLM4.5 default radiative transfer schemes in modeling absorbed photosynthetically active radiation, sensible/latent heat fluxes and $\mathrm{CO}_{2}$ flux, with reference to eddy covariance flux data from a mature oil palm plantation in Sumatra and an old-growth mountainous tropical rainforest in Central Sulawesi, Indonesia. Although the improvements on carbon and energy fluxes were not significant with the given set of inputs (e.g. LAI, climate forcing), the realistic representation of a multilayer canopy and sophisticated radiative transfer scheme at least allow enhanced adaptability and flexibility of the model to varying vegetation stand conditions and plant traits. More field data on the energy balance and radiation profile within the canopy are needed to evaluate the full capacity of the dynamic multilayer scheme.

The initial biases in simulating latent and sensible heat fluxes shown in Chapter 3 were not caused by the radiative transfer model but rather by the hydrodynamics and water use strategy of oil palm that are not represented in the model and by the deficiency of the default canopy water interception parameterization. The strength of CLM-Palm for simulating energy fluxes of sensible and latent heat is shown in Figure 4.3b after improving the canopy hydrology in Chapter 4.

\subsection{Water fluxes}

The water cycle and its interplay with plant canopy is a key determinant of energy flow and climate dynamics. The uniform canopy water interception parameterization used for all PFTs in CLM4.5 clearly lack the adaptability to varying stand structure, canopy traits and climatic conditions. When the default interception parameters were used for oil palm, the model showed biased energy partitioning between latent and sensible heat fluxes in Chapter 3. Comparison with evapotranspiration and sap flux data in Chapter 4 revealed significant errors in simulating water fluxes, e.g. overestimation of transpiration during both dry and rainy days and underestimation of canopy evaporation even during rainy days, which are responsible for the biased energy fluxes. The series of canopy hydrological experiments demonstrated that the oil palm should have substantially higher water interception efficiency and storage capacity (top middle, Fig. 7.1).

Increasing the interception parameters effectively reduced the model errors in canopy transpiration and evaporation which in turn improved the latent and sensible heat fluxes. 
Furthermore, a special treatment of oil palm's stem surface (e.g. rachis and axils) by differentiating its water storage capacity from that of leaves according to field observation further improved the accuracy of simulating water and energy fluxes.

Parameterizations of canopy water hydrology in CLM-Palm should be adapted to the regional climate condition (frequency, intensity and length of precipitation) and also to the canopy traits of oil palm. The two key parameters on interception efficiency and storage capacity can easily be set up as PFT-dependent parameters in CLM and even in other land surface models so as to enhance the accuracy in simulating the interconnected water, energy and carbon fluxes for diverse terrestrial vegetation types.

\subsection{Nitrogen cycle and fertilization effects}

Fisher et al. (2014) suggested that nitrogen cycling will remain at the top of the list of most prioritized processes expected in terrestrial biosphere model developments in the coming years (2014-2019). The implementation of the dynamic N scheme in CLM-Palm is meaningful for simulating C-N biogeochemistry in agricultural systems. Improved $\mathrm{N}$ cycle is essential for simulating crop growth and yield and can provide positive feedback to other biogeophysical and biogeochemical processes. The commonly used time-invariant $\mathrm{C}: \mathrm{N}$ ratios and the absolute coupling of $\mathrm{C}$ and $\mathrm{N}$ cycles regardless of soil $\mathrm{N}$ availability should be changed in the next generation land surface models. Although statistical approaches are available to downscale GPP when N supply is not sufficient at the plant level or when there is obvious vertical gradient in foliage $\mathrm{N}$ concentration, the dynamics of $\mathrm{N}$ at the plant level and its distribution among different canopy layers cannot be explicitly calculated with the fixed C:N stoichiometry.

Implementing the dynamic $\mathrm{N}$ scheme allows CLM-Palm to calculate $\mathrm{C}: \mathrm{N}$ ratios prognostically for all live tissues (upper-right, Fig. 7.1). Plant demand, competition (with soil microbes) and allocation of $\mathrm{N}$ are now connected with $\mathrm{C}$ cycles in a more relaxed relationship. The dynamic leaf $\mathrm{N}$ concentration allows synchronizing the coupled photosynthesis-stomatal conductance processes with soil $\mathrm{N}$ dynamics. In Chapter 5, the simulated long-term fertilization experiments with the oil palm plantation demonstrate some advantages and utility of the dynamic $\mathrm{N}$ scheme, including that: 1) it can simulate both $\mathrm{N}$ limitation and enhancement effects on LAI and yield, whereas the fixed C:N scheme is unable to capture $\mathrm{N}$ enhancement effects when fertilization surpasses the plant's minimum $\mathrm{N}$ demand; 2) testing different levels of fertilization with the new $\mathrm{N}$ scheme also allows calculating nitrogen use efficiency (NUE) and can guide agricultural practice of $\mathrm{N}$ fertilizer use. It reveals that the industrial oil palm plantation PTPN-VI was overly fertilized (456 $\mathrm{kg} \mathrm{N} \mathrm{ha}^{-1} \mathrm{yr}^{-1}$ ). Applying much lower $\mathrm{N}$ fertilizer (e.g. $100 \mathrm{~kg} \mathrm{~N} \mathrm{ha}^{-1} \mathrm{yr}^{-1}$ ) could 
have achieved the same high level of yield and much higher NUE. More investigations on the direct and indirect responses of photosynthesis, evapotranspiration and other biogeophysical properties to soil fertility and leaf $\mathrm{N}$ dynamics are needed to fully evaluate the new $\mathrm{N}$ scheme.

\subsection{Carbon fluxes}

Development of palm-specific phenology and allocation functions that operate on each phytomer (Chapter 2) provides the basis for accurately simulating the $\mathrm{C}$ dynamics in oil palm plantations. Improvements on energy (Chapter 3), water (Chapter 4) and nitrogen (Chapter 5) cycles further enhance the accuracy. Chapters 3 and 6 show the strength of CLM-Palm in simulating the diurnal and annual $\mathrm{C}$ fluxes compared with eddy covariance data. The good alignment between simulated and observed GPP and NEE for both young and mature oil palm plantations is consistent with the validated precision in simulating growth and yield through age in Chapter 2. This ensures reliable prediction of $\mathrm{C}$ sequestration potential and $\mathrm{C}$ stocks of oil palm plantation at different cultivation stages.

\subsection{Land use change effects}

Quantifying the effects of tropical land use change driven by oil palm expansion on landatmosphere energy, water and carbon fluxes is one of the major objectives of this study. Towards this aim, a series of new land model capacity and parameterizations have been developed in CLM-Palm. Employing these developments for the new oil palm PFT and the existing functions for the broadleaf evergreen tropical forest PFT, a 50-year simulation was conducted to model the land use transition, from rainforest to oil palm plantation in Jambi, Sumatra. It reveals that the oil palm plantation has high productivity measured by GPP and NEE, but has less biomass $\mathrm{C}$ retained on the site compared to the rainforest due to fruit harvest. Long-term oil palm cultivation will not restore the $\mathrm{C}$ storage capacity of the pre-clear-cut forested site and will decrease the soil C stock slowly and gradually. Comparisons of young and mature oil palm plantation with natural rainforest show that managed and unmanaged vegetation types have distinct biogeophysical effects on land surface carbon, water and energy fluxes at both daily and seasonally time scales, likely due to their different resource allocation patterns and water use strategies.

In sum, land use transformation from rainforests to oil palm plantations reduces the $\mathrm{C}$ storage capacity of tropical lands. The ecological and economical values of oil palm monoculture must be judged in a holistic view, considering the large amount of palm oil products including 
biofuels and social benefits provided to mankind, the loss of biodiversity, soil degradation, the biogeophysical functions of the monoculture system, and so on.

\subsection{Future perspectives}

The potential of applying the new model CLM-Palm to quantify the effects of oil palm-driven land use change has not been fully exploited. So far, it has only been used to simulate the growth and yield of oil palm and its associated carbon, water and energy fluxes at the site scale to compare with observation. The application to simulate land cover change effects was also limited to the plot scale to exemplify the sequential changes happening in one location. There remain key questions to examine, for example:

1) How sensitive is the current carbon sequestration capacity of tropical lands to further oil palm expansions over Southeast Asia or around the world in the current trend?

2) What are the consequences of future oil palm expansions if they happens over different land cover types and at different paces?

3) What are the direct feedbacks and interaction effects of oil palm expansion on regional climate considering the biogeophysical functions such as evapotranspiration, sensible and latent heat fluxes and surface albedo, as well as the biogeochemical functions such as GHG emission and $\mathrm{N}$ cycle?

4) And finally, it is interesting to find the balance between reducing carbon emission and ensuring crop yields in a context of accelerating growth in both economy and population around the developing countries.

To take the advantage of all the new model developments in CLM-Palm, further upscaling studies and application of the model at regional and even global scales are necessary to address the urgent land use change issues in the tropical countries. Both historical simulations using satellite-derived land cover data and future simulations with projected land use change and climate change in different scenarios should be conducted to analyze the effects of oil palm or other agriculture driven land use and land cover changes on carbon, water and energy cycles and climate dynamics, as well as other ecosystem services and socioeconomic functions. 


\section{References}

Allen, K., Corre, M.D., Tjoa, A., Veldkamp, E., 2015. Soil Nitrogen-Cycling Responses to Conversion of Lowland Forests to Oil Palm and Rubber Plantations in Sumatra, Indonesia. PLOS ONE 10, e0133325. doi:10.1371/journal.pone.0133325

Alton, P.B., 2011. How useful are plant functional types in global simulations of the carbon, water, and energy cycles? J. Geophys. Res. 116. doi:10.1029/2010JG001430

Alton, P., Ellis, R., Los, S., North, P., 2007. Improved global simulations of gross primary product based on a separate and explicit treatment of diffuse and direct sunlight. J. Geophys. Res. Atmospheres 112, D07203.

Baldocchi, D., 1997. Measuring and modelling carbon dioxide and water vapour exchange over a temperate broad-leaved forest during the 1995 summer drought. Plant Cell Environ. $20,1108-1122$.

Baldocchi, D.D., 2003. Assessing the eddy covariance technique for evaluating carbon dioxide exchange rates of ecosystems: past, present and future. Glob. Change Biol. 9, 479-492.

Baldocchi, D.D., Vogel, C.A., Hall, B., 1997. Seasonal variation of carbon dioxide exchange rates above and below a boreal jack pine forest. Agric. For. Meteorol. 83, 147-170.

Baldocchi, D.D., Wilson, K.B., Gu, L., 2002. How the environment, canopy structure and canopy physiological functioning influence carbon, water and energy fluxes of a temperate broad-leaved deciduous forest - an assessment with the biophysical model CANOAK. Tree Physiol. 22, 1065-1077.

Baldocchi, D., Harley, P., 1995. Scaling carbon dioxide and water vapour exchange from leaf to canopy in a deciduous forest. II. Model testing and application. Plant Cell Environ. $18,1157-1173$.

Ball, J.T., Woodrow, I.E., Berry, J.A., 1987. A model predicting stomatal conductance and its contribution to the control of photosynthesis under different environmental conditions, in: Progress in Photosynthesis Research. Springer, pp. 221-224.

Bonan, G.B., 2008. Forests and Climate Change: Forcings, Feedbacks, and the Climate Benefits of Forests. Science 320, 1444-1449. doi:10.1126/science.1155121

Bonan, G.B., Lawrence, P.J., Oleson, K.W., Levis, S., Jung, M., Reichstein, M., Lawrence, D.M., Swenson, S.C., 2011. Improving canopy processes in the Community Land Model version 4 (CLM4) using global flux fields empirically inferred from FLUXNET data. J Geophys Res 116, G02014.

Bonan, G.B., Levis, S., Kergoat, L., Oleson, K.W., 2002. Landscapes as patches of plant functional types: An integrating concept for climate and ecosystem models. Glob. Biogeochem. Cycles 16. doi:10.1029/2000GB001360

Bonan, G.B., Oleson, K.W., Fisher, R.A., Lasslop, G., Reichstein, M., 2012. Reconciling leaf physiological traits and canopy flux data: Use of the TRY and FLUXNET databases in the Community Land Model version 4: COMMUNITY LAND MODEL CANOPY SCALING. J. Geophys. Res. Biogeosciences 117. doi:10.1029/2011JG001913 
Bonan, G.B., Williams, M., Fisher, R.A., Oleson, K.W., 2014. Modeling stomatal conductance in the earth system: linking leaf water-use efficiency and water transport along the soilplant-atmosphere continuum. Geosci. Model Dev. 7, 2193-2222. doi:10.5194/gmd-72193-2014

Bondeau, A., Smith, P.C., Zaehle, S., Schaphoff, S., Lucht, W., Cramer, W., Gerten, D., LOTZE-CAMPEN, H., Müller, C., Reichstein, M., others, 2007. Modelling the role of agriculture for the 20th century global terrestrial carbon balance. Glob. Change Biol. $13,679-706$.

Brentrup, F., Pallière, C., 2010. Nitrogen use efficiency as an agro-environmental indicator, in: Proceedings of the OECD Workshop on Agrienvironmental Indicators, March. Leysin, Switzerland, pp. 23-26.

Breure, C., 1988. The effect of different planting densities on yield trends in oil palm. Exp. Agric. 24, 37-52.

Brumme, R., Beese, F., 1992. Effects of liming and nitrogen fertilization on emissions of $\mathrm{CO}_{2}$ and N2O from a temperate forest. J. Geophys. Res. Atmospheres 97, 12851-12858.

Calder, I.R., 1996. Dependence of rainfall interception on drop size: 1. Development of the two-layer stochastic model. J. Hydrol. 185, 363-378. doi:10.1016/00221694(95)02998-2

Carlson, K.M., Curran, L.M., Asner, G.P., Pittman, A.M., Trigg, S.N., Marion Adeney, J., 2012. Carbon emissions from forest conversion by Kalimantan oil palm plantations. Nat. Clim. Change 3, 283-287. doi:10.1038/nclimate1702

Carrasco, L., Larrosa, C., Milner-Gulland, E., Edwards, D., others, 2014. A double-edged sword for tropical forests. Science 346, 38-40.

Casson, A., 2000. The hesitant boom: Indonesia's oil palm sub-sector in an era of economic crisis and political change. CIFOR, Bogor, Indonesia.

Cerbu, G.A., Swallow, B.M., Thompson, D.Y., 2011. Locating REDD: A global survey and analysis of REDD readiness and demonstration activities. Environ. Sci. Policy 14, 168180.

Chapin III, F.S., Matson, P.A., Vitousek, P., 2011. Principles of terrestrial ecosystem ecology. Springer Science \& Business Media.

Chapman, G., Gray, H., 1949. Leaf analysis and the nutrition of the oil palm (Elaeis guineensis Jacq.). Ann. Bot. 13, 415-433.

Chazdon, R.L., 1986. Light variation and carbon gain in rain forest understorey palms. J. Ecol. 995-1012.

Clearwater, M.J., Meinzer, F.C., Andrade, J.L., Goldstein, G., Holbrook, N.M., 1999. Potential errors in measurement of nonuniform sap flow using heat dissipation probes. Tree Physiol. 19, 681-687. 
Collatz, G.J., Ball, J.T., Grivet, C., Berry, J.A., 1991. Physiological and environmental regulation of stomatal conductance, photosynthesis and transpiration: a model that includes a laminar boundary layer. Agric. For. Meteorol. 54, 107-136.

Combres, J.-C., Pallas, B., Rouan, L., Mialet-Serra, I., Caliman, J.-P., Braconnier, S., Soulié, J.-C., Dingkuhn, M., 2013. Simulation of inflorescence dynamics in oil palm and estimation of environment-sensitive phenological phases: a model based analysis. Funct. Plant Biol. 40, 263-279.

Corley, R., 2009. How much palm oil do we need? Environ. Sci. Policy 12, 134-139.

Corley, R.H.V., 1976. Photosynthesis and productivity. In: Oil palm research, ed. R. H. V. Corley, J. J. Hardon and B. J. Wood. Elsevier Scient. Pub., Amsterdam.

Corley, R.H.V., Tinker, P.B., 2016. The oil palm, Fifth edition. ed. John Wiley \& Sons, Hoboken, NJ.

Dai, Y., Dickinson, R.E., Wang, Y.-P., 2004. A two-big-leaf model for canopy temperature, photosynthesis, and stomatal conductance. J. Clim. 17, 2281-2299.

Davison, P.S., 2004. Estimating the direct radiative forcing due to haze from the 1997 forest fires in Indonesia. J. Geophys. Res. 109. doi:10.1029/2003JD004264

Dee, D., Uppala, S., Simmons, A., Berrisford, P., Poli, P., Kobayashi, S., Andrae, U., Balmaseda, M., Balsamo, G., Bauer, P., others, 2011. The ERA-Interim reanalysis: Configuration and performance of the data assimilation system. Q. J. R. Meteorol. Soc. 137, 553-597.

De Kauwe, M.G., Medlyn, B.E., Zaehle, S., Walker, A.P., Dietze, M.C., Hickler, T., Jain, A.K., Luo, Y., Parton, W.J., Prentice, I.C., Smith, B., Thornton, P.E., Wang, S., Wang, Y.P., Wårlind, D., Weng, E., Crous, K.Y., Ellsworth, D.S., Hanson, P.J., Seok Kim, H.-, Warren, J.M., Oren, R., Norby, R.J., 2013. Forest water use and water use efficiency at elevated $\mathrm{CO}_{2}$ : a model-data intercomparison at two contrasting temperate forest FACE sites. Glob. Change Biol. 19, 1759-1779. doi:10.1111/gcb.12164

De Vries, W., Posch, M., 2011. Modelling the impact of nitrogen deposition, climate change and nutrient limitations on tree carbon sequestration in Europe for the period 19002050. Environ. Pollut. 159, 2289-2299.

de Wit, C., 1965. Photosynthesis of leaf canopies. Cent. Agric. Publ. Doc. Wageningen.

de Wit, C. de, 1992. Resource use efficiency in agriculture. Agric. Syst. 40, 125-151.

Dickinson, R.E., 1983. Land surface processes and climate-surface albedos and energy balance. Adv Geophys 25, 305-353.

Dickinson, R.E., Kennedy, P., Henderson-Sellers, A., 1993. Biosphere-atmosphere transfer scheme (BATS) version 1e as coupled to the NCAR community climate model. National Center for Atmospheric Research, Climate and Global Dynamics Division.

Dirmeyer, P.A., Gao, X., Zhao, M., Guo, Z., Oki, T., Hanasaki, N., others, 2005. The second Global Soil Wetness Project (GSWP-2): Multi-model analysis and implications for our perception of the land surface. Center for Ocean-Land-Atmosphere Studies. 
Di Vittorio, A.V., Chini, L.P., Bond-Lamberty, B., Mao, J., Shi, X., Truesdale, J., Craig, A., Calvin, K., Jones, A., Collins, W.D., Edmonds, J., Hurtt, G.C., Thornton, P., Thomson, A., 2014. From land use to land cover: restoring the afforestation signal in a coupled integrated assessment-earth system model and the implications for CMIP5 RCP simulations. Biogeosciences 11, 6435-6450. doi:10.5194/bg-11-6435-2014

Dixon, R.K., Solomon, A., Brown, S., Houghton, R., Trexier, M., Wisniewski, J., 1994. Carbon pools and flux of global forest ecosystems. Science 263, 185-190.

Dowdell, R.J., Burford, J.R., Crees, R., 1979. Losses of nitrous oxide dissolved in drainage water from agricultural land. Nature 278, 342-343. doi:10.1038/278342a0

Drewniak, B., Song, J., Prell, J., Kotamarthi, V.R., Jacob, R., 2013. Modeling agriculture in the Community Land Model. Geosci. Model Dev. 6, 495-515. doi:10.5194/gmd-6-4952013

Du, E., Vittorio, A.D., Collins, W.D., 2016. Evaluation of hydrologic components of community land model 4 and bias identification. Int. J. Appl. Earth Obs. Geoinformation 48, 5-16. doi:10.1016/j.jag.2015.03.013

Dufrêne, E., Dubos, B., Rey, H., Quencez, P., Saugier, B., 1992. Changes in evapotranspiration from an oil palm stand (Elaeis guineensis Jacq.) exposed to seasonal soil water deficits. Acta Oecologica (1990) 13, 299-314.

Dykes, A., 1997. Rainfall interception from a lowland tropical rainforest in Brunei. J. Hydrol. 200, 260-279.

Euler, M., 2015. Oil palm expansion among Indonesian smallholders-adoption, welfare implications and agronomic challenges. Niedersächsische Staats-und Universitätsbibliothek Göttingen.

Fairhurst, T.H., 1998. The oil palm - leaf sampling. Potash and Phosphate Institute, Singapore.

Fan, Y., Roupsard, O., Bernoux, M., Le Maire, G., Panferov, O., Kotowska, M.M., Knohl, A., 2015. A sub-canopy structure for simulating oil palm in the Community Land Model (CLM-Palm): phenology, allocation and yield. Geosci. Model Dev. 8, 3785-3800. doi:10.5194/gmd-8-3785-2015

FAO, 2015. FAOSTAT [WWW Document]. FAOSTAT. URL http://faostat3.fao.org/home/E (accessed 10.31.15).

Fargione, J., Hill, J., Tilman, D., Polasky, S., Hawthorne, P., 2008. Land clearing and the biofuel carbon debt. Science 319, 1235-1238.

Farquhar, G., von Caemmerer, S. von, Berry, J., 1980. A biochemical model of photosynthetic $\mathrm{CO}_{2}$ assimilation in leaves of C3 species. Planta 149, 78-90.

Fernández-Martínez, M., Vicca, S., Janssens, I.A., Sardans, J., Luyssaert, S., Campioli, M., Chapin III, F.S., Ciais, P., Malhi, Y., Obersteiner, M., Papale, D., Piao, S.L., Reichstein, M., Rodà, F., Peñuelas, J., 2014. Nutrient availability as the key regulator of global forest carbon balance. Nat. Clim. Change 4, 471-476. doi:10.1038/nclimate2177 
Finzi, A.C., Norby, R.J., Calfapietra, C., Gallet-Budynek, A., Gielen, B., Holmes, W.E., Hoosbeek, M.R., Iversen, C.M., Jackson, R.B., Kubiske, M.E., Ledford, J., Liberloo, M., Oren, R., Polle, A., Pritchard, S., Zak, D.R., Schlesinger, W.H., Ceulemans, R., 2007. Increases in nitrogen uptake rather than nitrogen-use efficiency support higher rates of temperate forest productivity under elevated $\mathrm{CO}_{2}$. Proc. Natl. Acad. Sci. 104, 14014-14019. doi:10.1073/pnas.0706518104

Fisher, J.B., Huntzinger, D.N., Schwalm, C.R., Sitch, S., 2014. Modeling the Terrestrial Biosphere. Annu. Rev. Environ. Resour. 39, 91-123. doi:10.1146/annurev-environ012913-093456

Fitzherbert, E., Struebig, M., Morel, A., Danielsen, F., Bruhl, C., Donald, P., Phalan, B., 2008. How will oil palm expansion affect biodiversity? Trends Ecol. Evol. 23, 538-545. doi:10.1016/j.tree.2008.06.012

Friend, A.D., Lucht, W., Rademacher, T.T., Keribin, R., Betts, R., Cadule, P., Ciais, P., Clark, D.B., Dankers, R., Falloon, P.D., Ito, A., Kahana, R., Kleidon, A., Lomas, M.R., Nishina, K., Ostberg, S., Pavlick, R., Peylin, P., Schaphoff, S., Vuichard, N., Warszawski, L., Wiltshire, A., Woodward, F.I., 2014. Carbon residence time dominates uncertainty in terrestrial vegetation responses to future climate and atmospheric CO 2. Proc. Natl. Acad. Sci. 111, 3280-3285. doi:10.1073/pnas.1222477110

Galloway, J.N., Dentener, F.J., Capone, D.G., Boyer, E.W., Howarth, R.W., Seitzinger, S.P., Asner, G.P., Cleveland, C., Green, P., Holland, E., others, 2004. Nitrogen cycles: past, present, and future. Biogeochemistry 70, 153-226.

Gellert, P.K., 2005. The shifting natures of "development": Growth, crisis, and recovery in Indonesia's forests. World Dev. 33, 1345-1364.

Gent, P.R., Danabasoglu, G., Donner, L.J., Holland, M.M., Hunke, E.C., Jayne, S.R., Lawrence, D.M., Neale, R.B., Rasch, P.J., Vertenstein, M., Worley, P.H., Yang, Z.-L., Zhang, M., 2011. The Community Climate System Model Version 4. J. Clim. 24, 4973-4991. doi:10.1175/2011JCLI4083.1

Georgescu, M., Lobell, D.B., Field, C.B., 2011. Direct climate effects of perennial bioenergy crops in the United States. Proc. Natl. Acad. Sci. 108, 4307-4312.

Gerber, S., Hedin, L.O., Oppenheimer, M., Pacala, S.W., Shevliakova, E., 2010. Nitrogen cycling and feedbacks in a global dynamic land model: MODELING THE LAND NITROGEN CYCLE. Glob. Biogeochem. Cycles 24. doi:10.1029/2008GB003336

Gervois, S., de Noblet-Ducoudré, N., Viovy, N., Ciais, P., Brisson, N., Seguin, B., Perrier, A., 2004. Including croplands in a global biosphere model: methodology and evaluation at specific sites. Earth Interact. 8, 1-25.

Ghazoul, J., 2015. Forests: A Very Short Introduction. Oxford University Press, USA.

Gibbs, H.K., Johnston, M., Foley, J.A., Holloway, T., Monfreda, C., Ramankutty, N., Zaks, D., 2008. Carbon payback times for crop-based biofuel expansion in the tropics: the effects of changing yield and technology. Environ. Res. Lett. 3, 034001. doi:10.1088/17489326/3/3/034001 
Gibbs, H.K., Ruesch, A.S., Achard, F., Clayton, M.K., Holmgren, P., Ramankutty, N., Foley, J.A., 2010. Tropical forests were the primary sources of new agricultural land in the 1980s and 1990s. Proc. Natl. Acad. Sci. 107, 16732-16737. doi:10.1073/pnas.0910275107

Goel, N.S., 1988. Models of vegetation canopy reflectance and their use in estimation of biophysical parameters from reflectance data. Remote Sens. Rev. 4, 1-212.

Goel, N.S., Strebel, D.E., 1984. Simple beta distribution representation of leaf orientation in vegetation canopies. Agron. J. 76, 800-802.

Goh, K., 2000. Climatic requirements of the oil palm for high yields. Manag. Oil Palm High Yields Agron. Princ. 1-17.

Goudriaan, J., 1977. Crop micrometeorology: a simulation study. Pudoc, Center for Agricultural Publishing and Documentation.

Gough, B., 2009. GNU scientific library reference manual. Network Theory Ltd.

Goulding, K., Poulton, P., Webster, C., Howe, M., 2000. Nitrate leaching from the Broadbalk Wheat Experiment, Rothamsted, UK, as influenced by fertilizer and manure inputs and the weather. Soil Use Manag. 16, 244-250.

Granier, A., 1987. Evaluation of transpiration in a Douglas-fir stand by means of sap flow measurements. Tree Physiol. 3, 309-320.

Gruber, N., Galloway, J.N., 2008. An Earth-system perspective of the global nitrogen cycle. Nature 451, 293-296.

Guillaume, T., Damris, M., Kuzyakov, Y., 2015. Losses of soil carbon by converting tropical forest to plantations: erosion and decomposition estimated by $\delta^{13} \mathrm{C}$. Glob. Change Biol. 21, 3548-3560. doi:10.1111/gcb.12907

Gu, L., 2003. Response of a Deciduous Forest to the Mount Pinatubo Eruption: Enhanced Photosynthesis. Science 299, 2035-2038. doi:10.1126/science.1078366

Gunarso, P., Hartoyo, M., Agus, F., Killeen, T., 2013. Oil palm and land use change in Indonesia, Malaysia and Papua New Guinea. Rep. Tech. Panels 2nd Greenh. Gas Work. Group Roundtable Sustain. Palm Oil RSPO 29-64.

Hallé, F., Oldeman, R.A.A., Tomlinson, P.B., Hallé-Oldeman, 1978. Tropical trees and forests: an architectural analysis. Springer, Berlin.

Henson, I.E., Harun, M.H., 2005. The influence of climatic conditions on gas and energy exchanges above a young oil palm stand in north Kedah, Malaysia. J. Oil Palm Res. 17,73 .

Herwitz, S.R., 1985. Interception storage capacities of tropical rainforest canopy trees. J. Hydrol. 77, 237-252.

Hijmans, R.J., Cameron, S.E., Parra, J.L., Jones, P.G., Jarvis, A., 2005. Very high resolution interpolated climate surfaces for global land areas. Int. J. Climatol. 25, 1965-1978. 
Hoffmann, M., Vera, A.C., Van Wijk, M., Giller, K., Oberthür, T., Donough, C., Whitbread, A., 2014. Simulating potential growth and yield of oil palm (Elaeis guineensis) with PALMSIM: Model description, evaluation and application. Agric. Syst. 131, 1-10.

Hormaza, P., Fuquen, E.M., Romero, H.M., 2012. Phenology of the oil palm interspecific hybrid Elaeis oleifera×Elaeis guineensis. Sci. Agric. 69, 275-280.

Hungate, B.A., 2003. Nitrogen and Climate Change. Science 302, 1512-1513. doi:10.1126/science. 1091390

Huth, N.I., Banabas, M., Nelson, P.N., Webb, M., 2014. Development of an oil palm cropping systems model: Lessons learned and future directions. Environ. Model. Softw. 62, 411419. doi:10.1016/j.envsoft.2014.06.021

Janott, M., Gayler, S., Gessler, A., Javaux, M., Klier, C., Priesack, E., 2011. A one-dimensional model of water flow in soil-plant systems based on plant architecture. Plant Soil 341, 233-256.

Jasechko, S., Sharp, Z.D., Gibson, J.J., Birks, S.J., Yi, Y., Fawcett, P.J., 2013. Terrestrial water fluxes dominated by transpiration. Nature 496, 347-350. doi:10.1038/nature11983

Jenkins, J.P., Richardson, A.D., Braswell, B.H., Ollinger, S.V., Hollinger, D.Y., Smith, M.-L., 2007. Refining light-use efficiency calculations for a deciduous forest canopy using simultaneous tower-based carbon flux and radiometric measurements. Agric. For. Meteorol. 143, 64-79. doi:10.1016/j.agrformet.2006.11.008

Jin, J., Miller, N.L., 2011. Regional simulations to quantify land use change and irrigation impacts on hydroclimate in the California Central Valley. Theor. Appl. Climatol. 104, $429-442$.

Jones, C., Robertson, E., Arora, V., Friedlingstein, P., Shevliakova, E., Bopp, L., Brovkin, V., Hajima, T., Kato, E., Kawamiya, M., others, 2013. Twenty-first-century compatible $\mathrm{CO}_{2}$ emissions and airborne fraction simulated by CMIP5 earth system models under four representative concentration pathways. J. Clim. 26, 4398-4413.

Jordan, C.F., Heuveldop, J., 1981. Water budget of an Amazonian rain forest. Acta Amaz.

Knohl, A., Baldocchi, D.D., 2008. Effects of diffuse radiation on canopy gas exchange processes in a forest ecosystem. J. Geophys. Res. Biogeosciences 113. doi:10.1029/2007JG000663

Koh, L.P., Ghazoul, J., 2010. Spatially explicit scenario analysis for reconciling agricultural expansion, forest protection, and carbon conservation in Indonesia. Proc. Natl. Acad. Sci. 107, 11140.

Koh, L.P., Miettinen, J., Liew, S.C., Ghazoul, J., 2011. Remotely sensed evidence of tropical peatland conversion to oil palm. Proc. Natl. Acad. Sci. 108, 5127-5132. doi:10.1073/pnas.1018776108

Kotowska, M.M., Leuschner, C., Triadiati, T., Hertel, D., 2016. Conversion of tropical lowland forest reduces nutrient return through litterfall, and alters nutrient use efficiency and seasonality of net primary production. Oecologia 180, 601-618. 
Kotowska, M.M., Leuschner, C., Triadiati, T., Meriem, S., Hertel, D., 2015. Quantifying aboveand belowground biomass carbon loss with forest conversion in tropical lowlands of Sumatra (Indonesia). Glob. Change Biol. 21, 3620-3634. doi:10.1111/gcb.12979

Koven, C.D., Riley, W.J., Subin, Z.M., Tang, J.Y., Torn, M.S., Collins, W.D., Bonan, G.B., Lawrence, D.M., Swenson, S.C., 2013. The effect of vertically resolved soil biogeochemistry and alternate soil $\mathrm{C}$ and $\mathrm{N}$ models on $\mathrm{C}$ dynamics of CLM4. Biogeosciences 10, 7109-7131. doi:10.5194/bg-10-7109-2013

Krinner, G., Viovy, N., de Noblet-Ducoudré, N., Ogée, J., Polcher, J., Friedlingstein, P., Ciais, P., Sitch, S., Prentice, I.C., 2005. A dynamic global vegetation model for studies of the coupled atmosphere-biosphere system. Glob. Biogeochem. Cycles 19.

Langmann, B., 2007. A model study of smoke-haze influence on clouds and warm precipitation formation in Indonesia 1997/1998. Atmos. Environ. 41, 6838-6852. doi:10.1016/j.atmosenv.2007.04.050

Laurance, W.F., 1999. Reflections on the tropical deforestation crisis. Biol. Conserv. 91, 109117.

Lawrence, D.M., Oleson, K.W., Flanner, M.G., Thornton, P.E., Swenson, S.C., Lawrence, P.J., Zeng, X., Yang, Z.L., Levis, S., Sakaguchi, K., others, 2011. Parameterization improvements and functional and structural advances in version 4 of the Community Land Model. J. Adv. Model. Earth Syst. 3, 03001.

Lawrence, D.M., Thornton, P.E., Oleson, K.W., Bonan, G.B., 2007. The Partitioning of Evapotranspiration into Transpiration, Soil Evaporation, and Canopy Evaporation in a GCM: Impacts on Land-Atmosphere Interaction. J. Hydrometeorol. 8, 862-880. doi:10.1175/JHM596.1

Lee, J.S.H., Garcia-ulloa, J., Koh, L.P., 2012. Biofuel Expansion in Southeast Asia: Biodiversity Impacts and Policy Guidelines, in: Gasparatos, A., Stromberg, P. (Eds.), Socioeconomic and Environmental Impacts of Biofuels. Cambridge University Press, Cambridge, pp. 191-204.

Legros, S., Mialet-Serra, I., Caliman, J.-P., Siregar, F.A., Clement-Vidal, A., Dingkuhn, M., 2009. Phenology and growth adjustments of oil palm (Elaeis guineensis) to photoperiod and climate variability. Ann. Bot. 104, 1171-1182. doi:10.1093/aob/mcp214

Lemeur, R., 1973. A method for simulating the direct solar radiation regime in sunflower, Jerusalem artichoke, corn and soybean canopies using actual stand structure data. Agric. Meteorol. 12, 229-247.

Levis, S., Bonan, G.B., Kluzek, E., Thornton, P.E., Jones, A., Sacks, W.J., Kucharik, C.J., 2012. Interactive crop management in the Community Earth System Model (CESM1): seasonal influences on land-atmosphere fluxes. J. Clim. 25, 4839-4859. doi:10.1175/JCLI-D-11-00446.1

Levis, S., Bonan, G., Vertenstein, M., Oleson, K., 2004. The Community Land Model's dynamic global vegetation model (CLM-DGVM): Technical description and user's guide. NCAR Tech Note TN-459 IA 50. 
Li, Y., Ye, W., Wang, M., Yan, X., 2009. Climate change and drought: a risk assessment of crop-yield impacts. Clim. Res. 39, 31-46. doi:10.3354/cr00797

Li, Y., Zhao, M., Motesharrei, S., Mu, Q., Kalnay, E., Li, S., 2015. Local cooling and warming effects of forests based on satellite observations. Nat. Commun. 6, 6603. doi:10.1038/ncomms 7603

Lloyd, C., Gash, J., Shuttleworth, W.J., others, 1988. The measurement and modelling of rainfall interception by Amazonian rain forest. Agric. For. Meteorol. 43, 277-294.

Lloyd, J., Patino, S., Paiva, R., Nardoto, G., Quesada, C., Santos, A., Baker, T., Brand, W.A., Hilke, I., Gielmann, H., others, 2010. Optimisation of photosynthetic carbon gain and within-canopy gradients of associated foliar traits for Amazon forest trees. Biogeosciences 7, 1833-1859.

Lobell, D.B., Field, C.B., 2007. Global scale climate-crop yield relationships and the impacts of recent warming. Environ. Res. Lett. 2, 014002.

Lobell, D.B., Roberts, M.J., Schlenker, W., Braun, N., Little, B.B., Rejesus, R.M., Hammer, G.L., 2014. Greater sensitivity to drought accompanies maize yield increase in the US Midwest. Science 344, 516-519.

Lockwood, J., Sellers, P., 1982. Comparisons of interception loss from tropical and temperate vegetation canopies. J. Appl. Meteorol. 21, 1405-1412.

Luo, Y., Su, B., Currie, W.S., Dukes, J.S., Finzi, A., Hartwig, U., Hungate, B., Mc MURTRIE, R.E., Oren, R., Parton, W.J., Pataki, D.E., Shaw, M.R., Zak, D.R., Field, C.B., 2004. Progressive Nitrogen Limitation of Ecosystem Responses to Rising Atmospheric Carbon Dioxide. BioScience 54, 731.

Luyssaert, S., Schulze, E.-D., Börner, A., Knohl, A., Hessenmöller, D., Law, B.E., Ciais, P., Grace, J., 2008. Old-growth forests as global carbon sinks. Nature 455, 213-215.

Matheny, A.M., Bohrer, G., Stoy, P.C., Baker, I.T., Black, A.T., Desai, A.R., Dietze, M.C., Gough, C.M., Ivanov, V.Y., Jassal, R.S., Novick, K.A., Schäfer, K.V.R., Verbeeck, H., 2014. Characterizing the diurnal patterns of errors in the prediction of evapotranspiration by several land-surface models: An NACP analysis: Error patterns in modeled transpiration. J. Geophys. Res. Biogeosciences 119, 1458-1473. doi:10.1002/2014JG002623

Meador, W., Weaver, W., 1980. Two-stream approximations to radiative transfer in planetary atmospheres: A unified description of existing methods and a new improvement. J. Atmospheric Sci. 37, 630-643.

Meijide, A., Röll, A., Fan, Y., Herbst, M., Niu, F., Tiedemann, F., June, T., Rauf, A., Hölscher, D., Knohl, A., 2016. Controls of water and energy fluxes in oil palm plantations: effect of environmental variables and oil palm age. (in preparation).

Mercado, L.M., Bellouin, N., Sitch, S., Boucher, O., Huntingford, C., Wild, M., Cox, P.M., 2009. Impact of changes in diffuse radiation on the global land carbon sink. Nature 458, 1014-1017. doi:10.1038/nature07949 
Merten, J., Röll, A., Guillaume, T., Meijide, A., Tarigan, S., Agusta, H., Dislich, C., Dittrich, C., Faust, H., Gunawan, D., Hein, J., Hendrayanto, Knohl, A., Kuzyakov, Y., Wiegand, K., Hölscher, D., 2016. Water scarcity and oil palm expansion: social views and environmental processes. Ecol. Soc. (in press).

Miettinen, J., Shi, C., Liew, S.C., 2011. Deforestation rates in insular Southeast Asia between 2000 and 2010. Glob. Change Biol. 17, 2261-2270.

Myers, N., Mittermeier, R.A., Mittermeier, C.G., Da Fonseca, G.A., Kent, J., 2000. Biodiversity hotspots for conservation priorities. Nature 403, 853-858.

Navarro, M., Jourdan, C., Sileye, T., Braconnier, S., Mialet-Serra, I., Saint-Andre, L., Dauzat, J., Nouvellon, Y., Epron, D., Bonnefond, J., others, 2008. Fruit development, not GPP, drives seasonal variation in NPP in a tropical palm plantation. Tree Physiol. 28, 16611674.

Nelson, P., Webb, M., Banabas, M., Nake, S., Goodrick, I., Gordon, J., O’Grady, D., Dubos, B., 2014. Methods to account for tree-scale variability in soil-and plant-related parameters in oil palm plantations. Plant Soil 374, 459-471.

Nilson, T., 1971. A theoretical analysis of the frequency of gaps in plant stands. Agric. Meteorol. 8, 25-38.

Niu, F., Roll, A., Hardanto, A., Meijide, A., Kohler, M., Hendrayanto, Holscher, D., 2015. Oil palm water use: calibration of a sap flux method and a field measurement scheme. Tree Physiol. 35, 563-573. doi:10.1093/treephys/tpv013

Nogueira, E.M., Yanai, A.M., Fonseca, F.O., Fearnside, P.M., 2015. Carbon stock loss from deforestation through 2013 in Brazilian Amazonia. Glob. Change Biol. 21, 1271-1292.

Norman, J.M., 1979. Modeling the complete crop canopy, in: Barfield, B.J., Gerber, J.F. (Eds.), Modification of the Aerial Environment of Plants. American Society of Agricultural Engineers.

Oishi, A.C., Oren, R., Stoy, P.C., 2008. Estimating components of forest evapotranspiration: a footprint approach for scaling sap flux measurements. Agric. For. Meteorol. 148, $1719-1732$.

Olchev, A., Ibrom, A., Panferov, O., Gushchina, D., Kreilein, H., Popov, V., Propastin, P., June, T., Rauf, A., Gravenhorst, G., others, 2015. Response of $\mathrm{CO}_{2}$ and $\mathrm{H}_{2} \mathrm{O}$ fluxes in a mountainous tropical rainforest in equatorial Indonesia to El Niño events. Biogeosciences 12, 6655-6667.

Olchev, A., Ibrom, A., Priess, J., Erasmi, S., Leemhuis, C., Twele, A., Radler, K., Kreilein, H., Panferov, O., Gravenhorst, G., 2008. Effects of land-use changes on evapotranspiration of tropical rain forest margin area in Central Sulawesi (Indonesia): Modelling study with a regional SVAT model. Ecol. Model. 212, 131-137.

Oleson, K., Bonan, G., Levis, S., Vertenstein, M., 2004. Effects of land use change on North American climate: impact of surface datasets and model biogeophysics. Clim. Dyn. 23, $117-132$. 
Oleson, K., Lawrence, D., Bonan, G., Drewniak, B., Huang, M., Koven, C., Levis, S., Li, F., Riley, W., Subin, Z., Swenson, S., Thornton, P., 2013. Technical description of version 4.5 of the Community Land Model (CLM). doi:10.5065/D6RR1W7M

Oleson, K.W., Dai, Y., Bonan, G., Bosilovich, M., Dickinson, R., Dirmeyer, P., Hoffman, F., Houser, P., Levis, S., Niu, G.-Y., others, 2004. Technical description of the community land model (CLM). Tech Note NCARTN-461 STR.

Oren, R., Ellsworth, D.S., Johnsen, K.H., Phillips, N., Ewers, B.E., Maier, C., Schäfer, K.V., McCarthy, H., Hendrey, G., McNulty, S.G., others, 2001. Soil fertility limits carbon sequestration by forest ecosystems in a $\mathrm{CO}_{2}$-enriched atmosphere. Nature 411, 469472.

Osborne, T., Gornall, J., Hooker, J., Williams, K., Wiltshire, A., Betts, R., Wheeler, T., 2015. JULES-crop: a parametrisation of crops in the Joint UK Land Environment Simulator. Geosci. Model Dev. 8, 1139-1155. doi:10.5194/gmd-8-1139-2015

Pachauri, R.K., Allen, M., Barros, V., Broome, J., Cramer, W., Christ, R., Church, J., Clarke, L., Dahe, Q., Dasgupta, P., others, 2014. Climate Change 2014: Synthesis Report. Contribution of Working Groups I, II and III to the Fifth Assessment Report of the Intergovernmental Panel on Climate Change.

Piao, S., Sitch, S., Ciais, P., Friedlingstein, P., Peylin, P., Wang, X., Ahlström, A., Anav, A., Canadell, J.G., Cong, N., Huntingford, C., Jung, M., Levis, S., Levy, P.E., Li, J., Lin, X., Lomas, M.R., Lu, M., Luo, Y., Ma, Y., Myneni, R.B., Poulter, B., Sun, Z., Wang, T., Viovy, N., Zaehle, S., Zeng, N., 2013. Evaluation of terrestrial carbon cycle models for their response to climate variability and to $\mathrm{CO}_{2}$ trends. Glob. Change Biol. 19, 2117-2132. doi:10.1111/gcb.12187

Pisek, J., Sonnentag, O., Richardson, A.D., Mõttus, M., 2013. Is the spherical leaf inclination angle distribution a valid assumption for temperate and boreal broadleaf tree species? Agric. For. Meteorol. 169, 186-194.

Poulter, B., Ciais, P., Hodson, E., Lischke, H., Maignan, F., Plummer, S., Zimmermann, N.E., 2011. Plant functional type mapping for earth system models. Geosci. Model Dev. 4, 993-1010. doi:10.5194/gmd-4-993-2011

Reich, P.B., Walters, M.B., Ellsworth, D.S., 1997. From tropics to tundra: global convergence in plant functioning. Proc. Natl. Acad. Sci. 94, 13730-13734.

Reichstein, M., Falge, E., Baldocchi, D., Papale, D., Aubinet, M., Berbigier, P., Bernhofer, C., Buchmann, N., Gilmanov, T., Granier, A., Grunwald, T., Havrankova, K., Ilvesniemi, H., Janous, D., Knohl, A., Laurila, T., Lohila, A., Loustau, D., Matteucci, G., Meyers, T., Miglietta, F., Ourcival, J.-M., Pumpanen, J., Rambal, S., Rotenberg, E., Sanz, M., Tenhunen, J., Seufert, G., Vaccari, F., Vesala, T., Yakir, D., Valentini, R., 2005. On the separation of net ecosystem exchange into assimilation and ecosystem respiration: review and improved algorithm. Glob. Change Biol. 11, 1424-1439. doi:10.1111/j.1365-2486.2005.001002.x

Röll, A., Niu, F., Meijide, A., Hardanto, A., Hendrayanto, Knohl, A., Hölscher, D., 2015. Transpiration in an oil palm landscape: effects of palm age. Biogeosciences 12, 56195633. doi:10.5194/bg-12-5619-2015 
Ross, J., 1981. The radiation regime and architecture of plant stands. Springer Netherlands, Dordrecht.

Ross, J., 1975. Radiative transfer in plant communities, in: Monteith, J.L. (Ed.), Vegetation and the Atmosphere. Academic Press, pp. 13-55.

Roupsard, O., Bonnefond, J.-M., Irvine, M., Berbigier, P., Nouvellon, Y., Dauzat, J., Taga, S., Hamel, O., Jourdan, C., Saint-André, L., Mialet-Serra, I., Labouisse, J.-P., Epron, D., Joffre, R., Braconnier, S., Rouzière, A., Navarro, M., Bouillet, J.-P., 2006. Partitioning energy and evapo-transpiration above and below a tropical palm canopy. Agric. For. Meteorol. 139, 252-268. doi:10.1016/j.agrformet.2006.07.006

Roupsard, O., Dauzat, J., Nouvellon, Y., Deveau, A., Feintrenie, L., Saint-André, L., MialetSerra, I., Braconnier, S., Bonnefond, J.-M., Berbigier, P., Epron, D., Jourdan, C., Navarro, M., Bouillet, J.-P., 2008. Cross-validating Sun-shade and 3D models of light absorption by a tree-crop canopy. Agric. For. Meteorol. 148, 549-564. doi:10.1016/j.agrformet.2007.11.002

Ryu, Y., Baldocchi, D.D., Kobayashi, H., Ingen, C., Li, J., Black, T.A., Beringer, J., Gorsel, E., Knohl, A., Law, B.E., others, 2011. Integration of MODIS land and atmosphere products with a coupled-process model to estimate gross primary productivity and evapotranspiration from $1 \mathrm{~km}$ to global scales. Glob. Biogeochem. Cycles 25.

Sabajo, C., Le Maire, G., Knohl, A., 2016. Age of oil palm plantations causes a strong change in surface biophysical variables. (in preparation).

Sakaguchi, K., Zeng, X., 2009. Effects of soil wetness, plant litter, and under-canopy atmospheric stability on ground evaporation in the Community Land Model (CLM3.5). J. Geophys. Res. 114. doi:10.1029/2008JD010834

Schäfer, K.V., Oren, R., Ellsworth, D.S., Lai, C.-T., Herrick, J.D., Finzi, A.C., Richter, D.D., Katul, G.G., 2003. Exposure to an enriched $\mathrm{CO}_{2}$ atmosphere alters carbon assimilation and allocation in a pine forest ecosystem. Glob. Change Biol. 9, 1378-1400.

Sellers, P.J., 1985. Canopy reflectance, photosynthesis and transpiration. Int. J. Remote Sens. $6,1335-1372$.

Sellers, P.J., Dickinson, R.E., Randall, D.A., Betts, A.K., Hall, F.G., Berry, J.A., Collatz, G.J., Denning, A.S., Mooney, H.A., Nobre, C.A., 1997. Modeling the exchanges of energy, water, and carbon between continents and the atmosphere. Science 275, 502-509.

Sellers, P., Randall, D., Collatz, G., Berry, J., Field, C., Dazlich, D., Zhang, C., Collelo, G., Bounoua, L., 1996. A revised land surface parameterization (SiB2) for atmospheric GCMs. Part I: Model formulation. J. Clim. 9, 676-705.

Shuttleworth, W.J., 1988. Evaporation from Amazonian rainforest. Proc. R. Soc. Lond. B Biol. Sci. 233, 321-346.

Shuttleworth, W.J., Gash, J.H., Lloyd, C.R., Moore, C.J., Roberts, J., Ari De O Filho, M., Fisch, G., De Paula Silva Filho, V., Ribeiro, M.D.N.G., Molion, L.C., others, 1984. Eddy correlation measurements of energy partition for Amazonian forest. Q. J. R. Meteorol. Soc. $110,1143-1162$. 
Smith, P., Bustamante, M., Ahammad, H., Clark, H., Dong, H., Elsiddig, E.A., Haberl, H., Harper, R., House, J., Jafari, M., others, 2014. Agriculture, forestry and other land use (AFOLU), in: Climate Change 2014: Mitigation of Climate Change. Contribution of Working Group III to the Fifth Assessment Report of the Intergovernmental Panel on Climate Change. Cambridge University Press.

Sperry, J., Hacke, U., Oren, R., Comstock, J., 2002. Water deficits and hydraulic limits to leaf water supply. Plant Cell Environ. 25, 251-263.

Tang, J.Y., Riley, W.J., Koven, C.D., Subin, Z.M., 2013. CLM4-BeTR, a generic biogeochemical transport and reaction module for CLM4: model development, evaluation, and application. Geosci. Model Dev. 6, 127-140. doi:10.5194/gmd-6-1272013

Tan, G.-Y., Rajaratnam, J., 1978. Genetic variability of leaf nutrient concentration in oil palm. Crop Sci. 18, 548-550.

Taylor, K.E., Stouffer, R.J., Meehl, G.A., 2012. An Overview of CMIP5 and the Experiment Design. Bull. Am. Meteorol. Soc. 93, 485-498. doi:10.1175/BAMS-D-11-00094.1

Thornton, P.E., Lamarque, J.-F., Rosenbloom, N.A., Mahowald, N.M., 2007. Influence of carbon-nitrogen cycle coupling on land model response to $\mathrm{CO}_{2}$ fertilization and climate variability: INFLUENCE OF CARBON-NITROGEN COUPLING. Glob. Biogeochem. Cycles 21, doi:10.1029/2006GB002868

Tilman, D., Fargione, J., Wolff, B., D’Antonio, C., Dobson, A., Howarth, R., Schindler, D., Schlesinger, W.H., Simberloff, D., Swackhamer, D., 2001. Forecasting agriculturally driven global environmental change. Science 292, 281-284.

Tuzet, A., Perrier, A., Leuning, R., 2003. A coupled model of stomatal conductance, photosynthesis and transpiration. Plant Cell Environ. 26, 1097-1116.

Valade, A., Vuichard, N., Ciais, P., Ruget, F., Viovy, N., Gabrielle, B., Huth, N., Martiné, J.F., 2014. ORCHIDEE-STICS, a process-based model of sugarcane biomass production: calibration of model parameters governing phenology. GCB Bioenergy 6 , 606-620. doi:10.1111/gcbb.12074

Van Bodegom, P.M., Douma, J.C., Witte, J.P.M., Ordoñez, J.C., Bartholomeus, R.P., Aerts, R., 2012. Going beyond limitations of plant functional types when predicting global ecosystem-atmosphere fluxes: exploring the merits of traits-based approaches: Merits of traits-based vegetation modelling. Glob. Ecol. Biogeogr. 21, 625-636. doi:10.1111/j.1466-8238.2011.00717.x

Van Kraalingen, D., Breure, C., Spitters, C., 1989. Simulation of oil palm growth and yield. Agric. For. Meteorol. 46, 227-244.

Veldkamp, E., Keller, M., 1997. Nitrogen oxide emissions from a banana plantation in the humid tropics. J. Geophys. Res. Atmospheres 102, 15889-15898.

Verbeeck, H., Steppe, K., Nadezhdina, N., De Beeck, M.O., Deckmyn, G., Meiresonne, L., Lemeur, R., Ceulemans, R., Janssens, I., others, 2007. Model analysis of the effects of atmospheric drivers on storage water use in Scots pine. Biogeosciences 4, 657-671. 
Verheijen, L.M., Aerts, R., Brovkin, V., Cavender-Bares, J., Cornelissen, J.H.C., Kattge, J., van Bodegom, P.M., 2015. Inclusion of ecologically based trait variation in plant functional types reduces the projected land carbon sink in an earth system model. Glob. Change Biol. 21, 3074-3086. doi:10.1111/gcb.12871

Vitousek, P.M., Howarth, R.W., 1991. Nitrogen limitation on land and in the sea: how can it occur? Biogeochemistry 13, 87-115.

Wang, D., Wang, G., Anagnostou, E.N., 2007a. Evaluation of canopy interception schemes in land surface models. J. Hydrol. 347, 308-318.

Wang, K., Mao, J., Dickinson, R., Shi, X., Post, W., Zhu, Z., Myneni, R., 2013. Evaluation of CLM4 Solar Radiation Partitioning Scheme Using Remote Sensing and Site Level FPAR Datasets. Remote Sens. 5, 2857-2882. doi:10.3390/rs5062857

Wang, W.-M., Li, Z.-L., Su, H.-B., 2007b. Comparison of leaf angle distribution functions: effects on extinction coefficient and fraction of sunlit foliage. Agric. For. Meteorol. $143,106-122$.

Wang, Y.P., Law, R.M., Pak, B., 2010. A global model of carbon, nitrogen and phosphorus cycles for the terrestrial biosphere. Biogeosciences 7, 2261-2282. doi:10.5194/bg-72261-2010

White, M.A., Thornton, P.E., Running, S.W., 1997. A continental phenology model for monitoring vegetation responses to interannual climatic variability. Glob. Biogeochem. Cycles 11, 217-234.

White, M.A., Thornton, P.E., Running, S.W., Nemani, R.R., 2000. Parameterization and sensitivity analysis of the BIOME-BGC terrestrial ecosystem model: net primary production controls. Earth Interact. 4, 1-85.

Williams, D.G., Cable, W., Hultine, K., Hoedjes, J.C.B., Yepez, E.A., Simonneaux, V., ErRaki, S., Boulet, G., de Bruin, H.A.R., Chehbouni, A., Hartogensis, O.K., Timouk, F., 2004. Evapotranspiration components determined by stable isotope, sap flow and eddy covariance techniques. Agric. For. Meteorol. 125, 241-258. doi:10.1016/j.agrformet.2004.04.008

Wilson, K.B., Hanson, P.J., Mulholland, P.J., Baldocchi, D.D., Wullschleger, S.D., 2001. A comparison of methods for determining forest evapotranspiration and its components: sap-flow, soil water budget, eddy covariance and catchment water balance. Agric. For. Meteorol. 106, 153-168. doi:10.1016/S0168-1923(00)00199-4

Zaehle, S., Friedlingstein, P., Friend, A.D., 2010. Terrestrial nitrogen feedbacks may accelerate future climate change. Geophys. Res. Lett. 37.

Zaehle, S., Friend, A.D., 2010. Carbon and nitrogen cycle dynamics in the O-CN land surface model: 1. Model description, site-scale evaluation, and sensitivity to parameter estimates: SITE-SCALE EVALUATION OF A C-N MODEL. Glob. Biogeochem. Cycles 24. doi:10.1029/2009GB003521

Zeng, X., Barlage, M., Dickinson, R.E., Dai, Y., Wang, G., Oleson, K., 2005. Treatment of undercanopy turbulence in land models. J. Clim. 18, 5086-5094. 
Zhang, Q., Manzoni, S., Katul, G., Porporato, A., Yang, D., 2014. The hysteretic evapotranspiration-Vapor pressure deficit relation: ET-VPD hysteresis. J. Geophys. Res. Biogeosciences 119, 125-140. doi:10.1002/2013JG002484 


\section{CERTIFICATE OF AUTHORSHIP/ORIGINALITY}

I, Yuanchao Fan, hereby declare that I am the sole author of this dissertation entitled "Modeling oil palm monoculture and its associated impacts on land-atmosphere carbon, water and energy fluxes in Indonesia." All references, data sources and suggestions used in the dissertation have been appropriately acknowledged. The main content of Chapter 2 was published with me as the first author. Chapter 3 is in preparation for publication with me as first author too. All other chapters have been written by me independently. This dissertation is intended to fulfill the joint doctoral examination procedure of the University of Göttingen and AgroParisTech according to their Agreement for Joint Supervision of Doctoral Studies (Cotutelle), having regard to the Framework Agreement - Erasmus Mundus Joint Doctorate Programme - Agreement Number $-2010-0005 / 001$.

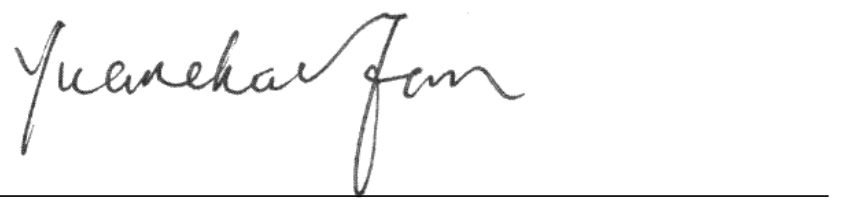

Göttingen, April 2016 


\title{
CURRICULUM VITAE
}

\author{
Yuanchao Fan \\ Born on 12 March 1985 in Hubei, China; Nationality: China
}

\section{EDUCATION}

2012-2016 Ph.D. Bioclimatology, University of Göttingen, Germany

2012-2016 Ph.D. EFSA-Écologie Fonctionnelle et Sciences Agronomiques, Doctoral School GAIA, AgroParisTech, Montpellier, France

Advisors: Dr. Alexander Knohl (Germany), Dr. Martial Bernoux (France) Dissertation: Modeling oil palm monoculture and its associated impacts on land-atmosphere carbon, water and energy fluxes in Indonesia

2008-2011 M.S. Environmental and Natural Resource Sciences, University of Nevada, Reno, USA

Advisor: Dr. Peter Weisberg, Great Basin Landscape Ecology Lab, UNR Thesis: Tree crown mortality associated with roads in the Lake Tahoe basin: a remote sensing approach

2003-2008 B.Eng. Remote Sensing Science and Technology, Wuhan University, China Advisor: Dr. Shenghui Fang

Thesis: On the method of retrieving land surface temperature using thermal infrared images of Wuhan

\section{RESEARCH EXPERIENCE}

09.2011-10.2012 Research Assistant in ecological modeling, Smithsonian Conservation Biology Institute, Smithsonian Institution, Front Royal, Virginia, USA Supervisor: Dr. Jonathan Thompson

07.2008-08.2011 Graduate Research Assistant in the Great Basin Landscape Ecology Lab, University of Nevada, Reno, USA

Advisor: Dr. Peter Weisberg

02-07. 2010

Joint Study at the Institute of Surveying, Remote Sensing and Land Information (IVFL), University of Natural Resources and Life Sciences (BOKU), Vienna, Austria

Advisor: Dr. Werner Schneider

\section{PUBLICATIONS}

Fan, Y., Roupsard, O., Bernoux, M., Le Maire, G., Panferov, O., Kotowska, M. M., and Knohl, A. (2015). A sub-canopy structure for simulating oil palm in the Community Land Model (CLM-Palm): phenology, allocation and yield, Geoscientific Model Development, 8, 3785-3800, 
doi:10.5194/gmd-8-3785-2015

Van Gunst, K., Weisberg, P. J., Yang, J., and Fan, Y. (2015). Do denser forests have greater risk of tree mortality: A remote sensing analysis of density-dependent forest mortality. Forest Ecology and Management, 359, 19-32, doi:10.1016/j.foreco.2015.09.032

Fan, Y., Koukal, T., and Weisberg, P. J. (2014). A sun-crown-sensor model and adapted Ccorrection logic for topographic correction of high resolution forest imagery. ISPRS Journal of Photogrammetry and Remote Sensing, 96, 94-105. doi: 10.1016/j.isprsjprs.2014.07.005

Fan, Y., Weisberg, P. J., and Nowak, R. S. (2014). Spatio-temporal analysis of remotely-sensed forest mortality associated with road de-icing salts. Science of The Total Environment, 472, 929-938. doi: 10.1016/j.scitotenv.2013.11.103.

Fang, S., Dian, Y., and Fan, Y. (2008). Inversion of surface temperature based on MODIS and ASTER imagery. Proceedings of the $8^{\text {th }}$ international symposium on spatial accuracy assessment in natural resources and environmental sciences, Shanghai, June 25-27, 2008, pp. 328-334.

Fan, Y. (2007). The measure of utilizing rural biomass resource rationally. Journal of Agricultural Mechanization Research 2007(12): 200-202, 217. (In Chinese: 范远超. (2007). 合理利用农村生物质资源的对策. 农机化研究, (12), 200-202.)

Fan, Y. (2007). "Hollow villages" exhausted rural areas. Ecological Economy 2007(8): 18-21. (In Chinese: 范远超. (2007). “空心村” 掏空了农村. 生态经济, (8), 18-21.)

\section{MANUSCRIPTS IN REVIEW/PREPARATION}

Thompson, J. R., Lambert, K. F., Foster, D. R., Broadbent, E., Blumstein, M., Almeyda, A., and Fan, Y. (In review). Scenarios, Services, and Society: A case study of stakeholder-defined land use scenarios and their consequences in Massachusetts, USA. (Submitted to Ecosphere)

Fan, Y. et al. (In Preparation). A dynamic multilayer scheme for radiative transfer and photosynthesis in the CLM-Palm model: applications to oil palm and rainforest.

Fan, Y. et al. (In Preparation). Rainforest to oil palm conversion reduces long-term C stocks and $\mathrm{C}$ sequestration capacity and has potential warming effects: results from CLM modeling on full rotations.

Fan, Y. et al. (In Preparation). Reconciling CLM4.5 canopy hydrology parameterization with observed water and energy fluxes.

Fan, Y. et al. (In Preparation). A modified dynamic carbon-nitrogen cycle coupling scheme in CLM4.5 for simulating fertilization effects in agricultural systems.

Meijide, A., Röll, A., Fan, Y., Herbst, M., Niu, F., Tiedemann, F., June, T., Rauf, A., Hölscher, D., and Knohl, A. (In Preparation). Controls of water and energy fluxes in oil palm plantations: effect of environmental variables and oil palm age. 
